WELLINGTON RODRIGO APARECIDO CECILIANO

APLICAÇÃO DE UM MÉTODO DE SIMULAÇÃO-OTIMIZAÇÃO NA CADEIA PRODUTIVA DE MINÉRIOS DE FERRO

São Paulo 
WELLINGTON RODRIGO APARECIDO CECILIANO

\section{APLICAÇÃO DE UM MÉTODO DE SIMULAÇÃO-OTIMIZAÇÃO NA CADEIA PRODUTIVA DE MINÉRIOS DE FERRO}

Dissertação apresentada à Escola Politécnica da Universidade de São Paulo, para obtenção do título de Mestre em Engenharia de Sistemas Logísticos. 
WELLINGTON RODRIGO APARECIDO CECILIANO

\section{APLICAÇÃO DE UM MÉTODO DE SIMULAÇÃO-OTIMIZAÇÃO NA CADEIA PRODUTIVA DE MINÉRIOS DE FERRO}

Dissertação apresentada à Escola

Politécnica da Universidade de São Paulo, para obtenção do título de Mestre em

Engenharia de Sistemas Logísticos.

Área de Concentração:

Sistemas Logísticos

Orientador: Prof. Titular.

Rui Carlos Botter

São Paulo 
Este exemplar foi revisado e alterado em relação à versão original, sob responsabilidade única do autor e com a anuência de seu orientador.

São Paulo, 24 de Setembro de 2007

Assinatura do autor:

Assinatura do orientador:

FICHA CATALOGRÁFICA

Ceciliano, Wellington Rodrigo Aparecido

Aplicação de um método de simulação-otimização na cadeia produtiva de minérios de ferro / W.R.A. Ceciliano. -- São Paulo, 2007.

237 p.

Dissertação (Mestrado) - Escola Politécnica da Universidade de São Paulo. Departamento de Engenharia de Transportes. Sistemas Logísticos.

1.Simulação 2.Minérios 3.Mineração 4.Logística (Administração de materiais) I.Universidade de São Paulo. Escola Politécnica. Departamento de Engenharia de Transportes II.t. 
FOLHA DE APROVAÇÃO

Wellington Rodrigo Aparecido Ceciliano

Aplicação de um método de simulação-otimização na cadeia produtiva de minérios de ferro

Dissertação apresentada à Escola Politécnica da Universidade de São Paulo, para obtenção do título de Mestre em Engenharia de Sistemas Logísticos.

Área de Concentração: Sistemas Logísticos

Aprovado em:

Banca Examinadora

Prof. Dr. Rui Carlos Botter

Instituição: EPUSP/PNV Assinatura

Prof. Dr. Claudio Barbieri da Cunha Instituição: EPUSP/PTR Assinatura

Prof. Dr. Luis Henrique Rodrigues

Instituição: UNISINOS Assinatura 
Dedico este trabalho aos meus pais, Alcides e Marlene, às minhas irmãs, Josislaine e Luana, e, especialmente, à minha namorada, noiva e esposa Fabiana. 


\section{AGRADECIMENTOS}

A Deus, pela vida e pelas graças alcançadas.

À minha esposa Fabiana, pela incansável compreensão, dedicação, amor e companheirismo durante toda nossa história de vida.

Ao meu amigo e Professor Rui Carlos Botter, pela dedicação, orientação, confiança e amizade.

À Samarco Mineração S/A, por esta maravilhosa oportunidade de realizar o mestrado.

Aos meus amigos, Eduardo Pessotti, Laherce de Casto Neto, Duílio Carvalho e Rafael Buback pela amizade, companheirismo e coragem de lutarmos juntos, há mais de 5 anos, inserindo estes conceitos dentro de nossa empresa.

Aos meus amigos, Alexandre Juliá, Vinicius Teixeira, Elton Dias, José Otavio, Gustavo Vargas, Cristiano Pimenta e a todos aqueles da família Samarco (da Engenharia Industrial, do Planejamento Integrado, da Gerência Geral de Planejamento e Gestão), que me ajudaram, direta ou indiretamente a conseguir realizar este sonho.

Aos meus amigos gaúchos, Luiz Henrique Rodrigues e Guilherme Vaccaro, pelos ensinamentos e orientações, durante este fantástico caminho de aprendizagem. 


\section{RESUMO}

O mercado de minérios de ferro e aço está extremamente aquecido nesta primeira década do século XXI, e como mostram os especialistas neste assunto deverá permanecer desta forma por no mínimo mais 5 ou 10 anos. Com o aumento substancial de preços das "commodities", principalmente os minérios de ferro, nesta década há nas indústrias ou corporações uma alta disponibilidade de recursos para bons projetos. Desta forma, a empresa que tiver condições de tomar decisões estratégicas melhores, mais rápidas e mais fundamentadas garantirá a perpetuidade do negócio neste mundo competitivo. O principal objetivo desta dissertação é o desenvolvimento e aplicação de um método de tomada de decisão, que utilize simulação-otimização durante o processo de planejamento do negócio. Este método será aplicado na cadeia produtiva de minérios de ferro da Samarco Mineração S/A, com o propósito de melhorar a qualidade das informações do processo de escolha da melhor alternativa de investimentos para os próximos 05 anos. Este método demonstrou uma melhora na qualidade do processo decisório de escolha dos investimentos, além disso, observou-se que o desdobramento em fases garantido pelo método proposto, converge diversos fatores, simplificando e otimizando a tomada de decisão gerencial. Ao avaliar e confrontar os conceitos de simulação e otimização, observou-se que existe um grande conjunto de experiências bem explorado de técnicas para resolução de problemas no sentido de aprimorar, em cada uma das áreas de conhecimento (simulação e otimização) separadamente a busca da melhor solução, deixando de se aproveitar o potencial que se pode conseguir com a integração dessas técnicas. Neste sentido procurou-se evidenciar que não era objetivo desta pesquisa analisar qual é a melhor técnica a ser empregada em cada problema que afeta os sistemas logísticos em geral, e sim potencializar a discussão, assim como muitos autores apresentados neste trabalho, que estas técnicas são complementares e que o sucesso da solução do problema ou oportunidade é proporcional a correta aplicação destas técnicas em seus pontos fortes de resolução de problema. $E$ os casos apresentados e o método aqui proposto

* conforme a ABNT NBR 6028 (2003). 
reforçam que a aplicação destas técnicas em conjunto garantem um melhor resultado do que o emprego destas ferramentas separadamente.

Palavras-chave: Simulação. Otimização. Minério de Ferro. 


\begin{abstract}
World demand for iron ore and steel industries are extremely high in the very beginning of the 21st century, and the analysts are foreseeing that it will last for a long period. Likewise the commodities in general, the prices of iron ore have been increasing considerably, mainly because of the disarticulation through this industry supply chain. Considering the systemic aspects of this particular market, the decisions to invest in upstream capacities to supply the demand is very complex and risky. The complexity is related with assets intensiveness, competitor's movements, time between decision to implant a project and startup, and the demand-price ups and downs cycles. The companies that make the right strategic decisions, at the right time, are the ones that will succeed in this competitive and global market. The objective of this dissertation is to develop a methodology, using simulationoptimization techniques that support strategic investments decisions. In the research part of this dissertation, a sort of concepts and techniques of simulation, heuristics and optimization were explored and it was possible to identify an opportunity to explore the potential integration of techniques. In particular, this dissertation aims to clarify that this techniques may be complementary, and the success if very much related with the correct approach to combine them considering the particularities of the studied problem. The results have shown that the proposed method clarify that the right combination of techniques, in this case, simulation-optimization, is produces better results and individual application of each one of them. The method was applied at Samarco in its business planning process, and it has been useful to support better investments decisions.
\end{abstract}

Key-words: Simulation. Optimization. Iron Ore. 


\section{LISTA DE FIGURAS}

Figura 2.1 - Taxa de crescimento do PIB e da indústria mundial................................. 14

Figura 2.2- Comportamento esperado da demanda de minério de ferro........................ 16

Figura 2.3- Comportamento esperado da demanda de pelotas................................... 17

Figura 2.4- Balanço oferta e demanda para o mercado de minério de ferro................... 18

Figura 2.5- Balanço oferta e demanda para o mercado de pelotas................................. 19

Figura 2.6- Market share do mercado transoceânico de minério de ferro e pelotas........ 20

Figura 2.7- Market share do mercado siderúrgico..................................................... 22

Figura 2.8- Market share do mercado transoceânico de minério de ferro e aço............... 22

Figura 2.9- Tecnologias de redução direta de finos de minérios de ferro........................ 23

Figura 2.10- Processo produtivo do aço................................................................ 25

Figura 2.11- Fluxograma típico de tratamento de minério......................................... 27

Figura 2.12- Trajetória de um sistema dinâmico de variável contínua (SDVC)............. 31

Figura 3.1 - Etapas de modelagem........................................................................ 33

Figura 3.2 - O processo de modelagem................................................................ 33

Figura 3.3- Atividade do processo de modelagem e simulação.................................... 34

Figura 3.4 - Classificação dos modelos de simulação................................................. 37

Figura 3.5 - Processo de decisão com modelos de simulação....................................... 47

Figura 3.6 - Processo de decisão com modelos de otimização........................................ 48

Figura 3.7 - Adequação de diferentes técnicas de modelagem em relação à complexidade e à variabilidade dos dados de um problema..................... 50

Figura 4.1 - O princípio da simulação-otimização...................................................... 67

Figura 4.2 - Esquema da simulação otimização........................................................ 67

Figura 4.3 - Estrutura da rede........................................................................ 70

Figura 4.4 - Ilustração do método de Granger.................................................................. 72

Figura 4.5 - Procedimento para otimização do sistema simulado.................................. 73

Figura 4.6 - Processo de transporte de cana de açúcar.................................................... 75

Figura 4.7 - Superfície de resposta das variáveis de saída do transporte de cana de açúcar, como uma função do número de caminhões e reboques................... 76

Figura 4.8 - Superfície de resposta das médias das variáveis de saída do tempo de ciclo das viagens, como uma função do número de caminhões e reboques.. 76

Figura 4.9 - Ilustração do método de Morito et al. (1999)................................................ 84 


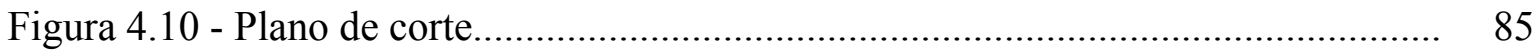

Figura 4.11 - Sistema logístico do SPJ................................................................ 86

Figura 4.12 - Exemplo simplificado de um sistema fluvial....................................... 88

Figura 4.13 - Fluxo do processo iterativo entre os modelos de simulação e otimização.. 90

Figura 4.14 - Fluxo de informação do processo iterativo................................................ 93

Figura 4.15 - Resumo dos métodos de simulaçã-otimização........................................... 95

Figura 5.1 - Modelo de simulação-otimização proposto................................................ 101

Figura 7.1 - Fluxograma de processo da unidade de Germano, Mariana (MG)............. 110

Figura 7.2 - Perfil do mineroduto da Samarco Mineração S/A ................................... 112

Figura 7.3 - Fluxograma representativo do processo produtivo de Ponta Ubu............... 113

Figura 7.4 - Passos num estudo de simulação................................................................ 115

Figura 7.5 - Fluxograma representativo do modelo computacional utilizado na Simulação. 


\section{LISTA DE GRÁFICOS}

Gráfico 8.1 - Comportamento da expectativa de produção de pelotas

e o nível de investimento durante a evolução do método............... 


\section{LISTA DE TABELAS}

Tabela 1.1 - Classificações de uma pesquisa.

Tabela 3.1 - Dados para um modelo de PL 45

Tabela 3.2 - Comparação qualitativa dos métodos de modelagem

Tabela 8.1 - Projetos originais e local de implantação.

Tabela 8.2 - Efeito dos projetos originais no processo produtivo

Tabela 8.3 - Investimento previsto para a implantação dos projetos originais

Tabela 8.4 - Efeitos individuais dos projetos no processo produtivo pós simulação.

Tabela 8.5 - Avaliação econômico-financeira dos projetos 128

Tabela 8.6 - Projetos viáveis que alimentarão o modelo de otimizaçã 129

Tabela 8.7 - Seqüência sugerida pelo modelo de otimização 130

Tabela 8.8 - Efeito cumulativo dos projetos da lista 3. 131

Tabela 8.9 - Resultado da simulação da lista 4

Tabela 8.10 - Lista de projetos que alimentarão o modelo de otimização $2^{\circ}$ ciclo

Tabela 8.11 - Resultados do modelo de otimização - $2^{\circ}$ ciclo 133

Tabela 8.12 - Verificação de capacidade pelo simulador $-2^{\circ}$ ciclo 134

Tabela 8.13 - Resumo das tabelas que auxiliaram a descrição da aplicação do método. 


\section{LISTA DE ABREVIATURAS E SIGLAS}

$\mathrm{BF}$

Do inglês "blast furnace" e representam as pelotas utilizadas no processo siderúrgico através de Alto Forno, e se denominam Pelotas BF ou PBF

BHPB Maior empresa mundial de mineração, a australiana BHP Billiton

CAPEX Total de Despesas de Capital por Período

CAGR "compound annual growth rate" - Taxa de Crescimento Anual Composta

CDs Centros de Distribuição

CEI Comunidade dos Estados Independentes

CFEM Compensação Financeira sobre Exploração de Recursos Minerais

COFINS Contribuição para o Financiamento da Seguridade Social

COTS "Commercial-Off-The-Shelf"

CV Carvão Vegetal

CVRD Companinha Vale do Rio Doce

DNA Ácido Desoxirribonucléico

DR Do inglês “Direct Reduction”, e representam as pelotas utilizadas no processo siderúrgico de Redução Direta, e se denominam Pelotas DR ou PDR

DRI Do inglês “Direct Reduced Iron”, ferro diretamente reduzido, mais conhecido como ferro esponja, é disponibilizado aos fornos elétrico para produção de aço de alta qualidade

FEA Forno Elétrico a Arco

GNA Gerador de Números Aleatórios

GRASP "Greedy Randomized Adaptive Search Procedure"

HBI Do inglês "Hot Briquetted Iron", ferro briquetado a quente

ICMS Imposto sobre circulação de Mercadorias e Prestação de Serviços

IOC “Iron Ore Company”, empresa canadense produtora de pelotas de minérios de ferro, cujo principal acionista é a Rio Tinto.

IR Imposto de Renda

ISS Imposto sobre Serviços de Qualquer Natureza

LD Convertedor LD ou BOF ( "Basic Oxigenion Furnace”), é um equipamento altamente eficiente para converter ferro gusa em aço por meio da injeção de oxigênio

LKAB Empresa estatal sueca de mineração de ferro 
MILP Programação Linear Inteira Mista

MIP Programa Inteiro-Misto

OPEX Do inglês “Operational Expenditure” - despesa operacional

PBF Do inglês "Pellets of Blast Furnace" - Pelotas de Alto Forno

PDR Do inglês "Pellets of Direct Reduction" - Pelotas de Redução Direta

PFN "Pellet Feed Normal Silica"

PMI "Project Management Institute"

PIB Produto Interno Bruto

PIS Plano de Integração Social

PL Programação Linear

PO Pesquisa Operacional

PPC Perda por Calcinação

ROM "Run of Mine"

SDED Sistema Dinâmico de Eventos Discretos

SDVC Sistema Dinâmico de Variável Contínua

SF "Sinter-feed"

SOFE Adiantamento de contratos de crédito

SPJ Serviço Postal Japonês

TMS Tonelada Métrica Seca

TUP Terminal de Uso Privativo

USP Universidade de São Paulo

VPL Valor Presente Líquido

WACC “Weighted Avarage Cost of Capital”- custo médio ponderado de capital 


\section{SUMÁRIO}

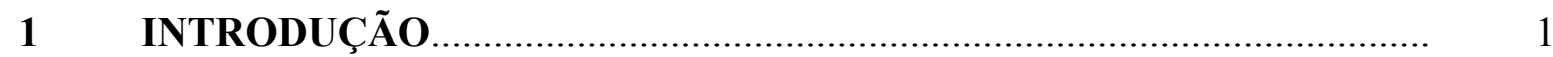

1.1 MOTIVAÇÃO PARA A PESQUISA........................................................ 2

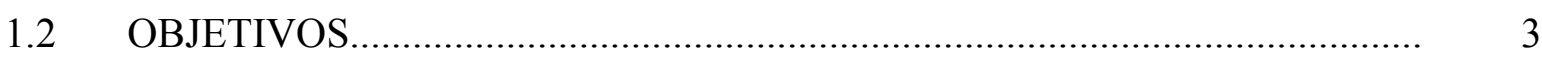

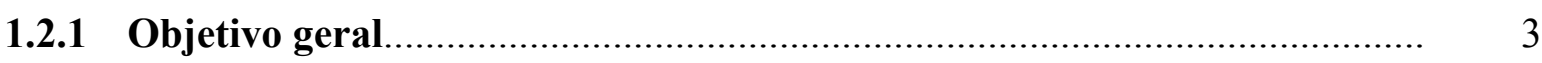

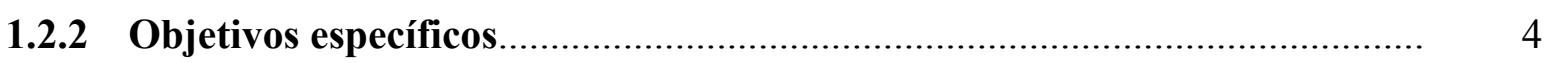

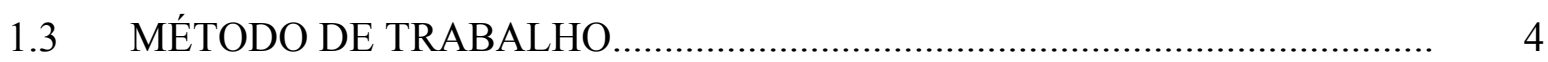

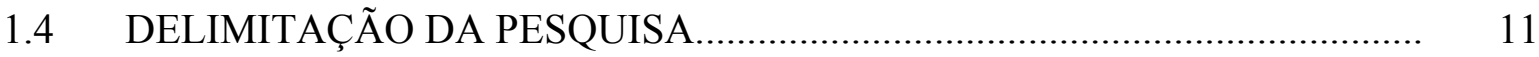

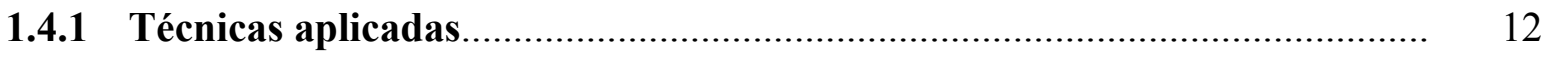

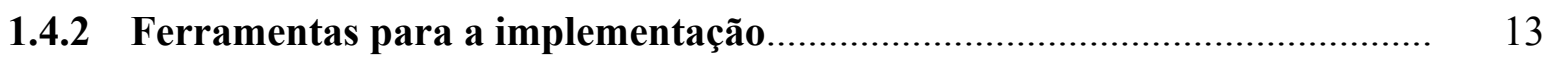

1.4.3 Período de validade dos dados...................................................................... 13

2 NEGÓCIO E OPERAÇÕES DA MINERAÇÃO DE FERRO..................... 14

2.1 RETRATO ATUAL DA ECONOMIA MUNDIAL........................................ 14

2.1.1 Implicações nos mercados de aço e minério de ferro..................................... 15

2.1.2 Implicações no mercado de pelotas.............................................................. 16

2.2 AVALIAÇÃO DO AUMENTO DA OFERTA PREVISTA NO MERCADO

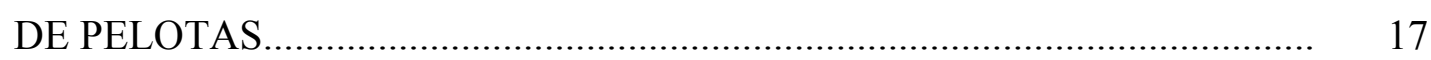

2.2.1 Análise de oferta e demanda de minérios de ferro e pelotas........................ 18

2.3 PRINCIPAIS PLAYERS DO MERCADO DE PELOTAS................................ 19

2.3.2 Nível de concentração do mercado e tendências............................................. 20

2.4 PODER DE BARGANHA DOS CONSUMIDORES....................................... 21

2.5 AMEAÇA DE PRODUTOS SUBSTITUTOS............................................... 22

2.6 INTRODUÇÃO AO PROCESSO PRODUTIVO DO MINÉRIO DE FERRO. 23

2.6.1 Incertezas inerentes ao processo de fabricação do minério......................... 28

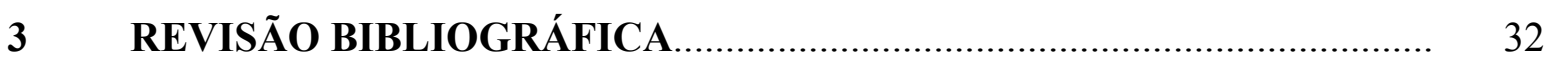

3.1 MODELOS DE SIMULAÇÃO............................................................... 32

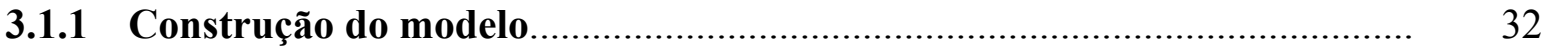

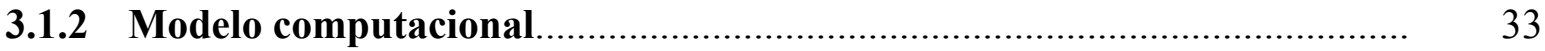

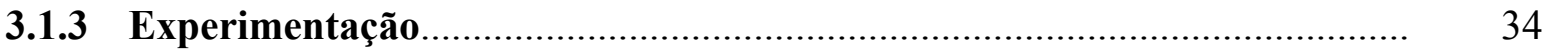

3.2 SIMULAÇÃO COMPUTACIONAL ......................................................... 34

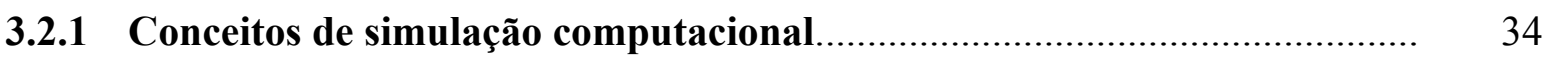


3.2.2 Tipos de simulação

3.2.3 Onde utilizar a simulação?.

3.2.4 Vantagens e desvantagens da simulação................................................... 39

3.3 PROGRAMAÇÃO LINEAR..................................................................... 42

3.3.1 Modelos de PL...................................................................................... 44

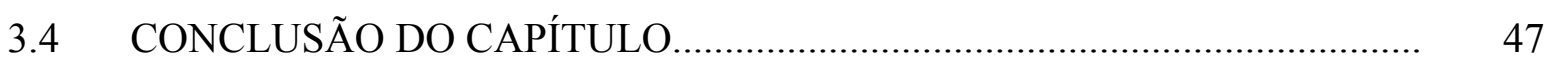

4 REVISÃO SOBRE MÉTODOS DE SIMULAÇÃO-OTIMIZAÇÃO........ 51

4.1 MÉTODOS DE PLANEJAMENTO.......................................................... 51

4.2 HISTÓRIA DA SIMULAÇÃO-OTIMIZAÇÃO............................................. 53

4.3 CARACTERÍSTICAS DA SIMULAÇÃO-OTIMIZAÇÃO............................ 54

4.4 VANTAGENS DE SIMULAÇÃO-OTIMIZAÇÃO.......................................... 57

4.5 DIFICULDADES DA SIMULAÇÃO-OTIMIZAÇÃO.................................. 57

4.6 APLICAÇÃO DA SIMULAÇÃO-OTIMIZAÇÃO......................................... 58

4.7 CLASSIFICAÇÃO DA SIMULAÇÃO-OTIMIZAÇÃO................................. 59

4.7.1 Problemas de objetivo único......................................................................... 59

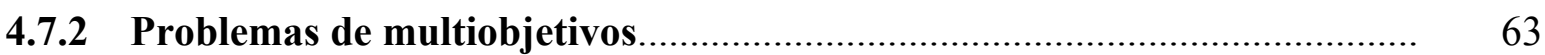

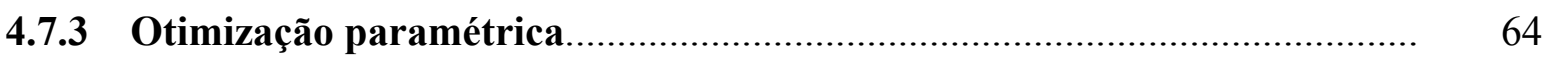

4.8 MÉTODOS DE SIMULAÇÃO-OTIMIZAÇÃO................................................ 66

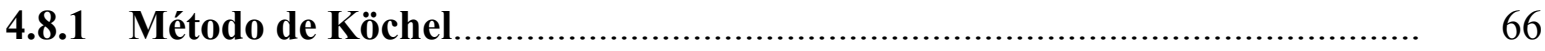

4.8.2 Método de Granger e sua aplicação.................................................................. 69

4.8.3 Método de Vashi e Bienstock aplicado por Díaz e Pérez (2000)................... 72

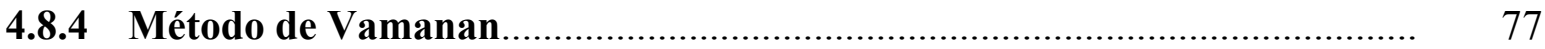

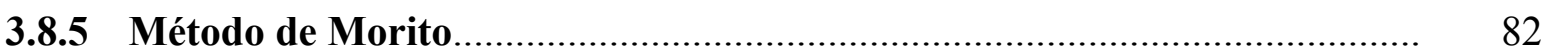

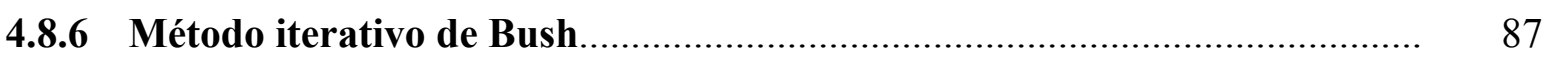

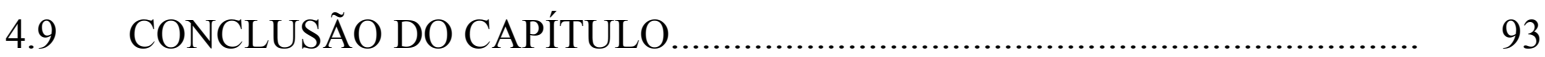

5 MODELAGEM CONCEITUAL DO PROBLEMA E APRESENTAÇÃO DO MÉTODO PROPOSTO............................................................... 97

5.1 MODELO DE SIMULAÇÃO-OTIMIZAÇÃO PROPOSTO............................. 100

6 DESCRIÇÃO DO MODELO DE OTIMIZAÇÃO...................................... 106

7 DESCRIÇÃO DO MODELO DE SIMULAÇÃO ........................................ 110

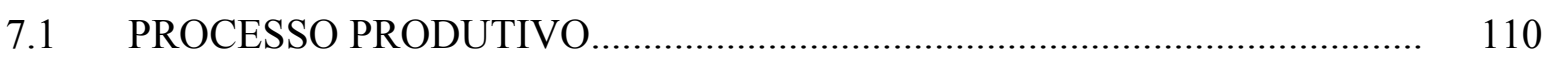

7.2 MÉTODO DE CONDUÇÃO DE PROJETOS DE SIMULAÇÃO PROJETOS DE COMPUTACIONAL ............................................................ 114

7.3 APLICAÇÃO DO MODELO DE SIMULAÇÃO........................................... 116 


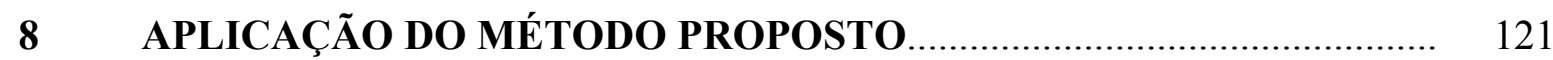

8.1 AVALIAÇÃO DOS DADOS DE ENTRADA.............................................. 121

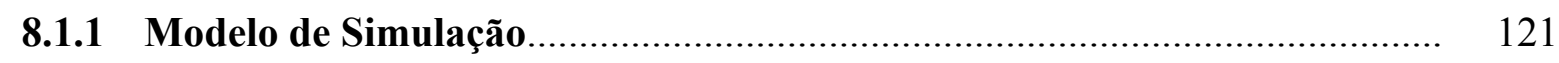

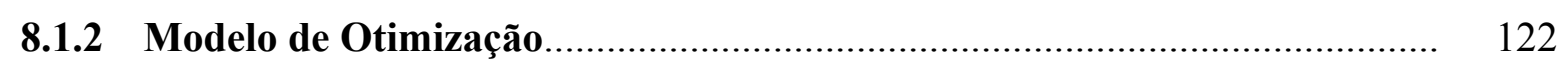

8.2 PASSO 01: CONSTRUÇÃO BÁSICA DOS MODELOS................................. 122

8.3 PASSO 02: EXECUÇÃO DA SIMULAÇÃO….............................................. 122

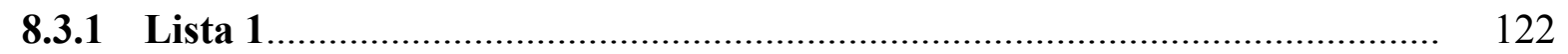

8.3.2 Simulação individual de cada projeto da lista 1 ........................................ 124

8.4 PASSO 03: ATENDE ÀS REGRAS DO NEGÓCIO......................................... 126

8.5 PASSO 04: AVALIAÇÃO ECONÔMICO-FINANCEIRA DOS PROJETOS.. 127

8.6 PASSO 05: O PROJETO É VIÁVEL?............................................................ 128

8.7 PASSO 06: TABULAÇÃO DE TODOS OS PROJETOS EM UMA ÚNICA

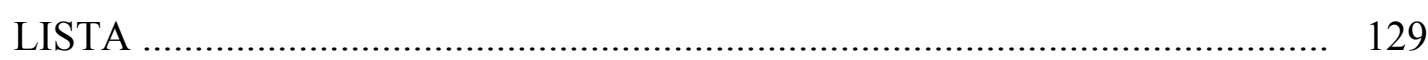

8.8 PASSO 07: EXECUÇÃO DO MODELO DE OTIMIZAÇÃO........................... 129

8.9 PASSO 08: AGRUPAMENTO DOS EFEITOS DE TODOS OS PROJETOS SUGERIDOS PELA OTIMIZAÇÃO EM UM ÚNICO PROJETO............................... 130

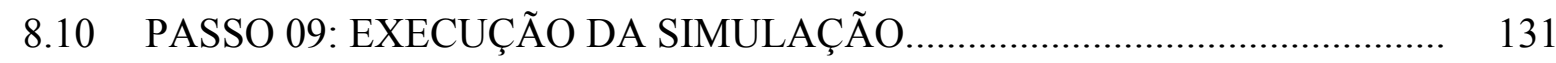

8.11 PASSO 10: AVALIAÇÃO DO RESULTADO DA SIMULAÇÃO................... 131

8.12 PASSO 11: ATENDE OS CRITÉRIOS DE PARADA..................................... 132

8.13 PASSO 12: AJUSTE DOS CRITÉRIOS OU PREMISSAS DOS PROJETOS.. 132

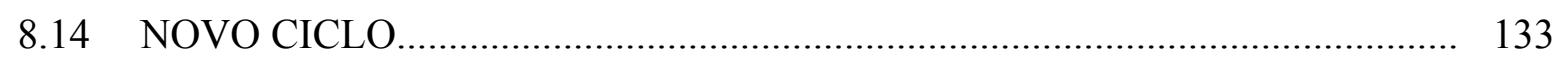

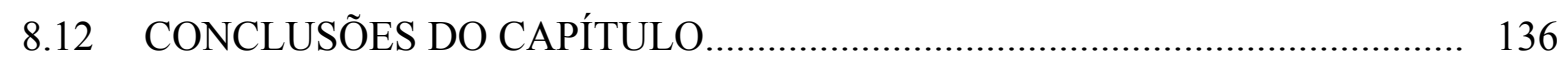

9 CONCLUSÕES E RECOMENDAÇÕES …............................................... 138

9.1 BENEFÍCIOS DO MÉTODO DE SIMULAÇÃO-OTIMIZAÇÃO..................... 139

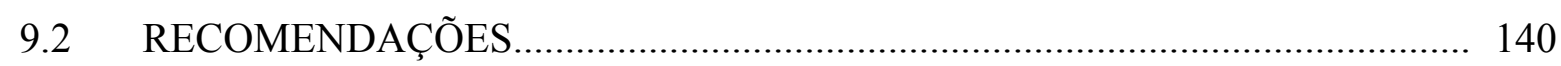

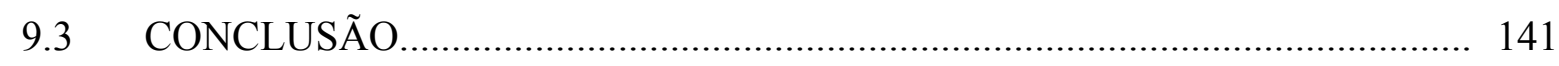

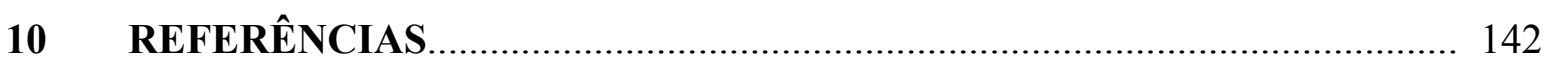

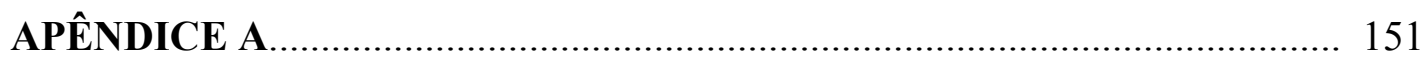

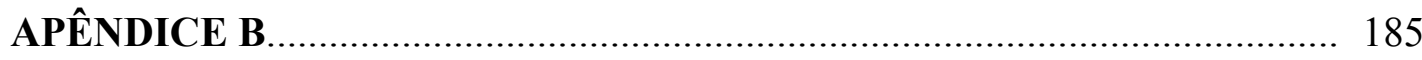




\section{INTRODUÇÃO}

O cenário econômico mundial vem se modificando em decorrência dos avanços tecnológicos, da globalização, das megafusões e da maior conscientização ecológica. Tais mudanças implicam aumento da competitividade, obrigando as organizações a criarem soluções inovadoras, para se manterem vivas no mercado.

O mercado global sinaliza para um novo modelo de gestão baseado principalmente, na redução: dos custos dos produtos e das margens de lucratividade, além da melhoria substancial do nível de serviços logísticos. Um sistema inteligente e eficaz de logística, interno e externo, é elemento fundamental para a manutenção ou estabelecimento da competitividade das organizações.

De maneira geral, os custos produtivos e a qualidade dos produtos tendem a um grau de semelhança cada vez mais elevado. Sendo assim, o diferencial está nas operações logísticas, ou seja, na capacidade dos produtos chegarem ao cliente final na quantidade e qualidade certa, no tempo esperado e a um preço justo.

As empresas que hoje se destacam pela excelência em logística vêm modelando problemas, utilizando mais intensamente as técnicas de Pesquisa Operacional (PO) como simulação e otimização, de maneira a minimizar o impacto das interfaces de processo, reduzindo custos e aumentando a competitividade.

Hoje, na Cadeia de Minérios de Ferro, devido às características específicas deste sistema, a evolução das ferramentas de Tecnologia da Informação e o avanço das técnicas de PO têm despertado interesses na procura de melhores soluções integradas, desde a lavra até o elo seguinte da cadeia, sendo este uma simples operação de metalurgia extrativa dentro da mesma empresa, ou uma interface de transporte e/ou de estocagem, de um cliente para outro.

Com o aprofundamento dos conceitos de programação matemática, o seu uso na tomada de decisão em sistemas com variáveis que possuem comportamentos estocásticos, como acontece na Cadeia de Minérios de Ferro, tem dado lugar à utilização de técnicas de simulação.

Essa mudança permite que, mediante a utilização de modelos probabilísticos, seja possível simular o processo com um nível de detalhamento mais aprofundado da cadeia, auxiliando na busca do gargalo, no dimensionamento dos recursos, na análise de custos logísticos e no nível de serviço associado aos diferentes cenários, 
por exemplo, subsidiando decisões técnicas e gerenciais que possam levar à otimização do negócio.

As características específicas ou abordagens que estas técnicas se propõem a resolver devem ser avaliadas. Algumas são para tomadas de decisão em que um conjunto de restrições é considerado e busca-se a decisão ótima, através da maximização ou minimização de um objetivo particular; e outras para testar os efeitos de uma decisão feita, anteriormente, por um gestor ou outro aplicativo qualquer.

Desta forma, o objeto de estudo deste trabalho é desenvolver e aplicar um método que combine técnicas de simulação e otimização, de forma a potencializar as principais características de cada uma destas técnicas, garantindo a integração, aprendizagem e o melhoramento das tomadas de decisões empresariais.

\subsection{MOTIVAÇÃO PARA A PESQUISA}

O mercado de minérios de ferro e aço está extremamente aquecido nesta primeira década do século $\mathrm{XXI}$, e, como mostram os especialistas neste assunto (conforme será apresentado no capítulo 2 deste trabalho), deverá permanecer desta forma por, no mínimo, mais 5 ou 10 anos.

Com o aumento substancial de preços das "commodities", principalmente os minérios de ferro, nesta década, há, nas indústrias ou corporações, uma alta disponibilidade de recursos para bons projetos.

Deste modo, a empresa que tiver condições de tomar decisões estratégicas melhores, mais rápidas e mais fundamentadas garantirá a perpetuidade do negócio neste mundo competitivo.

Assim, deve-se avaliar que o processo de tomada de decisões, em ambientes industriais, possui uma elevada complexidade, devido às suas características sistêmicas e estocásticas, uma vez que soluções otimizadas localmente podem prejudicar o desempenho global do sistema produtivo.

Entretanto, essa visão sistêmica é de difícil observação, quando tratada de uma maneira local e isolada, possibilitando a existência de um conjunto de 
percepções difusas sobre a realidade, que possa vir a prejudicar a solução do problema ou oportunidade.

A modelagem é uma abordagem fundamental para o melhor entendimento das complexas relações existentes em um processo empresarial. Essa modelagem é desenvolvida em vários níveis, desde o planejamento estratégico global até a programação final de curto prazo.

Ao longo desses diferentes níveis de planejamento, uma série de técnicas de modelagem pode ser utilizada na tentativa de compreensão do processo produtivo e de apoio à tarefa de tomada de decisões.

Para tanto, a modelagem matemática procura descrever um sistema real a partir de um conjunto de restrições (de capacidade, financeiras, de suprimento, de transporte, mercadológicas) e, conforme um determinado objetivo (maximização de lucro ou minimização de custos), procura uma solução ótima para o modelo desenvolvido. Entretanto, essa abordagem apresenta alguns pressupostos:

$\checkmark \quad$ Determinismo dos dados

$\checkmark \quad$ As informações são estáticas

$\checkmark \quad$ Consistência dos dados.

Isto posto, uma ferramenta que possa testar e quantificar o efeito de um projeto, seja ele para solução de um problema específico ou de busca de uma oportunidade, melhoraria tanto as informações de entrada em um processo de tomada de decisão, em que seria avaliado, por exemplo, o melhor período do investimento, quanto a acertividade das projeções econômico-financeiras do negócio, auxiliando na sustentabilidade do negócio.

\subsection{OBJETIVOS}

\subsubsection{Objetivo geral}

O principal objetivo é o desenvolvimento e aplicação de um método de tomada de decisão, que utilize simulação-otimização durante o processo de planejamento do negócio. 
Este método será aplicado na cadeia produtiva de minérios de ferro da Samarco Mineração S/A, com o propósito de melhorar a qualidade das informações do processo de escolha da melhor alternativa empresarial de investimentos para os próximos 05 anos do negócio desta empresa.

\subsubsection{Objetivos específicos}

1. Analisar a evolução das técnicas de simulação-otimização de forma a atender às necessidades atuais de integração na resolução de problemas de sistemas logísticos presentes na Cadeia de Minérios de Ferro.

2. Avaliar e confrontar os conceitos de simulação e otimização com as metodologias de simulação-otimização.

3. Construir um modelo de simulação por eventos discretos de uma cadeia produtiva de minérios, desde a lavra até o estoque de produto acabado.

4. Integrar as informações do simulador a um modelo matemático de otimização das decisões de negócio de uma indústria de beneficiamento e aglomeração de minérios de ferro, a um método de simulação-otimização.

5. Avaliar o benefício que a integração destes dois modelos (simulação e otimização) em um único método de tomada de decisão pode trazer para este tipo de indústria.

\subsection{MÉTODO DE TRABALHO}

"A elaboração de um projeto de pesquisa e o desenvolvimento da própria pesquisa, seja ela uma dissertação ou tese, necessitam, para que seus resultados sejam satisfatórios, estar baseados em planejamento cuidadoso, reflexões conceituais sólidas e alicerçados em conhecimentos já existentes" (SILVA; MENEZES, 2001, p. 29). 
Com base na abordagem acima, buscou-se uma metodologia para orientar o planejamento da pesquisa e a elaboração da dissertação, de forma que os resultados fossem satisfatórios e consistentes.

Este trabalho seguiu as seguintes etapas:

a) escolha do tema;

b) definição do problema;

c) revisão de literatura;

d) definição do método de pesquisa;

e) modelagem conceitual e construção dos modelos computacionais;

f) planejamento da investigação;

g) análise dos resultados e elaboração das conclusões;

h) recomendações finais.

a) Escolha do tema

O mundo presenciou na década de 90 o início do processo de criação de blocos econômicos que visam à facilitação de negociações entre diferentes países. (Cassel,1996)

Mais do que nunca, as distâncias existentes entre uma parte e outra do nosso planeta não são mais restrições para a realização de negócios.

Esta corrida intercapitalista vem fazendo com que as empresas, cada vez, mais procurem se sobressair e atender melhor aos seus clientes buscando obter seus nichos de mercado e evitando que seus concorrentes as ultrapassem. Este fato acarreta um mercado muito instável, em que, a cada dia, novas mudanças ocorrem visando à satisfação do cliente e à aquisição de uma fatia de mercado.

Esta nova postura dinâmica do mercado, em grande parte causada pela visão de várias companhias em diversificar seus centros de consumo, buscando globalizar seus mercados, fez com que as empresas começassem a se preocupar com o tempo requerido, para as tomadas de decisão dentro da corporação.

Para que empresas possam se manter competitivas, é necessário que tais decisões sejam tomadas de forma rápida e acertadas.

Existem formas de se tomar decisões rápidas, como a utilização da experiência empírica, mas que, no entanto, muitas vezes não levam às decisões acertadas, pois são tomadas no ímpeto de se resolver logo o problema, desconsiderando uma análise mais cuidadosa de suas possíveis conseqüências. 
Existem formas de se tomar decisões acertadas como, por exemplo, fazendose um estudo analítico do problema, mas que, muitas vezes, não são rápidas. Isto ocorre pelo fato de que estes estudos procuram analisar todas as possíveis conseqüências das decisões tomadas, fazendo com que se gaste muito tempo em sua análise.

Portanto, se fosse possível tomar uma decisão rápida e saber de antemão quais as conseqüências que esta decisão iria causar, muitos problemas seriam evitados e solucionados, de acordo com o que o mercado exige nos dias de hoje, rapidez e eficácia.

Em suma, o que se necessita é de uma ferramenta que consiga representar tanto a realidade do negócio, quanto do sistema produtivo, mostrando as conseqüências que algumas mudanças iriam causar no sistema econômico/financeiro e no processo produtivo real.

Assim, a escolha de um tema que ajude às tomadas de decisão empresariais buscando a melhor opção, integrada a um processo de simulação que avalie o efeito de qualquer mudança no sistema real está diretamente relacionada: à linha de pesquisa 1, "Modelagem, Projetos e Análise de Sistemas Logísticos" do Programa de Mestrado em Engenharia de Sistemas Logísticos da Escola Politécnica da Universidade de São Paulo (USP), linha que abrange o desenvolvimento e o uso de métodos quantitativos para projeto, geração e análise econômico-operacional de sistemas logísticos e aos argumentos apresentados, anteriormente, no subitem 1.1 "Motivação para a pesquisa", deste mesmo capítulo. É orientador deste trabalho o professor titular da USP, Dr. Rui Carlos Botter.

\section{b) Definição do problema}

Para Silva e Menezes (2001), na literatura da área de metodologia científica, podem-se encontrar muitas recomendações a respeito da formulação do problema de pesquisa. Os autores citam Gil (1999) que considera que as recomendações não devem ser rígidas e devem ser observadas como parâmetros para facilitar a formulação de problemas. Algumas dessas recomendações estão descritas abaixo:

- problema deve ser formulado como pergunta, para facilitar a identificação do que se deseja pesquisar; 
- problema tem que ter dimensão viável: deve ser restrito para permitir a sua viabilidade, uma vez que, formulado de forma ampla, poderá tornar inviável a realização da pesquisa;

- problema deve ter clareza: os termos adotados devem ser definidos para esclarecer os significados que estão sendo usados na pesquisa;

- problema deve ser preciso: além de definir os termos, é necessário que sua aplicação esteja delimitada.

Nos capítulos 1 e 2 deste trabalho, é apresentada toda a contextualização e identificação do problema de pesquisa, que fundamenta a aplicação do método que foi descrito e avaliado nos capítulos 5 e 6.

De forma resumida, a formulação de um problema empresarial qualquer, que também pode ser aplicado neste caso particular, pode ser apresentada pelas seguintes indagações:

- Como manter o negócio competitivo, garantindo o sucesso na escolha dos investimentos?

- Como integrar as decisões empresariais e operacionais?

- Como melhorar o desempenho na escolha da melhor decisão empresarial avaliando seus efeitos e reflexos no processo produtivo?

- Como melhorar as informações de projetos, com visão local, no processo decisório global de investimentos do negócio?

c) Revisão de literatura

Silva e Menezes (2001, p. 30) fazem valiosas considerações a respeito da revisão bibliográfica:

[...] Nesta fase deve-se responder às seguintes questões: quem já escreveu e o que já foi publicado sobre o assunto, que aspectos já foram abordados, quais as lacunas existentes na literatura. Pode objetivar determinar o "estado da arte", ser uma revisão teórica, ser uma revisão empírica ou ainda ser uma revisão histórica.

A revisão de literatura é fundamental, porque fornecerá elementos para se evitar a duplicação de pesquisas sobre o mesmo enfoque do tema. Favorecerá a definição de contornos mais precisos do problema a ser estudado.

Sendo uma das etapas mais importantes de um projeto de pesquisa a revisão de literatura refere-se à fundamentação teórica que será adotada 
para tratar o tema e o problema de pesquisa. Por meio da análise da literatura publicada será traçado um quadro teórico e será feita a estruturação conceitual que dará sustentação ao desenvolvimento da pesquisa. [...]

A revisão de literatura resultará do processo de levantamento e análise do que já foi publicado sobre o tema e sobre o problema de pesquisa escolhidos. Permitirá um mapeamento do que já foi escrito sobre o tema e/ou problema da pesquisa e de quem o escreveu.

A revisão de literatura deverá elucidar o tema, proporcionar melhor definição do problema de pesquisa, servir de sustentação ao processo de formulação das hipóteses e contribuir para a análise e discussão dos resultados.

A revisão de literatura será apresentada nos capítulos 3 e 4 e consistiu-se de consultas a artigos, periódicos, anais, livros, páginas especializadas da Internet e outros trabalhos de pós-graduação, por meio das quais foi possível fazer um levantamento das aplicações de simulação e otimização, além das técnicas e das características utilizadas pelos autores na aplicação de simulação-otimização.

\section{d) Método de pesquisa}

Este capítulo apresenta as considerações do autor, quanto ao método de pesquisa utilizado na elaboração desta dissertação.

Segundo Silva e Menezes (2000), "pesquisar significa, de forma bem simples, buscar respostas para indagações propostas", porém a pesquisa pode ser classificada segundo sua natureza, abordagem, objetivos e procedimentos técnicos, conforme apresentado na Tabela 1.1.

Levando-se em consideração a classificação e a tipologia de pesquisa apresentada na Tabela 1.1, este trabalho está enquadrado em uma pesquisa de natureza aplicada por objetivar a proposição de uma solução a um problema específico.

Quanto à sua abordagem, é uma pesquisa qualitativa, pois se desenvolve através um processo de interpretação dos fenômenos e a atribuição de significados são básicos no processo de pesquisa.

Quanto ao objetivo, está classificada como uma pesquisa exploratória, por buscar um maior entendimento do processo alvo. 
E, finalmente, quanto aos procedimentos técnicos, é uma pesquisa bibliográfica, pois, foi elaborada a partir de material já publicado, constituído principalmente de livros, artigos de periódicos e, atualmente, de material disponibilizado pela internet.

Segundo Pinsonneaut e Kraemer (1993), a pesquisa exploratória procura levantar características inéditas, possibilitando estabelecer prioridades para futuros estudos.

Seu objetivo principal é desenvolver hipóteses e proposições que irão redundar em pesquisas complementares. Desta forma, a pesquisa exploratória esforça-se em definir novos conceitos a serem estudados.

A pesquisa bibliográfica exploratória ajusta-se à proposta de pesquisas em temas que são pouco explorados e, portanto, torna-se difícil formular hipóteses operacionalizáveis.

Outro ponto em que a pesquisa bibliográfica exploratória se torna uma metodologia válida são os processos, que, devido a questões de temporalidade, o pesquisador prefere dividir o tema em etapas de desenvolvimento de familiarização com o conhecimento e este serve de base para outros trabalhos futuros.

Conforme descrito, nos objetivos deste trabalho, a meta é o desenvolvimento de um método de tomada de decisão, que de uma maneira geral busca um melhor de gerenciamento e/ou planejamento empresarial.

Não se trata, também, de um possível estudo de caso, pois se trata de um método considerado recente e faltam casos de implantação para estudo.

Portanto, a escolha de uma pesquisa exploratória bibliográfica cumprirá com o objetivo de trazer familiaridade com o objeto do estudo e preparará o caminho para outras pesquisas que deverão trazer aprofundamento no tema.

Este trabalho está estruturado no desenvolvimento de uma pesquisa bibliográfica exploratória na literatura disponível, buscando aspectos teóricos e práticos relacionados à aplicação de métodos de simulação-otimização. 
Tabela 1.1: Classificações de uma pesquisa.

\begin{tabular}{|c|c|c|}
\hline Classificação & Tipo de Pesquisa & Descrição \\
\hline \multirow{2}{*}{ Natureza } & Básica & $\begin{array}{l}\text { Pesquisa que objetiva gerar conhecimentos novos e úteis para o } \\
\text { avanço da ciência sem aplicação prática prevista. }\end{array}$ \\
\hline & Aplicada & $\begin{array}{l}\text { Objetiva gerar conhecimentos para a aplicação prática dirigida à } \\
\text { solução de problemas específicos. }\end{array}$ \\
\hline \multirow[b]{2}{*}{ Abordagem } & Quantitativa & $\begin{array}{l}\text { Pesquisa aplicada através de estudos estatísticos voltados à } \\
\text { quantificação do objeto de estudo. }\end{array}$ \\
\hline & Qualitativa & $\begin{array}{l}\text { Pesquisa em que o processo de interpretação dos fenômenos e } \\
\text { a atribuição de significados são básicos no processo de } \\
\text { pesquisa. Os dados são analisados indutivamente. }\end{array}$ \\
\hline \multirow{3}{*}{ Objetivos } & Exploratória & $\begin{array}{l}\text { Visa a proporcionar maior familiaridade com o objeto do estudo, } \\
\text { tentando torná-lo explícito, ou construir hipóteses. }\end{array}$ \\
\hline & Descritiva & $\begin{array}{l}\text { Visa a descrever as características de determinada população } \\
\text { ou fenômeno, ou ainda o estabelecimento de relação entre } \\
\text { variáveis. }\end{array}$ \\
\hline & Explicativa & $\begin{array}{l}\text { Visa a identificar fatores que determinam ou contribuem para a } \\
\text { ocorrência de fenômenos. Aprofunda o conhecimento porque } \\
\text { explica o "porquê" das coisas. }\end{array}$ \\
\hline \multirow{8}{*}{$\begin{array}{l}\text { Procedimentos } \\
\text { Técnicos }\end{array}$} & Bibliográfica & $\begin{array}{l}\text { Quando elaborada a partir de material já publicado, constituído } \\
\text { principalmente de livros, artigos de periódicos e, atualmente, de } \\
\text { material disponibilizado na Internet. }\end{array}$ \\
\hline & Documental & $\begin{array}{l}\text { Quando elaborada a partir de materiais que não receberam } \\
\text { tratamento analítico. }\end{array}$ \\
\hline & Experimental & $\begin{array}{l}\text { Quando se determina um objeto de estudo. Selecionam-se as } \\
\text { variáveis que seriam capazes de influenciá-lo. Definem-se as } \\
\text { formas de controle e de observação dos efeitos que a variável } \\
\text { produz no objeto. }\end{array}$ \\
\hline & Levantamento & $\begin{array}{l}\text { Quando a pesquisa envolve a interrogação direta às pessoas } \\
\text { cujo comportamento se deseja conhecer. }\end{array}$ \\
\hline & Estudo de Caso & $\begin{array}{l}\text { Quando envolve o estudo profundo de um ou poucos objetos de } \\
\text { maneira que se permita o seu amplo e detalhado conhecimento. }\end{array}$ \\
\hline & Pesquisa-Ação & $\begin{array}{l}\text { Quando concebida e realizada em estreita associação com uma } \\
\text { ação ou com a resolução de um problema coletivo. O } \\
\text { pesquisador e os participantes estão envolvidos de modo } \\
\text { cooperativo e participativo. }\end{array}$ \\
\hline & $\begin{array}{l}\text { Pesquisa- } \\
\text { Participante }\end{array}$ & $\begin{array}{l}\text { Quando a pesquisa se desenvolve a partir da interação entre } \\
\text { pesquisadores e os membros da situação investigada. }\end{array}$ \\
\hline & Expost-Facto & $\begin{array}{l}\text { Quando o "experimento" se realiza após o acontecimento dos } \\
\text { fatos. }\end{array}$ \\
\hline
\end{tabular}

Fonte: Adaptado de SILVA, E.L e MENEZES, E. M. (2000).

e) Modelagem conceitual e construção dos modelos computacionais

Após a caracterização do problema e a revisão bibliográfica, serão descritos no capítulo 5, "Aplicação de um método de simulação-otimização na cadeia produtiva de minérios de ferro", os modelos conceituais, representando o sistema produtivo de aglomerados de minérios de ferro e a conceitualção do modelo empresarial de tomada de decisão (com suas visões econômica e financeira). 


\section{f) Planejamento da investigação}

No capítulo 5, "Aplicação de um método de simulação-otimização na cadeia produtiva de minérios de ferro", será apresentado, por completo, o planejamento da investigação que avaliará os seguintes cenários:

1. Processo atual de busca de informação dos projetos,

2. Passagem das informações individuais de cada projeto pelo modelo de Simulação,

3. Passagem das informações da carteira de projetos sugerida pelo modelo de otimização no simulador,

mensurando seus resultados, através das saídas do modelo de otimização, em que este quantificará o valor da empresa em cada uma destas possíveis alternativas.

g) Análise dos resultados e elaboração das conclusões e recomendações

Nesta etapa serão feitas a interpretação e análise dos dados que foram tabulados e organizados na etapa anterior. Segundo Silva e Menezes (2001), a análise deve ser feita para atender aos objetivos da pesquisa e para comparar e confrontar dados e provas, com o objetivo de confirmar ou rejeitar a(s) hipótese(s) ou os pressupostos da pesquisa.

Os autores, ainda, argumentam que, nessa etapa, já se tem condições de sintetizar os resultados obtidos com a pesquisa. Deve-se explicitar se os objetivos foram atingidos, se a(s) hipótese(s) ou os pressupostos foram confirmados ou rejeitados. Principalmente, deve-se ressaltar a contribuição da pesquisa para o meio acadêmico ou para o desenvolvimento da ciência e da tecnologia. Essas considerações estarão apresentadas no capitulo 6, "Conclusões e Recomendações", deste trabalho.

\subsection{DELIMITAÇÃO DA PESQUISA}

O estudo aqui proposto delimita-se pelo escopo na modelagem do processo produtivo e decisório, aplicado em uma indústria de mineração, no caso a Samarco Mineração S/A, desde o beneficiamento dos minérios de ferro, transporte, 
aglomeração e estocagem, ao processo de tomada de decisão econômico-financeiro do planejamento do negócio.

O plano de negócio é uma ferramenta de visualização do desempenho esperado da companhia para os próximos 5 anos, alinhando as diversas iniciativas à estratégia de longo prazo. O plano de negócio também tem por objetivo assegurar que as questões críticas da empresa e suas metas de crescimento sejam endereçadas de forma estruturada e adequada, facilitando a priorização e o acompanhamento de projetos/iniciativas além de gerar informações relevantes para o processo de orçamentação anual.

A escolha desta empresa deve-se ao fato da facilidade de se obter dados e outras informações necessárias à elaboração deste trabalho.

Não foi objetivo desta pesquisa estudar as especificidades técnicas de cada processo de mineração nem de análise do processo financeiro de tomada de decisão.

O simulador criado servirá somente para análise de cenários específicos da Samarco Mineração S/A, pois os processos de produção de aglomerados de minérios de ferro se diferem de empresa para empresa, não sendo, portanto, aconselhável aplicá-lo em outros sistemas industriais, sem as devidas adaptações necessárias.

O modelo de otimização utilizado servirá somente para análise específica de cenários econômico-financeiros da Samarco Mineração S/A, pois envolve processos financeiros específicos de tomada de decisão desta empresa e se forem aplicados em outras organizações devem ser levadas em consideração as características específicas do negócio de cada empresa.

\subsubsection{Técnicas aplicadas}

Para este trabalho foram aplicadas técnicas de:

- modelagem matemática conceitual do negócio e das operações de produção de aglomerados de minérios de ferro;

- simulação probabilística por eventos discretos;

- programação linear. 


\subsubsection{Ferramentas para a implementação}

Para a implementação do método proposto neste trabalho, foram utilizadas algumas ferramentas computacionais, tais como:

- Microsoft Office Excel 2003

- Arena 8.0 - Rockwell Software Inc

- Lingo 10.0 - Lindo Inc.

\subsubsection{Período de validade dos dados}

Os dados utilizados para a validação dos modelos computacionais, criados neste trabalho, refletem o período de Janeiro de 2005 a Dezembro de 2006. 


\section{NEGÓCIO E OPERAÇÕES DA MINERAÇÃO DE FERRO}

\subsection{RETRATO ATUAL DA ECONOMIA MUNDIAL}

O mundo, nos 5 últimos anos, tem passado por um próspero período de crescimento. Os países alavancadores deste período são os Estados Unidos e principalmente a China, que, até hoje, vem usufruindo de uma fase de seu desenvolvimento espetacular, impulsionada por seu crescimento industrial.

As previsões feitas pelo 100 (2005) indicam uma prolongação desta tendência de crescimento mundial, com taxas de crescimento do $\mathrm{PIB}^{2}$ global por volta de $4 \%$ a.a. e do crescimento industrial de $5 \%$ a.a, conforme ilustrado na Figura 2.1.

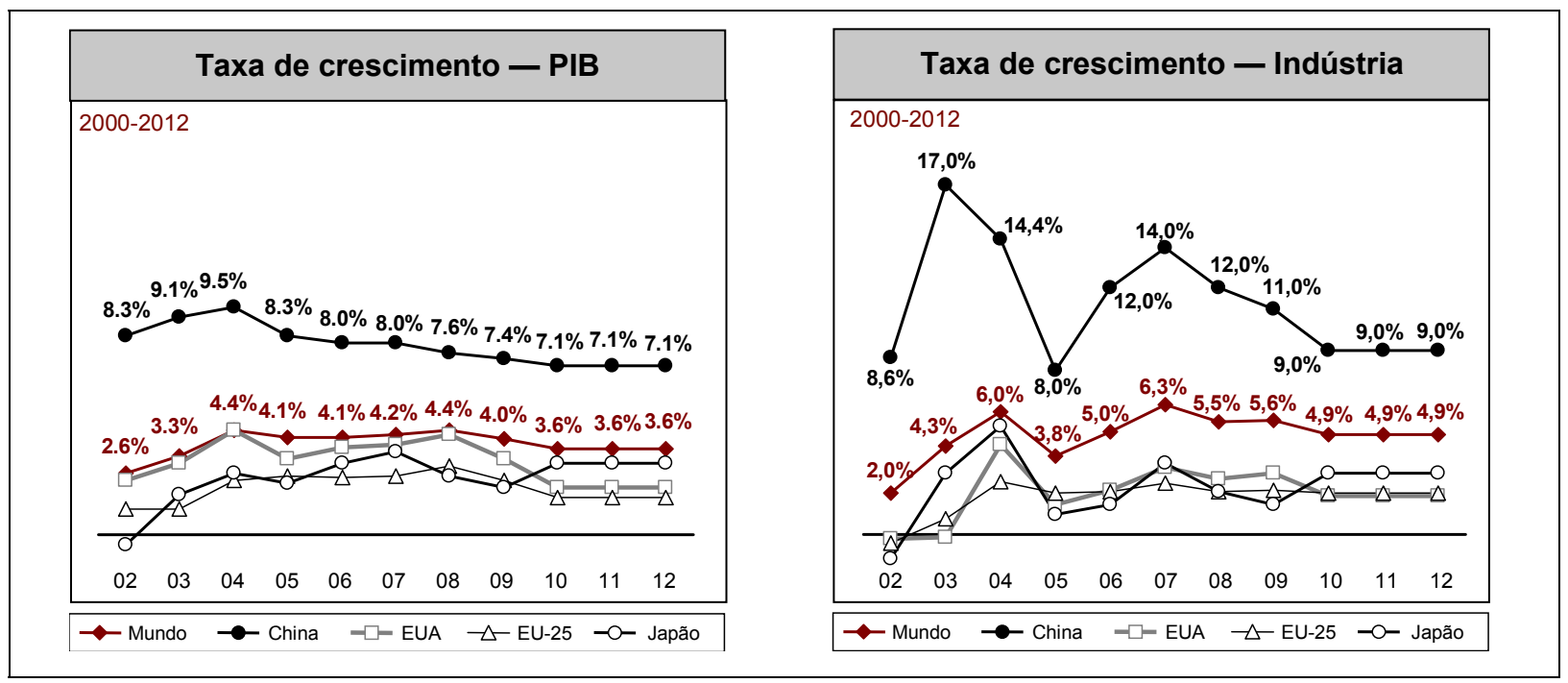

Figura 2.1: Taxa de crescimento esperada do PIB e da indústria mundial Fonte: 10O, 2005.

O viés expansionista da política monetária dos principais países, de acordo com as previsões de mercado, será removido de forma gradual, como forma de ajuste a um estágio mais avançado do ciclo. Como as expectativas de inflação seguem bem comportadas, acredita-se que as políticas monetárias não põem em risco a expansão da economia mundial.

\footnotetext{
${ }^{2}$ PIB - Produto Interno Bruto
} 


\subsubsection{Implicações nos mercados de aço e minério de ferro}

O IOO (2005) afirma que o crescimento mundial puxará a demanda mundial de aço, o que deverá ter reflexos positivos nos mercados de minérios de ferro e pelotas.

O maior aumento da demanda de aço deverá ocorrer na China e Índia devido a suas expansões urbanas e ao êxodo rural que se anuncia.

A produção chinesa de aço deverá ter um $\mathrm{CAGR}^{3}$ em torno de $7,6 \%$ entre 2005-12, passando a representar, desta forma, aproximadamente $40 \%$ da produção mundial. As previsões de consumo de aço na Índia também são expressivas.

É bom lembrar que a transformação da China de grande importadora de aço para grande exportadora, foi muito rápida e que novas mudanças podem ocorrer na mesma velocidade.

As políticas de não incentivo às exportações, de controle de produção e fechamento dos produtores de menor capacidade produtiva de aço podem emplacar, nestes próximos anos, podendo agravar, ainda mais, o mercado interno de preços, levando ao fechamento de usinas.

Os dois fatores mais significativos que podem afetar o mercado de minérios de ferro são: a participação do minério indiano que tem como principal destino a China, e a consolidação e a capacitação da indústria mineradora na região da $\mathrm{CEI}^{4}$.

O grande aumento da produção de aço alavancará a demanda por minério de ferro no mercado mundial, conforme apresentado na Figura 2.2.

O mercado transoceânico ("seaborne") de minérios de ferro crescerá a taxas mais elevadas do que o mercado global, devido ao descasamento entre os principais mercados produtores (Brasil, Austrália e outros) e consumidores (China, Japão, e outros).

A China, com um CAGR de $11 \%$ entre $2005-12$, será o maior consumidor do mercado seaborne de minérios de ferro no mundo.

\footnotetext{
${ }^{3}$ CAGR - "compound annual growth rate" - taxa de crescimento anual composta

${ }^{4} \mathrm{CEI}$ - Comunidade dos Estados Independentes
} 


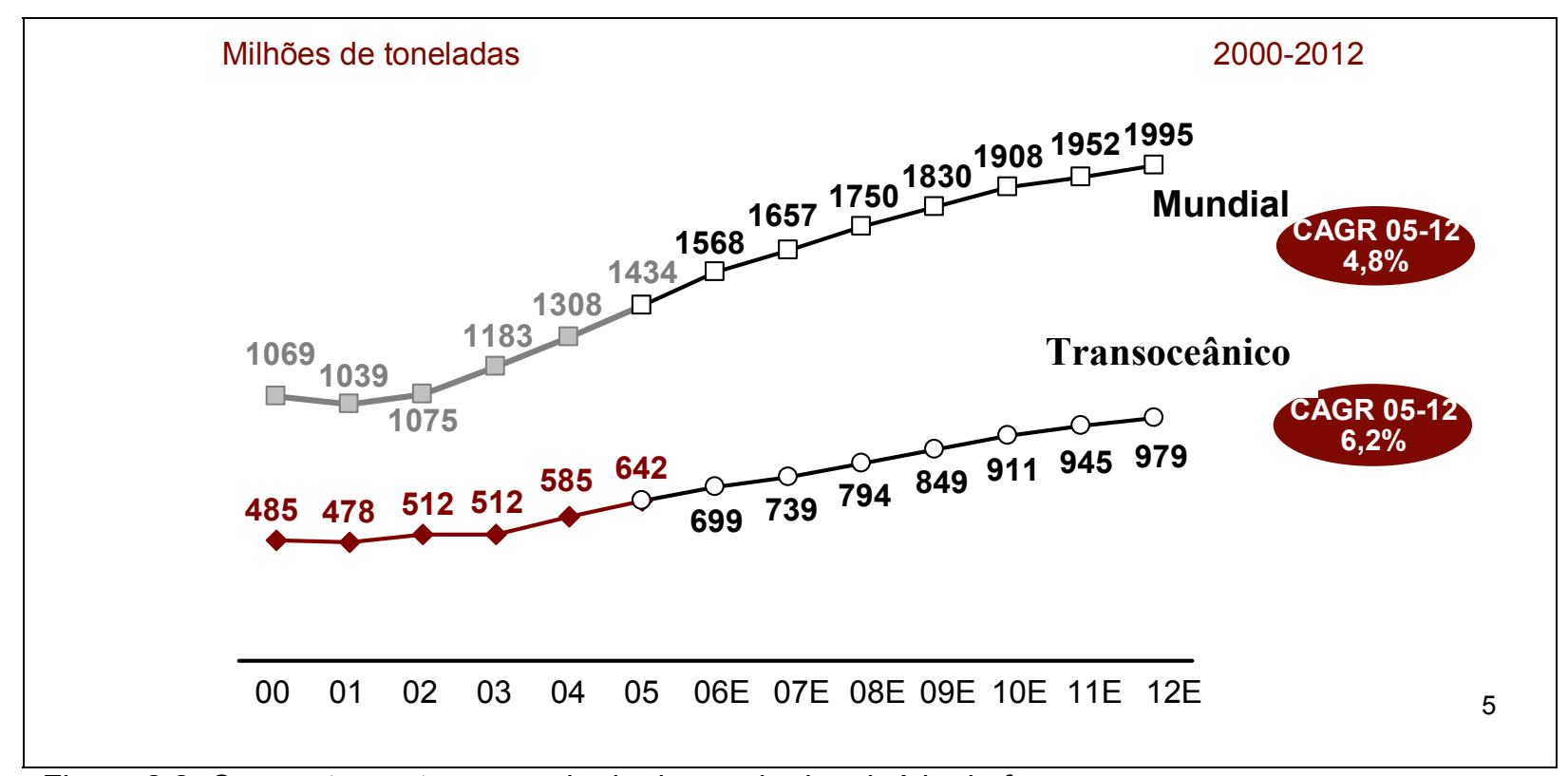

Figura 2.2: Comportamento esperado da demanda de minério de ferro Fonte: IOO, 2005.

\subsubsection{Implicações no mercado de pelotas}

O mercado mundial de pelotas é um segmento do mercado mundial de minérios de ferro e segue suas principais tendências, mas com algumas particularidades.

De acordo com o IOO (2005), a demanda de pelotas continuará crescente. No entanto, diferentemente do mercado de minérios de ferro, as importações crescerão menos (4,2\% a.a.) do que o mercado como um todo (5,9\% a.a.), principalmente em função das novas usinas de pelotização que estão sendo construídas próximas às siderúrgicas, conforme ilustrado na Figura 2.3.

O maior mercado consumidor de pelotas e o que terá maior crescimento será a China. No entanto, com o grande número de novas usinas de pelotização sendo construídas em território chinês, boa parte deste crescimento será absorvida internamente. O maior mercado importador de pelotas, em 2012, deverá ser a Índia e Oriente Médio. A Índia, em particular, deverá apresentar altas taxas de crescimento, contribuindo para maior demanda por pelotas.

\footnotetext{
${ }^{5} 06 \mathrm{E}, 07 \mathrm{E}, 08 \mathrm{E}, 09 \mathrm{E}, 10 \mathrm{E}, 11 \mathrm{E}$, e $12 \mathrm{E}$ : a letra "E" ao lado dos números representam que os anos do período de 2006 a 2012 são dados estimados.
} 


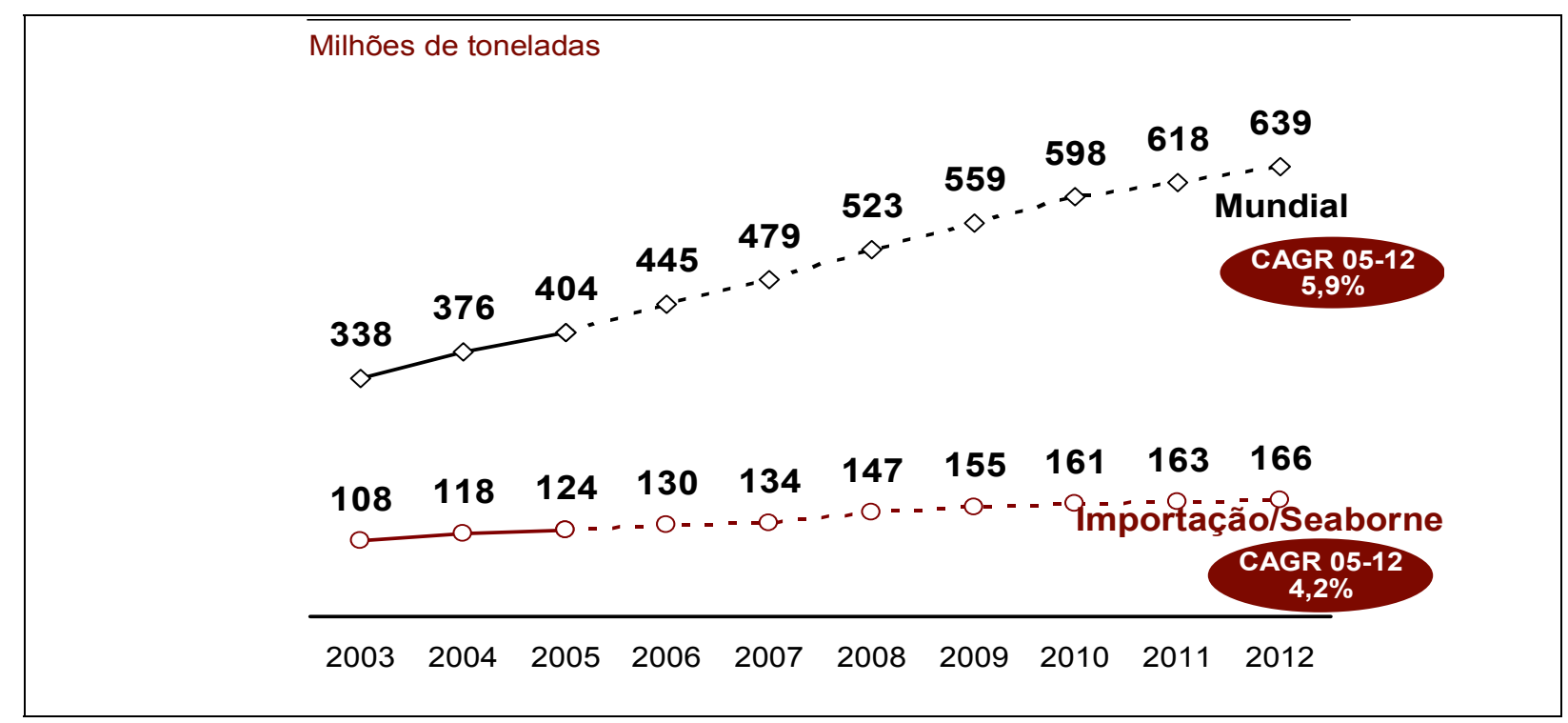

Figura 2.3: Comportamento esperado da demanda de pelotas

Fonte: CRU, 2006.

\subsection{AVALIAÇÃO DO AUMENTO DA OFERTA PREVISTA NO MERCADO DE PELOTAS}

Novos projetos de usinas de pelotização em estudo deverão tornar-se realidade ao longo dos cinco próximos anos. A maior parte dos investimentos será realizada por minas chinesas, pela indústria siderúrgica ou por outros pequenos players, denotando que, mesmo com a necessidade de altos investimentos, neste nível de preços, os projetos tornam-se atrativos.

Os investimentos "upstream" das siderúrgicas, na produção de pelotas, (observados, sobretudo na China) produzem um duplo efeito na demanda:

$\checkmark$ reduzem a demanda transoceânica, pela substituição pela produção doméstica de menor custo; e

$\checkmark$ alteram os padrões de qualidade exigidos, uma vez que a produção doméstica pode exigir diferentes materiais de blendagem para atingir a qualidade final exigida.

O aumento planejado de capacidade, com data de entrada em operação até 2010 , representa um acréscimo de $27 \%$ na capacidade mundial (base IOO, 2005). 
Novos "players" respondem por $83 \%$ do acréscimo planejado de capacidade em pelotas, com estes investimentos representando $25 \%$ da capacidade mundial de pelotas em 2010.

\subsubsection{Análise de oferta e demanda de minérios de ferro e pelotas}

O grande aumento de demanda de minérios de ferro elevou os preços no curto prazo, devido ao tempo necessário para o estabelecimento do novo patamar da oferta.

O aumento de oferta ocorrerá, nos próximos anos, melhorando o balanço oferta/demanda, que, no entanto, ainda permanecerá no limite da capacidade técnica, como ilustrado na Figura 2.4. Como conseqüência de um maior equilíbrio oferta/demanda, os preços diminuirão (em termos reais), mas mantendo-se ainda em um nível relativamente alto, conforme análises da Credit Suisse (2006) e IOO (2005).

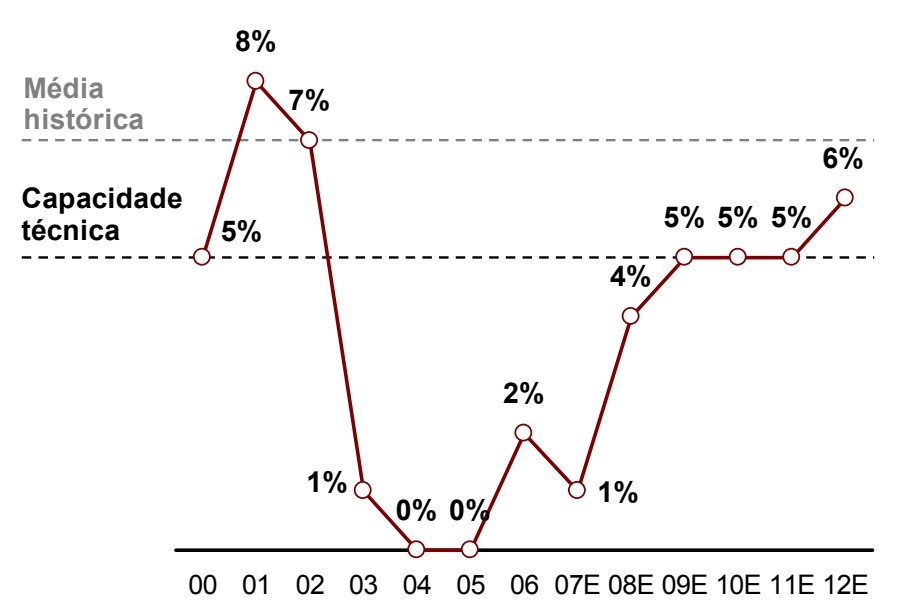

Nota:

1)Balanço é igual a (capacidade/demanda)-1

2)Capacidade Técnica é o limite o qual a indústria trabalha sem restrições

Figura 2.4: Balanço oferta e demanda para o mercado de minério de ferro Fonte:CREDIT SUISSE, 2006 e IOO, 2005;

\footnotetext{
${ }^{6} 07 \mathrm{E}, 08 \mathrm{E}, 09 \mathrm{E}, 10 \mathrm{E}, 11 \mathrm{E}$, e 12E: a letra "E" ao lado dos números representam que os anos do período de 2007
} a 2012 são dados estimados. 
Mesmo com a crescente demanda, não há um descasamento da oferta devido à criação de novas usinas de pelotização. Desta forma, o balanço oferta versus demanda mantém-se em um patamar acima da capacidade técnica (devido à capacidade ociosa ocorrida principalmente em usinas de pelotização, diretamente relacionadas a siderúrgicas chinesas, mas com baixa possibilidade de comercialização devido à falta de infra-estrutura).

No entanto, o preço de pelotas deverá manter a mesma trajetória do preço de minérios de ferro, por exemplo, o preço deverá cair em termos reais, mas sem voltar ao patamar mais baixo de antes dos grandes aumentos (2005), conforme se pode observar na Figura 2.5.

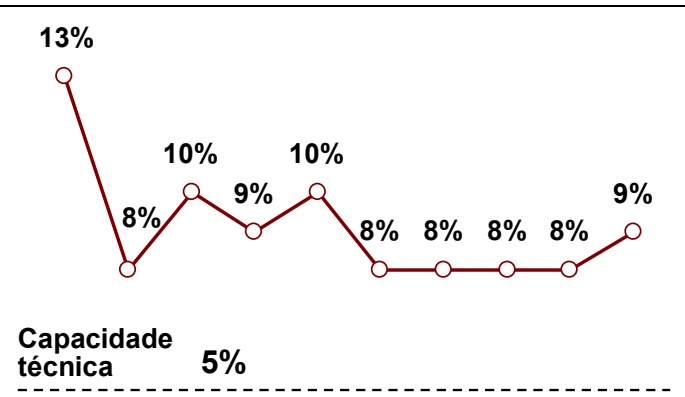

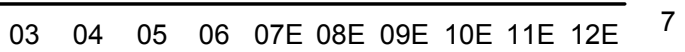

Nota:

1) Balanço é igual a (capacidade/demanda)-1

2)Capacidade técnica é o limite o qual a indústria trabalha sem restrições

Figura 2.5: Balanço oferta e demanda para o mercado de pelotas

Fonte: CREDIT SUISSE, 2006 e IOO, 2005

\subsection{PRINCIPAIS “PLAYERS” DO MERCADO DE PELOTAS}

O mercado mundial de minérios de ferro, conforme ilustrado na Figura 2.6, é dominado por três grandes corporações, a Companhia Vale do Rio Doce (CVRD), a Rio Tinto e a BHP Billiton (BHPB). No mercado de pelotas, os principais players são a própria CVRD, Samarco, LKAB e IOC.

\footnotetext{
${ }^{7}$ 07E, 08E, 09E, 10E, 11E, e 12E: a letra “E” ao lado dos números representam que os anos do período de 2007 a 2012 são dados estimados.
} 
Desta forma, observa-se que, através de suas próprias operações e as de suas subsidiárias, as três grandes empresas também dominam o mercado de pelotas.
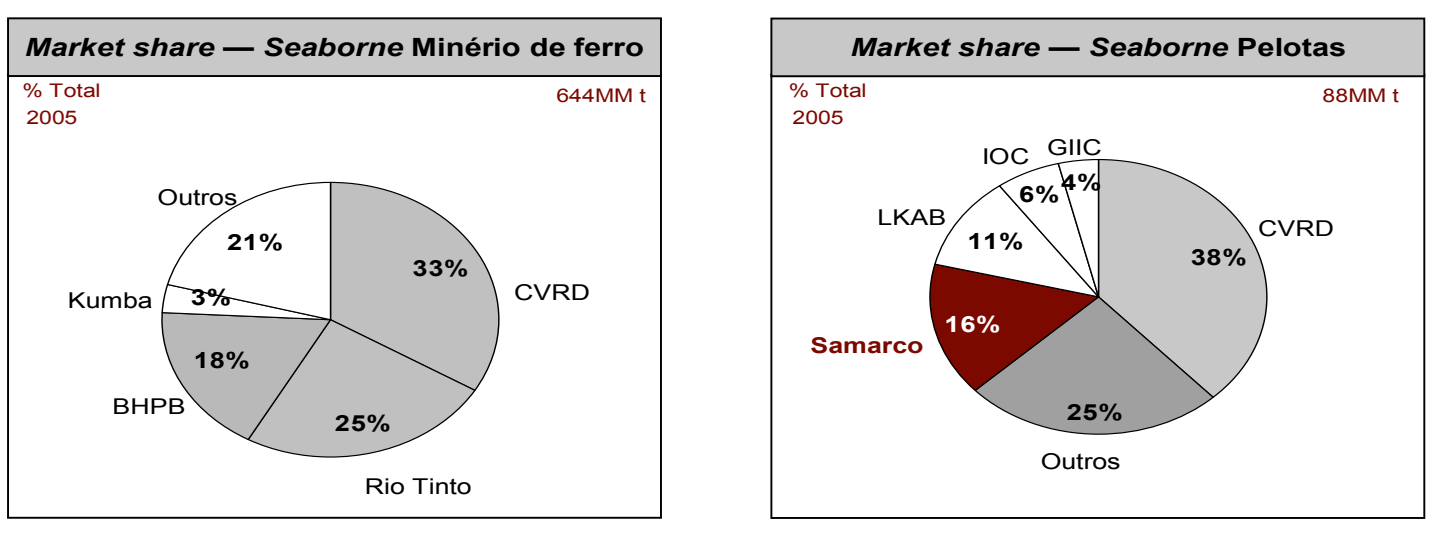

Figura 2.6: "Market share" do mercado transoceânico de minério de ferro e pelotas Fonte: CRU, 2006 e Relatórios anuais das empresas supracitadas.

\subsubsection{Nível de concentração do mercado e tendências}

A concentração observada no setor ocorreu simultaneamente à reestruturação do setor siderúrgico e ao rápido crescimento da produção de aço e importação de minérios de ferro da China.

As empresas mineradoras apresentam uma forte disciplina relativa a investimentos em adição de capacidade que, aliada ao rápido crescimento da demanda, levou a uma situação de aumento das margens e baixa rivalidade.

Esta situação tende a mudar no momento da entrada em produção das novas usinas de produção de pelotas, atualmente em desenvolvimento, em 2008 e 2009.

$\mathrm{O}$ aumento de capacidade poderá levar os produtores a reduzirem preços e margens, criando um ambiente mais competitivo. A disciplina, em relação a novos desenvolvimentos, ditará a duração deste período de competitividade aumentada.

Neste possível cenário de maior competitividade, será essencial, para qualquer empresa, manter-se como um produtor de baixo custo, de modo a poder continuar competindo eficazmente com seus concorrentes. 
A diferenciação entre os produtores é relativa principalmente a dois fatores:

1) Localização (proximidade de mercados consumidores): os fornecedores de pelotas localizados junto a grandes centros consumidores (LKAB - Europa, GIIC Oriente Médio, Cleveland Cliffs e Canadenses - EUA) possuem uma forte vantagem competitiva em relação aos com localização desfavorável (Brasil e Rússia). Esta diferenciação eleva a competição, forçando os produtores distantes a adotar políticas de preço mais agressivas em mercados de baixa demanda.

2) Qualidade: fornecedores de produtos de alta qualidade possuem grande vantagem competitiva, recebendo um prêmio por esta qualidade superior, notório no caso de pelotas $\mathrm{DR}^{8}$. Tradicionalmente, esta vantagem é observada pela CVRD, LKAB, GIIC, IOC e Samarco, enquanto a percepção de baixa qualidade penaliza produtores da Rússia, Ucrânia e Índia. Períodos de alta nos preços, naturalmente, levam os produtores a elevar a produtividade em detrimento da qualidade. A qualidade, neste momento, é medida através de padrões comparativos e a competitividade é mantida por produtores que reduzirem seus padrões de qualidade em linha com a prática do mercado, respeitando padrões mínimos estabelecidos pelas siderúrgicas.

\subsection{PODER DE BARGANHA DOS CONSUMIDORES}

Os principais clientes de minério de ferro, as siderúrgicas, constituem um mercado fragmentado, conforme ilustrado na Figura 2.7.

Nos últimos anos, teve início uma consolidação no setor, no entanto, mesmo com esse movimento, ainda está longe de se estabelecer, no setor siderúrgico, um mesmo nível de concentração que o de hoje existente no setor de mineração, conforme é ilustrado na Figura 2.8.

\footnotetext{
${ }^{8} \mathrm{DR}$ - Pelotas utilizadas no processo siderúrgico de redução direta, e se denominam Pelotas DR (PDR).
} 


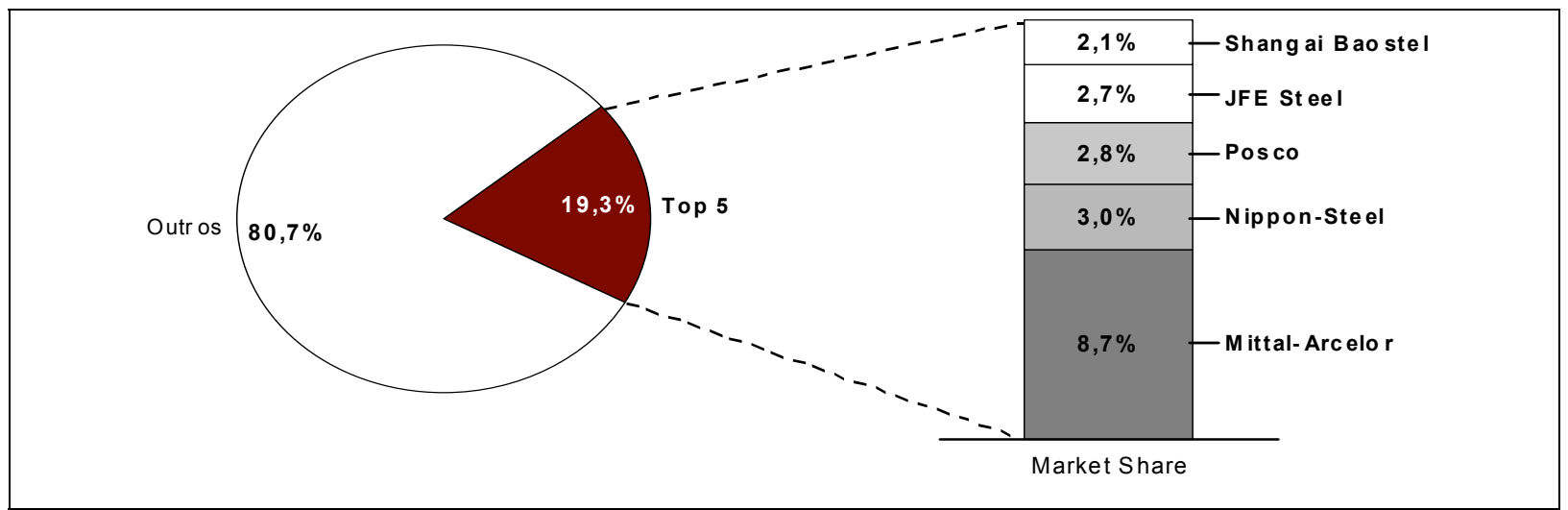

Figura 2.7; "Market share" do Mercado Siderúrgico Fonte: METAL BULETIN RESEARCH, 2006.

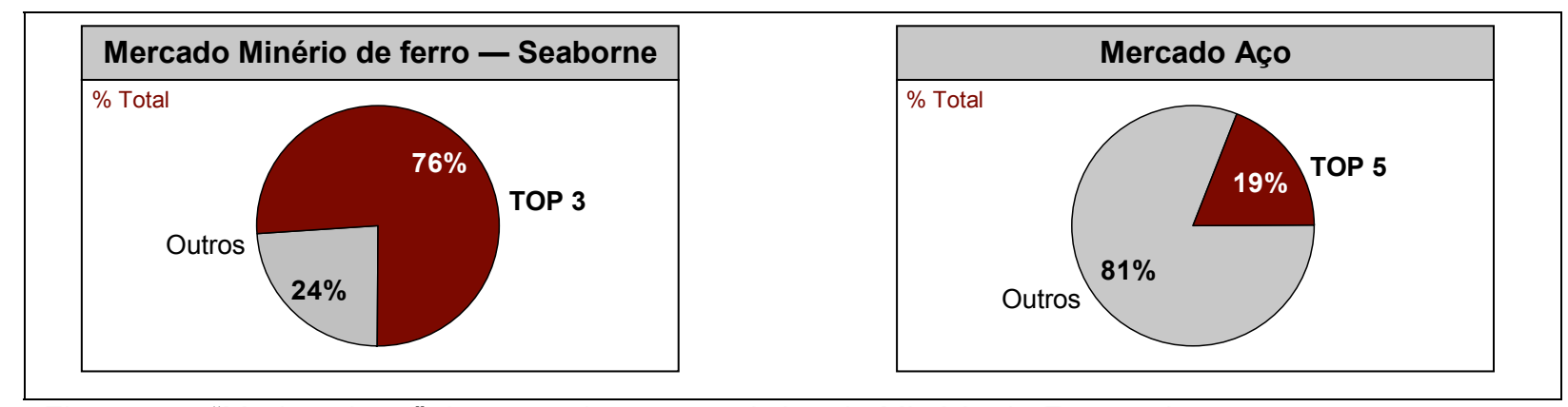

Figura 2.8: "Market share" do mercado transoceânico de Minério de Ferro e Aço Fonte: METAL BULETIN RESEARCH, 2006.

\subsection{AMEAÇA DE PRODUTOS SUBSTITUTOS}

O maior risco de substituição do uso de pelotas é o desenvolvimento de tecnologias para redução direta de finos, que é uma evolução natural para o processamento de finos de minério de ferro.

Conforme a Figura 2.9, a seguir, alguns processos e tecnologias de redução direta de finos de minérios de ferro vêm sendo desenvolvidos e testados em escalas reduzidas há vários anos e sua implementação, certamente, ocorrerá no longo prazo.

No entanto, no momento, estes processos apresentam alto custo de implementação e poucos casos de aplicação em escala industrial. A maior iniciativa, neste sentido, foi a instalação pela BHPB de dois reatores FINMET para produção de $\mathrm{HBI}$, a partir de finos de minério de ferro não pelotizáveis (investimento de US\$ 2,5 MM por módulo, sem sucesso operacional). 


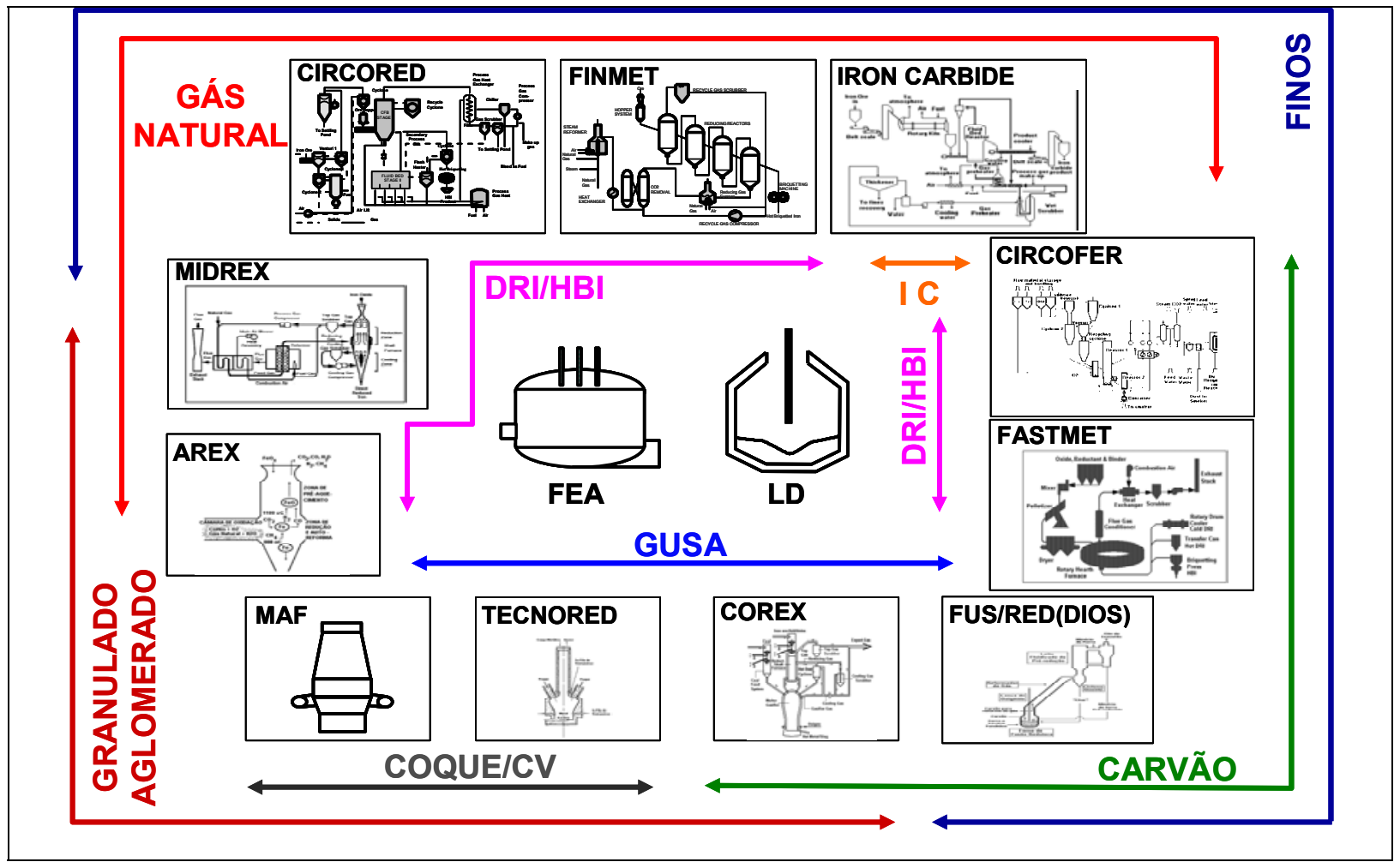

Figura 2.9: Tecnologias de redução direta de finos de minérios de ferro

A indústria siderúrgica somente será motivada a substituir as tecnologias de redução utilizadas atualmente com o desenvolvimento de processos de baixo risco e de custo compatível aos hoje existentes.

Existem grandes grupos envolvidos no desenvolvimento de novas tecnologias e as com maior potencial, atualmente, são o HISmelt (Rio Tinto), FINMET (VAI), Circofer (Outokumpu) e Fastmelt/ltmk3 (Midrex). No entanto, dada sua complexidade tecnológica, esta é uma ameaça que deverá se concretizar no longo prazo (em 15 ou 20 anos), tendo pouco efeito sobre a base já instalada.

\subsection{INTRODUÇÃO AO PROCESSO PRODUTIVO DO MINÉRIO DE FERRO}

Segundo dados obtidos na Companhia Vale do Rio Doce (CVRD) (2005), 99\% dos minérios de ferro produzidos são utilizados na produção de aço e de ferro fundido. Suas aplicações mais comuns ocorrem na construção civil, na indústria automotiva e na produção de eletrodomésticos. 
Devido ao baixo valor unitário da tonelada de minério de ferro, as operações de beneficiamento do produto somente se tornam economicamente viáveis, quando realizadas em grande escala (ordem de milhões de toneladas/ano), o que requer equipamentos de grande porte e elevada capacidade instalada.

Apesar de, usualmente, esses processos de beneficiamento serem relativamente simples, se comparados com os utilizados para outros minérios mais complexos, como alguns fosfatos, minérios de cobre e sulfetos polimetálicos (cobre, zinco, ouro, chumbo), é fundamental que todas as etapas do processamento sejam devidamente dimensionadas e controladas em função dos volumes processados, de modo a minimizar os custos e assegurar a qualidade dos produtos.

Os produtos de minério de ferro não são definidos apenas pelos teores mínimos de ferro $(\mathrm{Fe})$ e máximos das impurezas sílica $\left(\mathrm{SiO}_{2}\right)$, alumina $\left(\mathrm{Al}_{2} \mathrm{O}_{3}\right)$, fósforo $(P)$, perda por calcinação (PPC) entre outras, mas também pelas classes de frações granulométricas rigidamente controladas.

Isso requer que, mesmo para minérios de alto teor e baixo nível de impurezas, o processo seja controlado de tal forma que os produtos gerados atendam às especificações granulométricas. Para tanto, é necessário um rígido controle nas etapas de peneiramento e classificação.

Pfiffer (2004, p. 85) descreve que, embora o minério de ferro possa variar em função de suas características químicas, físicas e metalúrgicas, normalmente, ele é classificado, inicialmente, em quatro tipos, de acordo com sua granulometria, conforme apresentado a seguir e melhor ilustrado na Figura 2.10:

$\checkmark$ Granulado ou Lump: é o minério de ferro cujas partículas mais grossas variam de $6,35 \mathrm{~mm}$ a $50 \mathrm{~cm}$ de diâmetro. Pode ser utilizado como carga direta nos altos-fornos.

$\checkmark$ Finos de minério de ferro ou sinter feed: referem-se ao minério de ferro com partículas que variam de $0,15 \mathrm{~mm}$ a $6,35 \mathrm{~mm}$ de diâmetro, utilizados como matéria-prima para o processo de sinterização.

$\checkmark$ Ultrafinos de minério de ferro ou pellet-feed: são partículas de minério de ferro finas e ultrafinas (inferiores a $0,15 \mathrm{~mm}$ ), geradas nas etapas de lavra, classificação, manuseio e transporte do minério de ferro, que não têm aplicação prática direta na indústria siderúrgica. Este produto é matéria-prima do processo de pelotização. 
$\checkmark$ Pelotas ou pellets: são partículas finas e ultrafinas de minério de ferro aglomeradas na forma esférica, com tamanho e qualidade apropriados aos processos específicos de siderurgia. As pelotas, geralmente, são classificadas entre 6,3 e $18 \mathrm{~mm}$, ficando $90 \%$ entre 8,0 e $16,0 \mathrm{~mm}$.

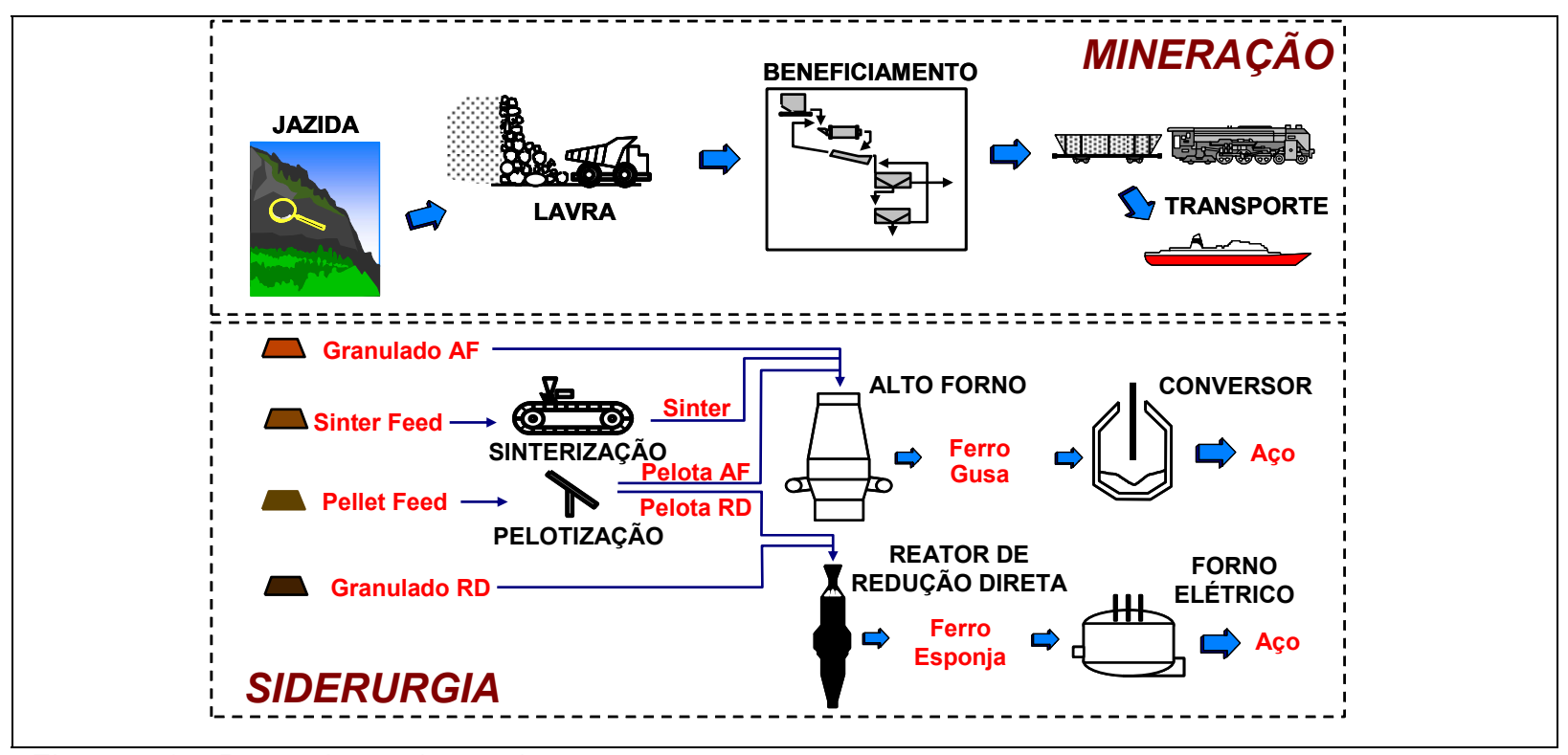

Figura 2.10: Rotas de produção de aço

Segundo Chaves (2002), o objetivo da atividade mineradora é a descoberta, a lavra e o beneficiamento de minérios. Nesse sentido, as atividades executadas dentro da mineração consistem em:

$\checkmark$ descobrir os recursos minerais existentes no subsolo;

$\checkmark$ trazer o bem mineral do subsolo até à superfície; e

$\checkmark$ colocar esse bem mineral em condições de ser utilizado pela indústria metalúrgica, cerâmica ou química.

Luz et al. (2004) definem:

$\checkmark$ mineral como todo corpo inorgânico de composição química e de propriedades físicas definidas, encontrado na crosta terrestre;

$\checkmark$ minério como toda rocha constituída de mineral ou agregado de minerais, contendo um ou mais minerais valiosos, possíveis de serem aproveitados economicamente denominados minerais-minério. O mineral ou conjunto de minerais não aproveitados de um minério é denominado ganga; 
$\checkmark$ estéril é outro termo muito usado na mineração, definido em Dias (2001, p. 95) como todo material sem valor econômico, extraído para permitir a lavra do mineral útil, o minério.

Chaves (2002) diz que o processamento do minério consiste em uma seqüência de operações industriais que se denominam operações unitárias, assim chamadas devido ao fato de somente variar a combinação e a seqüência dessas operações para atender a um determinado objetivo, ou para atender às características específicas de um determinado minério.

De uma maneira geral, as operações unitárias podem ser esquematicamente agrupadas em:

$\checkmark$ operações de cominuição que são basicamente os sucessivos estágios de britagem e moagem das partículas minerais para colocá-las no tamanho adequado a que se destinam; são sempre auxiliadas por operações de separação de tamanhos, geralmente em peneiras classificadoras, ciclones e/ou outro tipo de separadores por tamanho;

$\checkmark$ operações de concentração que visam a separar as partículas, não só por diferentes espécies minerais, mas também por distintos níveis de pureza;

$\checkmark$ operações auxiliares que armazenam e/ou transportam os diferentes produtos intermediários entre uma operação unitária e outra, além de permitir a separação da água contida nesses produtos; são classificadas em transporte de sólidos particulados, transporte de sólidos em suspensão em água (em polpa), estocagem e homogeneização em pilhas, estocagem em silos, espessamento, filtragem e secagem.

Ainda, segundo Chaves (2002), nunca uma operação unitária sozinha é suficiente para fornecer um produto final. Geralmente, são necessárias várias operações unitárias que, ao serem combinadas, constituem processos que abrangem desde o minério inicial ao produto final.

Luz et al. (2004) apresentam um fluxograma típico de tratamento de minérios na Figura 2.11, em que operações unitárias são assim classificadas:

$\checkmark$ cominuição: britagem e moagem;

$\checkmark$ classificação: peneiramento, ciclonagem e classificador espiral;

$\checkmark$ concentração: gravítica, eletrostática, por flotação e outros;

$\checkmark$ desaguamento: espessamento e filtragem;

$\checkmark$ secagem: secador rotativo e secador de leito fluidizado; disposição de rejeito . 


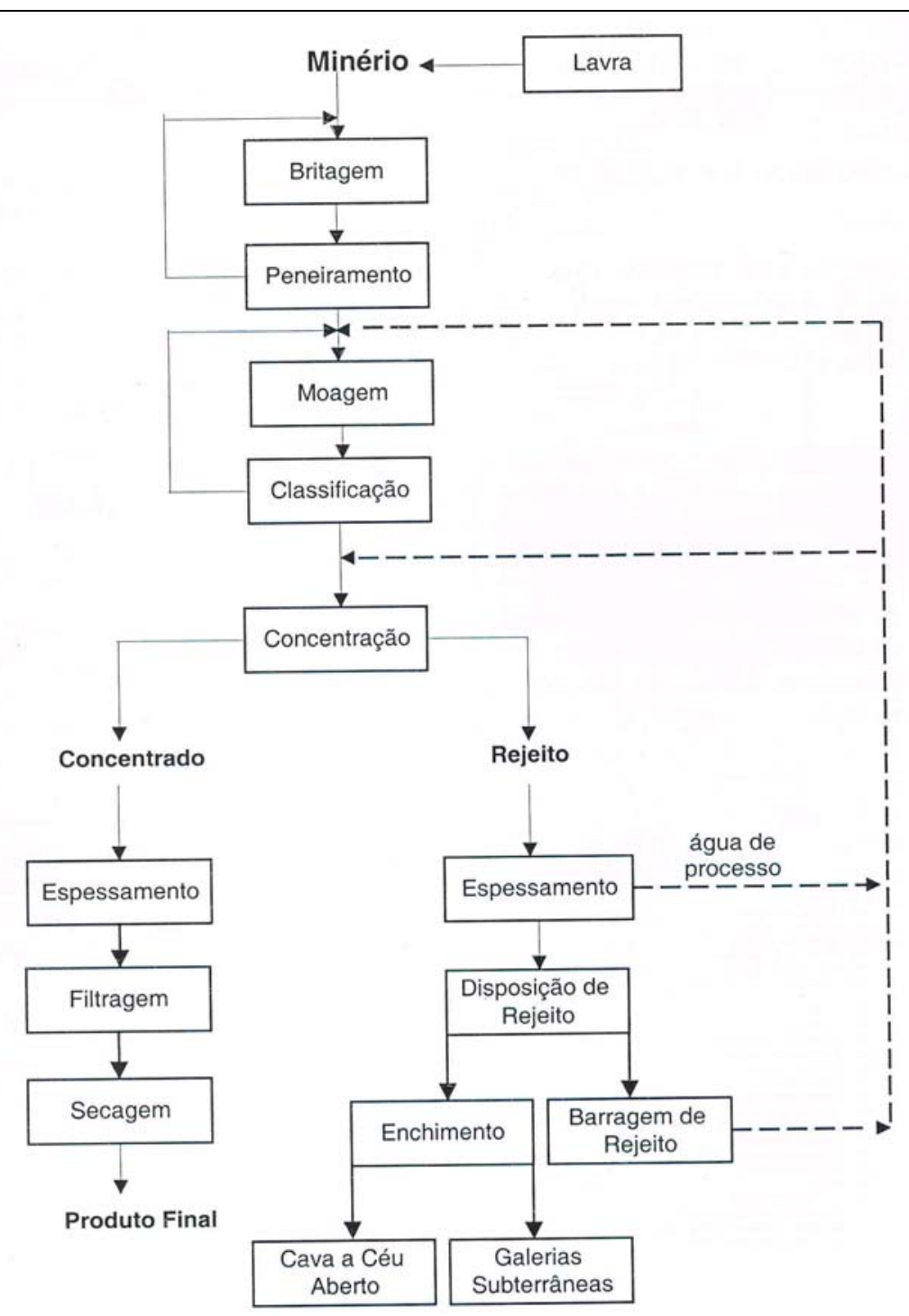

Figura 2.11: Fluxograma típico de tratamento de minério Fonte: CASTRO NETO, 2006.

O processo produtivo do minério de ferro, analogicamente aos conceitos colocados por Chaves (2002) e Luz et al (2004), é constituído por uma seqüência de operações unitárias, a saber:

$\checkmark$ lavra do minério: que abrange uma combinação das operações de extração do minério, cominuição e auxiliares;

$\checkmark$ beneficiamento: que corresponde a uma combinação das operações de cominuição, concentração e auxiliares;

$\checkmark$ transporte: que compreende a operação de transporte do minério até a unidade industrial onde ele será utilizado e processado para agregação de valor; 
$\checkmark$ aglomeração: que tem como finalidade a agregação de valor ao minério de ferro através da criação de características especiais, que tornam o produto muito mais atrativo no processo de fabricação do ferro primário a que são destinados os aglomerados na indústria siderúrgica; compreendem os processos de sinterização e/ou pelotização, que, geralmente, são combinados com operações de cominuição e auxiliares; e

$\checkmark$ estocagem e embarque: que integram o processo produtivo de uma parcela significativa das empresas de mineração que exportam seus produtos, através de transporte marítimo. Nesse sentido, as operações de estocagem, embarque e portuárias tornam-se parte integrante do processo produtivo em uma parcela significativa das empresas de mineração.

Como exemplo dos processos que constituem o processo produtivo do minério de ferro, citem-se CVRD (2005) e Samarco (2005).

\subsubsection{Incertezas inerentes ao processo de fabricação do minério}

De acordo com Castro Neto (2006), o processo produtivo do minério de ferro apresenta características que proporcionam um nível elevado de incerteza e complexidade ao sistema, o que caracteriza a natureza estocástica do processo. Operar esse sistema com o menor custo possível é um desafio à competitividade à indústria da mineração de ferro devido a:

a. variações no processo produtivo,

b. variabilidade minerológica das matérias-primas e insumos minerais,

c. incerteza na confiabilidade da quantificação das relações físico-químicas e metalúrgicas dos processos,

d. variações na quantidade entregue ao cliente.

a) Variações no processo produtivo da mineração do ferro

Juran (1998) define

$\checkmark$ processo como qualquer combinação de máquinas, ferramentas, métodos, materiais e pessoas empregadas para atingir qualidades específicas em um produto ou serviço; teoricamente, uma mudança em qualquer desses componentes deve, a rigor, resultar em um novo processo; 
$\checkmark$ controle de processo como uma avaliação de retorno pela qual são realizadas a medição do desempenho atual, a comparação com o desempenho padrão e alguma ação sobre a diferença; e

$\checkmark$ controle estatístico de processo como a aplicação de técnicas estatísticas, para medir e analisar as variações de processos.

Segundo Juran (1998), todos os processos industriais exibem alguma variação composta por uma componente permanente no tempo, inerente aos processos e, por uma outra, intermitente.

São atribuídas à componente permanente, chamada de variação aleatória, causas acidentais e indetermináveis, e à componente intermitente, causas determináveis ou especiais.

Este mesmo autor também diz que essa variação pode ser convenientemente quantificada por amostragem dos dados de saída dos processos e pela estimativa dos parâmetros de sua distribuição estatística.

Belém (2000) diz que todos os resultados apresentam variação e que esta é função de causas comuns e especiais. As causas comuns provocam, no efeito, uma variação previsível e natural dos processos.

Nesses processos, é possível antecipar os limites dentro dos quais variará o resultado. As causas especiais provocam, no efeito, uma variação peculiar ou fora do esperado, não natural ao processo. Nesse caso, não é possível antecipar qual a magnitude de variação.

Com base nas informações introdutórias sobre o processo produtivo do minério de ferro e o que foi revisto em Juran (1998) e Belém (2000), pode-se afirmar que existe variação nas operações de lavra do minério, de beneficiamento, de transporte, de aglomeração e de estocagem, embarque e portuárias.

Essa seqüência constitui o processo produtivo da mineração do ferro, o que evidencia a existência de variação no processo produtivo global.

A existência dessa variação caracteriza a existência de aleatoriedade nesse sistema, que pode ser traduzida em uma incerteza de mensuração dos resultados, sendo essa incerteza inerente ao processo produtivo.

Como já visto, de acordo com Juran (1998), as variações nos processos podem ser quantificadas pela construção da distribuição estatística dos resultados ("outputs") da variável resposta em questão. 
Desta forma, por meio de identificação dos resultados das variáveis relevantes para o estudo na saída de cada operação, é possível mensurar a variação dentro e na saída do processo produtivo da mineração do ferro.

b) Incerteza na confiabilidade da quantificação dos fluxos do processo produtivo da mineração do ferro

Martins, Pereira e Silva (2003) argumentam que para a avaliação do desempenho de uma usina de beneficiamento de minério e controle da sua operação são necessários dados confiáveis dos fluxos em termos de taxas mássicas ${ }^{9}$ e de seus constituintes metalúrgicos. É importante que se tenha um balanço de massas e metalúrgico obtido mediante o tratamento estatístico adequado dos dados medidos durante a operação em um período determinado. Esses dados podem ser medidos continuamente ou obtidos por meio de amostragens dos produtos e analisados em laboratório.

Segundo os mesmos autores, normalmente, em uma indústria mineral, ocorrem erros de medidas dos instrumentos que permitem contabilizar, de forma contínua, as taxas mássicas dos fluxos. Esses erros podem ser maiores ou menores, dependendo de vários fatores, como da própria limitação de precisão do instrumento de medição, da periodicidade de aferição ou até mesmo dos defeitos. Outros dados relativos aos vários fluxos de uma planta podem ser obtidos por meio de amostragem sistemática, que podem conter desvios dos valores reais, devido a erros de amostragem, preparação e análises em laboratório.

Cardoso et al. (1994) definem sistemas contínuos como sendo aqueles sistemas nos quais as variáveis de estado mudam continuamente no tempo, e que, grosso modo, pode-se dizer que, a cada fração de segundo, elas assumem novos valores. A Figura 2.12 mostra uma representação esquemática de um sistema contínuo.

\footnotetext{
${ }^{9}$ É a mensuração da quantidade de material processado por unidade de tempo. Por exemplo, toneladas por hora.
} 


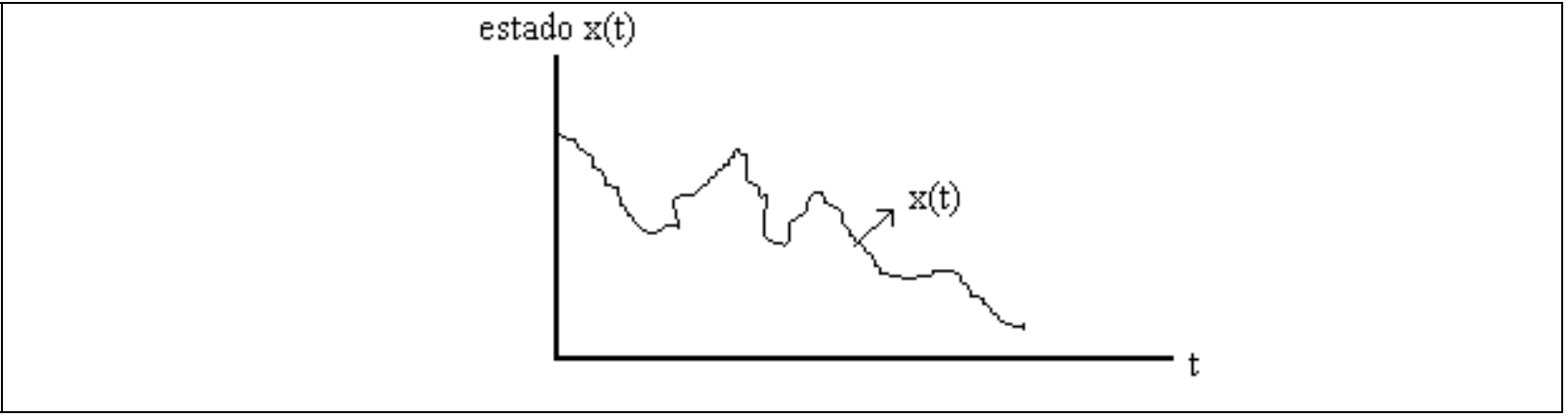

Figura 2.12: Trajetória de um sistema dinâmico de variável contínua (SDVC) Fonte: CARVALHO, 2006.

Com base nas informações de Martins, Pereira e Silva (2003), de Cardoso et al. (1994) e pela natureza das operações em grande escala (milhões de toneladas por ano), o processo produtivo da mineração de ferro é caracterizado como um sistema contínuo, com fluxos de massas em larga escala.

Esse fato leva a uma tendência de ampliação dos fatores que são causadores dos erros de medidas dos instrumentos que contabilizam, de forma contínua, as taxas mássicas.

A existência desse erro traduz-se em uma incerteza na quantidade real que está sendo processada a cada instante em comparação com a quantidade que está sendo contabilizada pelos instrumentos de medição.

c) Incerteza na quantidade entregue ao cliente

Segundo Castro Neto (2006), a incerteza na quantidade entregue ao cliente é caracterizada pela tolerância de carregamento. É prática comum no afretamento de granéis sólidos, como minério e carvão, o armador ter a opção de exercer o direito de $10 \%$ de tolerância na quantidade da carga a ser transportada.

Essa flexibilidade, estipulada em contrato, garante ao armador a possibilidade de balanceamento das cargas, para otimizar a utilização do navio e gera uma incerteza na quantidade real entregue ao cliente, que pode ser traduzida em uma entrega com quantidade maior ou menor que a planejada.

A seqüência de vários desbalanceamentos no processo de carregamento configura problema, ou de falta de estoque e aumento do tempo de sobreestadia decorrente de uma sucessão de entregas em quantidades maiores que a planejada, ou de geração indevida de estoque, decorrente de entregas em quantidades menores que as planejadas. 


\section{REVISÃO BIBLIOGRÁFICA}

Antes da discussão sobre a integração de simulação e otimização propriamente dita, devem-se considerar alguns conceitos intrinsecamente relacionados a esse processo, cuja discussão facilitará o seu entendimento. Por esse motivo, apresenta-se a seguir uma descrição dos principais conceitos sobre simulação e otimização abordados neste estudo.

\subsection{MODELOS DE SIMULAÇÃO}

Segundo Soares (1990), os modelos são uma descrição dos sistemas e, apesar de serem dependentes do problema a resolver, requerem uma estrutura organizada qualquer. Uma linguagem ou pacote para simulação fornece uma dessas estruturas e é a sua compilação que vai traduzir o sistema em uma forma aceitável para um sistema computacional.

\subsubsection{Construção do modelo}

Segundo Pidd (1998), "um modelo é uma representação externa e explícita de uma parte da realidade, tal como vista por aqueles que desejam utilizá-lo para entender, alterar, gerenciar e controlar parte da realidade".

Rodrigues (1994) afirma que construir um modelo que melhor represente o funcionamento do problema em estudo é, sem dúvida, uma das principais etapas do processo de simulação, pois exige, necessariamente, um conhecimento minucioso do cenário ou do arranjo estudado.

A etapa de modelagem é caracterizada por uma mistura de doses de empirismo com outras doses de técnicas, mesmo quando se dispõe de ferramentas muito poderosas, pois nenhuma ferramenta pode superar o poder criativo do ser humano; pode, sim, potencializá-lo, conforme Figura 3.1. 


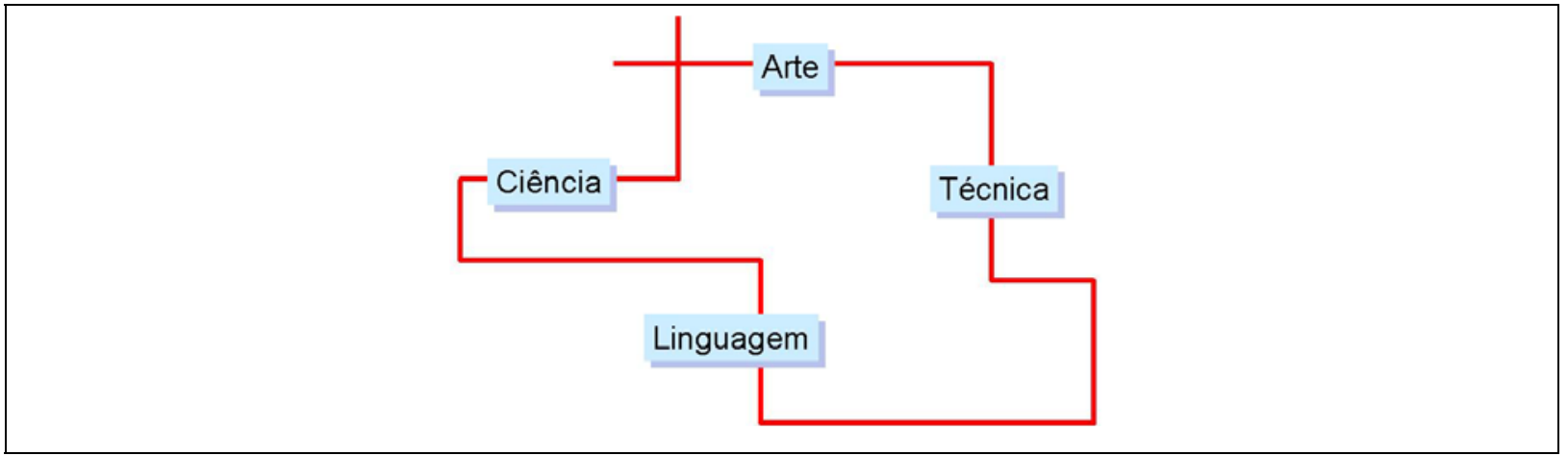

Figura 3.1 - Etapas de modelagem

Fonte: Adaptado de RODRIGUES, 1994.

\subsubsection{Modelo computacional}

Na modelagem computacional, afirma Rodrigues (1994), é utilizada uma série de ações coordenadamente planejadas para transformar o modelo lógico em um modelo operacional. Tais ações, fundamentais no processo de modelagem e simulação, podem ser descritas como:

$\checkmark$ Coleta de dados e sua modelagem estatística

$\checkmark$ Programação, mediante o uso de um software apropriado à natureza do problema

$\checkmark$ Verificação e validação.

Deste modo, uma operação ou sistema é traduzido em termos de regras, ações e tempos de processo, conforme Figura 3.2.

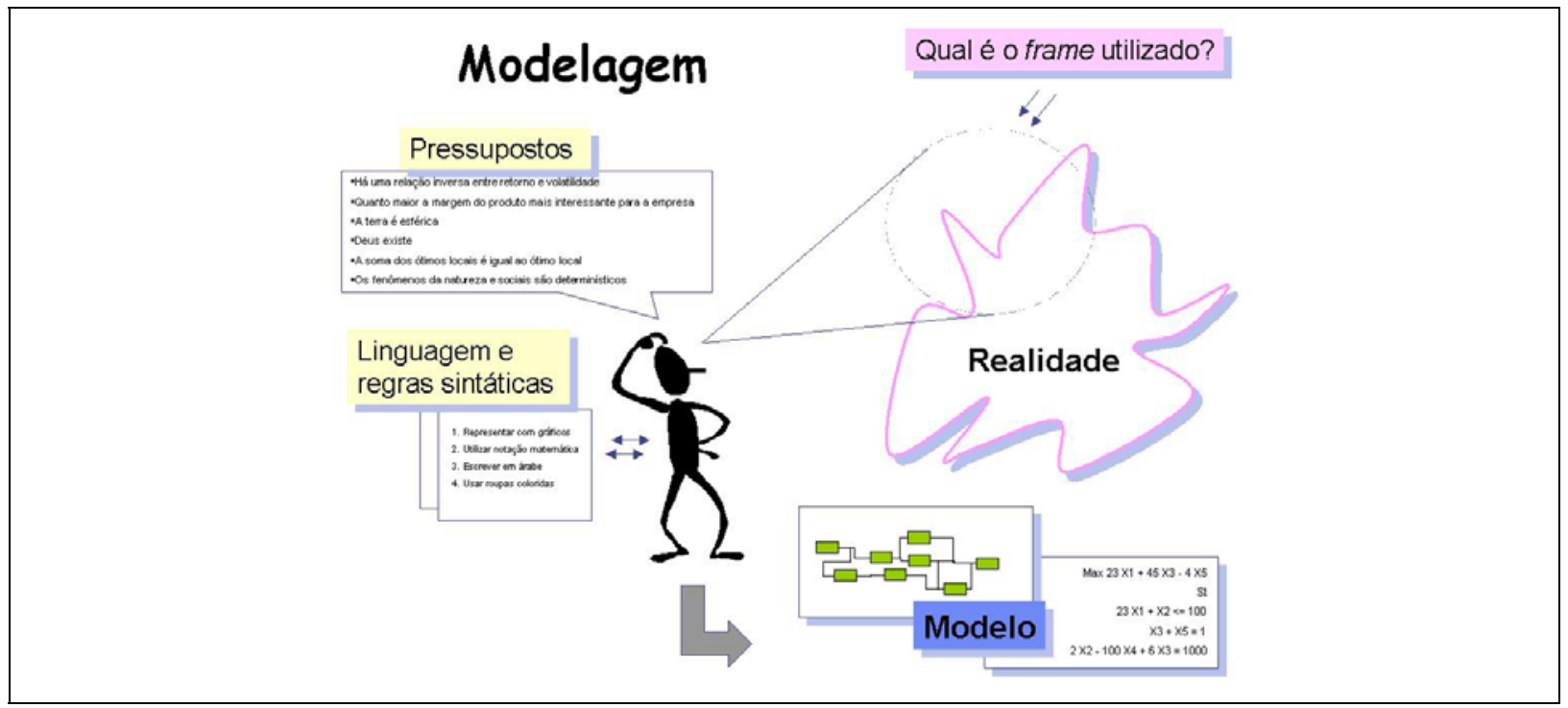

Figura 3.2 - O processo de modelagem Fonte: Adaptado de RODRIGUES, 1994. 


\subsubsection{Experimentação}

Rodrigues (1994) ainda afirma que, após a construção e validação do modelo computacional, se retorna à fase experimental, na qual várias alternativas propostas serão consideradas e testadas (Figura 3.3). É nessa fase que ocorrem as simulações, por meio das quais se podem fazer análises, a fim de avaliar o efeito de possíveis alterações, antes que elas ocorram de fato.

Esse efeito é caracterizado como o ponto focal desse processo: testar várias soluções para um determinado problema, antes que sejam implementadas. Isso implica uma otimização significativa de recursos, que só serão investidos em propostas exaustivamente testadas, que, comprovadamente, tenham retorno esperado.

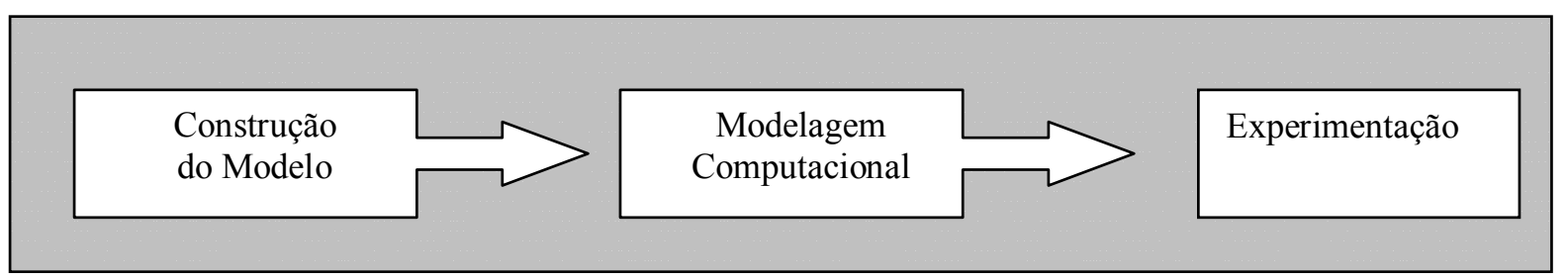

Figura 3.3 - Atividade do processo de modelagem e simulação Fonte: Adaptado de RODRIGUES, 1994.

Nos softwares de modelagem e simulação, o processo de experimentação está lastreado por análises estatísticas consistentes. A esse respeito Rodrigues (1994) conclui que é possível sugerir melhores alternativas ou recomendações utilizando modelo de simulação na busca da otimização.

\subsection{SIMULAÇÃO COMPUTACIONAL}

\subsubsection{Conceitos de simulação computacional}

A técnica de simulação computacional é conceituada de diversas maneiras por diferentes autores, porém todos convergem para o fato de que a simulação é útil 
na resolução de problemas muito complexos nas organizações. A seguir, são apresentados alguns desses conceitos.

Schriber (1974) define simulação da seguinte maneira: "simulação implica na modelagem de um processo ou sistema, de tal forma que o modelo imite as respostas do sistema real numa sucessão de eventos que ocorrem ao longo do tempo".

Nessa definição, Schriber não especifica se o modelo tem necessariamente que ser computacional. O motivo é que, na época, ainda era comum a utilização de modelos analógicos e físicos para analisar o comportamento de sistemas. Atualmente, a simulação é quase sinônimo de simulação computacional.

Shannon (1995) dá a seguinte definição para este tipo de modelo: "um modelo computacional é um programa de computador cujas variáveis apresentam o mesmo comportamento dinâmico e estocástico do sistema real que ele representa".

Já Szymankiewci, Mcdonald e Turner (1988) conceituam simulação da seguinte forma, "Simulação é uma das mais poderosas técnicas disponíveis para a solução de problemas. Ela consiste na construção de um programa matemático, correspondente ao sistema real, que pode ser experimentado e avaliado, quando submetido a diversos cenários de ação".

Pegden, Shannon e Sadowski (1990) definem simulação como sendo, "o processo de projetar um modelo computacional de um sistema real e conduzir experimentos com este modelo com o propósito de entender seu comportamento e/ou avaliar estratégias para sua operação".

A definição de Hollocks (1992) é: "simulação é uma técnica de PO que envolve a criação de um programa computacional que represente alguma parte do mundo real de forma que experimentos no modelo é uma antevisão do que acontecerá na realidade".

Segundo Prado (1999), "simulação é uma técnica de solução de problemas pela análise de um modelo que descreve o comportamento do sistema, usando um computador digital".

Apesar da existência de linguagens de simulação com propósito definido e pacotes de sistemas para facilitar a tarefa do usuário, algumas simulações podem requerer longos programas computacionais com certa complexidade.

Daí, em determinadas situações, produzir resultados úteis de uma simulação, pode ser um processo moroso. Diante disso, Pidd (1998) defende a idéia de que 
"simulação computacional deveria ser considerada como um último recurso, para ser utilizado se todos os outros métodos falharem". Contudo, há casos em que o emprego da simulação pode ser a única maneira de abordar determinados problemas, em particular aqueles que envolvam variáveis aleatórias.

O objetivo de um estudo de simulação, segundo Borges (2000), consiste em modelar um sistema específico, para que se possa observar o seu comportamento sob determinadas condições, de forma científica.

Um modelo de simulação envolve probabilidades, oferecendo uma resposta aproximada do problema. A cada simulação do problema modelado obtêm-se respostas diferentes, ao contrário de modelos analíticos, em que as respostas são calculadas e, na maioria das vezes, preferidas às soluções por simulação.

Em muitos casos, não existe uma solução analítica e, em muitos problemas reais, a maioria dos dados não é determinística, como, por exemplo, demandas, preços futuros, fatores de operação de máquinas. Para tanto, necessita-se criar um laboratório virtual do ambiente ou processo em estudo, ou seja, um modelo computacional com comportamento semelhante ao real.

A inserção de dados estatísticos históricos no modelo e as relações matemáticas ou lógicas de suas diversas etapas devem ser realizadas para verificação de sua funcionalidade, cuja meta é chegar o mais próximo possível do real.

Segundo Borges (2000), "a tarefa de análise estatística dos resultados do modelo se tornou muito mais fácil de ser executada, já que os pacotes de softwares disponíveis hoje no mercado incluem relatórios detalhando a sensibilidade do resultado do modelo às variáveis, tornando a identificação das irrelevantes menos árdua".

\subsubsection{Tipos de simulação}

Toda simulação requer a construção de um modelo pelo qual serão feitos os experimentos. Segundo Barton (1970), um modelo de simulação deve:

$\checkmark$ representar a totalidade ou parte de um sistema;

$\checkmark$ poder ser executado ou manipulado; 
$\checkmark$ ter o tempo ou um contador de repetições como uma de suas variáveis;

$\checkmark$ auxiliar no entendimento do sistema, o que significa apresentar um ou mais dos seguintes itens do sistema em estudo:

i. uma descrição parcial;

ii. uma explicação do comportamento passado;

iii. uma projeção do comportamento futuro;

iv. uma explicação da teoria existente pela qual o sistema pode ser entendido.

Segundo Gavira (2003), pode-se dividir os modelos de simulação do mesmo modo que se dividem os modelos em geral. Um tipo de classificação é resumido na Figura 3.4.

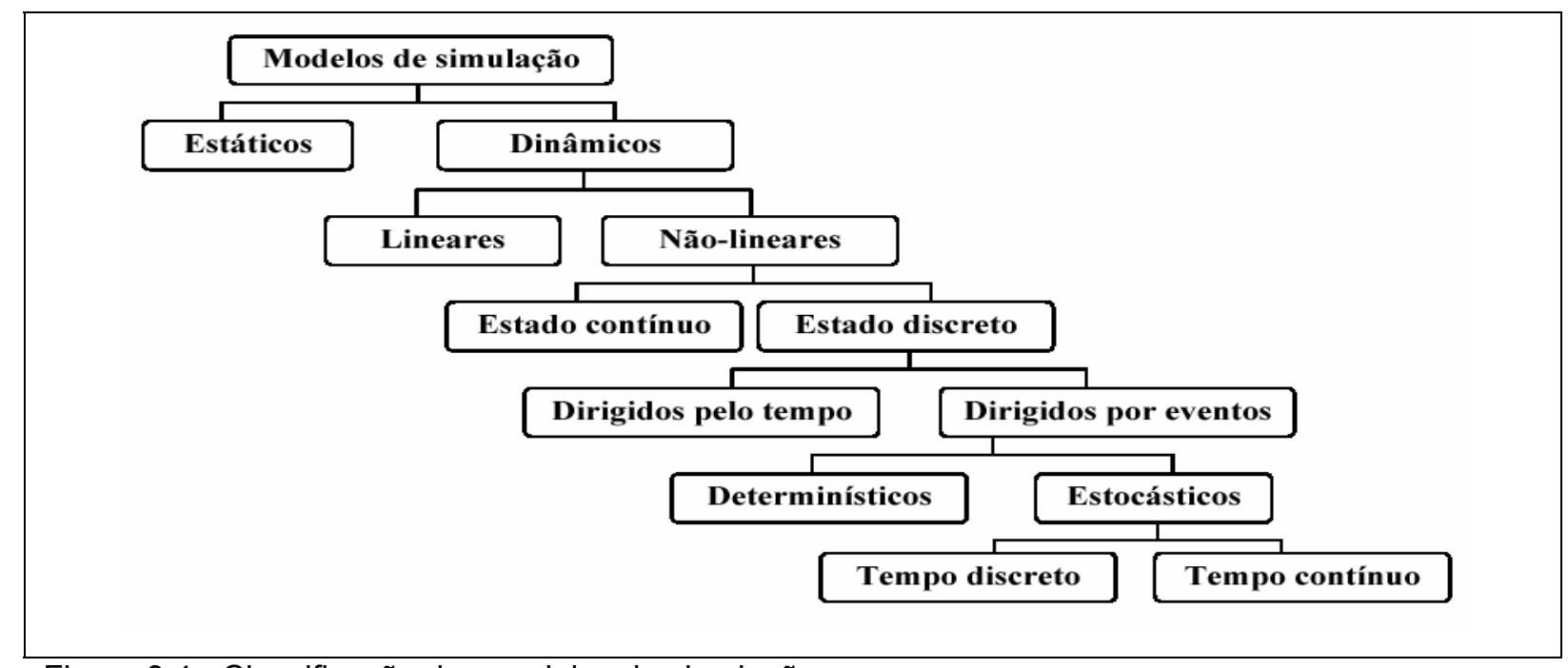

Figura 3.4 - Classificação dos modelos de simulação

Fonte: GAVIRA, 2003.

\subsubsection{Onde utilizar a simulação?}

De acordo com Saliby (1989), tomar decisões estratégicas traz conseqüências financeiras e, na maioria das vezes, de grande monta. Logo, analisar e avaliar alternativas para a tomada de decisão não é tarefa fácil, principalmente, quando os resultados da escolha de uma determinada alternativa não são totalmente previsíveis.

A maioria das operações logísticas tem um alto grau de complexidade, devido às suas articulações com diversos atores da cadeia de suprimentos. 
Decisões de produção, compra, políticas de estocagem e reposição, movimentação de materiais e distribuição física devem ser tomadas de forma sistêmica e integrada.

Por isso, a modelagem e a simulação são as ferramentas apropriadas para aferir os potenciais ganhos em cada alternativa e os efeitos dessas relações, uma vez que, antes de se implementar uma nova operação ou processo, é preciso ter uma idéia prévia dos possíveis resultados e conseqüências, a fim de identificar pontos de melhoria visando a otimizá-los.

Por conta dessas características é que a modelagem e a simulação são ferramentas indicadas para sistemas e/ou operações logísticas em que os resultados das possíveis ações são pouco previsíveis e muito difíceis de serem identificados de maneira analítica.

De acordo com Saliby (1989), Banks e Gibson (1996), Banks (2000), Pegden (1995), Law e Kelton (2000), entre outros, a modelagem e a simulação podem ser aplicadas em diversas situações:

$>$ saber identificar a melhor estratégia de um investimento futuro para iniciar uma operação ou novo projeto, ou ainda, ampliar e desenvolver um já existente, antes que haja algum comprometimento da organização;

$>$ identificar gargalos e/ou pontos críticos no processo (estoques desnecessários, recursos ociosos, "setups" desnecessários, entre outros);

$>$ ter uma idéia e/ou compreensão mais clara do processo que se deseja melhorar;

$>$ testar novas alternativas e métodos, antes de sua implementação, de forma a não causar interferências no processo em uso naquele momento.

Nas operações logísticas, especificamente, pode-se destacar:

$\checkmark$ determinação do sistema de transporte mais adequado quanto a números, tipo e tamanho dos veículos, a depender dos produtos, rotas, tempos de carga e descarga, vida útil dos veículos, entre outras;

$\checkmark$ dimensionamento de estoques de segurança, a partir de incertezas no suprimento;

$\checkmark$ determinação da localização de estoques - centralizados ou distribuídos;

$\checkmark$ determinação do tipo de centro de distribuição - central ou regional - e do custo de se elevar o nível de serviço e a disponibilidade de produtos; 
$\checkmark$ dimensionamento das operações de movimentação, levando-se em consideração equipamentos, área de preparação e de separação, quantidade de docas, entre outros aspectos;

$\checkmark$ estruturação do arranjo produtivo com o dimensionamento de máquinas, equipamentos, estações de trabalho, recursos humanos.

\subsubsection{Vantagens e desvantagens da simulação}

Os benefícios da simulação também são citados por Saliby (1989), Banks e Gibson (1996), Banks (2000), Cassel (1996), Hollocks (1992), Pegden (1995), Law e Kelton (2000), entre outros, e estão relacionados abaixo:

$>$ Uma vez criado, um modelo pode ser utilizado inúmeras vezes para avaliar projetos e política propostos.

> A metodologia de análise utilizada pela simulação permite a avaliação de um sistema proposto, mesmo que os dados de entrada estejam, ainda, na forma de esquemas ou rascunhos.

$>$ A simulação é, geralmente, mais fácil de aplicar do que os métodos analíticos.

$>$ Enquanto modelos analíticos requerem um número muito grande de simplificações para torná-los matematicamente tratáveis, as análises recaem, apenas, sobre um número limitado de medidas de desempenho. De maneira contrária, as informações geradas pelos modelos de simulação permitem a análise de, praticamente, qualquer medida concebível.

> Uma vez que os modelos de simulação podem ser quase tão detalhados quanto os sistemas reais, novas políticas e procedimentos operacionais, regras de decisão, fluxos de informações, entre outros, podem ser avaliados sem que o sistema real seja perturbado.

> Hipóteses sobre como ou por que certos fenômenos acontecem, podem ser testadas para confirmação, sem que o modelo real seja perturbado.

$>$ O tempo pode ser controlado. Pode ser comprimido ou expandido, permitindo reproduzir os fenômenos de maneira lenta ou acelerada, para que se possa melhor estudá-los. 
> Pode-se compreender melhor quais variáveis são as mais importantes em relação ao desempenho e como interagem entre si e com os outros elementos dos sistemas, mas isso é custoso (projeto experimentos).

> A identificação de "gargalos", preocupação maior no gerenciamento operacional de inúmeros sistemas, tais como fluxos de materiais, de informações e de produtos, pode ser obtida de forma facilitada, principalmente com ajuda visual.

$>$ Um estudo de simulação costuma mostrar como realmente um sistema trabalha em oposição à maneira como todos pensam que ele opera.

$>$ Novas situações sobre as quais se tenha pouco conhecimento e experiência podem ser tratadas de tal forma que se possa ter, teoricamente, alguma preparação diante de futuros eventos. A simulação é uma ferramenta especial para explorar questões do tipo: "o que aconteceria se"?

$>$ Sistemas complexos que contenham elementos estocásticos, que não conseguem ser descritos perfeitamente por modelos matemáticos resolvidos analiticamente, podem ser estudados por simulação.

$>$ A simulação fornece um melhor controle sobre as condições experimentais do que seria possível no sistema real, pois se pode fazer várias replicações no modelo designando-se os valores que se deseja para todos os parâmetros.

> A simulação admite a replicação precisa dos experimentos, podendo-se, assim, testar alternativas diferentes para o sistema.

> A simulação permite simular longos períodos em um tempo reduzido.

$>$ É, em geral, mais econômico que testar o sistema real e evitam-se gastos inúteis na compra de equipamentos desnecessários.

Segundo os autores, Saliby (1989), Banks e Gibson (1996), Banks (2000), Cassel (1996), Hollocks (1992), Pegden (1995), Law e Kelton (2000) existem algumas desvantagens da simulação, como por exemplo:

$\checkmark$ A construção de modelos requer treinamento especial. A técnica é aprendida e aperfeiçoada com o tempo e através da experiência.

$\checkmark$ Os resultados da simulação podem ser difíceis de interpretar, pois, geralmente, as saídas da simulação são variáveis aleatórias.

$\checkmark$ A modelagem e a análise da simulação podem ser dispendiosas em termos de recursos financeiros e tempo. 
$\checkmark$ Esses autores citam como desvantagem a difícil implementação dos resultados, mas dizer que os resultados da simulação podem ser de difícil implementação não seria uma desvantagem única e exclusiva da simulação, pois isso poderia acontecer independentemente da técnica ou do método.

$\checkmark$ Dificuldade de modelagem (construção dos modelos computacionais).

$\checkmark$ A programação de um modelo de simulação pode tornar-se uma tarefa altamente dispendiosa e desgastante, se os recursos computacionais não forem apropriados.

$\checkmark$ Devido a sua natureza estocástica, os modelos de simulação devem ser rodados várias vezes, para poder prever o desempenho do sistema.

$\checkmark$ A simulação é muito dependente da validade do modelo desenvolvido, ou seja, de nada adianta se fazer um estudo detalhado dos dados de saída, encontrar uma solução para o problema e, então, o modelo criado não representar fidedignamente o sistema, ou se os dados de entrada não forem corretos.

$\checkmark$ A simulação não é uma técnica otimizante, ela só testa as alternativas dadas pelo usuário.

Atualmente, muitas pessoas vêm trabalhando na resolução de alguns dos problemas citados. As deficiências da simulação têm sido resolvidas por meio de simuladores mais rápidos, simples, amigáveis e flexíveis, de novos métodos de análise de saída, de equipamentos de informática mais eficientes, entre outros.

Empresas de programas de simulação têm desenvolvido produtos que facilitam a modelagem: pacotes com modelos que precisam apenas dos dados de entrada e pacotes que possuem capacidade de análise de saída. Esses produtos permitem a redução de necessidades de conhecimentos computacionais dos usuários, além de reduzirem o tempo de projeto.

Um erro cometido por alguns analistas e usuários de simulação consiste em considerar a simulação como uma simples cópia da realidade ou como um exercício de programação em computador. Por causa desse tipo de pensamento, muitos estudos de simulação têm sido submetidos a verificações e validações insuficientes.

A simulação é uma poderosa ferramenta de avaliação de cursos de ações, mas requer um grande esforço metodológico e um rigoroso estudo estatístico para levar a conclusões satisfatórias. 


\subsection{PROGRAMAÇÃO LINEAR}

Segundo Andrade (1998), problemas de alocação de recursos incidem sobre as diversas tarefas ou atividades que devem ser realizadas. Normalmente, os recursos disponíveis não são suficientes para que todas elas sejam executadas no nível mais elevado que se possa desejar. O que se procura, nesses casos, é encontrar a melhor distribuição possível dos recursos entre as diversas tarefas ou atividades, de forma a atingir um valor ótimo do objetivo estabelecido.

Assim, esse tipo de problema é caracterizado pelos seguintes fatos:

$\checkmark$ existência de um objetivo que pode ser explicado em termos das variáveis de decisão do problema;

$\checkmark$ existência de restrições à aplicação dos recursos com relação, tanto às quantidades disponíveis quanto à forma de emprego.

Outra característica desse tipo de problema é que ele pode ser representado por um modelo de otimização em relação ao qual todas as relações matemáticas são lineares.

Desenvolvida após a Segunda Guerra Mundial, como instrumento de administração, a programação linear (PL), segundo Andrade (1998), por esforços concentrados em pesquisas econômicas e econométricas, rapidamente tornou-se uma das ferramentas mais eficazes para estudo de gestão: organização de transportes, determinação de política de estoques, estudos de fluxos de caixa e investimentos, estudos de sistemas de informações, além dos tradicionais problemas de produção e mistura de componentes.

Prado (1999) conceitua PL como ferramenta de otimização utilizada para encontrar o lucro máximo ou o custo mínimo em situações para as quais há diversas alternativas de escolha, sujeitas a algum tipo de restrição ou regulamentação.

A PL é uma ferramenta importante no planejamento e controle empresarial. Ehrlich (1991, p.21) menciona:

[...] PL é uma ferramenta de planejamento que nos ajuda a selecionar que atividades (variáveis de decisão) empreender, dado que essas atividades (diversas alternativas) competem entre si pela utilização de recursos escassos (restrições) ou então precisam satisfazer certos requisitos mínimos. O objetivo será maximizar (minimizar) uma função das atividades, geralmente lucros (perdas). 
A PL vale-se da Matemática para equacionar e resolver problemas que envolvem funções lineares. Goldberg (2000, p.15) explica que "A programação matemática na prática é fortemente direcionada ao apoio da tomada de decisão no gerenciamento de sistemas de grande porte, especialmente no que se diz respeito ao tratamento de variáveis qualificadas".

Conforme Andrade (1998), os estudos de PL permitem responder a questões como:

$\checkmark$ Estando presentes certas condições de produção, qual a quantidade de um determinado produto, entre vários, que se pode produzir para obter o maior lucro possível?

$\checkmark$ Sendo impostas algumas especificações, qual é a composição da mistura que corresponde ao custo mínimo?

$\checkmark$ Conhecendo certo número de condições de mercado (produtos, fornecedores e consumidores), como estabelecer os circuitos de distribuição de forma a minimizar o custo total?

$\checkmark$ Estando impostas as condições de trabalho, como repartir o contingente de mão-de-obra entre as diferentes tarefas e especialidade, com o objetivo de minimizar as despesas ou maximizar a eficiência?

$\checkmark$ Conhecido o valor nutritivo de certos alimentos que compõem uma ração, quais quantidades de cada um se devem especificar para satisfazer determinadas condições nutricionais e dar ao animal o crescimento desejado com o custo mínimo?

Assim como Andrade (1998), Prado (1999) também apresenta a PL aplicada na prática em diversas áreas:

$\checkmark$ Rotas de Transportes - Qual deve ser o roteiro de transporte de veículos de carga de modo que entreguem toda a carga no menor tempo e com menor custo total?

$\checkmark$ Manufatura - Qual deve ser a composição de produtos a serem fabricados por uma empresa de modo a atingir o lucro máximo, respeitadas as limitações ou exigências do mercado comprador e a capacidade de produção da fábrica?

$\checkmark$ Mineração - Em que seqüência se devem lavrar blocos de minérios, dada sua composição, posicionamento e custos de extração? 
$\checkmark$ Siderurgia - Quais minérios devem ser carregados nos reatores de redução de modo a se produzir, ao menor custo, uma liga metálica dentro de determinadas especificações?

$\checkmark$ Localização Industrial - Onde devem ser localizadas as fábricas e os depósitos/estoques de um novo empreendimento industrial, de modo que os custos de entrega do produto sejam minimizados?

Um problema de PL apresenta-se da seguinte forma:

Maximizar $z=c_{1} x_{1}+c_{2} x_{2}+\ldots+c_{n} x_{n} \Rightarrow$ Função Objetivo

Sujeito

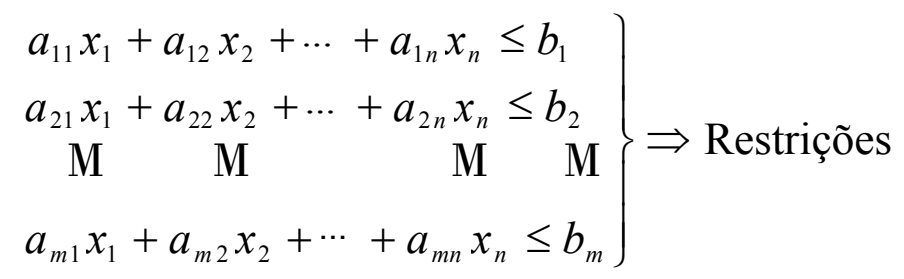

onde $c_{i}$, $a_{i j}$ e $b_{j}$ são constantes e $x_{i}$ são as variáveis do problema.

A função que se deseja maximizar ou minimizar é denominada função objeto, e as variáveis presentes na função objeto estão sujeitas a certas restrições.

\subsubsection{Modelos de PL}

Segundo Baldissera (2003), a PL se aplica principalmente na solução de problemas de maior porte. Geralmente, nesses problemas, muitas variáveis e restrições devem ser consideradas. Neste caso, a aplicação de sistemas computacionais potentes é o mais recomendado por Pidd (1998). Neste sentido, verifica-se que, na solução de modelos matemáticos, as variáveis e restrições envolvidas requerem recursos computacionais compatíveis e modelos de programação específicos.

Hillier (1998, p.32) assim descreve:

[...] agora suponhamos que exista qualquer número (chamado de $\mathbf{m}$ ) de recursos limitados de qualquer tipo, para ser alocado a qualquer número (chamado $\mathbf{n}$ ) de atividades em competição de qualquer tipo. Designemos números aos recursos $(1,2, \ldots, m)$ e atividades $(1,2, \ldots n)$. Consideremos $x_{j} \circ$ nível de atividade $\mathbf{j}$ (uma variável de decisão) para $\mathrm{j}=1,2, \ldots, \mathrm{n}$, e 
consideremos $\mathbf{Z}$ a medida geral de eficácia. Então, consideremos $c_{j} \circ$ aumento em $Z$ que resultaria de cada unidade acrescentada em $x_{j}$ (para $j=1,2, \ldots, n)$. A seguir, consideremos $b_{i}$ como denotando a quantidade do recurso i disponível para a alocação (para $\mathrm{i}=1,2, \ldots, \mathrm{m}$ ). Finalmente, definamos $a_{i j}$ como a quantidade do recurso i consumida em cada unidade de atividade $\mathrm{j}$ (para $\mathrm{i}=1,2, \ldots, \mathrm{m}$ e $\mathrm{j}=1,2, \ldots, \mathrm{n}$ ).

Nesta citação, mostra-se como pode ser definido um modelo de PL, identificando os recursos limitados, as atividades em competição e uma variável como medida geral de eficácia. Verifica-se que estes dados simbolizados por letras e números representam um modelo de PL e, na Tabela 3.1, podem ser visualizados como exemplo.

Tabela 3.1 - Dados para um modelo de PL

\begin{tabular}{|c|c|c|c|c|c|}
\hline & \multicolumn{4}{|c|}{ Uso do recurso/unidade } & \multirow[b]{2}{*}{ Quantidade de recurso disponivel } \\
\hline Recurso & 1 & 2 & $\ldots$ & $n$ & \\
\hline 1 & $a_{11}$ & $a_{12}$ & $\ldots$ & $a_{l n}$ & $b_{1}$ \\
\hline 2 & $a_{21}$ & $a_{22}$ & $\ldots$ & $a_{2 n}$ & $b_{2}$ \\
\hline$\vdots$ & & & $\vdots$ & & $\vdots$ \\
\hline$m$ & $a_{m I}$ & $a_{m 2}$ & $\ldots$ & $a_{m n}$ & $b_{m}$ \\
\hline AZ/unidade & $c_{1}$ & $c_{2}$ & $\ldots$ & $c_{n}$ & \\
\hline Nível & $x_{1}$ & $x_{2}$ & $\ldots$ & $x_{n}$ & \\
\hline
\end{tabular}

Com base no exposto, a formulação do modelo matemático pode ser escrita, conforme Hillier (1988, p.34), do seguinte modo:

$$
\begin{aligned}
& \text { Maximizar } Z=c_{1} x_{1}+c_{2} x_{2}+\ldots+c_{n} x_{n}, \\
& \text { Sujeitos às restrições } \\
& a_{11} x_{1}+a_{12} x_{2}+\ldots+a_{1 n} x_{n} \leq b_{1} \\
& a_{21} x_{1}+a_{22} x_{2}+\ldots+a_{2 n} x_{n} \leq b_{2} \\
& a_{m 1} x_{1}+a_{m 2} x_{2}+\ldots+a_{m n} x_{n} \leq b_{m} \\
& e \\
& x_{1}>=0, x_{2}>=0, \ldots, x_{n}>=0 .
\end{aligned}
$$

Assim, a função a ser maximizada $c_{1} x_{1}+c_{2} X_{2}+\ldots+c_{n} x_{n}$, é a função objetivo. Por sua vez, as variáveis $x_{1}, x_{2}, e x_{n}$ não podem ser negativas.

Verifica-se que a função objetivo a ser maximizada é $Z=c_{1} x_{1}+c_{2} X_{2}+\ldots+c_{n} x_{n}$. Também na PL as variáveis de decisão $x_{1}, x_{2}$, e $x_{n}$ não podem assumir valores menores ou iguais a zero. 
Prado (1999, p15) afirma que "a PL é uma técnica de otimização. A PL é uma ferramenta utilizada para encontrar o lucro máximo ou o custo mínimo em situações nas quais temos diversas alternativas de escolha sujeitas a algum tipo de restrição ou regulamentação".

A PL é aplicável em diversas áreas das empresas, principalmente quando, no dia-a-dia, aparecem situações reais de alguma complexidade, em que a decisão requer uma ferramenta mais adequada e não apenas o bom senso do gestor. Baldissera, cita Horngren, Foster e Datar (2000, p.286), que afirmam que "a PL é uma técnica de otimização usada para maximizar a margem de contribuição total (função objetivo), dadas múltiplas restrições".

Baldissera (2003, p.48) afirma que a otimização de resultados com a utilização da margem de contribuição é relevante, principalmente, quando se utiliza de instrumentos matemáticos, por haver, normalmente no processo produtivo, muitas restrições e variáveis de decisão.

Baldissera cita Leone (2000, p.407) que afirma que "quando a empresa tem muitos fatores que limitam a produção, as vendas e, consequentemente, os lucros, a gerência terá, em conjunto com a contabilidade dos custos, que analisar a situação empregando uma técnica chamada PL".

A PL torna-se, portanto, de acordo com Baldissera (2003), instrumento de auxílio no processo de decisões sobre a utilização de recursos limitados, buscando a maximização de resultados ou minimização de custos.

O Método Simplex é uma técnica utilizada em PL, para solução de problemas de otimização. Ela é utilizada, especialmente, em problemas que possuem um grande número de variáveis de decisão.

Goldbarg (2000) conceitua o Método Simplex como "um algoritmo que se utiliza de um ferramental baseado na álgebra linear para determinar, por um método iterativo, a solução ótima de um problema de PL”. Também é conhecido como Método de Dantzig. O Método Simplex foi desenvolvido por Dantzig, nos Estados Unidos, logo depois da Segunda Guerra Mundial, iniciando, a partir de então, seu desenvolvimento de forma mais sistemática.

O Método Simplex é um artifício matemático utilizado em programação que torna possível, de forma mais rápida e segura, a resolução de problemas com muitas equações e variáveis. 
Para Hillier (1988), "é um método notavelmente eficiente usado rotineiramente para resolver os enormes problemas dos computadores de hoje".

Uma forma simples de definir algoritmo pode ser: definição detalhada e estruturada de um método com início e fim definidos.

\subsection{CONCLUSÃO DO CAPÍTULO}

Modelos de simulação procuram oferecer uma representação do mundo real com o objetivo de permitir a geração e análise de alternativas, antes da implementação de qualquer uma delas. Por isso, dão ao analista um considerável grau de liberdade e flexibilidade com relação à escolha da ação mais conveniente.

Isso significa que o administrador pode criar ambientes futuros possíveis e testar alternativas, procurando responder a questões do tipo: "e se?", "o que acontecerá se?".

Uma característica importante é que o critério de escolha da melhor alternativa não é fixado na estrutura do modelo e é aplicado pelo analista, conforme representa a Figura 3.5.

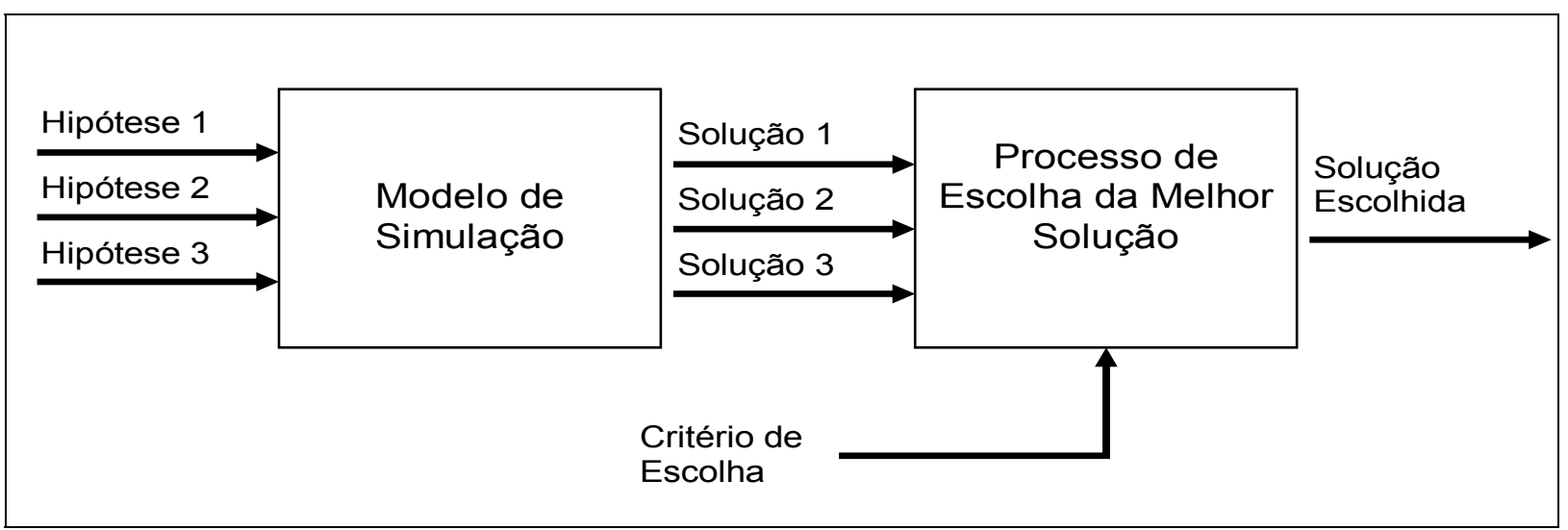

Figura 3.5 - Processo de decisão com modelos de simulação Fonte: Adaptado de ANDRADE, 1998.

Ao contrário do modelo anterior, o modelo de otimização não permite flexibilidade na escolha da alternativa, já que é estruturado para selecionar uma única, que será considerada "ótima", segundo o critério estabelecido pelo analista.

O critério faz parte da estrutura do modelo, que encontra a melhor alternativa através de uma análise matemática. Essa análise matemática é processada por métodos sistemáticos de solução chamados algoritmos. 
A "solução ótima" encontrada, segundo o critério, é tomada como referência para a decisão real. A Figura 3.6 ilustra o processo.

\begin{tabular}{|c|c|}
$\begin{array}{c}\text { Dados e Informações do } \\
\text { Sistema }\end{array}$ & \multicolumn{1}{|c|}{$\begin{array}{l}\text { Modelo de Otimização: } \\
\text { - Representação do Sistema } \\
\text { - Critério de seleção da } \\
\text { alternativa }\end{array}$} \\
\cline { 2 - 2 }
\end{tabular}

Figura 3.6 - Processo de decisão com modelos de otimização

Fonte: Adaptado de ANDRADE, 1998.

De acordo com o entendimento dos conceitos de, simulação e otimização apresentados neste capítulo, pode-se comparar, de forma qualitativa, as seguintes características, conforme apresentada na Tabela 3.2. Além disso, de acordo com a análise de Ackoff e Sasieni (1977), mesmo que um fenômeno tenha muitas variáveis envolvidas, cabe ao modelador a expertise de resumi-lo de forma a traduzir o evento no menor número possível de variáveis para facilitar seu entendimento.

Tabela 3.2 - Comparação qualitativa dos métodos de modelagem

\begin{tabular}{|l|c|c|}
\hline \multicolumn{1}{|c|}{ Características } & Simulação & Otimização \\
\hline Simplificações do sistema real & Baixa & Alta \\
\hline Investimento no desenvolvimento da ferramenta & Alto & Baixo \\
\hline Risco de desestabilizar o sistema real & N/A & N/A \\
\hline Flexibilidade & Alta & Média \\
\hline Complexidade na construção da ferramenta & Alta & Média \\
\hline Complexidade da análise da resposta & Média & Baixa \\
\hline Desde o início o objetivo está definido & Regra & Fundamental \\
\hline Utilização de variáveis aleatórias & Aplicável & Difícil aplicação \\
\hline Repetibilidade & Alta & Alta \\
\hline Realização de análise de sensibilidade & Baixa & Alta \\
\hline Identificação de gargalos & Alta & Média \\
\hline
\end{tabular}

$\left({ }^{*}\right) \mathrm{N} / \mathrm{A}=$ não se aplica

Esta decisão deve estar intrinsecamente relacionada aos objetivos de resolução do problema e a qualidade da solução dependerá das políticas de delimitação das fronteiras, níveis de detalhamento, além do conhecimento técnico tanto da ferramenta a ser utilizada como do sistema que está em análise.

Analisando-se os comentários feitos por Arcaute et al. (2001), verifica-se que eles adaptam uma ferramenta que fora desenvolvida especialmente para sistemas discretos e tenta aplicá-la em sistemas contínuos.

Desta forma, é de se esperar que se tenham perdas e limitações, se comparado à aplicação em um sistema na qual foi objeto fim de criação da 
ferramenta. Isto é, de forma geral, a qualidade da solução do problema é diretamente relacionada à ferramenta certa às características apresentadas pelo problema. Assim, dependendo do problema, o mesmo sistema será modelado de diversas maneiras, de forma a tentar resolver um específico problema.

Já de acordo com Rodrigues (1994), utilizar um ou outro método depende de como o modelador compreende o problema. A utilização de outra metodologia também dependerá dos modelos mentais da equipe envolvida para a resolução daquele referido problema. Neste sentido, além da ferramenta certa deve-se envolver as pessoas certas para resolver tal problema.

Além disso, Rodrigues (1994) relata que, a questão de quando se deve utilizar uma das técnicas de PO não possui uma resposta única, mas depende das restrições ambientais e dos objetivos do estudo que se está realizando.

A determinação de quais questões devem ser respondidas pelo estudo em questão é, possivelmente, o ponto de partida para a determinação de qual tipo de modelagem e análise se deverá adotar.

Outros fatores também devem ser levados em conta nesta escolha. Dentre eles, Rodrigues (1995) relata que os mais importantes são o grau de aleatoriedade dos dados e o grau de complexidade do sistema em estudo.

Para sistemas simples e cuja variabilidade dos dados possa ser desprezada sem detrimento da qualidade da análise realizada, o mais indicado, talvez, sejam modelos de otimização clássicos, baseados em Cálculo Diferencial e Integral e em Programação Matemática.

Permanecendo no caso de sistemas simples, mas havendo alto grau de variabilidade nos dados - isto é, havendo presença de componentes fortemente aleatórios no sistema - o mais adequado, talvez, seja uma abordagem baseada em modelos probabilísticos estáticos, tais como Distribuições Clássicas de Probabilidade e distribuições obtidas por convolução de distribuições clássicas.

No caso de sistemas com maior grau de complexidade em que o grau de variabilidade dos dados é desprezível, possivelmente serão obtidas soluções de alta qualidade, se foram empregadas heurísticas adequadas. É o caso de muitos problemas de otimização encontrados em setores produtivos, como no caso de escalonamento de produção.

Finalmente, no caso de sistemas com elevado grau de complexidade e alto grau de aleatoriedade dos dados, o uso de simulação poderá ser mais vantajoso, 
uma vez que os esforços de modelagem e, principalmente de análise dos resultados, serão compensatórios. Estes conceitos foram abordados por Rodrigues (1995) e são ilustrados na Figura 3.7.

Analisando a frase de Pidd (1998), em que ele defende que "simulação computacional deveria ser considerada como último recurso, para ser utilizado se todos os outros métodos falharem" é muito pertinente após estes comentários. Pois, devido à facilidade de se incorporar detalhes no modelo computacional quando se utiliza a simulação, pode-se inserir um detalhamento tamanho, que a complexidade do modelo se assemelha ao sistema real e, desta forma, só se transporta o problema para o computador. O único ganho, neste caso, seria analisar cenários sem afetar o mundo real. Caso este não seja o objetivo fundamental da análise, pode-se somente estar transferindo o problema.

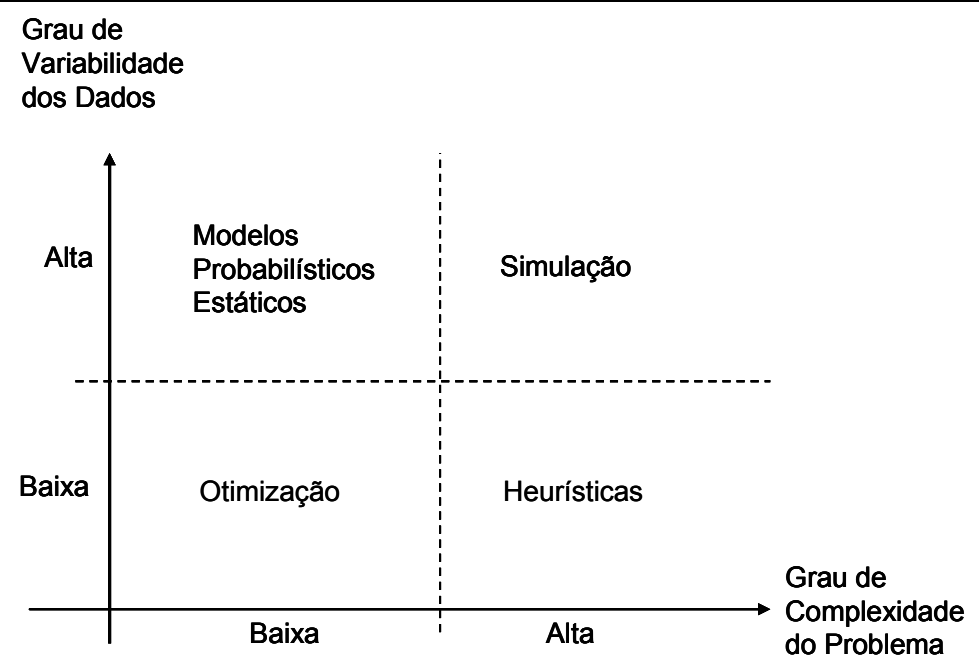

Figura 3.7 - Adequação de diferentes técnicas de modelagem em relação à complexidade e à variabilidade dos dados de um problema.

Fonte: Adaptado de RODRIGUES,1995.

Como se pode observar, existe um caminho bem explorado de técnicas para resolução de problemas, no sentido de aprimorar, em cada uma das áreas de conhecimento, separadamente, a busca da melhor solução, deixando de se aproveitar o potencial que se pode conseguir com a integração dessas técnicas.

O próximo capítulo explorará os métodos que têm sido desenvolvidos atualmente, com o objetivo de integrar técnicas de simulação com otimização, e algumas aplicações em problemas de sistemas logísticos. 


\section{REVISÃO SOBRE MÉTODOS DE SIMULAÇÃO-OTIMIZAÇÃO}

De acordo com Granger, Krishnamurthy e Robinson (2002), a partir da metade do século passado, os analistas de PO vêm desenvolvendo um grande conjunto de técnicas e conhecimentos, como comentado no capítulo anterior. Foram modelados muitos problemas importantes, de tipos diferentes, e os métodos mostraram, não só como modelar as cadeias, mas também como mudá-los, investindo em recursos adicionais ou usando outros meios de movimentação de materiais na cadeia, para aperfeiçoar alguma medida de desempenho.

Métodos de otimização constroem os seus planos baseados na premissa de que o parâmetro de informação subjacente esteja correto. Os planos são, assim, os melhores possíveis. Isso pode ocorrer desde que essa premissa seja verdadeira, caso contrário não existe garantia alguma de que os planos sejam ótimos ou até mesmo muito bons.

\subsection{MÉTODOS DE PLANEJAMENTO}

Muito da teoria disponível para lidar com cadeias logísticas assume que os dados do problema são determinísticos. Porém Granger, Krishnamurthy e Robinson (2002) dizem que isso não é verdade, para muitos problemas, na prática. Por exemplo, se a aeronave tem que parar em rota para reabastecimento e/ou manutenção, então, a sua duração de tempo no solo pode variar consideravelmente por causa de ineficiência de equipamentos ou de imprevistos que podem requerer manutenção corretiva adicional antes da aeronave prosseguir.

Tempos de vôo podem variar por causa de condições de tempo ou demoras operacionais ocasionadas por outros elementos do sistema de transporte, como acontece devido à capacidade de aterrissagem reduzida no aeroporto receptor. Embora se utilize aeronave aqui, para propósitos ilustrativos, outros meios de transporte também podem estar sujeitos a incertezas no seu desempenho operacional. 
A diferença entre sistema determinístico e sistema estocástico é muito importante, particularmente para métodos que tentam aperfeiçoar o desempenho do sistema. Granger, Krishnamurthy e Robinson (2002) mencionam que um dos melhores exemplos conhecidos disso acontece com um modelo de fila simples. $O$ sistema determinístico corresponde a chegadas em intervalos regulares e cada chegada requer o mesmo tempo para o serviço. A pessoa pode planejar as chegadas de forma que a unidade seguinte chegue e comece o serviço da mesma maneira que ele é completado. Desse modo, o tempo entre chegadas se igualará aos tempos de serviço.

Caso se introduza uma medida de utilização, como o tempo de serviço dividido pelo tempo entre chegadas, então, este tipo de plano terá $100 \%$ de utilização. Além disso, um método de otimização determinístico, que busca maximizar o processamento (quer dizer, minimizar o tempo total requerido por unidade), planejará desse único modo.

Porém, uma vez que o tempo entre chegadas e de serviço se torna estocástico, a situação é bem diferente. Para um simples modelo de fila (de $M / M / 1$ fila), é bem fácil mostrar que, com algum nível de utilização menor que $100 \%$ e aumento da média do tempo entre chegadas e tempos de serviço, tanto o tempo de espera em fila quanto o número esperado no sistema, se aproximam do infinito. A situação é semelhante para muitas outras filas. Para não haver demoras excessivas e bloqueios em tais sistemas, deve-se ter cuidado para manter a utilização abaixo de $100 \%$.

Bush, Niles e DePuy (2003) argumentam que a aplicação de uma técnica de otimização isolada para uma situação real conduz a uma valiosa informação sobre o sistema. Obviamente, a relevância dos resultados depende da qualidade do modelo e dos dados de entrada. Bush, Niles e DePuy (2003) afirmam que a otimização é útil para planejamento estratégico de longo prazo. O programa linear não é útil no dia-adia para planejamento operacional.

Ainda, segundo esses autores, a aplicação de otimização para um grande problema pode conduzir a dificuldades de interpretação e validação dos resultados. A primeira questão é se a solução determinada pela otimização é realmente uma solução possível que se refere a uma solução que não só é possível para a otimização, mas também para o sistema real. Uma solução viável é possível para o 
modelo de otimização, se os parâmetros da otimização forem aceitáveis em um modelo de simulação.

Em certas situações, não é possível incluir todas as restrições e procedimentos operacionais de um sistema real em um modelo de otimização. Nessas circunstâncias, uma ferramenta útil pode ser a simulação, que pode incorporar todos os procedimentos exigidos e todas as restrições do sistema real.

\subsection{HISTÓRIA DA SIMULAÇÃO-OTIMIZAÇÃO}

Segundo Morito et al. (1999), existem muitos sistemas complexos aperfeiçoados, de grande importância, que têm que ser projetados de forma que certas metas sejam otimizadas. Modelagem e análises são freqüentemente críticas para o sucesso do projeto de um bom sistema. Nesse sentido, a programação matemática é uma ferramenta poderosa de otimização, enquanto a simulação é bem apropriada para avaliação de desempenho com maior flexibilidade.

Do ponto de vista histórico, a necessidade de resolver problemas logísticos foi um dos motivos do surgimento da pesquisa operacional. Os sistemas de hoje, de acordo com Köchel, Kunze e Nieländer (2003), que tiveram que ser projetados de forma a controlar um caminho ótimo, são tão complexos que aproximações analíticas tradicionais isoladas não direcionam as soluções suficientes. Então, esses autores sugerem uma combinação de métodos de pesquisa operacional com ciência da computação.

Um resultado de tal combinação é a simulação-otimização, que, por meio de um simulador do sistema real a ser investigado, é integrado com métodos de otimização satisfatórios para um determinado problema.

O desenvolvimento de métodos de simulação-otimização é, atualmente, um campo ativo de pesquisa. Um dos primeiros métodos propostos de acordo com Granger, Krishnamurthy e Robinson (2002), foi o de aproximação estocástica.

Os problemas de como avaliar o desempenho logístico e então decidir como alocar recursos limitados para melhorá-lo é semelhante a esses enfrentados por gerentes de instalações industriais. Essas instalações também correspondem a cadeias estocásticas e tanto a estrutura de cadeia quanto as características 
estocásticas dos componentes representam papéis importantes no eventual desempenho dos sistemas.

Segundo Granger, Krishnamurthy e Robinson (2002), os analistas têm aplicado técnicas de aproximação (heurísticas), originalmente desenvolvidas por pesquisadores que utilizavam teoria de filas, para produzir ferramentas de avaliação mais rápidas e simplificadas, com vista a melhorar o desempenho de sistemas industriais.

Esses métodos de aproximação dão estimativas de fatores-chave de desempenho, como tempos de espera em vários locais na cadeia, mas eles fazem isso sem requerer simulações completas em cada avaliação. A carga computacional requerida corresponde à resolução de um sistema de equações não-lineares e o tempo de execução necessário é, geralmente, muito menor que o utilizado em uma simulação.

\subsection{CARACTERÍSTICAS DA SIMULAÇÃO-OTIMIZAÇÃO}

Para Azadivar (1999), o uso de simulação como uma ajuda à otimização apresenta vários desafios específicos. Alguns desses são abordados na otimização de qualquer função complexa e/ou não-linear. Outros mais específicos são relacionados à natureza especial de modelagem da Simulação.

Azadivar (1999) relata que as principais características, quando se compara a simulação-otimização com problemas genéricos de programação não-lineares, são:

$\checkmark$ Não há uma expressão analítica da função-objetivo ou das restrições. Isso elimina a possibilidade de diferenciação ou cálculo exato de gradientes locais.

$\checkmark$ A(s) função(ões) objetivo e as restrições são funções estocásticas de variáveis de decisão determinísticas. Isso representa o maior problema na estimação de variáveis locais (pontuais). Além disso, trabalha-se contra o uso da varredura completa, porque, baseado em uma só observação de cada ponto, não se pode determinar o melhor ponto de decisão.

$\checkmark$ Programas de simulação computacional são muito mais caros do que a avaliação de funções analíticas. Isso torna a eficiência dos algoritmos de otimização mais crucial. 
$\checkmark$ A maioria dos usuários utiliza algumas linguagens de simulação para modelar seus sistemas. Por sua vez, a otimização requer o uso de algumas linguagens que diferem de um usuário para o outro. Conectar modelos de simulação com modelos genéricos de otimização não é sempre uma tarefa fácil.

Vale ressaltar que estas vantagens apresentadas por Azadivar (1999) são muito genéricas e não se aplicam de uma forma segura e consistente. Além disso, muitas das alternativas apresentadas como vantagens, cabe analisar a sua viabilidade técnica ou a necessidade das mesmas, o que reforça a necessidade de um maior aprofundamento na integração destes conceitos de PO.

Morito et al. (1999) afirmam que as forças e fraquezas da programação matemática e da simulação são complementares.

Isso quer dizer que, enquanto a programação matemática é fraca em alguns fatores, como o desconhecimento da relação de "input/output", o dinamismo de sistema, a não-linearidade, a ausência de aleatoriedade e detalhes de sistemas, a simulação é fraca em sua capacidade de otimização.

É, então, natural pensar na combinação deles, contanto que existam problemas apropriados satisfatórios para a combinação de simulação e otimização. De fato, há muitos problemas de importância que são de natureza da otimização, contudo, é muito complicado incluir todos os seus detalhes. Para esses problemas, Morito et al. (1999) indicam o método de planos de corte como "framework" para a combinação de simulação e otimização.

A formulação de sistemas de simulação-otimização é freqüentemente feita por maximização ou minimização de valores esperados da função-objetivo do sistema. Porém, esse não tem que ser o caso.

De acordo com Azadivar (1999), a operação de um de sistema pode ser considerada ótima, se o risco de exceder certo limiar for minimizado.

Em outras situações, a pessoa poderia estar interessada em minimizar a dispersão da resposta, ao invés de seu valor esperado. Azadivar (1999) limita-se à otimização dos valores esperados.

Outro assunto pertinente na formulação de problemas de simulaçãootimização é o tratamento de restrições estocásticas. Essas restrições, como as funções-objetivo, são, às vezes, funções de variáveis de decisão determinísticas e premissas para definir uma região determinística possível. 
Por exemplo, a meta em um problema de alocação de recurso pode ser minimizar o "lead-time" sujeito a um inventário em processo limitado. O "lead-time" e inventários em processo podem ser respostas estocásticas de um modelo de simulação.

A pessoa pode tentar propor valores ótimos para as variáveis de decisão, tais que o valor esperado do "lead-time" seja minimizado. Porém, declarar que a otimização deve ser feita de tal forma que o valor esperado do estoque em processo não exceda certo limiar, pode não ser a aproximação mais correta.

Inventários são entidades físicas e requerem espaço físico. Mesmo que seus valores esperados estejam dentro de limites aceitos, seus valores atuais podem exceder as restrições de espaços físicos.

Na prática, Azadivar (1999) relata que muitos tomadores de decisão preferem lidar com restrições, como o risco de violação de uma restrição particular, a estar dentro de determinado conjunto de respostas para o valor esperado da região possível.

Uma característica comum a todos estes métodos de simulação-otimização convencionais, de acordo com Granger, Krishnamurthy e Robinson (2002), é a simulação repetitiva do sistema: a cada passo de melhoria, o desempenho do sistema deve ser avaliado, pelo menos uma vez, pela simulação.

Para sistemas grandes e complexos, essa exigência envolve gastos muito altos, tanto de tempo quanto de recursos computacionais. Então, é de grande importância tentar achar modos de reduzir essas exigências de recurso.

De acordo com Bush, Biles e Depuy (2003), os métodos de simulação e otimização são aplicados principalmente ao mesmo problema, por duas razões.

Primeiro, porque permite que um analista simule um sistema específico e então determine o valor ótimo para algum parâmetro dentro do problema, mediante a aplicação de uma técnica de otimização.

Segundo, porque a simulação é aplicada, freqüentemente, aos resultados de um problema de otimização, para conferir a validade dos resultados. Os resultados do modelo de otimização são usados como “inputs" aos modelos de simulação. 


\subsection{VANTAGENS DE SIMULAÇÃO-OTIMIZAÇÃO}

As principais vantagens da simulação-otimização, de acordo com Azadivar (1999), são:

- a complexidade do sistema modelado não afeta, significantemente, o desempenho do processo de otimização;

- para sistemas estocásticos, a discrepância da resposta é controlável por meio de várias técnicas de análise de dados de saída;

- onde estruturas de sistemas de otimização são consideradas, a simulação provê uma vantagem que não é freqüentemente possível em procedimentos clássicos de otimização, caso em que, mediante o emprego de técnicas apropriadas, a função-objetivo ou as restrições podem ser mudadas de uma iteração a outra para refletir os planos alternativos do sistema.

\subsection{DIFICULDADES DA SIMULAÇÃO-OTIMIZAÇÃO}

Segundo Granger, Krishnamurthy e Robinson (2002), simulação é bem conhecida e extensamente usada para modelar muitos tipos diferentes de sistemas estocásticos. Esses autores mencionam que a simulação é ativamente usada em ferramentas como o Modelo de Fluxo de Transporte Aéreo da Força Aérea Americana e a Simulação de Operações de Mobilidade Aérea.

A Força Aérea Americana parece considerar isto como o método de escolha para planejamento de transporte aéreo detalhado.

Porém, a simulação pode requerer tempos de execução muito longos se o problema for grande ou complexo.

Além disso, Granger, Krishnamurthy e Robinson (2002) comentam que há um problema mais significante em que a simulação é projetada para que dê e faça um retrato estático da operação de um sistema com determinadas características. 
Mas o que se quer freqüentemente saber não é somente como um determinado sistema opera, mas também como se deve mudar esse sistema para trazer seu desempenho mais próximo a algum conjunto de padrões que se tem em mente. Por exemplo:

$\checkmark$ pode haver recursos limitados disponíveis para investir no melhoramento de várias partes do sistema;

$\checkmark$ pode haver necessidade de expandir a capacidade de campos aéreos para executar carregamento aéreo ou operações de serviço;

$\checkmark$ podem-se abrir novos campos aéreos, ou até mesmo adquirir tipos diferentes de aeronave.

Cada uma dessas ações tem um impacto no sistema e cada uma requer alguns recursos escassos. Granger, Krishnamurthy e Robinson (2002), analisando como se deve investir para melhorar o desempenho do sistema, concluem que, não existe problema de análise estática, mas de otimização e, finalizam, afirmando que a simulação ainda é essencial, pois é a única ferramenta genérica conhecida, por avaliar o desempenho de muitos tipos diferentes de sistemas estocásticos, mas tem que ser uma etapa dentro do método de simulação-otimização.

\subsection{APLICAÇÃO DA SIMULAÇÃO-OTIMIZAÇÃO}

"Commercial-Off-The-Shelf" (COTS) são produtos disponíveis no mercado para indústrias com necessidades específicas. Esses produtos, de acordo com Vamanan et al. (2002), na maioria dos casos, têm aplicações restritas.

Enquanto os fabricantes de produtos COTS normalmente permitem integração com programas de linguagem (C, C++, BASIC, Java e outros) e fornecem aos seus clientes instruções detalhadas de como eles podem utilizar essa interface, eles, raramente, documentam a possibilidade de integrar seus produtos COTS com os de outros fabricantes.

Dessa forma, Vamanan et al. (2002) demonstram os mecanismos de integração dos dois softwares de PO, CPLEX e ARENA. Tal integração analisa uma provisão de amostras de aplicação na cadeia de suprimentos na área de logística e estoques, além de discutir resultados e desvantagens dessa aproximação. 
De acordo com Díaz e Pérez (2000), a colheita de cana de açúcar é uma operação logística complexa, que envolve o corte, o carregamento de cana nos campos, o transporte por caminhão/reboque para as fábricas e a descarga da cana na fábrica.

Cada fábrica de açúcar tem várias frotas, que cortam a cana com várias máquinas, buscando cumprir uma meta diária. Então, dependendo da meta de um dia particular, recursos como caminhões, reboques e tratores são nomeados.

Devido às mudanças de um ano para o outro na quantidade de cana disponível nos campos e devido às mudanças nas fábricas, um método fidedigno tinha de ser encontrado para assegurar que, no futuro, aquelas exigências pudessem ser eficazmente atendidas.

Neste sentido, Díaz e Pérez (2000) criaram um método com um número mínimo de replicações de um modelo de simulação. O resultado da simulação é a entrada de uma otimização que determina a ótima alocação de recursos pertinentes às variáveis de saída.

\subsection{CLASSIFICAÇÃO DA SIMULAÇÃO-OTIMIZAÇÃO}

A partir de agora, serão apresentados alguns procedimentos sucintos de soluções disponíveis para várias classes dos problemas relatados por Azadivar (1999).

Primeiro, serão discutidos procedimentos aplicados para separar problemas de objetivo único com variáveis de decisão quantitativas, contínuas ou discretas, sujeitos a restrições determinísticas ou estocásticas. Depois, serão apresentados problemas de objetivos múltiplos.

Finalmente, será apresentada uma discussão sobre problemas de otimização não-paramétricos. Em cada caso, serão explorados os assuntos que, especificamente, pertencem à simulação. 


\subsubsection{Problemas de objetivo único}

Algumas aproximações populares para resolver problemas de objetivos únicos são:
A. gradiente baseado em métodos de busca;
B. métodos estocásticos de aproximação;
C. métodos de superfície de respostas;
D. otimização de caminhos por amostragem;
E. métodos de heurística de busca.

\section{A - Gradiente baseado em métodos de busca}

Estes métodos tentam tirar proveito da vasta literatura disponível sobre métodos de busca, desenvolvidos para problemas de programação não-lineares.

A maior contribuição dos usuários de simulação-otimização para este campo têm sido os vários métodos de gradientes de estimação eficientes. Dois fatores principais na determinação do sucesso desses métodos são a confiabilidade e a eficiência.

A confiabilidade é importante porque respostas de simulação são estocásticas. Um grande erro em estimação de gradiente pode resultar em um movimento em direção completamente errada.

A eficiência é o principal fator experiências de simulação são caras e é desejável calcular gradientes com número mínimo de avaliações da função.

$O$ fato de todos os derivativos poderem ser resultantes da mesma corrida de simulação, representa uma vantagem significante para a análise de perturbação infinitesimal em termos de eficiência. Porém, algumas condições restritivas têm que ser satisfeitas para ser aplicável.

Por exemplo, se o resultado da perturbação de um determinado parâmetro for uma sucessão de eventos que governam o comportamento das mudanças do sistema, os resultados obtidos por análise de perturbação podem não ser fidedignos.

B) Métodos de aproximação estocásticos

Métodos de aproximação estocásticos referem-se a uma família de procedimentos recursivos, que se aproximam do mínimo ou do máximo da função de 
regressão teórica de uma superfície de resposta estocástica, que usa observações minuciosas feitas na função. Esses métodos estão baseados no trabalho original de Robbins e Monro (1951) e Kiefer e Wolfowitz (1952).

Uma característica do método de aproximação estocástico, quando aplicado à simulação-otimização é que o valor ótimo esperado da resposta pode ser alcançado mediante observações minuciosas.

A dificuldade é que um grande número de replicações da fórmula recursiva é exigido para obter o ótimo. Além disso, para vetores de decisão multidimensionais e tendo $\mathbf{p}$ como número de observações, são necessárias p+1 observações para cada replicação. Glynn (1986) proveu estimativas de velocidade de convergência para algumas variações desse método. A outra dificuldade com esses métodos é a incorporação das restrições dentro da otimização.

Um método que aplica a aproximação estocástica para simulação-otimização, é reportado por Azadivar e Talavage (1980). Nesse trabalho, foi desenvolvido um algoritmo automático que poderia ser conectado independentemente com qualquer modelo de simulação construído. Esse algoritmo também se aplica em problemas com um conjunto de restrições determinísticas lineares de variáveis de decisão.

\section{C) Metodologia de superfície de resposta}

Metodologia de superfície de resposta é o procedimento de ajustar uma série de modelos de regressão às respostas do modelo de simulação, avaliado sob vários pontos, para tentar otimizar o resultado da função de regressão.

O processo, normalmente, começa com uma função de regressão de primeira ordem e, depois, busca, na vizinhança, o ótimo. Para isso, são utilizadas funções de regressão de grau mais elevado.

Entre os trabalhos mais recentes de aplicação da metodologia de superfície de resposta para simulação-otimização estão os de Biles (1987) e Smith (1976). Outros trabalhos adicionais foram informados por Daugherty e Turnquist (1978) e Wilson (1987).

Smith (1976) desenvolveu um programa automático, buscando o ótimo baseado na metodologia de superfície de resposta, o qual poderia ser conectado com modelos de simulação, construídos independentemente. Esse programa foi desenvolvido para problemas restritivos ou não. 
Comparado a muitos métodos baseados em gradientes, o método de superfície de resposta é um método relativamente eficiente para simulaçãootimização, em termos do número de experimentos de simulação necessários. Porém, Azadivar e Talavage (1980) mostram que, para funções complexas com ápices mais pontiagudos e vales mais planos (suaves), o método de superfície de resposta não provê respostas boas.

\section{D) Otimização de caminhos por amostragem}

Neste método de otimização de caminhos por amostragem, as técnicas de otimização determinísticas são aplicadas a certas amostras observadas no modelo de simulação. O valor esperado da função-objetivo é estimado pela média de um grande número de observações de cada ponto. Algumas descrições e condições desses métodos citados na literatura são determinadas por Chen e Schmeiser (1994) e Shapiro (1996). O problema deste método, com respeito à simulaçãootimização, é o grande número de avaliações envolvidas no sistema.

\section{E) Métodos heurísticos de busca}

Há dois métodos heurísticos que mostraram a aplicação promissora de simulação-otimização. O método de busca complexa (Box, 1965) e o "simulated annealing", que já foi apresentado no capítulo anterior.

Busca complexa é uma extensão do "simplex" de busca de Nelder e Mead (1976), que foi modificado para problemas restritivos. A busca começa com a avaliação de pontos de um "simplex" e, tendo $\mathbf{p}$ o número de vértices, consiste em $p+1$ vértices na região viável. Isso prossegue derrubando o pior ponto entre os pontos do "simplex" e somando um novo ponto determinado pela reflexão desse ponto, por meio do centróide dos vértices restante.

O aspecto principal desse procedimento, em modelos de simulação, é a determinação do pior ponto. Considerando-se que as respostas são estocásticas, um ponto aparentemente ruim pode ser, de fato, um dos melhores, e, derrubando-se este, pode-se levar a busca da região ótima para longe.

Azadivar e Lee (1988) desenvolveram um programa baseado em busca complexa que, automaticamente, aplica este processo para qualquer modelo de simulação. 
As variáveis de decisão desses modelos podem ser restritivas, mediante restrições determinísticas, como também estocásticas, podendo, também, ser respostas de outros modelos de simulação.

Para evitar uma tomada de decisão errada, comparam-se os piores valores dos vértices das respostas estatisticamente. Se o resultado da comparação múltipla for conclusivo e mostrar que aquele ponto é significativamente pior que os outros, ele é derrubado. Caso contrário, são feitas iterações adicionais de simulação, para reduzir a discrepância e a comparação é repetida.

\subsubsection{Problemas de multiobjetivos}

Além das dificuldades comuns a todos os outros problemas de otimização multicriterial, a simulação-otimização multicriterial apresenta suas próprias complexidades, que estão principalmente relacionadas à natureza estocástica das funções de resposta.

A maioria dos trabalhos feitos nessa área são modificações simples das técnicas usadas em operações pesquisadas, para a otimização genérica de multiobjetivos. Algumas dessas aproximações são:

- Uso de uma das respostas como a resposta primária a ser otimizada, sujeito a certos níveis de ativação nas outras funções-objetivo. Bile (1979) usa essa aproximação junto com uma versão do método complexo utilizado por Box (1965) e, alternativamente, com uma variação de gradiente e de método de projeção de gradiente.

- Variações do objetivo de programação aproximando daqueles métodos relatados por Biles Swain (1979), Clayton, Weber e Taylor (1982), e Rees, Clayton e Taylor (1985).

- Métodos de função de valor de multiatributo como o usado por Mollaghasemi, Evans e Biles (1991).

Teleb e Azadivar (1994) exploram a natureza estocástica das respostas como vantagem de otimização. Eles utilizam o método de busca complexa, mas sugerem um modo alternativo de comparar os vértices de respostas. 
Para cada ponto, calculam uma probabilidade de o vetor de resposta pertencer ao vetor aleatório que representa o melhor valor de todas as funçõesobjetivo. O ponto de menor probabilidade é derrubado e sua reflexão, com respeito ao centróide do resto dos pontos, é somada ao "simplex".

\subsubsection{Otimização paramétrica}

Muitos sistemas complexos, como o industrial, o de serviços e outros que são modelados por meio de simulação computacional, necessitam ser otimizados em termos de suas estruturas organizacionais e políticas operacionais.

Por exemplo, em vez do número ótimo de máquinas em uma estação de trabalho, a pessoa poderia interessar-se pelo modo como são organizadas as estações de trabalho do chão de fábrica, ou, em vez do nível de inventário em processo em cada estação, o problema de interesse poderia ser as políticas de roteamento para os produtos acabados que saem de cada estação. Técnicas de programação matemática não são normalmente aplicáveis nessas situações.

Para resolver esses problemas, cada função de avaliação requer uma nova configuração do modelo de simulação. Isso é equivalente a mudar a função-objetivo em cada replicação.

Além disso, quando as variáveis de decisão não são quantitativas, a análise de perturbação infinitesimal e métodos de aproximação estocásticos não são muito aplicáveis. Para lidar com esses problemas, uma nova geração automática de modelo e um procedimento novo de otimização têm de ser desenvolvidos.

As aproximações mais comuns para resolver esses problemas têm sido a varredura completa ou a amostragem aleatória. A varredura completa só será possível, se o número de configurações para o sistema for pequeno.

Porém, até mesmo para um problema modesto, como um sistema de produção com apenas quatro estações, três tipos de produtos, três políticas de roteamento para cada estação e quatro políticas de manutenção diferentes, 144 diferentes modelos de simulação precisariam ser construídos para uma varredura completa. 
A próxima melhor etapa para a varredura completa é avaliar uma amostra aleatória de configurações de sistema e selecionar o melhor, usando algum tipo de seleção e análise de comparação. A amostragem aleatória, ainda, é uma das melhores alternativas, quando o número de possíveis configurações é muito grande.

Poderiam ser usadas várias regras para selecionar a amostra aleatória de todas as possíveis alternativas dos casos. Porém, freqüentemente, a pessoa tem que selecionar todas as alternativas candidatadas ao mesmo tempo. A aproximação "espere e veja" ("wait and see") em problemas quantitativos comuns de otimização, não pode ser implementada aqui. Na busca aleatória "wait and see", a pessoa pega uma pequena amostra e, baseada na informação obtida sobre essa amostra, seleciona pontos adicionais mais inteligentemente do que se todos os pontos fossem selecionados imediatamente.

A busca de gradiente e os métodos "simplex" são exemplos dessa filosofia, na qual o próximo ponto a considerar é selecionado por um movimento definido no espaço geométrico das variáveis de decisão n-dimensionais. Na otimização nãoparamétrica, porém, o espaço da solução não pode ser definido geometricamente. Não há direção crescente ou decrescente para o valor que uma variável de decisão pode assumir.

Algoritmos genéticos têm recentemente surgido como uma poderosa aproximação para resolver esses problemas. Com os algoritmos genéticos, a busca pode ser guiada sistematicamente de uma amostra para a próxima sem a necessidade de definir o espaço geométrico das variáveis de decisão.

Os algoritmos genéticos são imitações computacionais da evolução simplificada e idealizada. O ácido desoxirribonucléico (mais conhecido pela sigla DNA) é representado por um gene em que cada posição pode assumir um dos finitos conjuntos de valores. A afinidade com o organismo é determinada por uma função de aptidão. A função decodifica o gene e retorna um valor de escala real, o valor mais desejável (maior para a maximização e menor para problemas de minimização) que sirva para o indivíduo. Um grupo de genes forma, juntos, população.

A transição de uma população para a próxima é ativada pelo desempenho dos operadores de "crossover" e de mutação do algoritmo genético entre os membros individuais da população. Com a operação de "crossover", os genes que representam dois membros individuais da população são trocados em porções 
quebradas e, assim, certos genes entre os dois cromossos que criam dois novos cromossos.

Em mutação, é selecionada certa posição (um gene ao acaso) e, com uma probabilidade predeterminada, é mudado o valor da variável representada por aquela posição. Depois de "crossovers" e mutações, uma nova população é selecionada, e bem como os novos membros da população prévia. Davis (1991) e Goldberg (1989) apresentam descrições inclusivas dos conceitos e técnicas de algoritmos genéticos. O último passo do sistema biológico ao sistema real é feito pela união de um gene a um sistema. Para realizar isso, dois passos devem ser considerados. Primeiro, precisa ser desenvolvido um mecanismo pelo qual os sistemas possam ser representados por um gene, contendo lugares para o acesso crítico dos parâmetros do sistema. Segundo, a informação contida em um gene precisa ser traduzida, automaticamente, em um modelo de simulação do sistema.

Azadivar e Tompkins (1999) desenvolveram um procedimento que utiliza algoritmo genético em projetos de otimização de sistemas industriais flexíveis. Esse procedimento envolve um algoritmo genético agregado com um modelo de simulação automatizado que interagem entre si. Também contém uma coleção de dados de entrada, por meio da qual os usuários podem prover dados na estrutura do sistema.

\subsection{MÉTODOS DE SIMULAÇÃO-OTIMIZAÇÃO}

\subsubsection{Método de Köchel ${ }^{10}$}

Köchel, Kunze e Nieländer (2003) assumem que um problema de otimização é definido pelo par ( $\boldsymbol{f}, \mathbf{D})$, em que $\mathbf{f}$ é a função objetivo e $\mathbf{D}$ é o conjunto de decisões admissíveis. A maioria dos métodos de otimização é baseada na premissa de que $\boldsymbol{f}$ é determinado de uma forma analítica e que seus valores podem ser calculados exatamente.

\footnotetext{
${ }^{10}$ Método de Köchel - nome simplificado dado ao método criado por Köchel, Kunze e Nielander, em 2003.
} 
Para sistemas complexos, tal premissa não é mais válida. Valores da função de $\boldsymbol{f}$ só podem ser calculados na saída de uma simulação. No caso de sistemas estocásticos, a pessoa terá somente estimações. Porém, o cálculo ou a estimativa por experiências de simulação não resolve um problema de otimização. Para isso a pessoa tem que combinar um simulador correspondente ao sistema a ser otimizado com uma ferramenta de otimização apropriada.

Essa aproximação é chamada simulação-otimização. O princípio da simulação-otimização é esboçado na Figura 4.1, cujo esquema mostra que otimização e simulação se alternam de tal um modo que o simulador coleta a informação sobre o desempenho de cada decisão sugerida pelo otimizador.

Otimização e simulação empurram um ao outro até que uma decisão aceitável seja encontrada. Do esquema da Figura 4.1, segue a principal pergunta: Como liberar o otimizador?

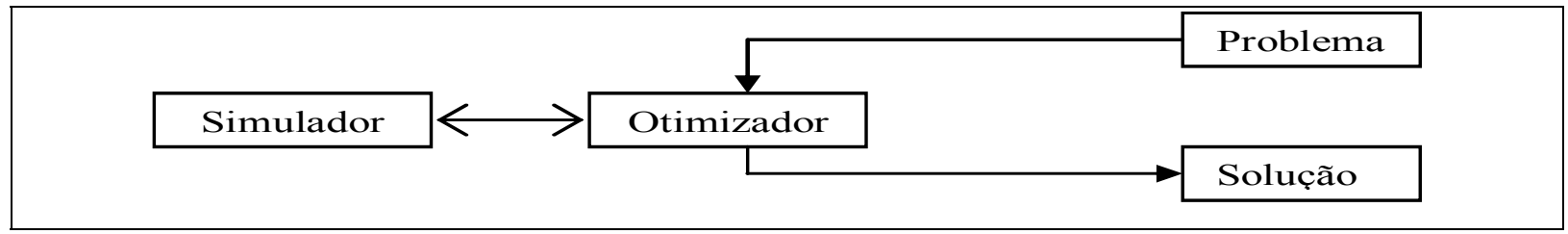

Figura 4.1 - O princípio da simulação-otimização

Fonte: KÖCHEL; KUNZE; NIELÄNDER, 2003.

Em geral, se a interface entre o simulador e o otimizador for bem definida então, com um determinado simulador, um método de otimização arbitrário pode ser acoplado. Em todas as implementações de Köchel, Kunze e Nieländer (2003), o otimizador consiste em quatro partes (Figura 4.2).

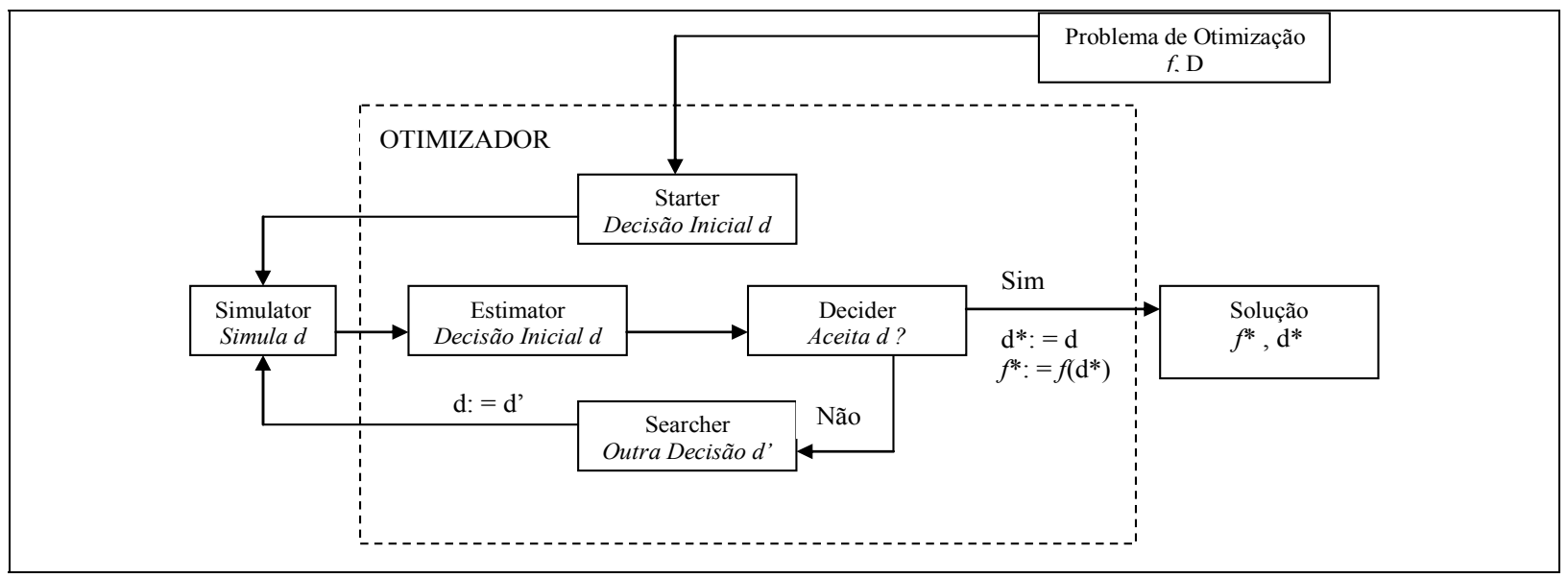

Figura 4.2 - Esquema da simulação otimização

Fonte: KÖCHEL; KUNZE; NIELÄNDER, 2003. 
O Starter escolhe uma condição inicial que será dada ao simulador. Como resultado de uma experiência de simulação com a configuração de sistema correspondente à decisão escolhida, adquire-se uma amostra do histórico do sistema.

O "Estimator" transforma essa informação em uma estimativa para $\mathbf{f}(\mathbf{d})$, que é o desempenho da decisão $\mathbf{d}$. Com base nessa estimativa e, possivelmente, mais adiante, assim que a informação esteja disponível, o "Decider" pode aceitar, imediatamente, a decisão investigada como (aproximadamente) ótima e o processo de busca é parado, ou o "Searcher" assume a ordem, para achar uma nova decisão possivelmente melhor.

Assim, o processo de busca para uma decisão ótima será executado pelo repetido processamento de quatro fases:

$>$ proposta de uma solução;

> geração relevante para os dados do problema por uma experiência de simulação;

> análise de desempenho dessas bases de dados;

$>$ decisão para aceitar a solução proposta ou continuar o processo de busca.

Esse ciclo será executado até que um critério de parada seja cumprido. Uma vez iniciado o processo de busca, ele corre, automaticamente, sem interação com o usuário. Depois de deixar o ciclo, a melhor das soluções consideradas é retomada. A saída do processo inteiro pode ser mais ampla, por exemplo, pode ser retornada à segunda melhor solução e assim por diante.

$\mathrm{Na}$ Figura 4.2, fica claro que a aproximação permite um procedimento seqüencial, em que, de acordo com as exigências e a continuidade do processo de otimização, dados adicionais e informações podem ser incluídos durante o processo de busca.

Assim, a aproximação proposta será flexível de tal modo que permita uma distribuição eficiente de recursos finitos, já que se pode utilizar informação obtida e conter o ótimo local. A Figura 4.2 aponta para os principais problemas que devem ser resolvidos para aplicar simulação-otimização.

O primeiro é como achar uma decisão inicial. Em muitos casos, uma solução é óbvia. Por exemplo, para um problema de inventário, uma decisão inicial pode ter zero de inventário. Em casos em que $\mathbf{D}$ é definido por uma grande quantidade de 
complexas restrições, pode ser necessário desenvolver um algoritmo especial para definir a decisão inicial.

O segundo é como calcular o desempenho de uma decisão simulada. Normalmente, são computadas amostras para calcular a média dos intervalos de confiança correspondentes.

O terceiro é como decidir por parar ou continuar o processo de busca. A solução mais simples é definir um critério de parada com um número finito de diferentes decisões investigadas ou tempo finito de execução.

Finalmente, é o pesquisador ter que resolver o problema mais importante - a definição de outra decisão, se o processo de busca for continuado.

A solução desse problema é, mais ou menos, a essência do otimizador de simulação-otimização. Implementando diferentes algoritmos nesse ponto, o que influencia essencialmente a qualidade de todo o processo de otimização descrita é o desempenho da decisão aceita e o tempo de computação requerido para achar tal decisão.

\subsubsection{Método de Granger e sua aplicação ${ }^{11}$}

Granger, Krishnamurty e Robinson (2002) introduziram uma tática simples da cadeia de transporte aéreo que ilustra seu método de melhoria. A estrutura da cadeia é observada na Figura 15.

O problema utilizado por esses autores para ilustração é o de administrar uma tática de ressuprimento de cadeia. A carga é movida de um par de bases de suprimento, cujas capacidades são assumidas para serem grandes, mediante duas áreas intermediárias no campo aéreo, com capacidade limitada, para duas bases operacionais seguidas.

A aeronave, então, retorna pelas bases intermediárias. $O$ transporte, 0 reabastecimento, a manutenção e/ou outras operações podem acontecer nessas bases intermediárias, mas, como premissa da ilustração, todos esses tempos são

\footnotetext{
${ }^{11}$ Método de Granger - nome simplificado dado ao método criado por Granger, Krishnamurty e Robinson em 2002.
} 
agregados em um único "tempo de solo". Eles poderiam ser desagregados para construir um modelo mais detalhado.

Tempos de vôo e tempos de solo são modelados como uma variável aleatória, com distribuição gama e uma média apropriada. Considerando que esta cadeia é assimétrica, rastrearam-se os tempos de fluxo para cada rota. Quer dizer, até mesmo se os tipos das aeronaves fossem todos iguais, mesmo assim elas seriam diferenciadas de acordo com a rota a ser cumprida. No início da análise, foi utilizada uma cadeia desbalanceada.

O objetivo de Granger, Krishnamurty e Robinson (2002) foi alocar um número limitado de espaços extras de redução de velocidade entre o estágio 1 e 2 para equilibrar a cadeia da melhor maneira possível.

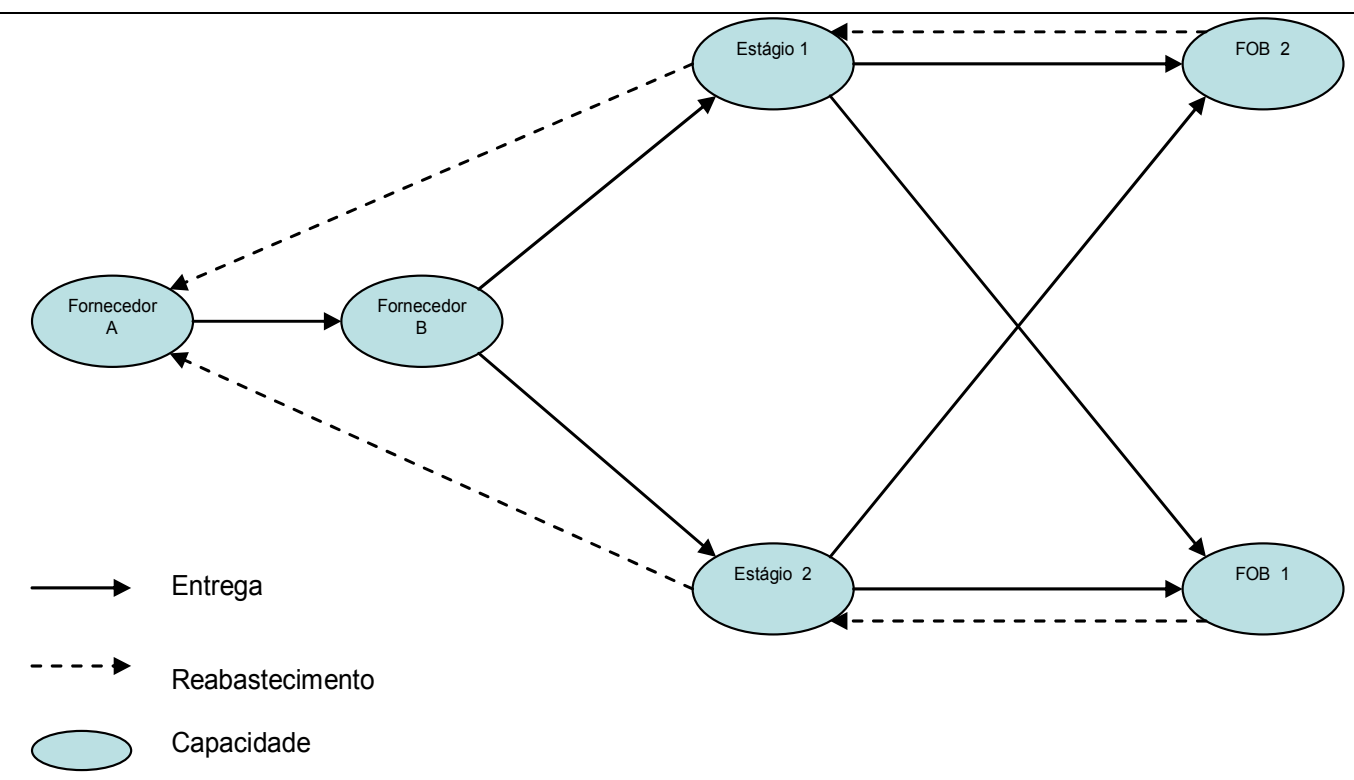

Figura 4.3 - Estrutura da rede

Fonte: GRANGER; KRISHNAMURTHY; ROBINSON, 2002.

Para o modelo de simulação de Granger, Krishnamurty e Robinson (2002), foi utilizado o ProModel $R$ - Versão 4.3, um pacote de simulação de eventos discretos comercialmente disponível, usado para simular sistemas industriais. A cadeia de transportes aéreos é modelada como uma cadeia industrial, com espaços aéreos e aeronaves considerados, respectivamente, como localizações e entidades.

Granger, Krishnamurty e Robinson (2002) construíram um modelo de aproximação de cadeia que usa MPX Versão 3.3 (Dinâmica de Cadeia, Inc., 1999), um pacote comercial para modelagem de produção. O pacote MPX modela cadeias 
industriais como cadeias abertas de filas, enquanto a rede de transportes aéreos tática é similar (quer dizer, tem um número fixo de entidades que é igualado ao número total de aeronaves). Foram introduzidos dois diferentes "tipos de parte" na estrutura da MPX, um para aeronaves de entrega, que avançam aos FOBs, e outro para as aeronaves de reabastecimento, que voltam dos FOBs.

De acordo com a Figura 4.4, observa-se que, para balancear a cadeia, foi primeiro executada uma simulação simples, a fim de coletar os dados base.

Depois de identificado o gargalo, o próximo passo foi usar o método de aproximação de cadeia, para avaliar o efeito de alocar mais aeronaves no espaço da rampa entre os dois espaços aéreos (Estágio 1 e 2).

Granger, Krishnamurty e Robinson (2002) alocaram unidades de forma a deixar as utilizações de S1 e S2 essencialmente iguais. Nesse sentido, utilizaram-se do seu método de aproximação para trabalhar com os dados de capacidade, balanceando o restante da cadeia e fazendo interpolações lineares, de forma a garantir esse seu objetivo de igualar as utilizações de S1 e S2. Cada interpolação, afirmaram os autores, requer uma única execução do método de aproximação, mas nenhuma simulação.

Para confirmar que as estimativas produzidas pelo procedimento de aproximação fossem fidedignas, os autores realizaram uma corrida de simulação adicional.

Granger, Krishnamurty e Robinson (2002) concluem que o ponto-chave aqui é dispensar o procedimento de simulação-otimização habitual de produção de uma corrida de simulação a cada passo do processo. Ao invés disso, utilizaram somente duas: uma corrida base no princípio e, então, uma complementar, ao final, confirmando.

Para cada passo intermediário, usou somente uma corrida do método de aproximação de cadeia. Cada corrida levou não mais de cinco segundos, considerando que uma corrida de simulação leva substancialmente muito mais tempo. Deve-se ressaltar que esse diferencial de tempo se expande a um exemplo maior e mais realista (para a vantagem do método de aproximação de cadeia).

$\mathrm{Na}$ cadeia um pouco mais complexa, concluíram Granger, Krishnamurty e Robinson (2002) que as corridas de aproximação de cadeia foram mais rápidas que as de simulação por um fator de 60 . 
Realmente, um método computacional que integre um procedimento de otimização com o de simulação da cadeia (permitindo, assim, que o otimizador use informação adicional gerada durante o desenvolvimento da resolução das equações para as aproximações de cadeia) deveriam ser ambos mais poderosos e mais flexíveis.

De acordo com Granger, Krishnamurty e Robinson (2002), construir a experiência para desenvolver um método e utilizar um software apropriado como base provavelmente seria um próximo passo razoável. Tal método combinado abriria uma ampla variedade de possibilidades e permitiria uma análise teórica adicional, ganhando conhecimento sobre condições de convergência de tal procedimento de otimização, pelo menos, localmente.

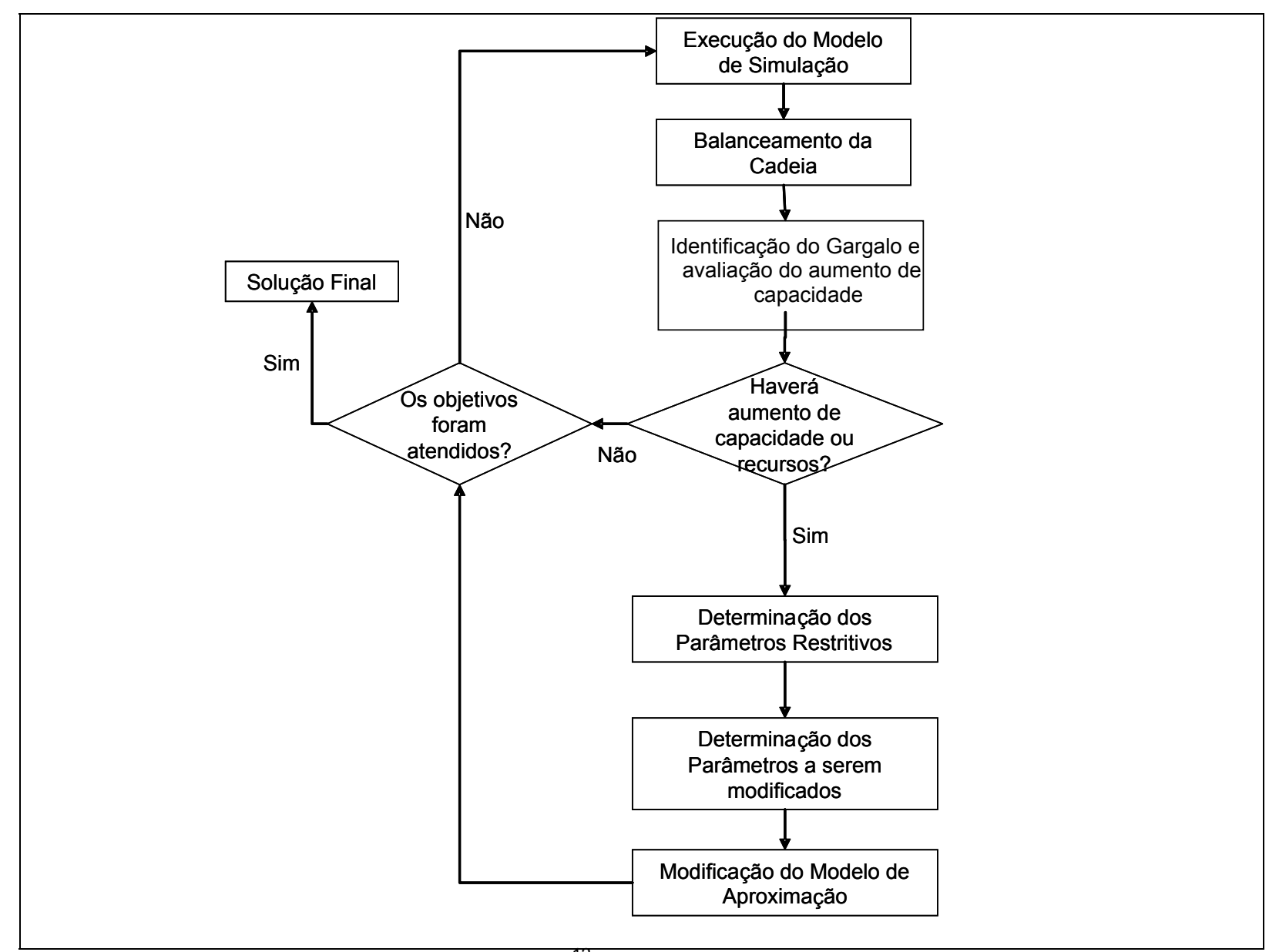

Figura 4.4 - llustração do método de Granger ${ }^{12}$

\footnotetext{
${ }^{12}$ Figura criada a partir da descrição apresentada por Granger, Krishnamurty e Robinson (2002).
} 


\subsubsection{Método de Vashi e Bienstock aplicado por Díaz e Pérez (2000)}

Díaz e Pérez (2000) aplicaram o Método de Vashi e Bienstock na cadeia produtiva de cana de açúcar. A colheita de cana de açúcar é uma operação logística complexa, que envolve o corte, o carregamento de cana nos campos, o transporte por caminhão/reboque para as fábricas e a descarga da cana na fábrica. Cada fábrica de açúcar tem várias frotas que cortam cana com várias máquinas para executar uma meta diária.

Então, dependendo da meta de um dia particular, recursos como caminhões, reboques e tratores são nomeados. Devido às mudanças de um ano para o outro na quantidade de cana disponível nos campos e devido a mudanças nas fábricas, um método tinha de ser encontrado para assegurar que, no futuro, as exigências pudessem ser atendidas.

A fim de poder entender as mudanças na colheita de estação para estação, Díaz e Pérez (2000) afirmavam que deveria haver uma constante e contínua análise da organização atual sobre a disponibilidade de infra-estrutura e necessidades futuras. Os autores possuíam três metas principais:

1. Identificação do gargalo logístico no transporte de cana de açúcar.

2. Provisão de soluções para este gargalo, que suportarão a tomada de decisão do processo.

3. Desenvolvimento de um sistema efetivo de tomada de decisão, para a alocação de recursos de cada frota com base diária.

O objetivo era conseguir um número mínimo de replicações de um modelo de simulação, de forma que o seu resultado pudesse ser a entrada de uma otimização, determinando a alocação ótima de recursos.

O processo de simulação-otimização desenvolvido por Vashi e Bienstock (1995) é ilustrado na Figura 4.5. A operação do sistema, como representado pelo modelo de simulação, é executada em um especifico período de tempo. $O$ desempenho do sistema é baseado na saída do modelo de simulação e na resposta a ser otimizada. 


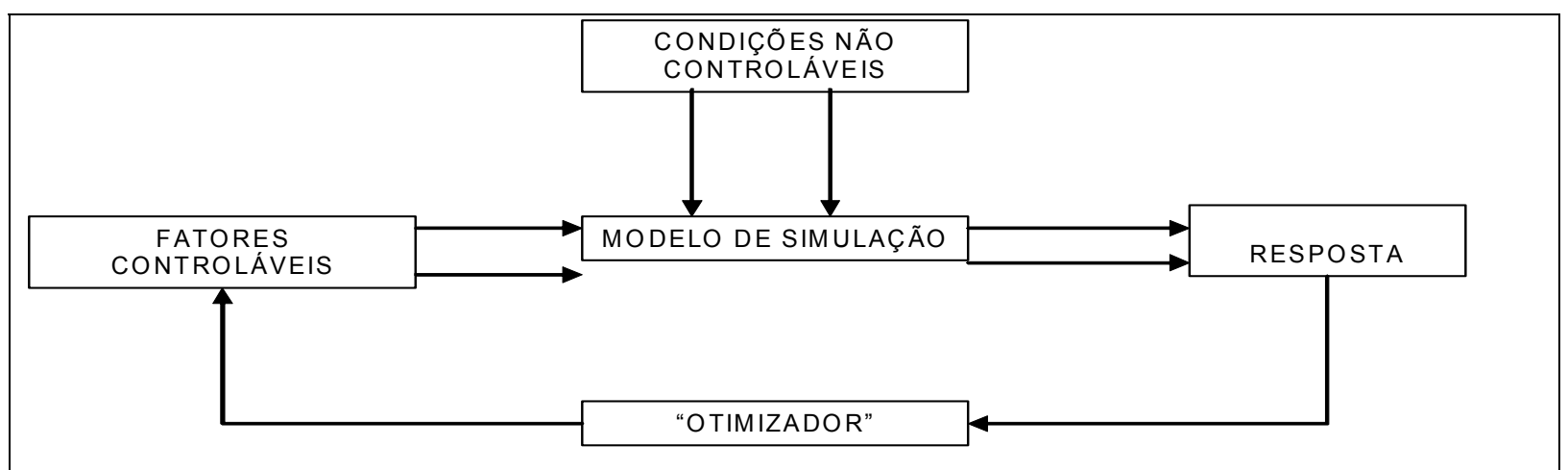

Figura 4.5 - Procedimento para otimização do sistema simulado Fonte: DÍAZ; PÉREZ, 2000.

O procedimento ilustrado na Figura 4.5, utilizado por Díaz e Pérez (2000), envolve três fases, como segue.

A primeira é típica de qualquer problema de modelagem logística e envolve a identificação das variáveis de resposta a serem otimizadas e das variáveis independentes que o afetam.

A segunda fase compreende o agrupamento dos dados das variáveis para um caso teste. Esses dados são usados para futuro refino da definição das relações das variáveis, por conseguinte, para a construção do modelo de simulação. Depois da construção, uma série de corridas é conduzida para validar o modelo e testar suas hipóteses. A simulação não provê mecanismo para achar a solução ótima do problema; ela apenas indica a melhor solução dentre aquelas examinadas.

A terceira fase é o ponto no qual a função de resposta é trazida em uso para achar a solução ótima, neste caso, com a utilização da metodologia de superfície de resposta. O objetivo preliminar do método de superfície de resposta é aproximar a função de uma região pequena, relativa às variáveis independentes a alguma função simples (VASHI; BIENSTOCK, 1995).

A análise de superfície de resposta de nenhuma maneira limita o número de variáveis que pode ser incluído na análise. Um analista pode incluir tantas variáveis quantas julgar necessárias para tentar resolver o problema.

O fluxo completo do processo de colheita da cana de açúcar, do campo para a fábrica, é ilustrado na Figura 4.6 e é um retrato do modelo utilizado por Díaz e Pérez (2000) aplicado em ARENA.

Dois subsistemas foram diferenciados por Díaz e Pérez (2000), baseados no processo que envolve reboques e caminhões. 
Reboques: este subsistema começa com um reboque vazio no campo, pronto para ser carregado. O reboque a ser carregado é engatado a um trator. Depois o trator retira o reboque do campo, desacopla-o e libera-o até ser engatado a um caminhão carregado e levado para a fábrica. Caminhões: este subsistema começa com um caminhão vazio no campo, pronto para ser carregado.

Quando uma máquina cortadeira está disponível, o caminhão é carregado, daí, então, um reboque carregado é engatado a ele para ir à fábrica. Uma vez na fábrica, caminhão e reboque são pesados. Então o reboque é descarregado e, em seguida, o caminhão. Feito isso, um reboque vazio é engatado ao caminhão e devolvido ao campo.

Díaz e Pérez (2000) comentam sobre esse processo, argumentando que, entre o campo e a fábrica, a cana de açúcar passa por vários processos, que serão levados a cabo pelos recursos gargalos. Os "lead-times" exigidos são resultados de tempos de processamento e de esperas potenciais que poderão existir se filas surgirem.

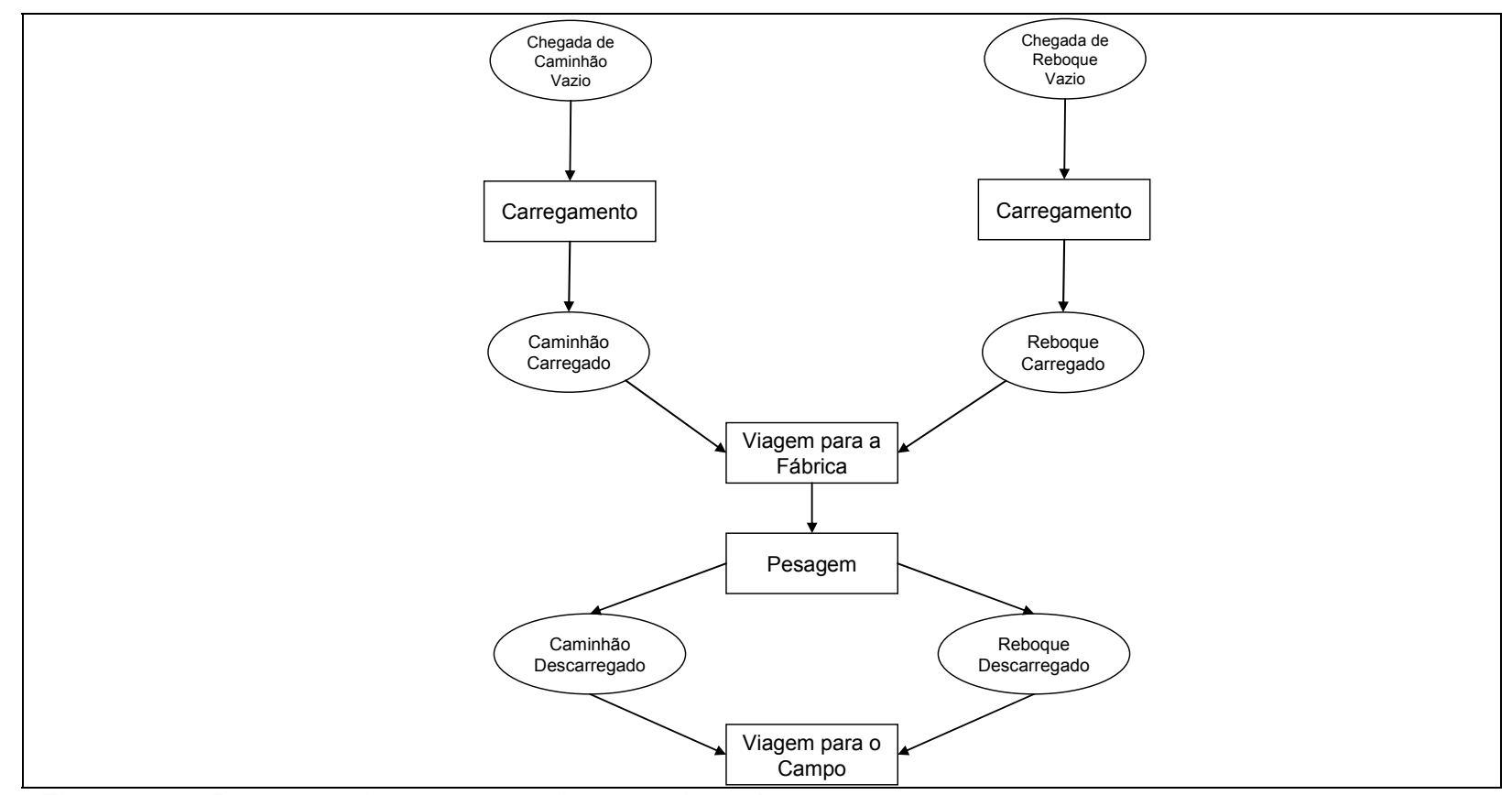

Figura 4.6 - Processo de transporte de cana de açúcar

Fonte: DÍAZ; PÉREZ, 2000.

No modelo elaborado por pelos autores, a informação de cada frota é agrupada em relação à utilização de recurso, ao tempo de espera, à duração de fila e quantidade total de cana transportada. 
Uma vez construído o modelo de simulação representando a operação real do sistema, Díaz e Pérez (2000) especificaram os campos a serem colhidos, como também as distâncias para a fábrica. Então, executaram corridas de simulação, com várias alternativas de fatores controláveis, baseados em diversos experimentos que tornavam possível obter a superfície de resposta requerida.

De acordo com a simulação-otimização, os principais fatores controláveis considerados para todo o time, foram o número de recursos alocados e a velocidade do caminhão. A quantidade total de cana a ser transportada e a média do tempo de transporte, durante um ciclo completo, foram consideradas como variáveis de saída. As Figuras 4.7 e 4.8 mostram exemplos das superfícies de resposta obtidas pelos autores.

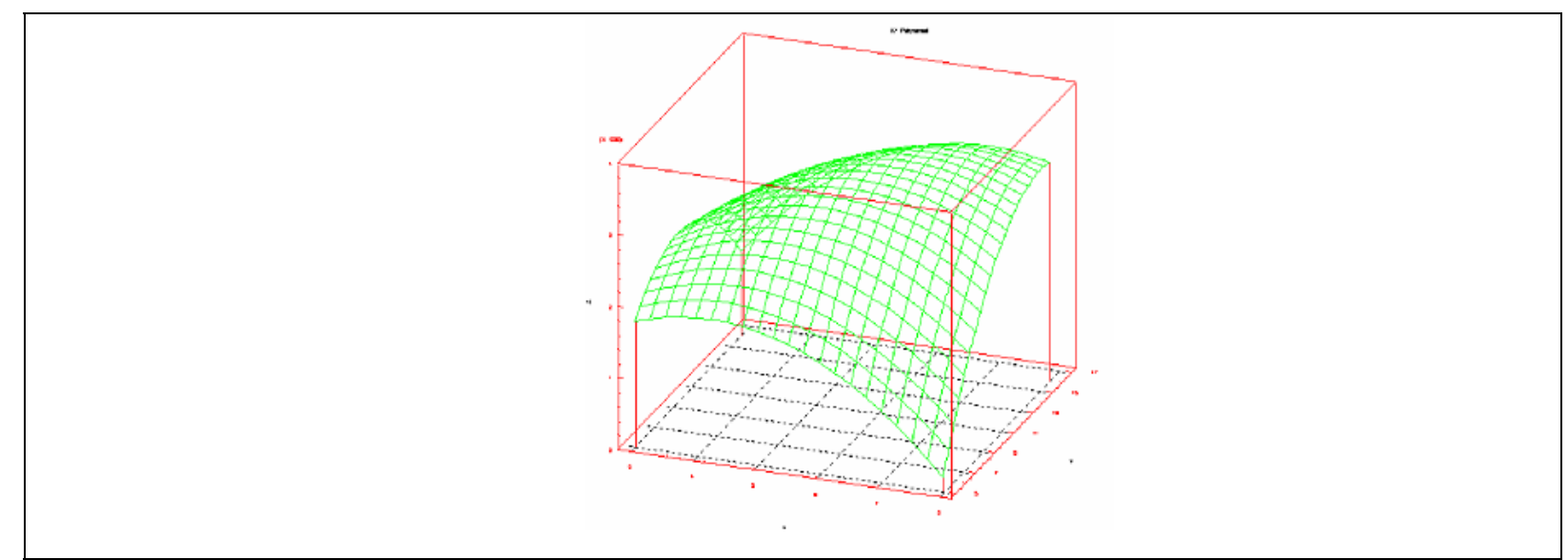

Figura 4.7 - Superfície de resposta das variáveis de saída do transporte de cana de açúcar como uma função do número de caminhões e reboques

Fonte: DÍAZ; PÉREZ, 2000.

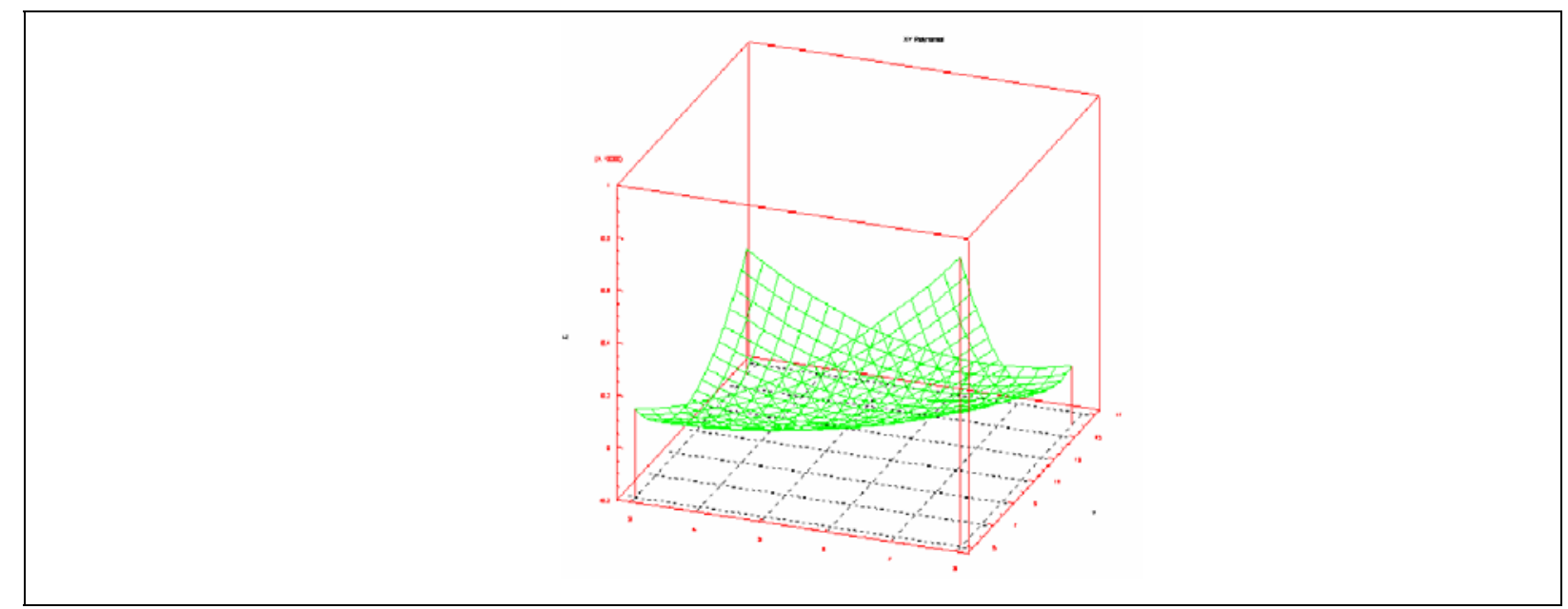

Figura 4.8 - Superfície de resposta das médias das variáveis de saída do tempo de ciclo das viagens como uma função do número de caminhões e reboques

Fonte: DÍAZ; PÉREZ, 2000. 
De acordo com Díaz e Pérez (2000), a simulação-otimização resultou em quantidades enormes de saída, que foram traduzidas em avaliações do fluxo de cana de açúcar, em utilização de recursos, em tempos de espera e em todos os outros critérios de desempenho.

Essa informação quantitativa serve como material de suporte para o Ministério da Indústria de Açúcar de Cuba, na tomada de decisões sobre distribuição de recursos para fábricas, de forma a predizer gargalo e prover soluções que evitassem problemas e riscos no futuro.

\subsubsection{Método de Vamanan ${ }^{13}$}

Commercial-Off-The-Shelf (COTS) são produtos disponíveis para indústrias com necessidades específicas existentes no mercado. Estes produtos, na maioria dos casos, têm aplicações restritas. Os autores argumentam que, enquanto os fabricantes de produtos COTS normalmente permitem integração com programas de linguagem ( $\mathrm{C}, \mathrm{C}++, \mathrm{BASIC}$, Java, entre outros) e fornecem aos seus clientes instruções detalhadas de como podem utilizar essa interface, eles raramente documentam a possibilidade de integrar seus produtos COTS com os de outros fabricantes.

O propósito do trabalho de Vamanan et al. (2002) é demonstrar os mecanismos de integração de dois softwares de PO, CPLEX e ARENA. No trabalho destes autores, foi analisada a aplicação desses mecanismos na cadeia de suprimentos e de estoques, além das desvantagens dessa aproximação.

CPLEX é uma ferramenta desenvolvida para resolver amplos problemas de otimização linear (também pode ser usada para programas quadráticos). Inclui um sistema básico interativo e uma biblioteca. Usa uma programação linear baseada no algoritmo "branch-and-bound" para chegar a uma solução, depois de uma série de relaxamentos de programações lineares.

ARENA é uma ferramenta de simulação computacional em que os usuários podem modelar sistemas complexos, utilizando módulos, blocos e elementos

\footnotetext{
${ }^{13}$ Método de Vamanan - nome simplificado dado ao método criado por Vamanan et al., 2002.
} 
disponíveis nos modelos de ARENA, que usam operações simples de clicar e arrastar. ARENA utiliza o SIMAN como a linguagem de simulação. Assim, toda vez que o usuário coloca um módulo na janela e completa os campos exigidos, o ARENA escreve seu próprio código em SIMAN.

Vamanan et al. (2002) apresentam uma amostra de um problema de cadeia de suprimentos que quer integração COTS. Eles utilizaram um pequeno segmento dessa cadeia com centros de distribuição geograficamente dispersos, cujos estoques são reabastecidos com produtos das respectivas instalações da companhia fabril.

Esses centros de distribuição são requeridos para satisfazer as exigências dos clientes, como as demandas para os vários grupos de produtos que entram em uma estação de administração de ordem central.

A função da estação central de administração de ordens é organizar a distribuição desses produtos, agrupar os clientes dos vários centros de distribuição e satisfazer a demanda e, também, as devidas datas.

O caminho das ordens é dividido por centros de distribuição (CDs) que podem variar de acordo com a política de exigência de ordem e de lugar.

Vamanan et al. (2002) assumem que, para cada combinação de produto/CD, existe um nível de inventário mínimo e máximo específico (s; $\mathbf{S})$ do sistema de inventário.

Os autores consideram uma situação em que uma ordem vem de um cliente com demanda $\mathbf{D}=\left(\mathbf{d}_{1} ; \mathbf{d}_{2} ;::: ; \mathbf{d}_{\mathrm{m}}\right)$. Sem perda de generalidade, Vamanan et al. (2002) assumem que os CDs são etiquetados $(1 ; 2 ;::: ; \mathbf{N})$ em ordem crescente de distância desse cliente. Consideram o vetor $\mathbf{s}_{1 \mathrm{j}} ; \mathbf{s}_{2 \mathrm{j}} ;::: ; \mathbf{s}_{\mathrm{mj}}$, onde $\mathbf{s}_{\mathrm{ij}}$ é o nível de estoque de produto i em CD j. Deixam $\mathbf{n}$ ser o CD mais próximo, que pode exigir a ordem inteira $\mathbf{D}$, como, por exemplo, $\mathbf{s}_{\text {in }}>=\mathbf{d}_{i}$;.

Para qualquer $\mathbf{i}$, mas qualquer $\mathbf{J}<\mathbf{n}$, lá existe um $\mathbf{i}$ tal que $\mathbf{s}_{\mathbf{i}^{\prime} \mathbf{j}}<\mathbf{d}_{\mathbf{i}^{\prime} \text {. Se }}$ nenhum $\mathbf{n}$ existe, $\mathbf{n}$ fixa $\mathbf{n}=\mathbf{N}$. Então, foi necessário considerar CDs $1 ; 2 ;::: ; \mathbf{n}$ para esta ordem.

Assumindo que o custo de transporte do centro de distribuição é uma função da carga transportada daquele centro particular, o problema para minimizar o custo de transporte e o custo de falta para aquela ordem específica, o problema poderia ser representado pelo Programa Inteiro-Misto (MIP) seguinte: 


\section{Notação}

$\mathbf{a}_{\mathrm{i}} \quad$ volume de produto i por unidade;

$\mathbf{T}$ tempo restante para completar a ordem;

$\mathbf{L}_{\mathbf{j}} \quad$ carga mínima para garantir que o carregamento seja feito dentro de período de tempo $\mathbf{T}$ do $C D \mathbf{j}$, e $\mathbf{L}_{\mathbf{j}}>0$;

$\mathbf{c}_{\mathbf{j k}} \quad$ custo de transporte do CD j, quando a carga está no intervalo de $\left[l_{j ;} ;-1 ; l_{j k}\right)$;

$\mathbf{p}_{\mathbf{i}} \quad$ custo da penalidade por falta por unidade de produto;

M um número muito grande.

Variáveis de decisão

$\mathbf{x}_{\mathrm{ij}} \quad$ quantidade de unidade i exigida por CD $\mathbf{j}$;

$\mathbf{y}_{\mathbf{i}} \quad$ carga paga por CD j;

$\mathbf{u}_{\mathbf{j}} \quad 1$ se $\mathbf{y}_{\mathbf{j}}>0,0$ caso contrário;

$\mathbf{z}_{\mathbf{j k}} 1$ se $\mathbf{y}_{\mathbf{j}}$ estiver no intervalo $\left[\mathbf{l}_{\mathbf{j}, \mathbf{k}-1}, \mathbf{l}_{\mathbf{j k}}\right), 0$ caso contrário;

$\mathbf{f}_{\mathbf{i}} \quad$ unidades de escassez de produto $\mathbf{i}$.

Formulação

Minimizar $\sum_{j=1}^{n} \sum_{k} c_{j k} z_{j k}+\sum_{i=1}^{m} p_{i} f_{i}$

Sujeito às Restrições

$$
\begin{array}{ll}
\sum_{j=1}^{n} x_{i j}+f_{i}=d_{i}, & \forall i=1, \ldots, m \\
\sum_{i=1}^{m} a_{i} x_{i j} \leq y_{i}, & \forall j=1, \ldots, n \\
L_{i} u_{j} \leq y_{i} \leq M u_{j} & \forall j=1, \ldots, n \text { e } \forall i=1, \ldots, m \\
\sum_{k} l_{j k} z_{j k} \geq y_{j} & \forall j=1, \ldots, n \\
\sum_{i=1}^{m} z_{j k}=1, & \forall j=1, \ldots, n \\
0 \leq x_{i j} \leq s_{i j}, y_{i}, f_{i}, \geq 0, u_{j}, z_{j k} & \text { binário, } \forall i=1, \ldots, m, \forall j=1, \ldots, n \quad \forall k .
\end{array}
$$

A função-objetivo (0) busca minimizar o custo total que inclui o custo de transporte e o de falta.

A restrição 1 obriga que a falta de produto i seja a diferença entre a demanda e o ressuprimento. 
A restrição 2 garante que a carga paga seja maior ou igual à carga atual utilizada.

A restrição 3 garante que, uma vez os produtos transportados de CD j, a carga mínima de CD j a ser paga seja, pelo menos, Lj para garantir que a remessa alcance o cliente, antes da devida data (Vamanan et al. (2002) assumem que uma carga maior leva menos tempo que uma menor).

A restrição 4 é escrita para determinar o intervalo no qual a carga é aceita e a restrição 5 assegura que a carga entre em um e só um intervalo.

Isso é aparente em tal caso, pois, para estudar a ordem de exigência em detalhes e, possivelmente, comparar os custos de operação desta política, é necessário simular os eventos que acontecem no segmento da cadeia de suprimentos, incluindo a resolução pelo MIP, toda vez que uma ordem de um dos clientes entrar.

Fazendo isso, é indispensável chamar um "solver" matemático, como o CPLEX, para resolver esse MIP, de forma que a estação central de gerenciamento de ordem possa dividir os pedidos do cliente no centro de distribuição apropriado para minimizar custos de transporte e de estoque. Assim, é necessário chamar o CPLEX de dentro do ARENA para resolver o MIP, toda vez que uma ordem chegar à estação de gerenciamento.

A partir de então, a sucessão de eventos que acontece na simulação é como segue:

> As demandas de clientes chegam de acordo com uma distribuição de probabilidade, baseada em dados históricos.

$>$ A demanda para cada grupo de produto é a entrada do sistema na estação de gerenciamento de ordem.

> O CPLEX é chamado para resolver o MIP.

$>$ A tarefa de atribuição acontece. O colapso atual da ordem em várias partes é obtido pela solução do CPLEX no MIP.

> Os níveis de estoque são atualizados; os custos de transporte e estoque são calculados, baseados na solução dos vários centros de distribuição.

$>$ Os custos de estoque parado nos centros de distribuição são calculados para o período anterior.

$>$ Os níveis de estoque são conferidos, de forma que o reabastecimento das instalações industriais possa acontecer, quando o estoque específico baixar 
ao nível mínimo. O reabastecimento acontece com certo "lead-time" fixo e pára quando o estoque atinge o máximo. Vamanan et al. (2002) afirmam que o reabastecimento acontece a uma taxa constante, ao invés de a uma única entrega com quantia igual a $\mathbf{S}$ - nível de estoque atual.

Vamanan et al. (2002) concluem que a integração COTS é eficiente em certos casos. Nesse caso, o desempenho da aproximação da integração é melhor que a tradicional heurística baseada na aproximação ("greedy order fulfillment policy") de ordem de exigência.

Porém, os autores alertam que há limitações ao uso dessa integração COTS. O tempo de resolução para um MIP que usa o esquema "branch-and-bound" (como o CPLEX) aumenta exponencialmente com o tamanho do problema. Quando as ordens do cliente são nomeadas de forma sequencial e o CPLEX é chamado separadamente a cada tempo e uma demanda entra no sistema, o número de clientes não aumenta o tamanho do problema.

Um aumento de centros de distribuição faz, porém, com que, gradativamente, aumente o número de elementos na função-objetivo. Aumento dos grupos de produto não tem o mesmo efeito drástico no tempo de resolução, porque há um maior número de variáveis somado para cada centro de distribuição. Neste caso, Vamanan et al. (2002) concluem que o CPLEX leva um tempo muito longo para resolver o MIP, no que tange ao problema realista relacionado.

Alternativas para integração de COTS incluem algoritmos matemáticos especializados para resolver o MIP. O CPLEX usa uma programação linear, baseada no algoritmo "branch-and-bound", para chegar a uma solução depois de uma série de relaxamentos de programações lineares. Esse pode não ser o modo mais eficiente para resolver o MIP. De acordo com Vamanan et al. (2002), solução de MIP que usa relaxamento Lagrangeano e princípios de dualidade é freqüentemente mais eficiente.

Também podem ser usados algoritmos "cutting-plane" para resolver o MIP. Incorporar tais características pode ser um código de aplicação em uma linguagem de programação de alto-nível como $\mathrm{C}$ e chamar o ARENA direto do $\mathrm{C}$.

É provável que essa aproximação, porém, tenha muito mais tempo de execução. Também, é menos versátil que a integração COTS, desde mudanças na formulação do MIP. Para responder a outras restrições, por exemplo, poderia ser muito mais fácil, se construída usando a aproximação de integração COTS. 
É muito interessante a análise final de Vamanan et al. (2002), que menciona uma alternativa efetiva em lidar com tempos de soluções inaceitáveis para CPLEX, a fim de resolver grandes MIPs. Pode-se terminar CPLEX com uma solução que esteja dentro de certo nível aceitável de otimalidade: fala-se em $95 \%$ ou $98 \%$ da solução ótima, de acordo com Vamanan et al.

Embora o tempo para encontrar a solução ótima aumente exponencialmente com o tamanho do problema, o tempo para achar a solução próxima do ótimo é razoável, na maioria dos casos. Também é notável que o CPLEX ofereça, em seu próprio conjunto de características, oportunidades para seu algoritmo. Isso pode reduzir o tempo necessário para alcançar uma solução aceitável. Uma implementação de produtos COTS com terminação prematura do chamado CPLEX pode ser uma alternativa viável.

\subsubsection{Método de Morito ${ }^{14}$}

De acordo com Morito et al. (1999), se as alternativas estão limitadas em número, cada uma delas pode ser avaliada por simulação. Com o aumento do número de alternativas, porém, a repetição de muitas corridas de simulação pode ser demorada e cara.

Neste sentido, para Morito et al. (1999), a programação matemática é a melhor opção para tal situação.

Além disso, modelar todos os detalhes do sistema projetado por um programa matemático pode ser computacionalmente impróprio ou impossível. Uma escolha natural seria combinar otimização, através de programação matemática, com avaliação por simulação.

Morito et al. (1999) apresentam um "framework" genérico de combinação simulação-otimização no qual são usados resultados de simulação para identificar restrições, que são acrescentadas ao modelo de otimização para "re-otimização".

O procedimento é iterativo e pode ser considerado como uma classe de aproximações de "cutting-plane" que terminam quando uma solução "ótima" do

\footnotetext{
${ }^{14}$ Método de Morito - nome simplificado dado ao método criado por Morito et al., 1999.
} 
programa matemático é obtida, passando por todo critério de desempenho estabelecido para a avaliação da simulação.

Morito et al. (1999) aplicam seu método em um caso logístico real cuja interface proposta trabalha eficazmente para o caso em que a otimização por MIP é combinada com uma avaliação por simulação de eventos discretos.

O "framework" básico de Morito et al. (1999), como ilustrado na Figura 4.9, segue os seguinte passos:

- Passo 1 (construção básica do modelo): Constrói-se um modelo básico de otimização que leve em consideração fatores essenciais do problema e também um modelo de simulação que possa incluir detalhes do sistema.

- Passo 2 (otimização): Resolve-se o modelo de otimização resultante e obtémse uma solução "ótima".

- Passo 3 (simulação): Simula-se a solução "ótima" obtida no Passo 2, e avaliase seu desempenho para ver se a solução é aceitável ou não.

- Passo 4 (geração das restrições): Se a solução é aceitável, a solução ótima encontrada é "verdadeira", então se pára. Caso contrário, identificam-se as restrições necessárias para fazer uma solução aceitável. Acrescentam-se as restrições ao programa matemático atual, e retorna-se ao Passo 2 para otimizar novamente.

Alguns comentários de Morito et al. (1999), relativos ao "framework" básico, devem ser lembrados:

i. O caminho normal dos Passos 1 até o 3 é natural e comumente usado, mas freqüentemente se usa uma aproximação heurística, para criar uma solução possível, quando a solução encontrada como resultado da simulação não foi desejável.

ii. O modelo de otimização inclui considerações econômicas na forma de minimização de custo ou maximização de lucro.

iii. Depois que uma candidata de solução for avaliada pela simulação, no Passo 3, é conferida sua viabilidade. A viabilidade ou não será determinada, se as condições específicas foram satisfeitas ou não. Essa avaliação pode ser feita por uma conferência no modelo de programação matemática.

iv. Restrições identificadas no Passo 4, apenas "cortes" de programação matemática, que eliminam "a solução atual" encontrada para ser não-aceitável no Passo 3. A adição dos cortes faz a solução atual inviável somente como 
algoritmo de plano de corte de programação inteira que elimina uma parte da região viável, como mostra a Figura 4.10(a).

v. No "framework" de Morito et al. (1999), o modelo é, geralmente, um relaxamento do "verdadeiro" modelo, no sentido de que o "verdadeiro" é bemdefinido, mas não é definido completamente pelo modelo de programação matemático. Uma solução "ótima" aceitável é a que está ótima, de acordo com a função-objetivo definida no programa matemático e satisfaz todas as condições especificadas no "verdadeiro" modelo. Remetendo-se à Figura 4.10(b), soluções aceitáveis são os "pontos" na região amoldada, que é incluída na programação matemática de relaxamento do "verdadeiro" modelo. A combinação de simulação com otimização, de acordo com Morito et al. (1999), foi explorada no passado em muitas pesquisas de vários modos diferentes. Em particular, quando a medida de desempenho que aparece na função-objetivo é avaliada por simulação, várias aproximações têm sido desenvolvidas e são chamadas, freqüentemente, de simulação-otimização.

A aplicação do "framework" básico de Morito et al., nos correios japoneses, deu-se da seguinte forma.

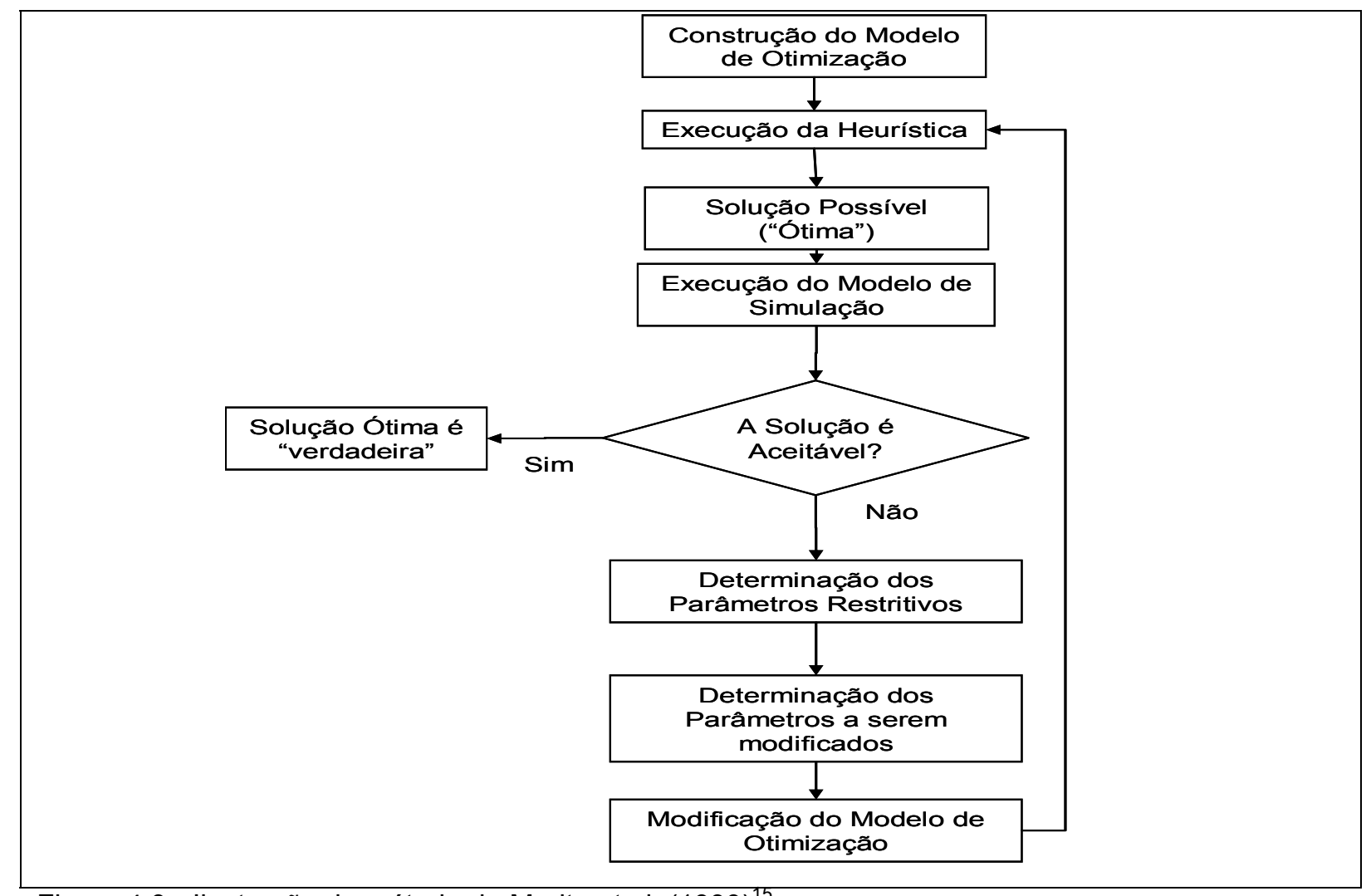

Figura 4.9 - Ilustração do método de Morito et al. (1999) ${ }^{15}$

\footnotetext{
${ }^{15}$ Figura criada a partir da descrição apresentada por Morito et al. (1999).
} 
O serviço postal pode ser considerado como um sistema logístico gigantesco. Nesta economia mais apertada de hoje e num ambiente mais competitivo, a melhoria de eficiência foi considerada por Morito et al. (1999) como uma das missões mais importantes do Serviço Postal Japonês.

O caso descrito por esses autores reflete um estudo quantitativo para analisar planos alternativos de distribuição de equipamentos para as agências postais e a busca de um plano "ótimo" de distribuição.

A análise é executada tomando-se como base a otimização da alocação de equipamentos, via um problema de MIP, e, também, a simulação para analisar a viabilidade da otimização gerada do plano de alocação de equipamentos por meio de um ambiente mais realista e dinâmico.

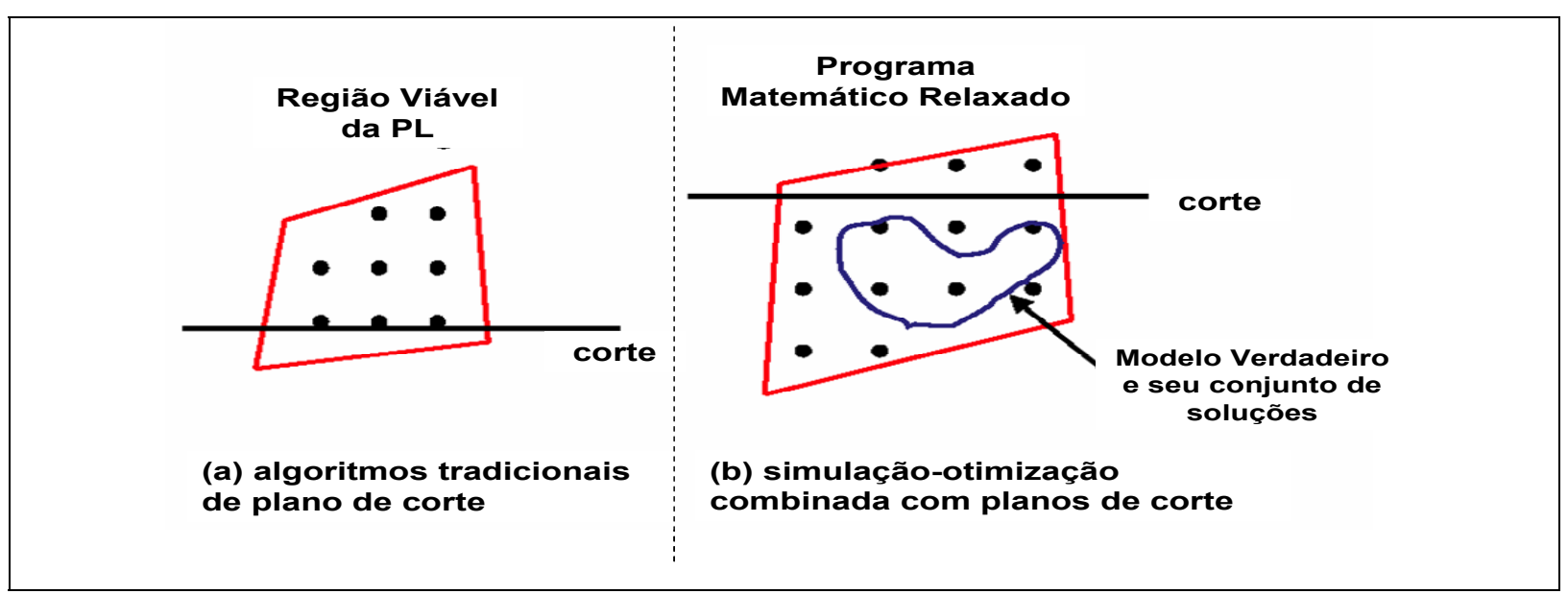

Figura 4.10 - Plano de corte

Fonte: Adaptado de MORITO et al., 1999.

De acordo com Morito et al. (1999), um código postal de 7 dígitos, junto com um código de barras, foi introduzido no Serviço Postal Japonês (SPJ) em 1998. Eficientes, mas de custo elevado, máquinas de sorteio automáticas foram utilizadas para a regional principal, como também para as grandes agências postais das cidades.

Com a introdução de máquinas com leitura de códigos postais numéricos e/ou código de barras para ordenar, afirmam Morito et al. (1999) que o SPJ, naturalmente, quer processar mais correspondências em um menor número de máquinas. Uma possível alternativa para aumentar a utilização da máquina é centralizar o processamento das agências postais equipadas com máquinas de ordenamento. 
Essas agências postais equipadas com máquinas de ordenamento são só uma pequena porção das agências postais que executam essas operações. Em alguns escritórios, são executadas operações de ordenamento ainda manualmente.

Com a introdução de máquinas de ordenamento mais poderosas, uma possibilidade é centralizar algumas dessas operações em escritórios equipados com tais máquinas.

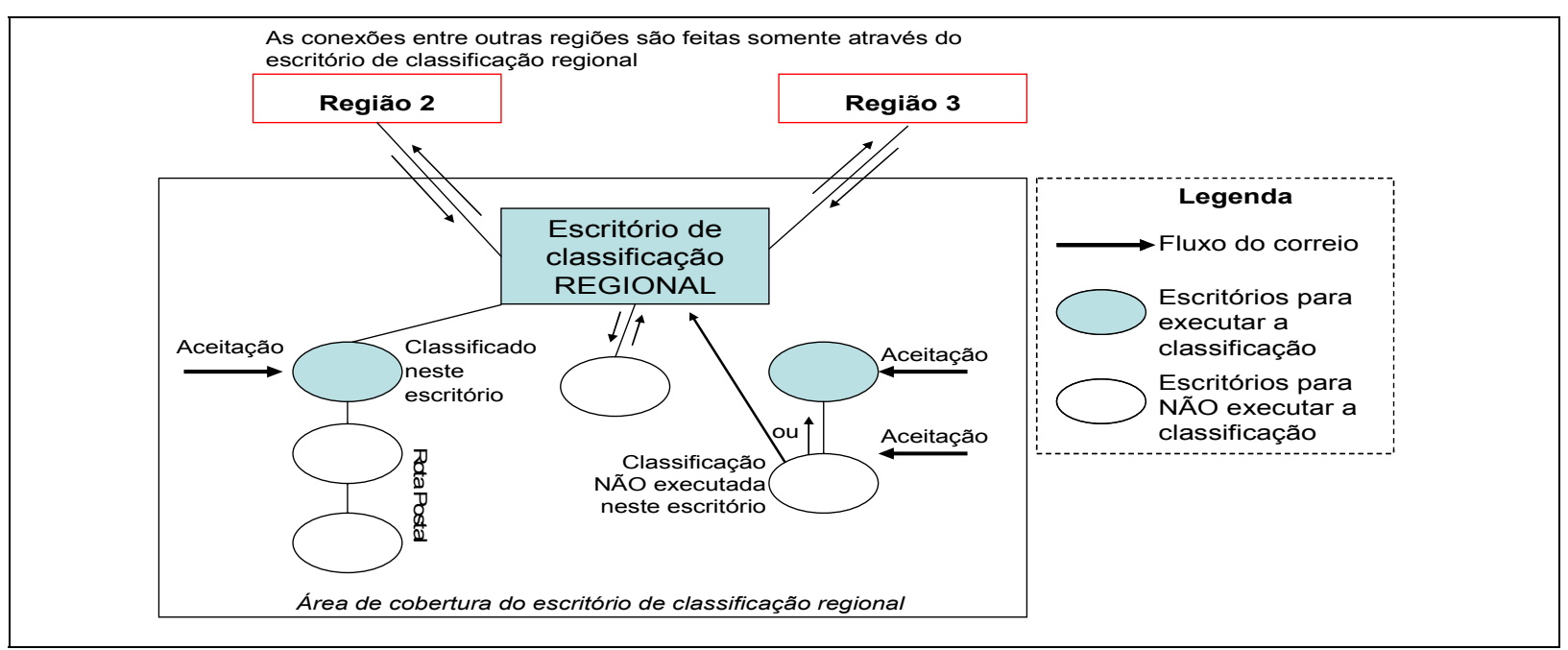

Figura 4.11 - Sistema logístico do SPJ

Fonte: Adaptado de MORITO et al., 1999.

A troca do dispendioso trabalho manual pela máquina de ordenamento, junto com espaço muito escasso em agências postais das principais cidades japonesas, torna a centralização atraente.

A centralização tende a aumentar a utilização das máquinas em geral, e também o transporte e o manuseio extra para mover as correspondências de um escritório de aceitação para um escritório de operações de ordenamento.

Segundo Morito et al. (1999), o MIP formulado pode ser resolvido por um software de otimização padrão. Os resultados, para o caso de uma agência postal regional em Tóquio, com 14 rotas para caminhão e 30 agências postais, mostram que as agências para ordenamento de correspondências assumem 3 valores diferentes de custo de transporte por unidade.

Uma solução "ótima" obtida pela otimização é avaliada por meio de simulação em um ambiente mais realista e dinâmico. Especificamente, são incluídos padrões de chegada de correspondências, de hora em hora e seqüenciamentos, por 
caminhões detalhados na análise da simulação, para conferir se o ordenamento termina no prazo final.

A simulação, de acordo com Morito et al. (1999), localiza, dinamicamente, o progresso do processamento das correspondências e permite julgar se o ordenamento termina antes do prazo final ou não.

Os autores (1999) consideram necessário, um método de geração de restrição quando resultados de simulação não são aceitáveis. Neste caso, a inviabilidade acontece em algumas agências onde $\mathrm{O}$ processamento de correspondências não é completado no tempo predeterminado. Isso pode acontecer, quando as correspondências recebidas nas agências $\mathbf{i}$, que são ordenadas em outra agência j, e a capacidade de processamento na agência j não são suficientes.

É, então, possível calcular a capacidade de processamento necessária, digase c, nas agências j para conhecer o prazo final, e a restrição, que diz "a capacidade de processamento na agência j deveria ser pelo menos $\mathbf{c}$, se as correspondências recebidas na agência i são para ser ordenadas na agência j", é acrescentada.

Obviamente, existem muito mais padrões de processamento que o daquelas correspondências recebidas de certa agência em outra agência. Se um padrão específico de processamento é determinado, a capacidade de cada agência que executa o ordenamento pode ser calculada e, assim, o parâmetro c pode ser determinado.

Então, existem muitas restrições possíveis, embora o valor do parâmetro c dependa de uma combinação particular e deva ser avaliado através do resultado da simulação. No entanto, o processo de sempre acrescentar restrições não pode continuar e a aproximação termina depois de um número finito de adições.

\subsubsection{Método iterativo de Bush ${ }^{16}$}

O método iterativo de Bush, Biles e DePuy sugere o desenvolvimento do modelo de otimização, separado do modelo de simulação, para permitir que níveis diferentes de detalhamento sejam incluídos em cada um desses modelos,

\footnotetext{
${ }^{16}$ Método de Bush - nome simplificado dado ao método proposto por Bush, Biles e DePuy (2003)
} 
respeitando suas potencialidades. O procedimento iterativo busca a solução ótima mais próxima.

Esse método aplica um modelo iterativo de simulação e otimização em um problema específico do mundo real. A aplicação dá-se no tráfego de barcaças na região mais baixa do Rio Mississipi.

Barcaças entram nessa área do rio pelo Golfo do México e, também, por vários afluentes. A Figura 4.12 mostra um exemplo simplificado do sistema de um rio.

O fluxo básico de tráfego começa com barcaças, que são trazidas por reboques no sistema. As entradas e saídas para o sistema são ilustradas pelas setas (Figura 4.12). O reboque consiste em um grupo de barcaças que são movidas por um rebocador. As barcaças são descarregadas em locais específicos. São carregados, inicialmente, reboques que estão em certa posição (locais organizados para movimentação de reboques) onde é possível reagrupá-los e enviá-los para seu destino de descarregamento. Os reboques podem ser de tamanho, capacidade e custos operacionais distintos.

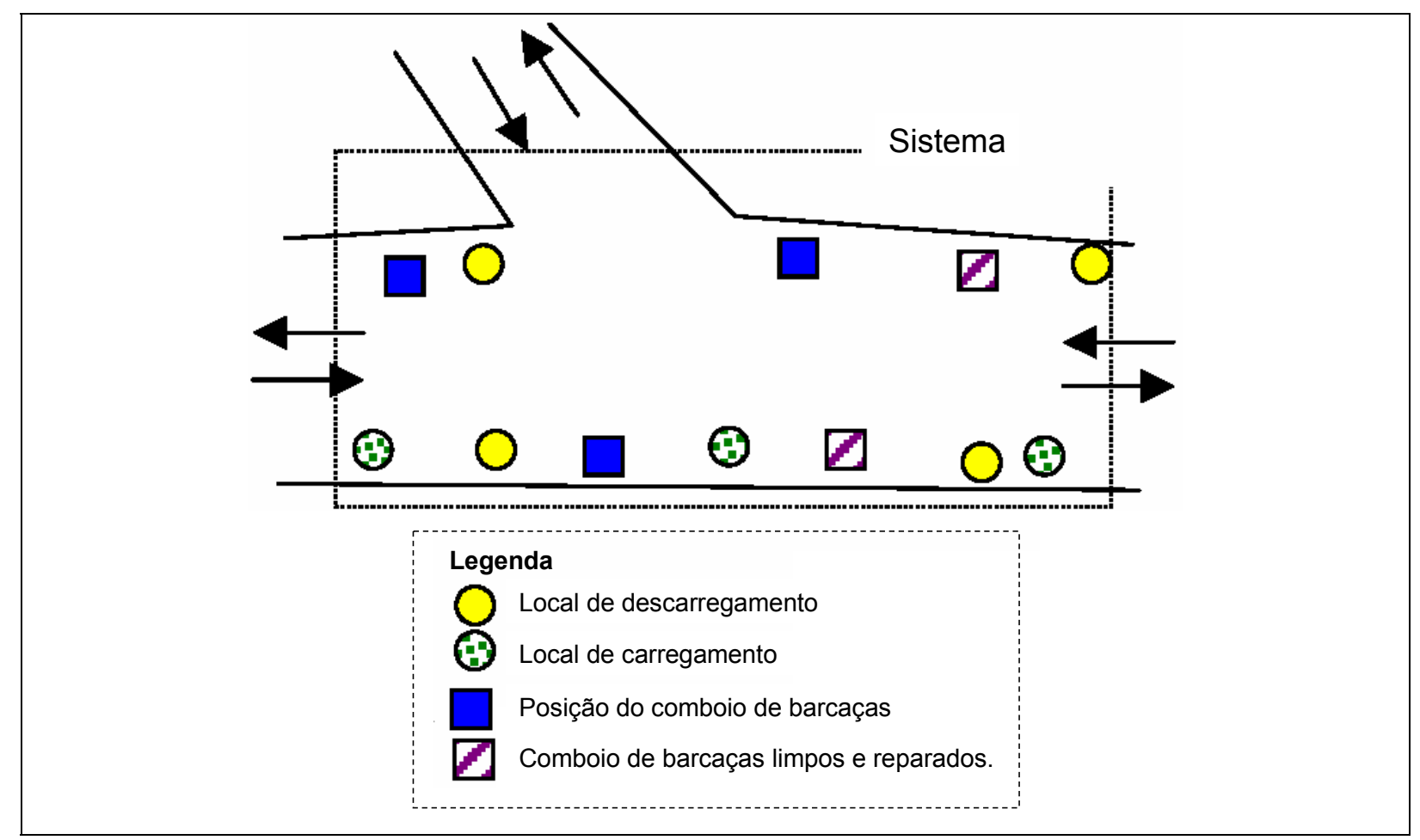

Figura 4.12 - Exemplo simplificado de um sistema fluvial

Fonte: Adaptado de BUSH; BILES; DePUY, 2003. 
As barcaças são entregues em seu local de descarregamento e enviadas a várias posições para limpeza e atividades de manutenção, quando requerido. Depois do reparo e da limpeza, são redistribuídas para carregar. As barcaças carregadas são enviadas a locais onde são reorganizadas em reboques e retiradas do sistema na direção apropriada.

O sistema de transporte de barcaças é estudado para determinar rotas de forma a minimizar o custo de movimentação. As rotas são baseadas em locais de descarregamento e direção de saída.

Essas rotas são críticas, pois as barcaças podem ter vários caminhos a percorrer até encontrar o seu destino. Isso significa determinar os locais onde elas devem ser redistribuídas e organizadas nos reboques, como também os locais de limpeza e manutenção. Esse tipo de análise pode ser benéfico, se a capacidade do barco for adequada ou se a adição de espaço for justificada.

a) Fluxo de processo iterativo

O objetivo desta técnica é determinar uma solução ótima realista para um problema de otimização, um programa linear, neste caso.

Uma solução realista refere-se a uma possível solução gerada pelo modelo de otimização, que também é viável no modelo de simulação. Isso permite resultados viáveis baseados nos dois modelos, garantindo as diferenças de construção e de regras.

A base para o método iterativo proposto é mostrada na Figura 4.13. Caixas com uma linha pontilhada representam passos que são executados por um computador, enquanto um analista qualificado realiza os outros passos. As explicações seguintes correspondem aos elementos numerados na Figura 4.13.

b) Execução do modelo de otimização

O primeiro passo no processo iterativo envolve a solução do modelo de otimização e a determinação de uma solução. O modelo de otimização pode ser resolvido, utilizando-se qualquer "solver" disponível, dependendo da técnica de otimização aplicada. Essa é uma tarefa para um computador executar.

Os resultados dessa corrida podem ou não encontrar uma possível solução para o modelo de otimização. Esse passo pode envolver qualquer solução inicial do 
modelo de otimização desenvolvido, ou resolver um problema de otimização com parâmetros iniciais modificados pelo processo iterativo

c) Envio dos parâmetros da otimização para a simulação

O próximo passo consiste em enviar os resultados e parâmetros do modelo de otimização para o de simulação. O modelo de simulação inicial é baseado nos mesmos parâmetros do modelo de otimização inicial.

Esse passo é executado manualmente. $O$ analista determina quais parâmetros enviar ao programa de otimização e, manualmente, inclui esses parâmetros no modelo de simulação.

d) Execução do modelo de simulação

O modelo de simulação é executado. Este é o outro único passo executado por computador nesse processo iterativo. Qualquer software de simulação pode ser aplicado. O modelo de simulação gera os parâmetros de desempenho predeterminados, que são usados para definir se os resultados do modelo de simulação são aceitáveis.

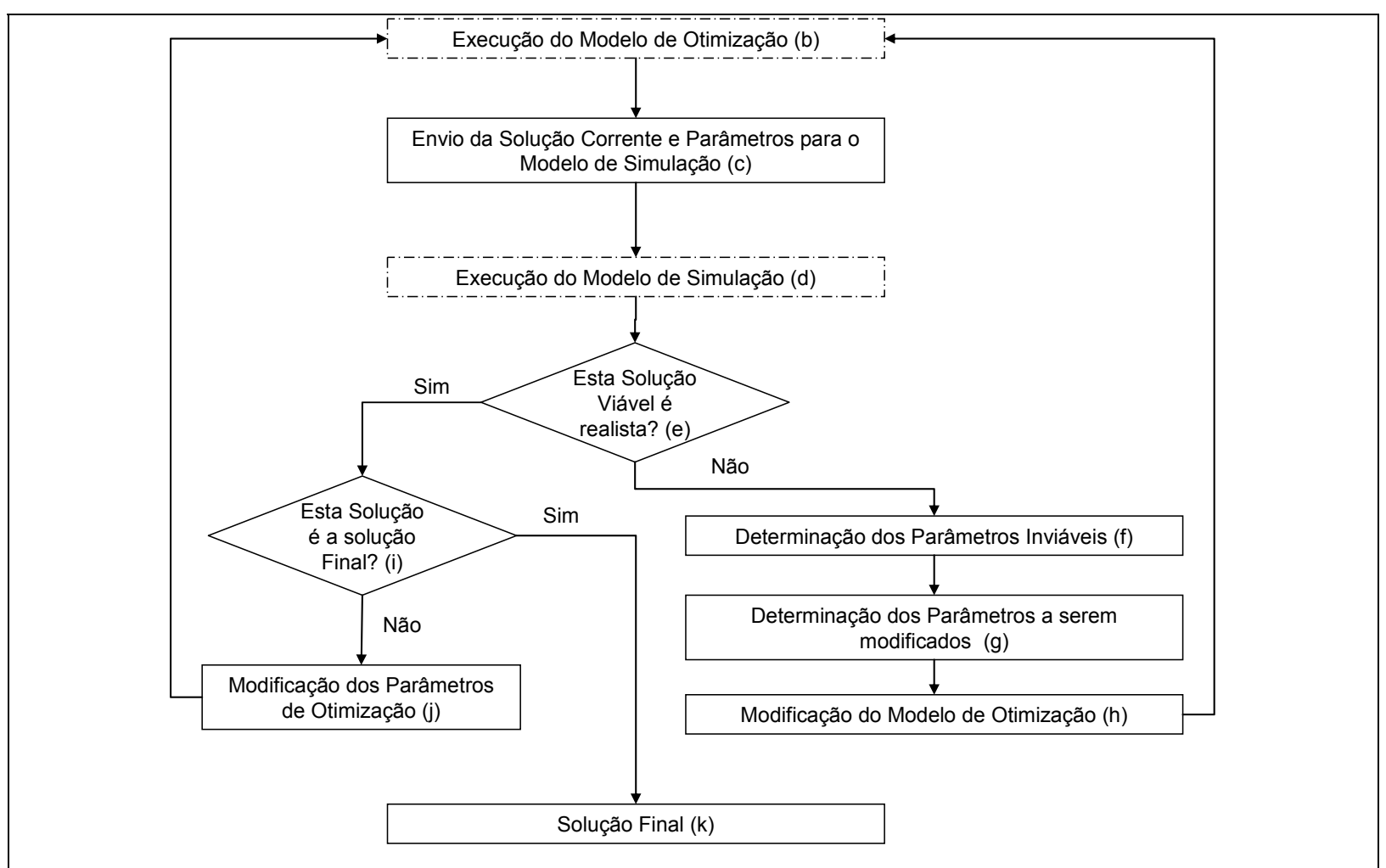

Figura 4.13 - Fluxo do processo iterativo entre os modelos de simulação e otimização Fonte: BUSH; BILES; DePUY, 2003. 
e) A solução encontrada é viável e realista?

Esta decisão é executada manualmente pelo analista. Nesse passo, os resultados são analisados para verificar se os parâmetros do modelo de otimização conduziram a uma solução viável e realista do modelo de simulação.

Uma solução é julgada viável se diversas medidas de desempenho geradas pela simulação estiverem dentro de níveis aceitáveis predeterminados de decisão.

O conjunto de estatísticas e seus valores aceitáveis serão determinados antes da execução do modelo de simulação. As medidas de desempenho são específicas do sistema estudado.

f) Determinação dos parâmetros inviáveis

Caso a solução encontrada pela simulação for considerada viável, mas não realista, o analista determinará, manualmente, os parâmetros do modelo de otimização responsáveis por esse resultado, baseado na lista de medidas de desempenho, discutida no passo anterior. Cada medida de desempenho está associada a parâmetros de otimização específicos.

Esses parâmetros são os do modelo de otimização que afetam a medida de desempenho no modelo de simulação. As medidas de desempenho que não estão em níveis aceitáveis, são usadas para determinar quais parâmetros serão modificados no modelo de otimização.

g) Determinação dos parâmetros a serem modificados

Baseado na resposta obtida no passo "e", o analista determinará os parâmetros inviáveis a serem modificados no modelo de otimização.

A determinação dos parâmetros a serem modificados, quando mais de um é identificado, é baseado em um sistema de ranqueamento, fundamentado em uma análise de sensibilidade dos parâmetros, na variação percentual de valores de medidas aceitáveis de desempenho ou em outros fatores de custo.

Um parâmetro é mudado por iteração se, de alguma forma, os efeitos da mudança estiverem claros. Isso ajudará na determinação do motivo pelo qual o procedimento iterativo parou, isto é, na determinação de que uma solução viável realista foi alcançada. 
h) Modificação no modelo de otimização

Este passo envolve a mudança de parâmetros inviáveis no modelo de otimização e é realizada manualmente pelo analista. A otimização é executada novamente para determinar uma nova solução e o processo iterativo retorna ao começo.

i) Esta é a solução final?

A determinação de parada, caso um critério seja encontrado, é igualmente um passo de decisão manual executado pelo analista. Envolve uma análise cuja finalidade é saber se as medidas de desempenho para uma solução viável realista são suficientes como solução final para a resposta do processo iterativo.

j) Modificando os parâmetros da otimização

Este passo envolve a modificação de parâmetros, quando uma solução viável e realista é julgada inaceitável. Isso também pode acontecer se o analista quiser melhorar a medida de desempenho específica.

k) Solução final

A solução final é uma solução considerada realista e viável para as operações atuais. Quando ela for encontrada, o processo iterativo pode ser terminado.

I) Fluxo de informação

A Figura 4.14 mostra o fluxo de informação ao longo do processo iterativo. A informação flui entre os modelos de otimização e simulação e o tomador de decisão.

Como ilustrado na Figura 4.14, o modelo de otimização é executado com os parâmetros originalmente estabelecidos. Esses parâmetros e as soluções do modelo de otimização são usados como "input” no modelo de simulação.

A resposta do modelo de simulação é a medida de desempenho, que é usada pelo analista, para modificar os parâmetros da otimização e executar novamente o modelo.

O tomador de decisão é a chave do processo. Esse passo envolve a união das medidas de desempenho para parâmetros do modelo de otimização. Assim, 
quando uma medida de desempenho está fora de alcance, os parâmetros podem ser modificados em relação àquela medida de desempenho específica.

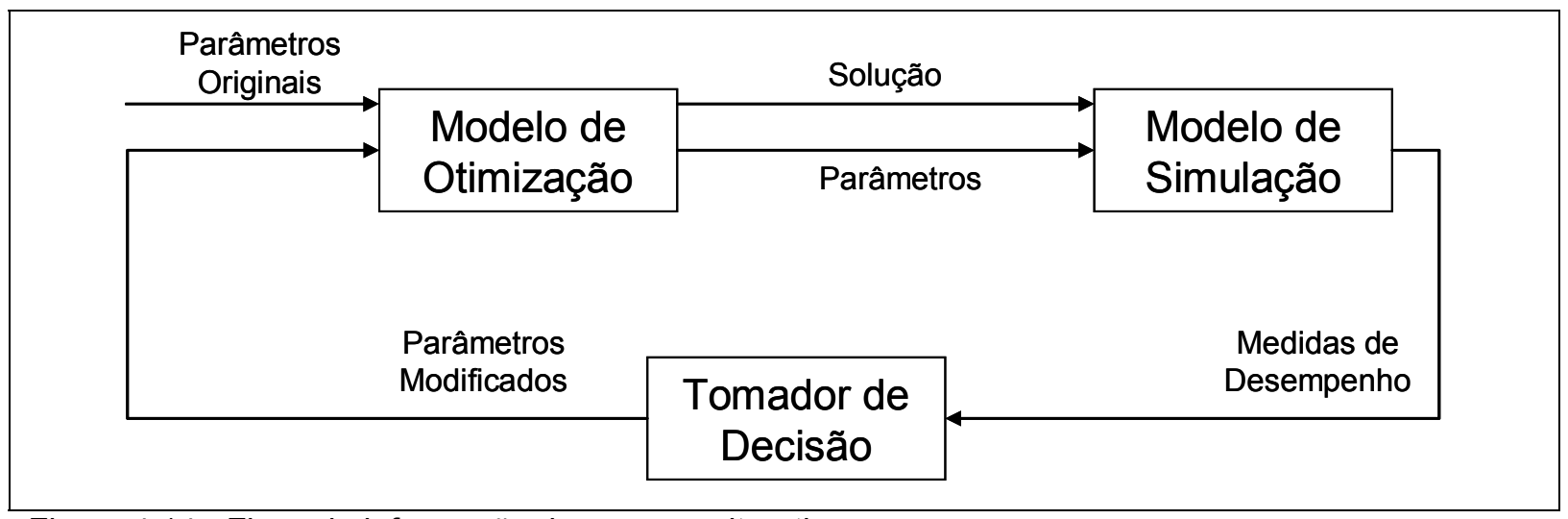

Figura 4.14 - Fluxo de informação do processo iterativo

Fonte: BUSH; BILES; DePUY, 2003.

Bush, Biles e DePuy (2003) afirmam que um analista qualificado é requerido para tomar decisão no procedimento proposto. Pode ser possível, em pesquisa futura, automatizar este passo do processo, mas o estado atual de desenvolvimento precisa de alguém que dê início à avaliação da resposta do programa linear "a priori”, a fim de estabelecer o "input” para o modelo de simulação e vice-versa.

\subsection{CONCLUSÃO DO CAPÍTULO}

Dos cinco métodos analisados, pode-se afirmar que, quanto à definição de simulação, todos estão alinhados ao tradicional conceito de simulação computacional e, ainda, utilizam simulação discreta por eventos.

Mesmo que Bush, Biles DePuy (2003) e Morito et al. (1999) não tenham mencionado, pode-se concluir, de acordo com as áreas de aplicação e seus métodos, que eles também usaram simulação discreta por eventos.

Quanto à otimização propriamente dita, esses autores divergem um pouco e utilizam heurísticas e/ou meta-heurísticas na busca da melhor aproximação do ótimo. Nesse sentido, eles até tendem a um mesmo entendimento.

Granger, Krishnamurthy e Robinson (2002) aplicam, no transporte aéreo, como ferramenta de simulação, o software ProModel R_Versão 4.2 e, como 
"otimizador", o MPX Versão 3.3, que eles próprios o caracterizam como uma aproximação e não como uma otimização.

Díaz e Pérez (2000) aplicam o método de Vashi e Bienstock (1995), na cadeia produtiva de cana-de-açúcar, e Vamanan et al. (2002) aplicam, na cadeia de suprimentos fabril, o software Arena, da Rockwell Software, como ferramenta de simulação. Mas os primeiros utilizam, como "otimizador", a heurística de superfície de resposta, enquanto os segundos o "branch-and-bound".

Morito et al. (1999) aplicam nos correios japoneses uma "otimização" de planos de corte, juntamente com um modelo de simulação de eventos discretos que já era utilizado anteriormente.

Bush, Bile e DePuy (2003) não citam quais ferramentas utilizaram em seu método, mas, pelos seus comentários, dão a entender que fizeram uso da programação linear, para encontrar, quando necessário, a solução ótima em seu método iterativo.

Não é objetivo desta pesquisa analisar qual é a melhor técnica a ser empregada em cada problema que afeta os sistemas logísticos em geral, mesmo que, em alguns dos casos analisados, os autores tendem a evidenciar.

O que se pode verificar é que todos estes autores, de uma forma ou de outra, comentam que estas técnicas são complementares e que o sucesso da solução do problema ou da oportunidade é proporcional à correta aplicação destas técnicas em seus pontos fortes de resolução de problema. E estes casos mostram que a aplicação destas técnicas, em conjunto, garantem um melhor resultado do que analisadas separadamente.

Além disso, na maioria das vezes, qualquer uma destas técnicas, seja de simulação, otimização e suas derivadas, para ser aplicada, em quaisquer problemas, depende exclusivamente do conhecimento do analista do problema real e do conhecimento da técnica de PO a ser utilizada.

O que ainda é evidenciado é que a união das duas técnicas pode facilitar a decisão e até mesmo tornar o sistema modelado mais próximo do sistema real com menos exigência computacional; ou mesmo, torná-lo mais fácil para a tomada de decisão gerencial.

O que a Figura 4.15 ilustra é que independente de se iniciar por simulação ou por otimização, todos os métodos buscam melhorar a tomada de decisão gerencial através da sinergia, ou complementariedade, destas técnicas. 
Observa-se, no entanto, que através da análise dos métodos, verifica-se que um modelo de tomada de decisão já existia inicialmente, e que os pesquisadores quando propuseram seu método, buscavam sempre a melhoria da qualidade das respostas ao problema.

No entanto, o esforço computacional necessário para se alterar o modelo existente era muito grande e dispendioso. Desta forma, optaram por criar outro modelo e integrá-lo ao existente, almejando responder algumas perguntas que até então não estavam sendo respondidas a contento.

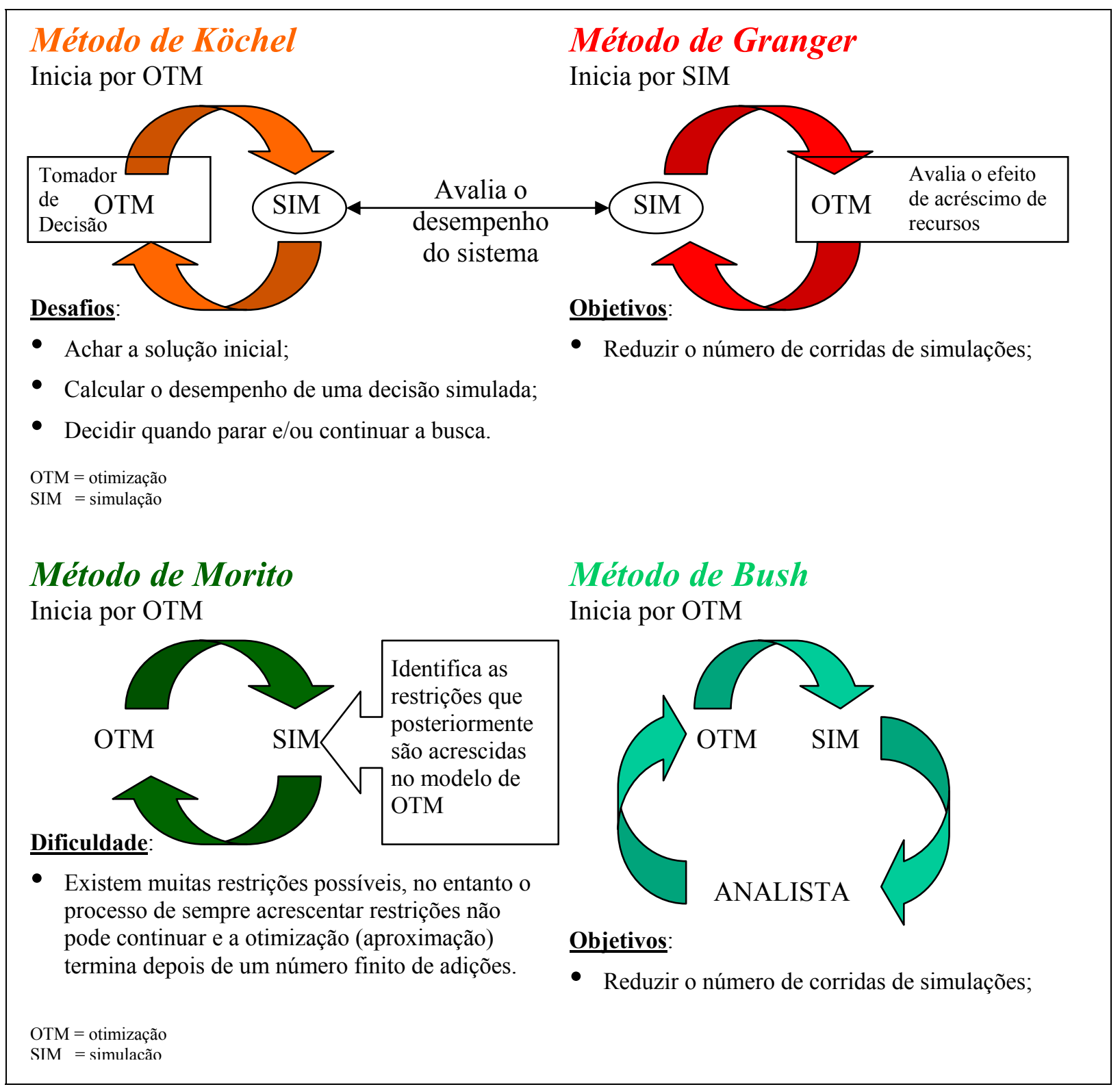

Figura 4.15 - Resumo dos métodos de simulação-otimização 
Bush, Niles e DePuy (2003) afirmam que a otimização é útil para planejamento estratégico de longo prazo e que a PL não é útil no dia-a-dia para planejamento operacional. Mas, dependendo do tipo de problema que está sendo analisado, é muito difícil concluir que uma ou outra técnica é melhor empregada, analisando-se somente o horizonte de planejamento. Mas também não se pode negligenciar nos métodos de planejamento a serem utilizados o seu horizonte de tempo a ser estudado, assim como Granger, Krishnamuthry e Robinson (2002) em que pressupõem que a questão da diferença da utilização de um sistema determinístico e estocástico é o mesmo para qualquer horizonte de tempo.

Avaliando os pontos abordados por Rodrigues (1994) e apresentados no Capítulo 03, vale relembrar que "a questão de quando se deve utilizar uma das técnicas de PO não possui uma resposta única, mas depende das restrições ambientais e dos objetivos do estudo que se está realizando. A determinação de quais questões devem ser respondidas pelo estudo em questão é, possivelmente, o ponto de partida para a determinação de qual tipo de modelagem e análise se deverá adotar".

O entendimento do problema, através da modelagem das suas premissas e simplificações da realidade, de acordo com a correta aplicação das ferramentas nos locais onde se pode potencializar as vantagens de cada uma, ditará o sucesso dos planos gerados pelo método ou ferramenta. É interessante notar que alguns autores, como Morito et al (1999) e Granger, Krishnamuthry e Robinson (2002), utilizam, no método proposto, a simulação como avaliadora do desempenho do sistema, tanto para estudo e reconhecimento do gargalo, como "teste de capabilidade", isto é, se o sistema é capaz de realizar tal decisão tomada.

Argumentam que, devido à dificuldade de se conhecer todas as interrelações, a complexidade, e a variabilidade dos processos em análise, é melhor se aplicar a simulação. Além disso, frequentemente, o objetivo não é só encontrar a solução ótima, mas também achar como mudar o sistema em estudo, para trazer o desempenho mais próximo do ótimo e, neste caso, caracteriza-se uma aplicação de simulação.

Enquanto que, para decidir a melhor opção, seja de distribuição de recursos ou melhor opção de investimento, utilizam a otimização, pois, neste caso, as relações conhecidas e as variáveis de decisão normalmente são determinísticas e não tão complexas. 


\section{MODELAGEM CONCEITUAL DO PROBLEMA E APRESENTAÇÃo DO MÉTODO PROPOSTO}

A situação atual da Cadeia Produtiva de Minérios de Ferro, aplicada na Samarco Mineração S/A, é representada por uma carteira de 25 clientes e capacidade produtiva de 14 milhões de toneladas de pelotas de minérios de ferro.

Conforme todas as características atuais deste mercado, apresentadas anteriormente, e de acordo com as informações de projeções de oferta e demanda, a única opção para este tipo de negócio é crescer.

Desta maneira, é essencial, no entanto, para qualquer empresa, manter sua posição de liderança, de modo a poder competir nesta nova configuração de mercado.

Sendo assim, o objetivo da empresa em estudo é se antecipar aos acréscimos de produção, por hora apenas planejados por parte de novos entrantes, de forma a reforçar seu poder agressivo neste mercado e poder desestimular a real concretização destes novos projetos.

As opções para realizar este crescimento (aumento da produção de pelotas) podem ser feitas através de três formas: aquisições, expansões de capacidade produtiva (aumentos de patamares de produção) ou de melhorias operacionais (aumentos incrementais de produção ao longo do período). Este trabalho contempla apenas as duas últimas opções.

Cada uma destas alternativas podem ser realizadas por meio de projetos ou portfólio de projetos, e, devem, necessariamente, ter suas características de tempo, custo e seu efeito (isto é, aumento de produção esperado no término do projeto) na capacidade produtiva bem definidos, através de aumentos de produtividade, disponibilidade ou mesmo de aumento de utilização de capacidade.

Primeiramente, antes da discussão sobre gerenciamento de projetos, faz-se necessário uma conceituação de projeto, e de acordo com o PMI - "Project Management Institute", projeto é um empreendimento temporário com o intuito de criar um produto ou serviço único (PMBoK, 2006).

Um projeto é único porque é finito, isto é, tem um início e término bem definidos. O fim de um projeto é definido pela realização dos objetivos estabelecidos, ou pela conclusão de que os mesmo são inviáveis. 
O fato do projeto ser temporário não significa que o produto ou serviço dele resultante também o seja, pelo contrário, muitos deles são concebidos para ter uma vida longa.

A maior dificuldade da gestão desta empresa, no entanto, no que diz respeito ao planejamento dos projetos, é avaliar a real contribuição que o projeto efetivamente dará ao processo produtivo global em termos de aumento de produção.

Porque é através destes resultados de produção que, utilizando-se a premissa de que tudo que é produzido é vendido, calcula-se a viabilidade econômico-financeira do empreendimento. Pois, segundo a abordagem tradicional, uma empresa ou investimento em uma empresa vale pela sua capacidade futura de geração de fluxos de caixa.

O fluxo de caixa consiste no resultado do confronto entre as entradas e as saídas esperadas de recursos de determinado investimento. Seus componentes são expectativas e representam fluxo de caixa esperados ou fluxos de caixa projetado. (BRASIL, 2007)

Atualmente os projetos, na sua grande maioria, são planejados ou elaborados pelos departamentos da empresa, sendo assim, descentralizados, e, em geral, existem incertezas intrínsecas dos projetos e incertezas quanto ao efeito do mesmo no sistema produtivo global, pois, estas áreas não possuem a visão holística da cadeia necessária para um bom planejamento.

De acordo com Maximiano (2002), todos os projetos têm uma componente de incerteza. A incerteza é uma escala, e significa desconhecimento do resultado ou do caminho para chegar até ele, ou ambos. Quanto maior o desconhecimento, maior será a incerteza e o risco.

A principal conseqüência da incerteza é a dificuldade de fazer previsões. Devido à incerteza, um projeto pode começar com definições imprecisas à respeito das três variáveis críticas de desempenho: escopo, prazo e custo.

Para estes departamentos, as incertezas intrínsecas dos projetos são, na medida do possível, identificadas e classificadas de modo a serem gerenciadas.

Em contrapartida, devido às incertezas presentes na cadeia produtiva global e o desconhecimento do efeito do projeto sobre este grande processo produtivo, o analista responsável pelo planejamento do projeto pode prever um resultado operacional distorcido para o cálculo futuro de geração do fluxo de caixa, que poderá 
refletir em uma análise econômico-financeira viável neste primeiro momento, e que na realidade, pode não ser tão atrativa, ou até mesmo, inviável.

Para o cálculo da viabilidade econômico-financeira do investimento é utilizado o efeito global de aumento de produção do projeto ou do conjunto de projetos.

Deste modo, como os cálculos de todos os projetos são o ponto de partida para o planejamento do negócio da empresa, se eles estiverem distorcidos, então o plano de médio prazo, também ficará, representando um risco tanto para a alta administração, como para o próprio negócio.

Neste sentido, o risco para o planejamento do negócio é utilizar projetos que dão retornos localmente (visão do departamento - uso de premissas com uma visão restrita), e que, na verdade, além de não darem o resultado planejado isoladamente, não dão o retorno projetado na concepção original do projeto e distorcem o plano como um todo.

Como os projetos de investimentos não possuíam ferramenta de análise que permitissem avaliar as flexibilidades inerentes à cadeia produtiva e ao negócio, a companhia precisava de um procedimento estruturado de avaliação de projetos que analisasse tanto as premissas (entradas e saídas) dos projetos individualmente, quanto a interação entre eles, no que diz respeito à alocação do conjunto destes projetos no tempo.

Assim, utilizou-se um modelo de otimização para decidir quais e quando, os projetos deverão ser executados para maximizar o $\mathrm{VPL}^{17}$ do fluxo de caixa descontado da empresa, ao longo de um período de tempo.

Admite-se, neste momento, que as informações de tempo, custo e efeito no sistema produtivo local de cada projeto são verdadeiros e de responsabilidade de cada departamento.

No entanto, este efeito contabilizado pelo projeto, que será diretamente relacionado à função objetivo do modelo de otimização, não pode ser utilizado diretamente para o cálculo do VPL, devido à falta da visão sistêmica necessária para esta análise, podendo distorcer bastante o resultado deste cenário, conforme comentado anteriormente.

\footnotetext{
${ }^{17}$ O VPL é uma sigla que representa o valor presente líquido de um fluxo de caixa é o valor monetário do ponto zero da escala do tempo, que é equivalente à soma de suas parcelas futuras, descontadas para o ponto zero, com uma determinada taxa de juros. (PUCCINI, 2001)
} 
Assim, um dos objetivos desta dissertação é desenvolver um modelo de simulação que avalie o sistema produtivo global da empresa, com um nível de detalhamento de suas variáveis que facilite a tomada de decisão gerencial. Este modelo possui, como cenário base, o mesmo a ser utilizado pelo de otimização.

Neste modelo, cada projeto proposto, sob o ponto de vista operacional, é testado pela simulação isoladamente dos outros projetos, e "seteris paribus" para todas as outras variáveis do cenário base.

Com isso, é obtido o efeito individual do referido projeto no sistema produtivo global. Posteriormente, este efeito de aumento de produção alimenta o modelo de otimização.

Usando este procedimento para com todos os projetos da lista prevista para o período, tem-se todas as informações operacionais necessárias para a execução do modelo de otimização: tempo, custo e efeito global.

A saída do modelo de otimização será a melhor sugestão para a alocação da execução do portfólio de projetos.

Esta solução otimizada (sem o inter-relacionamento entre os projetos) será novamente alimentada no modelo de simulação, de forma a conferir a capacidade do sistema e buscar o efeito da inter-relação entre os projetos, avaliando se a alocação sugerida pela otimização é viável, isto é, se os parâmetros do conjunto de projetos alteram o efeito da soma individual dos efeitos globais de cada projeto individualmente informados no início deste processo.

\subsection{MODELO DE SIMULAÇÃO-OTIMIZAÇÃO PROPOSTO}

De acordo com Brasil (2007) otimizar uma decisão quando não existe incerteza é relativamente simples: basta calcular o valor presente líquido de vários projetos de investimentos e escolher aqueles que oferecem maior retorno. $\mathrm{Na}$ prática, porém, as decisões são quase sempre cercadas de incerteza. No caso de projetos da cadeia produtiva de minérios de ferro, as decisões de investimentos são afetadas por componentes econômicos e técnicos da incerteza.

Assim, de acordo com as informações iniciais deste capítulo e com a ilustração da Figura 5.1, o modelo proposto neste trabalho, avaliará estas incertezas através dos seguintes passos: 


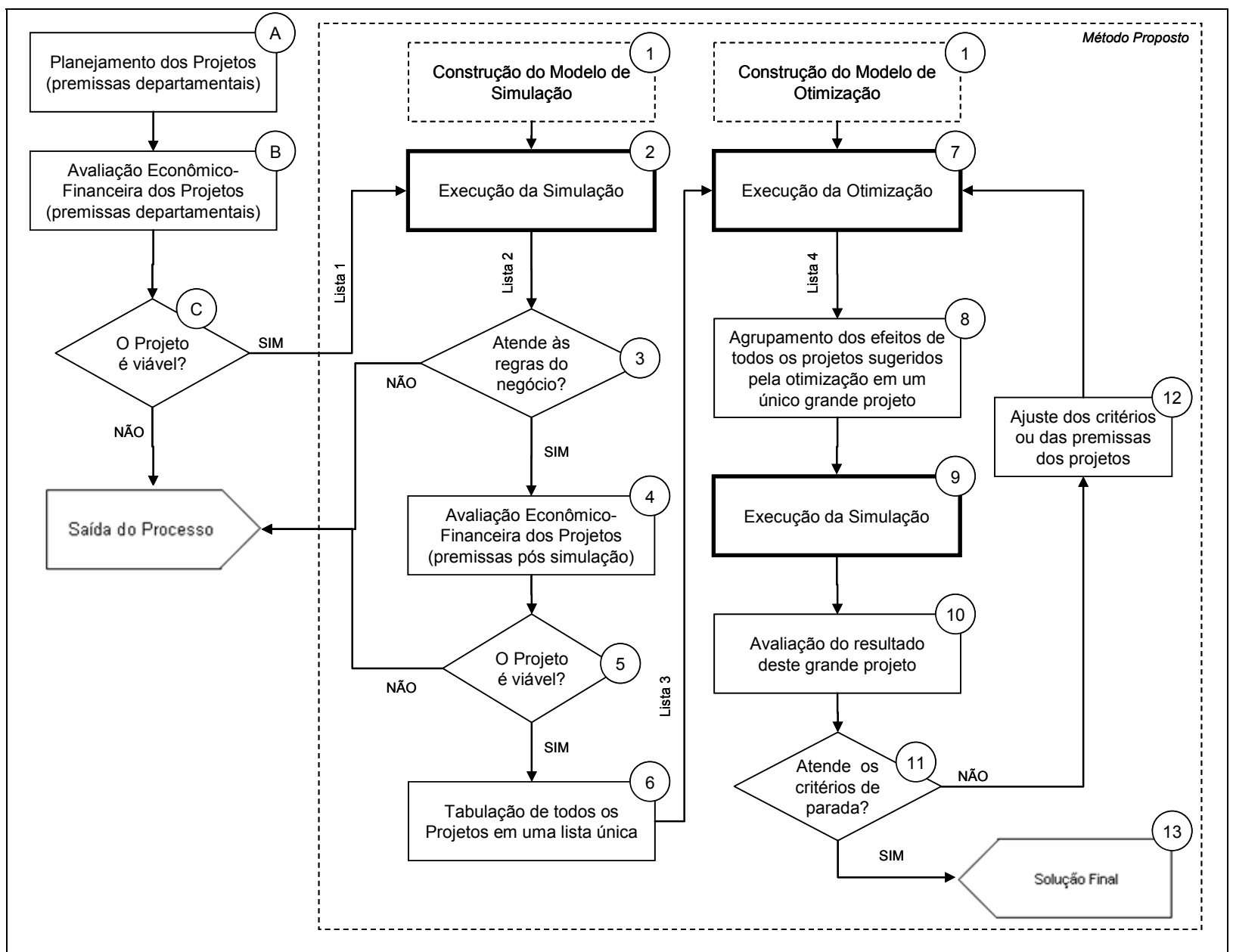

Figura 5.1 - Modelo de simulação-otimização proposto

Antes de inciar o método propriamente dito, vale ressaltar que existem algumas etapas a serem realizadas. Neste caso, as etapas A, B e C, ilustradas na Figura 5.1, representam os planejamentos dos projetos e a avaliações econômicofinanceiras feitos pelos próprios departamentos.

Assim, os projetos que entram no método proposto são aqueles que possuem além da viabilidade técnica (responsabilidade dos departamentos), a viabilidade econômico-financeira.

Uma observação importante a ser feita sobre este método é que, os critérios utilizados para as decisões presentes no fluxo são válidos apenas para a aplicação nesta empresa em estudo.

A definição destes critérios e regras do negócio determinam os "cortes" nas etapas 3,5 e 11, e, além disso, auxiliam na construção dos modelos tanto de simulação quanto de otimização. 
Passo 01 - Construção básica dos modelos

Constrói-se um modelo de simulação, representando a cadeia de produção em estudo, capaz de avaliar, de forma quantitativa, o efeito de um projeto ou da carteira de projetos no sistema produtivo global.

Terá como variáveis principais: produtividade, disponibilidade e utilização dos recursos, além da variabilidade intrínseca de cada etapa do processo.

Neste passo, também é construído um modelo de otimização que representa a tomada de decisão empresarial em que se considera, dentre outras variáveis: custo de capital, endividamentos, taxas, impostos e todo o sistema contábil necessário para avaliar o valor do empreendimento em cada um dos possíveis cenários em estudo.

\section{Passo 02 - Execução da Simulação}

Neste passo, não será avaliada a forma como cada área ou departamento encontrou ou avaliou o efeito que o projeto trará localmente para aquela unidade produtiva.

Esta informação poderá vir tanto de um simulador altamente especializado naquela operação, quanto de uma simples decisão gerencial.

Como já informado anteriormente, não é objetivo deste processo verificar a veracidade destas informações, nesta etapa parte-se do pressuposto que tudo que é enviado para este modelo de tomada de decisão é verdade.

Isto posto, nesta etapa, cada projeto presente na lista 1, que compõe a tabulação de todos os projetos viáveis planejados pelos departamentos, traduzido pelas variáveis: variabilidade do processo, produtividade, disponibilidade e utilização; serão um a um simulados, mantendo-se todas as informações restantes iguais ao cenário base, e refazendo-se uma nova lista (lista 2) com os efeitos de cada projeto, agora de acordo com as saídas do simulador.

\section{Passo 03 - Atende às regras do negócio}

Após executar o Passo 02 para cada um dos projetos da carteira de projetos planejados pelos departamentos, tem-se a lista 2, com todos os projetos iniciais da lista 1, mas com as premissas ou os efeitos dos projetos sobre o sistema produtivo global, atualizados pela simulação. 
De posse desta lista 2, verificar-se-á se estes empreendimentos não infringem as regras do negócio estabelecidas pela empresa. Como neste caso, uma regra estabelecida, como exemplo, foi que serão considerados projetos que não atendem às regras do negócio, aqueles que reduzem a produção de pelotas.

Estes procedimentos de criação de regras durante o processo de tomada de decisão retiram a liberdade das ferramentas de pesquisa operacional restringindo o campo de solução. Neste caso, mesmo ciente destas implicações, viu-se necessário a usar estas regras como forma de gerar aprendizado.

\section{Passo 04 - Avaliação econômico-financeira dos prjetos}

Neste passo, será avaliado se os projetos, com as novas premissas e/ou efeito sobre o sistema produtivo global, atualizados pela simulação, que fazem parte da lista 2, ainda são viáveis, sob o aspecto econômico-financeiro.

Nesta etapa é utilizada a mesma ferramenta de avaliação econômicofinanceira do passo $\mathrm{B}$, realizada pelos departamentos.

Passo 05 - $\underline{\text { O projeto é viável? }}$

De posse da lista 2, cada projeto será avaliado se ainda continua econômicamente viável após a alteração de suas premissas ou efeito sobre o sistema produtivo global, atualizados pela simulação.

Passo 06 - Tabulação de todos os projetos em uma lista única

Neste passo, todos os projetos economicamente viáveis avaliados no passo anterior, são tabulados em uma única lista (lista 3) que será alimentada no modelo de otimização.

Esta lista contém os efeitos dos projetos sobre o sistema produtivo global, o período e plano de desembolso (investimento), que também representa o período de execução do projeto, e os períodos que o empreendimento pode iniciar.

\section{Passo 07 - Execução da Otimização}

Tendo todas as restrições econômico-financeiras e técnicas estabelecidas, e o efeito global de cada um dos projetos em estudos quantificados pela simulação, o otimizador buscará o melhor conjunto e alocação das possíveis soluções de execução da lista 3. 
O otimizador poderá tanto ordenar os projetos quanto decidir em fazê-los ou não, dependendo da viabilidade encontrada diante das restrições de negócio impostas inicialmente.

A saída da otimização é uma lista ordenada de projetos (lista 4).

Passo 08 - Agrupamento dos efeitos de todos os projetos sugeridos pela otmização em um único projeto

Com a lista 4, neste passo será agrupado, de acordo com a alocação sugerida pela simulação, todas as informações de efeitos dos projetos sobre o sistema produtivo global e o período e plano de desembolso (investimento), como se a partir de agora fosse um único projeto. Após este agrupamento estas informações serão alimentadas no modelo de simulação.

\section{Passo 09 - Execução da Simulação}

Neste passo, será simulado e quantificado o efeito global de todos os projetos sugeridos pela otimização no espaço de tempo pré-definido.

Isto se faz necessário para reduzir a quantidade de experimentos ou simulações que deveriam ser feitas para identificar as interferências entre os projetos.

\section{Passo 10 - Avaliação do resultado da Simulação}

Nesta etapa, tem-se o efeito do conjunto de projetos ordenadamente sugeridos pela otimização (lista 4) no sistema global verificado e avaliado pela simulação.

O objetivo é conferir a capacidade do sistema e a inter-relação entre os projetos, verificando se a alocação sugerida pela otimização é viável e se os parâmetros do conjunto de projetos alteram o efeito da soma dos efeitos de cada projeto individualmente.

\section{Passo 11 - Atende os critérios de parada?}

Neste passo, será verificada a viabilidade da lista 4 , isto é, se a capacidade produtiva da cadeia foi obedecida após a junção de todos os projetos sugeridos. Se a solução for viável, então, se tem a solução final. Caso contrário ajusta-se os 
parâmetros necessários identificados e sugeridos pela simulação (Passo 12), ou por outras regras ou restrições do negócio, e retorna-se ao Passo 07.

Este ciclo será executado até se encontrar uma convergência dos resultados, isto é, quando o volume de produção sugerido pelo agrupamento da lista 4 em um único projeto e o resultado da simulação (passo 9) não exceder uma percentagem pré-definida. 


\section{DESCRIÇÃO DO MODELO DE OTIMIZAÇÃO}

Neste capítulo, será apresentado o modelo matemático de otimização utilizado para a quantificação dos cenários presentes no processo de planejamento do negócio.

Este processo de planejamento é um instrumento de orientação e consulta que permite a análise e o acompanhamento de um empreendimento. É uma linguagem de comunicação com o próprio empresário e com agentes externos.

Ele mostra em detalhes quem são os empreendedores, qual é o produto, quais e quantos são os clientes, qual é o processo tecnológico de produção e vendas, qual é a estrutura de gerenciamento, quais são as projeções financeiras para fluxo de caixa, receitas, despesas, custos e lucros.

Com o plano de negócios é possível identificar os riscos e propor ações para minimizá-los, e até mesmo evitá-los; identificar seus pontos fortes e fracos em relação à concorrência e ao ambiente de negócio em que você atua; conhecer seu mercado e definir estratégias de marketing para seus produtos e serviços; analisar o desempenho financeiro de seu negócio, avaliar investimentos, retorno sobre o capital investido; enfim, é um poderoso guia que norteará todas as ações da empresa.

Como se nota, o Plano de Negócios não é uma ferramenta estática, pelo contrário, é uma ferramenta extremamente dinâmica e deve ser atualizado periodicamente.

O planejamento do negócio indica novos caminhos. É um espaço onde os erros saem mais baratos. É também uma linguagem entre o empreendedor e todos os seus parceiros: sócios, empregados, investidores, bancos, contadores, agências governamentais de financiamento, etc.

Este plano deve ser feito com o objetivo de identificar as possíveis oportunidades e ameaças, e de facilitar as decisões que o empreendedor deverá tomar para se tornar bem sucedido. 
Ele é um instrumento que permite ao empreendedor condensar as informações que são obtidas no mercado, buscando sensibilizar os parceiros e os investidores. Através do plano, o empreendedor vai poder verificar as diversas influências ambientais incidentes sobre o seu novo negócio, podendo assim, minimizar o seu risco.

Desta forma, este modelo de otimização foi costruído pela empresa em estudo, e utilizado nesta dissertação, com o objetivo de aprimorar o processo de planejamento de negócios da Samarco Mineração S/A, de forma a visualizar a projeção futura do que a empresa pretende ser e indicar como a deverá canalizar seus investimentos.

Este modelo foi construído pela empresa em estudo e utilizado nesta dissertação, utilizando modelagem matemática via programação linear inteira mista (MILP). A implementação foi realizada através do "solver" Lingo 10.0, utilizando como interface de dados o Microsoft Office Excel 2003.

Por este modelo ser muito complexo, neste trabalho será apresentado os principais aspectos contextualizando suas restrições, variáveis e função objetivo.

De acordo com Brasil (2007) a criação de valor é uma premissa das corporações e a avaliação de projetos é uma etapa fundamental do gerenciamento baseado no valor.

As técnicas de análise de investimentos incorporam questões relativas ao risco assumido, retorno esperado, custo do capital, racionameno do capital e relação entre capital de terceiros e capital próprio.

Desta forma, a função objetivo deste modelo é maximizar uma combinação linear entre o valor presente líquido dos fluxos de caixa futuros e seus pagamentos de dividendos no horizonte de tempo determinado, através da alocação dos projetos sugeridos no início da otimização, de forma a maximizar o valor da empresa.

Brasil (2007) afirma, que o valor de um investimento ou de uma empresa deve considerar a sua capacidade de geração de caixa mais o valor das oportunidades gerenciais embutidas. 
Um projeto ou uma empresa pode ter opção de:

- expandir suas atividades no futuro;

- abandonar o investimento a qualquer momento em função da possível entrada de novos competdores ou de alterações expectacionais;

- investir para aprender e entrar em determinado setor;

- adiar determinado desembolso de capital;

- trocar ou flexibilizar o processo de produção;

- combinar diversas flexibilidades diferenciadas

- contrair a utilização da capacidade.

Estas opções lembradas por Brasil (2007) pode ser traduzidas em projetos, e assim, testadas nesta ferramento de auxílio ao planejamento do negócio.

O horizonte de planejamento desta ferramenta é de seis anos, ou melhor, de 72 períodos. Isto é, um horizonte de 6 anos com sensibilidade mensal.

Os principais dados de entrada do modelo de otimização são:

- custos variáveis por família de produto,

- custos fixos,

- impostos devidos,

- mix de produção,

- capacidades,

- produtividades,

- disponibilidades,

- gastos operacionais,

- informações de gastos de capital na forma de projetos com a

- declaração de suas classificações para termos contábeis,

- informações do período de desembolso (que representam o período de execução do empreendimento), 
- a janela de tempo de interesse da empresa em que o investimento deve ser iniciado

○ e o efeito do projeto nos custos, depreciação e receita.

Além destas variáveis internas da empresa, existem também outras variáveis de mercado, como por exemplo:

- projeções de preço de minério de ferro;

- projeçõe de preço e consumo de insumos: como o próprio minério de ferro, petróleo e energia elétrica;

- projeções de câmbio;

- projeções de inflação brasileira.

$E$ além do mais, algumas restrições do negócio, como, endividamento, empréstimos de médio e longo prazo e política de pagamento de dividendos.

Como saídas do modelo de otimização, pode-se citar além dos projetos escolhidos e alocados na janela de tempo pré-determinada, o valor presente líquido do fluxo de caixa futuro da empresa de acordo com a carteira de projetos alocadas, o próprio fluxo de caixa, os resultados de EBIT e EBITA, de faturamento, de retorno sobre o investimento, de retorno sobre o capital empregado e os dividendos projetados a serem pagos por período dentre outros.

Maiores detalhes sobre este modelo de otimização pode ser encontrado no apêndice B. 


\section{DESCRIÇÃO DO MODELO DE SIMULAÇÃO}

Neste item será apresentada a análise do modelo de simulação utilizado para avaliar o efeito de um projeto, ou de um conjunto de projetos, na capacidade produtiva global do cenário base.

\subsection{PROCESSO PRODUTIVO}

O processo produtivo da Samarco Mineração S/A, conforme ilustrado na Figura 7.1, inicia-se nas operações das minas de Alegria, na Unidade de Germano, em Mariana (Quadrilátero Ferrífero), Minas Gerais. Seguindo as orientações das setas da Figura 7.1, o minério lavrado é encaminhado através de correias $(9 \mathrm{~km})$ até o circuito de peneiramento e britagem, para iniciar o processo de adequação granulométrica. Em seguida, é enviado para a pilha do "tripper-car" (que funciona como um estoque intermediário).

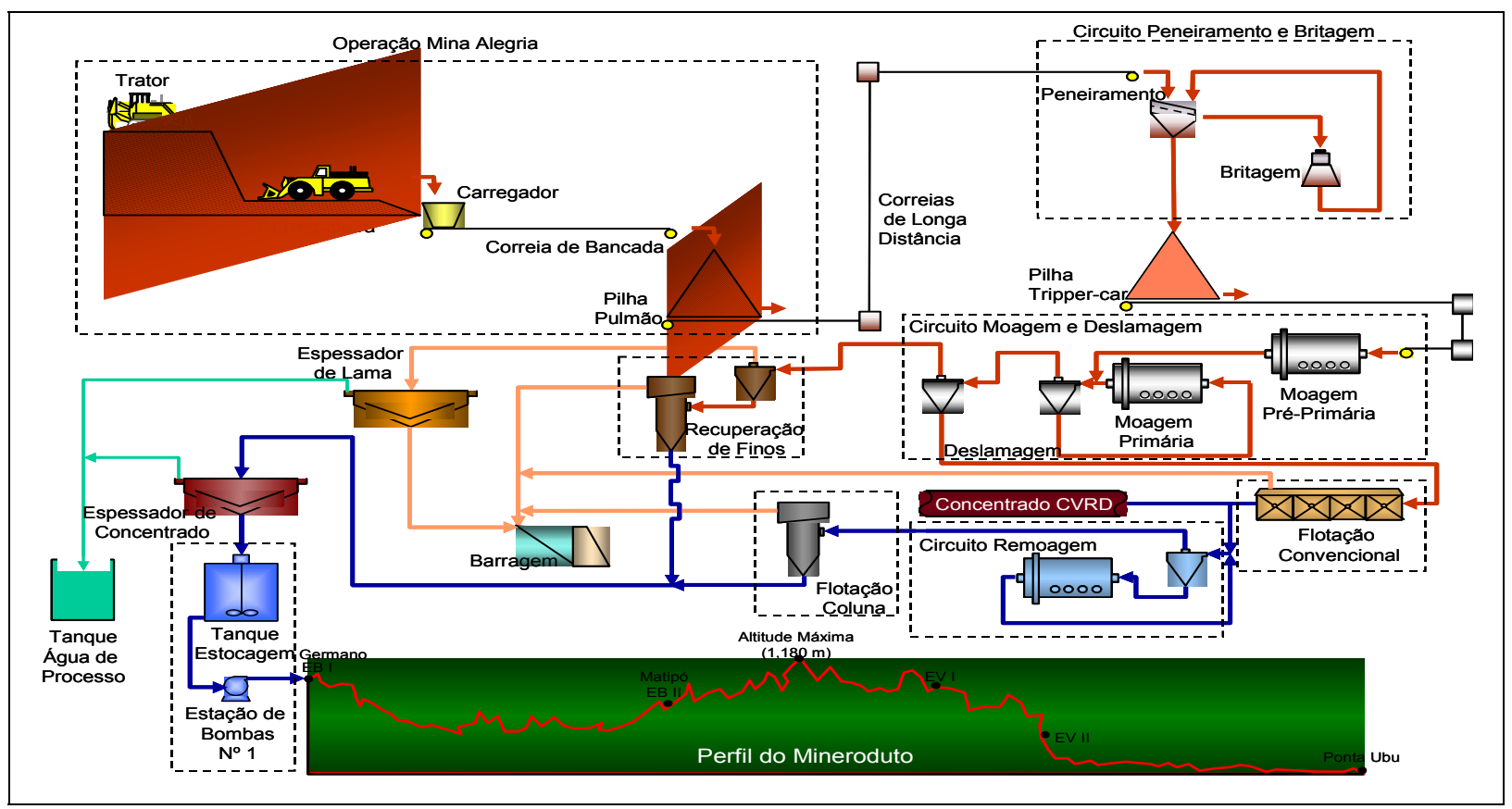

Figura 7.1 - Fluxograma de processo da unidade de Germano, Mariana (MG) Fonte: SAMARCO MINERAÇÂO S/A, 2006. 
Posteriormente, o minério britado segue para os circuitos de moagem e deslamagem, passando, primeiramente, por um circuito aberto de moagem (moagem pré-primária) e, depois, por um circuito fechado denominado moagem primária. Somente após uma granulometria predeterminada, o minério passa à etapa de deslamagem, que separa o minério da lama ${ }^{18}$.

Após a retirada da lama, o material é enviado à primeira etapa de concentração de ferro, que á a flotação convencional, no final da qual ocorre uma partição do material bom, rico em ferro, do material ruim, mais lama, que, novamente, é enviada à barragem de rejeito.

Em seguida, acontece mais um processo de ajuste de granulometria chamado de remoagem, em que, novamente, se procura quebrar as partículas de sólidos, de forma a separar fisicamente o ferro da sílica (processo de liberação) e, posteriormente, através de outro processo de concentração (flotação por colunas), separar um minério rico em ferro, da lama.

Todo esse material que sai da flotação em colunas segue para o espessador de concentrado, responsável por ajustar o percentual de sólidos adequado para o processo de transporte executado pelo mineroduto.

Esse concentrado é, então, transportado pelo mineroduto (396 km) até a unidade de Ponta Ubu, em Anchieta, Espírito Santo, com um perfil similar ao apresentado na Figura 7.1.

O transporte por mineroduto é um dos grandes diferenciais da Samarco Mineração S/A. Esse sistema opera com baixos custos operacionais e elevada confiabilidade, o que proporciona segurança operacional e proteção ambiental.

Há 25 anos em atividade, o mineroduto da Samarco Mineração é o maior do mundo para transporte de minérios de ferro, com $396 \mathrm{~km}$ de extensão. Integra a unidade de Germano, em Mariana (MG), à unidade de Ponta Ubu, em Anchieta (ES), atravessando centenas de propriedades em 25 municípios (Figura 7.2).

Projetado para transportar 12 milhões de toneladas por ano, o mineroduto Samarco tem, hoje, capacidade para bombear 16,5 milhões de toneladas por ano de concentrado de minérios de ferro.

\footnotetext{
${ }^{18}$ Lama - material fino, pobre em ferro, que é enviado para o espessador de lama, onde se recupera a água e de onde os sólidos são enviados à barragem de rejeito
} 


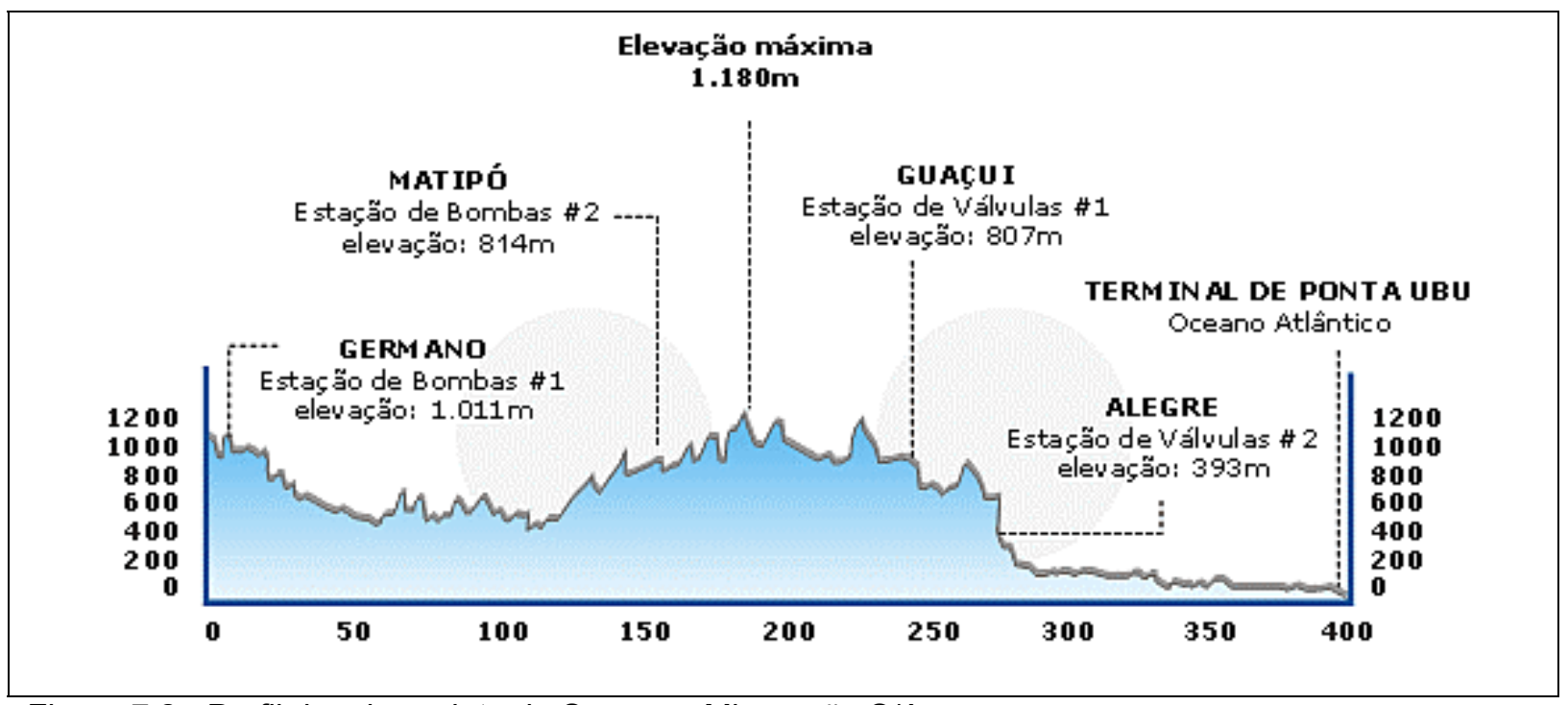

Figura 7.2 - Perfil do mineroduto da Samarco Mineração S/A Fonte: SAMARCO MINERAÇÂO S/A, 2006.

Em Ponta Ubu, a Samarco Mineração S/A possui duas das maiores plantas de pelotização do mundo, com capacidade de produção anual de 14 milhões de toneladas de pelotas de minérios de ferro.

A primeira planta iniciou sua operação em 1977 e a segunda em 1997. Em 2008, entrará em operação a terceira planta de pelotização, com capacidade de 8 milhões de toneladas por ano.

Nesta unidade de produção, a polpa de minério concentrado é recebida nos espessadores, onde passa pelos primeiros processos de adequação de suas características físicas e químicas necessárias à produção de "pellet-feed" e pelotas. Em seguida é direcionada para a filtragem, em que é retirada a água utilizada no transporte pelo mineroduto.

O processo de espessamento é a primeira etapa para desaguamento da polpa de minérios de ferro. Para isso, os sólidos em suspensão na polpa sedimentam-se em tanques apropriados, espessadores, de modo a se obter uma lama densa no fundo e um líquido clarificado na parte superior.

O processo produtivo da unidade de Ponta Ubu da Samarco Mineração S/A pode ser observado na Figura 7.3.

A Samarco Mineração S/A tem, atualmente, quatro tanques homogeneizadores, cujas funções são armazenar e promover a homogeneização da polpa oriunda dos espessadores, que, posteriormente, será bombeada para a filtragem. 


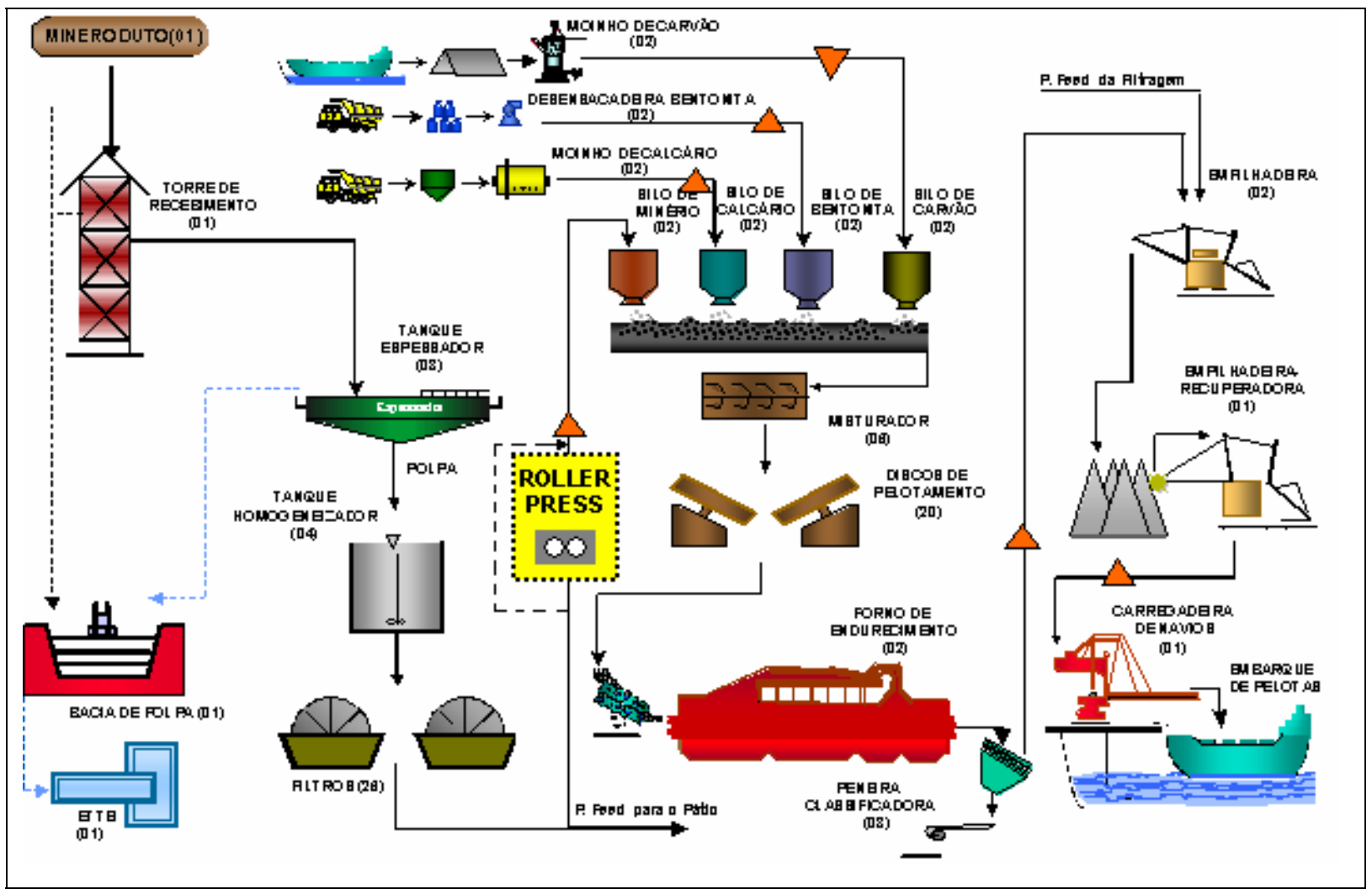

Figura 7.3 - Fluxograma representativo do processo produtivo de Ponta Ubu Fonte: SAMARCO MINERAÇÂO S/A, 2006.

A operação de filtragem é realizada por meio de filtros contínuos, a vácuo, responsáveis pela separação de sólidos e líquido. Esse é um processo muito semelhante ao da produção de café, mas, aqui, diferentemente, o material de interesse é a borra de café e, neste caso, o chamado "filter cake" ou "pellet-feed".

Com teor de umidade adequado após a filtragem, o minério de ferro recebe a adição de insumos, como calcário, carvão, bentonita e aglomerante orgânico, formando uma mistura homogênea a ser utilizada no processo seguinte, que é o de pelotamento. Esses insumos são essenciais para que as pelotas adquiram as características físicas, químicas e metalúrgicas necessárias à sua utilização nos processos subseqüentes.

As pelotas cruas formadas no pelotamento são queimadas nos fornos de endurecimento. As pelotas queimadas são, então, transportadas por correias até o pátio de estocagem, com capacidade para 2 milhões de toneladas.

Para que as pelotas formadas nos discos pelotizadores possam resistir às operações de manuseio e transporte até o cliente, ou seja, estocagem no pátio, carregamento, transporte e descarregamento do navio, e para que suportem as pressões e os choques térmicos dentro dos reatores de redução de minérios de ferro 
(fornos) dos clientes, durante sua transformação em ferro gusa (alto-forno) ou ferro esponja (redução direta), torna-se necessário submetê-las a um tratamento térmico cuidadoso e bem balanceado, que proporcione a elas resistência física e mecânica apropriada. A esse tratamento dá-se o nome de processo de endurecimento, ou processo de queima, o qual é realizado no forno de pelotização, ou também chamado forno de endurecimento.

O processo seguinte, o de estocagem e embarque, tem como objetivo dar um tratamento adequado aos produtos acabados (pelotas, "pellet-feed", "pelletscreening") de modo a propiciar a recuperação adequada desses produtos para o embarque, assegurando-lhes a manutenção de suas características de forma a atender aos quesitos de qualidade, custos, segurança, prazo de entrega e meio ambiente necessários.

\subsection{MÉTODO DE CONDUÇÃO DE PROJETOS DE SIMULAÇÃO COMPUTACIONAL}

Law e Kelton (1991) desenvolveram uma estrutura para gerenciar as diferentes etapas de um trabalho de simulação computacional.

A Figura 7.4 ilustra a seqüência de etapas a serem consideradas. Em seguida, uma breve explicação de cada etapa.

a) Formulação do problema e planejamento do estudo - Todo estudo deve começar com o estabelecimento claro de seu objetivo principal e dos pontos específicos a serem verificados. Nesta etapa, também se definem as alternativas a serem testadas e os pressupostos a serem adotados.

b) Coleta de dados e formulação do modelo conceitual - As informações e os dados de interesse devem ser coletados e usados para esclarecer os procedimentos operacionais e definir as distribuições de probabilidades para as variáveis utilizadas no modelo. 


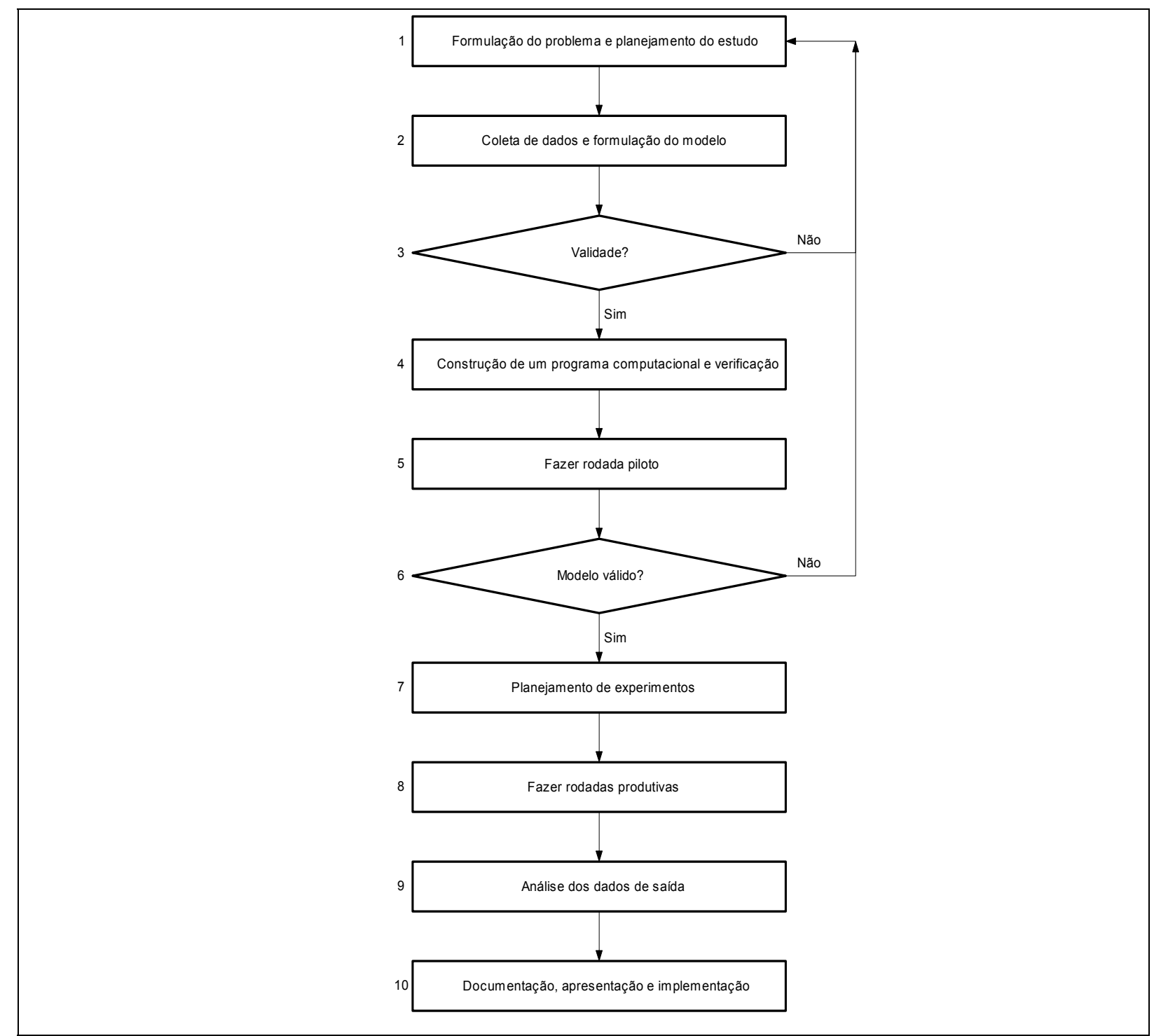

Figura 7.4 - Passos num estudo de simulação.

Fonte: CASTRO NETO, 2006.

c) Validade - É necessário que o usuário interaja com as pessoas que conhecem o processo intimamente, para verificar se seu modelo é válido em termos conceituais e nos dados coletados.

d) Construção de um programa computacional e verificação - Nessa etapa, deve-se escolher um software de simulação e transformar o modelo teórico em um programa computacional. A escolha do software dependerá das características que se deseja dele. Depois de o programa estar pronto, deve-se verificá-lo, mediante técnicas de verificação, para checar se há erros de lógica e sintaxe.

e) Replicação piloto - As rodadas piloto são necessárias para validar o programa na fase seguinte. 
f) Validação - A validação é adotada para atestar se as rodadas piloto têm como saída informações que refletem o sistema real.

g) Planejamento do experimento - Como a simulação tem uma natureza estocástica, ela apenas estima o comportamento do sistema para determinados parâmetros. Por isso, é necessário planejar o experimento definitivo. É importante salientar a importância da definição do período de tempo, para que os parâmetros estejam em condições apropriadas para a simulação daquele instante. Esse intervalo de tempo é conhecido como aquecimento, e seus resultados são desprezados.

h) Fazer rodadas produtivas - Considerando-se os parâmetros estabelecidos na etapa anterior, fazem-se as rodadas para levantamento dos resultados dos cenários escolhidos.

i) Análise dos dados de saída - Técnicas estatísticas devem ser utilizadas para analisar os dados de saída. Nos casos de várias alternativas, escolhe-se a melhor opção.

j) Documentação, apresentação e implementação - Como os projetos de simulação quase sempre são usados novamente, é necessário documentar todo o projeto, a fim de poder utilizá-lo no futuro. Para que o estudo seja um sucesso, é preciso que o mesmo seja apresentado e implementado.

\subsection{APLICAÇÃO DO MODELO DE SIMULAÇÃO}

O processo produtivo da Samarco Mineração S/A pode ser considerado como um sistema logístico complexo, devido as suas especificidades do processo de mineração, de abastecimento de insumos tanto no beneficiamento quanto na pelotização, além de suas operações portuárias.

Além destas características abordadas anteriormente, vale lembrar que este processo é contínuo, linear e sem expressivas capacidades intermediárias de estocagem que possam absorver grandes variações de produção. Desta forma, é difícil mensurar qual será o real efeito de um projeto de aumento de capacidade sem utilizar uma ferramenta tal qual a simulação. 
Assim, o modelo de simulação foi criado especialmente para avaliar estes efeitos na cadeia produtiva global, a fim de melhorar a qualidade da informação de entrada para um processo decisório (otimização) e verificar se a capacidade operacional foi obedecida.

Para isso, como se pode observar na Figura 7.5, o modelo utilizado para a construção do simulador foi uma síntese do processo atual comentado no início deste capítulo, além do acréscimo de alguns conceitos que já estão sendo utilizados durante o projeto de expansão de capacidade produtiva de pelotas, chamado de Projeto Terceira Pelotização, que entrará em operação em 2008 e que aumentará as capacidades do beneficiamento e do transporte de 16,5 para 24 milhões de toneladas, e da pelotização dos atuais 14 para 21 milhões de toneladas métricas secas de pelotas.

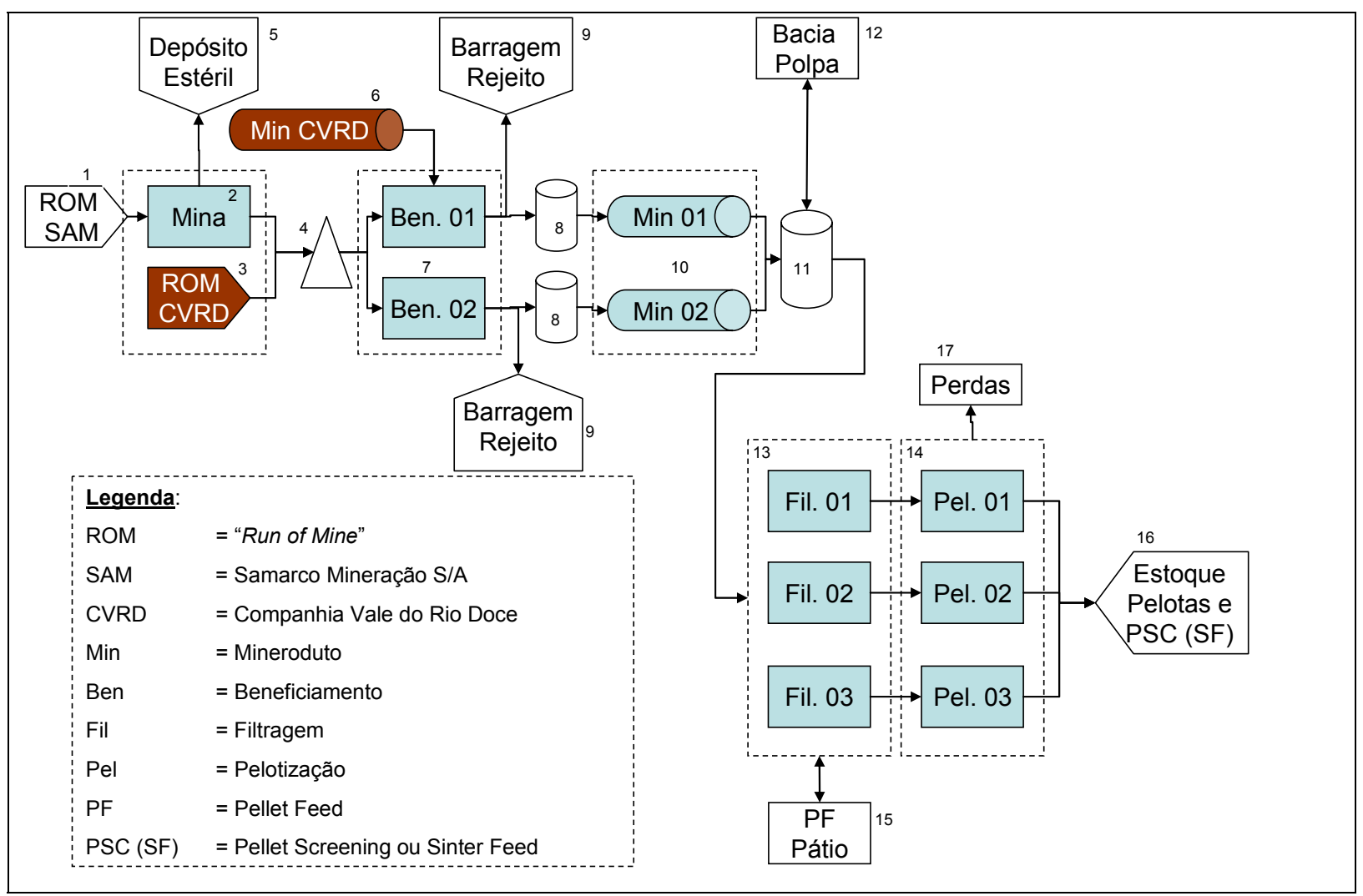

Figura 7.5 - Fluxograma representativo do modelo computacional utilizado na simulação

De acordo com a legenda numérica (de 1 a 16), presente na Figura 7.5, o processo produtivo inicia-se pela retirada dos minérios de ferro das minas da Samarco Mineração S/A (item 1). Não serão abordadas, nesta simulação, todas as possíveis entradas, misturas ("blendagem") e logística de equipamentos da 
mineração, pois existe um software especialista para este assunto que alimentou este modelo com informações de massa de ROM, produzida por hora.

No item 2, observa-se a retirada e deposição de estéril (item 5) da mina simplesmente através de uma partição da produção de ROM conforme informado pelo plano de lavra. Esta separação possui uma relação de que a cada 2 toneladas de Rom retira-se mais de 1 tonelada de minério, isto é, em torno de $33 \%$ de todo material que é movimentado nas minas.

Devido às características mineralógicas do minério da Samarco Mineração S/A, é necessária uma quantidade de ROM com propriedades complementares, de modo que o beneficiamento consiga realizar seu processo de concentração de ferro. Outrossim, o processo é alimentado diretamente na mina, por uma quantidade regular de ROM da CVRD (item 3).

Após este processo de "blendagem" e retirada de estéril (itens 1, 2 e 3), o material é depositado em uma pilha (item 4) que serve como um estoque intermediário, responsável por amortecer as variações de produção das diferentes frentes de lavra da mina e pela alimentação regular do processo de beneficiamento (item 7).

Durante o processo de beneficiamento, há uma separação entre o minério de ferro e suas impurezas, especialmente a sílica $\left(\mathrm{SiO}_{2}\right)$. O ROM alimentado no beneficiamento possui um teor de ferro em torno de $45 \%$ e o concentrado (produto do beneficiamento) de, aproximadamente, 68\%. Ao mesmo tempo, uma porção do material alimentado, em torno de $42 \%$ em massa, é eliminada do sistema, através de partições durante o processo de concentração, e esse material recebe o nome de lama. Esta lama é enviada para uma barragem de rejeito que é responsável pelo depósito final deste material (item 9).

Ainda devido às características mineralógicas, o concentrado produzido pela Samarco Mineração S/A não possui as propriedades ideais para um bom desempenho do processo de pelotamento. Desta maneira, é necessário adquirir um material com atributos complementares para minimizar as perdas na pelotização. Sendo assim, é incorporada, continuamente ao processo de beneficiamento, uma quantidade de concentrado da CVRD (item 6) em torno de 2 milhões de toneladas ano.

Após a concentração do minério de ferro da Samarco Mineração S/A e adição do concentrado da CVRD, este material é homogeneizado em tanques (item 8) que 
preparam o material (uma polpa) a um percentual de sólidos em torno de $70 \%$, para ser transportado através dos minerodutos (item 10). Vale ressaltar que, até esta etapa, as duas linhas de produção: beneficiamento 1 (Ben.1) - mineroduto 1 (Min.1), e beneficiamento 2 (Ben.2) - mineroduto 2 (Min.2), operam independentemente.

Estes tanques do item 8 também funcionam como um pulmão do processo produtivo bem como a pilha de minério da mineração (item 4), responsável por absorver as variações da usina de beneficiamento e garantir uma uniformidade do processo de bombeamento. Vale ressaltar que a capacidade destes tanques equivale, no limite, a apenas $11 \mathrm{~h}$ de produção da usina de beneficiamento. Este processo não representa um problema, devido aos altos índices de disponibilidade e utilização que a empresa mantém.

Após o transporte pelos minerodutos (item 10), todo o concentrado bombeado é adicionado em tanques representados pelo item 11. Neste momento, todo o material produzido nas usinas de beneficiamento são misturados e preparados para serem enviados à filtragem (item 13).

Eventualmente, quando ocorrem problemas operacionais e a capacidade dos tanques não é suficiente para absorver todo o concentrado que está em trânsito, este material é enviado para a Bacia de Polpa (item 12), mas, posteriormente, pode retornar ao processo.

Dos tanques de homogeneização (item 11) a polpa é enviada para a filtragem em que será retirado o excesso de água, e o material resultado deste processo, "pellet-feed", poderá ser transportado diretamente para a pelotização (item 14), ou armazenado no pátio de estocagem (item 15). Esta segunda opção pode ocorrer devido a problemas operacionais na pelotização, ou simplesmente, porque a capacidade da filtragem é superior à necessidade da pelotização. Este "pellet-feed" armazenado pode ser vendido como produto final ou retornado à filtragem para alimentar a pelotização, em situações em que há problemas operacionais na filtragem ou restrições a processos anteriores.

Na pelotização (item 14), o "pellet-feed" é transformado em pelotas e estas são queimadas no forno de endurecimento para criar características que atendam às especificações dos clientes. Durante este processo de pelotização e queima, ocorrem perdas, tanto através de liberação de gases que interagem com o carvão e os óxidos presentes no "pellet-feed" como de perdas de materiais, característica 
intrínseca dos processos de metalurgia extrativa. Estas perdas estão ilustradas na Figura 7.4, através do item 17.

Após o processo de pelotização, o produto final, seja de pelotas ou "pelletscreening" (pelotas fora de especificação), é armazenado no pátio de estocagem (item 16) pronto para ser embarcado e enviado aos clientes.

As operações portuárias possuem um simulador específico e alimentam este modelo com informações de retirada do produto final do estoque.

Este processo de escoamento não foi considerado neste modelo, devido às suas complexas características (abordadas e analisadas em recentes trabalhos como o de CASTRO NETO, 2006) e, assim poderiam distorcer os objetivos e as discussões da proposta inicial que é simplesmente a integração deste modelo de simulação a um de otimização que melhore o planejamento do negócio da empresa em estudo, conforme supracitado. 


\section{APLICAÇÃO DO MÉTODO PROPOSTO}

Este capítulo tem como objetivo aplicar o método proposto no capítulo 5, "Modelagem conceitual do problema e apresentação do método proposto", e apresentar os ganhos possíveis de serem obtidos, quando as técnicas de simulação e otimização são integradas em um mesmo processo de tomada de decisão.

Antes de iniciar a simulação-otimização, é necessário esclarecer algumas simplificações utilizadas nos modelos computacionais que refletem na condução do método.

Primeiramente, vale notar que a simulação, neste método, está sendo empregada em uma das três possíveis áreas de aplicação neste processo decisório, como por exemplo: a simulação poderia ser utilizada para a avaliação do mercado, no estudo da variabilidade da demanda de minérios de ferro e seus principais mercados correlacionados, como ferro e aço.

Esta, também, poderia ser usada para estudar o comportamento das variáveis financeiras, considerando, tanto as variáveis macroeconômicas quanto internas, neste caso, câmbio, taxas de crescimento da indústria e do país, inflação e outras. Todas essas possíveis aplicações podem afetar tanto a viabilidade dos empreendimentos, como também a seqüência sugerida para realização dos mesmos.

\subsection{AVALIAÇÃO DOS DADOS DE ENTRADA}

\subsubsection{Modelo de Simulação}

A fase de coleta e análise de dados desenvolveu-se com base em informações recebidas da Samarco Mineração S/A. Essas informações foram tratadas e analisadas, estatisticamente, com auxílio dos softwares "Minitab" e "Input Analyser", este último um aplicativo do software Arena. 


\subsubsection{Modelo de Otimização}

A coleta e a avaliação de dados também foram feitas com base em informações recebidas da mesma empresa em estudo.

Para preservar as informações mais sensíveis do negócio em que a Samarco Mineração S/A está inserida, muitas informações relacionadas ao sistema financeiro, tributário e outras que a empresa julgou estratégicas, foram suprimidas; mesmo assim, foram avaliadas.

\subsection{PASSO 01: CONSTRUÇÃO BÁSICA DOS MODELOS}

Este passo já foi detalhado nos capítulos 6, "Descrição do modelo de otimização" e, 7, "Descrição do modelo de simulação". Além disso, o detalhamento dos modelos está presente nos apêndides A e B.

\subsection{PASSO 02 - EXECUÇÃO DA SIMULAÇÃO}

\subsubsection{Lista 1}

Antes de iniciar o processo de simulação individual de cada empreendimento é apresentada a seguir a lista de projetos que serão estudados por este método (lista 1). Esta listagem dos projetos é simplesmente uma tabulação dos diversos projetos que esta empresa tem a intenção de executar.

São chamados de projetos originais aqueles empreendimentos recebidos pela equipe de gestão de projetos diretamente das áreas ou departamentos da empresa, contendo as informações sem tratamento, isentas de qualquer tipo filtro ou consolidação. São informações que possuem uma visão restrita da cadeia produtiva, isto é, uma visão local da área na qual este projeto se propõe atuar. 
Tabela 8.1 - Projetos originais e local de implantação

\begin{tabular}{|r|l|l|}
\hline \multicolumn{2}{|c|}{ Lista 1 - Projetos Originais } & \multicolumn{1}{|c|}{$\begin{array}{c}\text { Local de } \\
\text { Implantação }\end{array}$} \\
\hline 1 & Aumento de $20 \%$ produção na mina & Mina \\
\hline 2 & Aumento de $10 \%$ produção no beneficiamento 1 & Beneficiamento \\
\hline 3 & Aumento de $\%$ da disponibilidade no beneficiamento 1 & Beneficiamento \\
\hline 4 & Redução de $20 \%$ da variabilidade na produção do beneficiamento 1 & Beneficiamento \\
\hline 5 & Aumento de $10 \%$ no bombeamento de concentrado & Mineroduto \\
\hline 6 & Redução de $1 \%$ na disponibilidade do mineroduto & Mineroduto \\
\hline 7 & Redução de $10 \%$ da variabilidade do bombeamento & Mineroduto \\
\hline 8 & Aumento de $10 \%$ no bombeamento de concentrado - Complexo Germano & Germano \\
\hline 9 & Aumento de $10 \%$ na capacidade da filtragem 1 e 2 & Filtragem \\
\hline 10 & Aumento de $5 \%$ na disponibilidade da filtragem 1 e 2 & Filtragem \\
\hline 11 & Redução de $10 \%$ da variabilidade da produção da filtragem 1 e 2 & Filtragem \\
\hline 12 & Aumento de 10\% na capacidade das usinas 1 e 2 & Pelotização \\
\hline 13 & Redução de $10 \%$ da variabilidade da produção das usinas 1 e 2 & Pelotização \\
\hline 14 & Aumento de $2 \%$ da disponibilidade nas usinas 1 e 2 & Pelotização \\
\hline
\end{tabular}

É interessante indicar, na próxima tabela, antes de apresentar os resultados das simulações individuais de cada projeto, o efeito no processo produtivo global informado, inicialmente, pelas áreas proponentes, apresentando o resultado esperado, após a execução de cada um dos empreendimentos da lista 1.

Tabela 8.2 - Efeito dos projetos originais no processo produtivo

\begin{tabular}{|r|l|r|r|r|}
\hline \multicolumn{2}{|l|}{ Lista 1 - Projetos Originais } & \multicolumn{2}{c|}{ Efeito no Processo Produtivo [tms] } \\
\cline { 3 - 5 } \multicolumn{2}{|l|}{} & Pelotas & Pellet-feed & $\begin{array}{r}\text { Pellet- } \\
\text { screening }\end{array}$ \\
\hline 1 & Aumento de 20\% produção na mina & - & 3.000 .000 & - \\
\hline 2 & Aumento de 10\% produção no beneficiamento 1 & - & 1.650 .000 & - \\
\hline 3 & Aumento de 2\% da disponibilidade no beneficiamento 1 & - & 350.000 & - \\
\hline & $\begin{array}{l}\text { Redução de 20\% da variabilidade na produção do } \\
\text { beneficiamento 1 }\end{array}$ & - & 350.000 & - \\
\hline 5 & Aumento de 10\% no bombeamento de concentrado & - & 1.650 .000 & - \\
\hline 6 & Redução de 1\% na disponibilidade do mineroduto & - & 170.000 & - \\
\hline 7 & Redução de 10\% da variabilidade do bombeamento & - & 170.000 & - \\
\hline & $\begin{array}{l}\text { Aumento de 10\% no bombeamento de concentrado - } \\
\text { Complexo Germano }\end{array}$ & - & 1.650 .000 & - \\
\hline 9 & Aumento de 10\% na capacidade da filtragem 1 e 2 & - & 1.700 .000 & - \\
\hline 10 & Aumento de 5\% na disponibilidade da filtragem 1 e 2 & - & 920.000 & - \\
\hline 11 & $\begin{array}{l}\text { Redução de 10\% da variabilidade da produção da } \\
\text { filtragem 1 e 2 }\end{array}$ & - & 950.000 & - \\
\hline 12 & Aumento de 10\% na capacidade das usinas 1 e 2 & 1.400 .000 & $(1.491 .000)$ & 35.000 \\
\hline & $\begin{array}{l}\text { Redução de 10\% da variabilidade da produção das } \\
\text { usinas 1 e 2 }\end{array}$ & 600.000 & $(639.000)$ & 15.000 \\
\hline 14 & Aumento de 2\% da disponibilidade nas usinas 1 e 2 & 445.000 & $(473.925)$ & 11.125 \\
\hline & TOTAL & $\mathbf{2 . 4 4 5 . 0 0 0}$ & $\mathbf{9 . 9 5 6 . 0 7 5}$ & $\mathbf{6 1 . 1 2 5}$ \\
\hline
\end{tabular}

Obs.: os números positivos representam acréscimo na produção do referido produto, em relação ao cenário base, e os negativos, de redução. 
Verifica-se nestas informações, a presença do pressuposto de que, qualquer incremento de produção no início da cadeia, se reverte em um aumento de produto final (neste caso, Pelotas, Pellet-feed e Pellet-Screening), proporcional no final do processo produtivo, não levando em consideração as capacidades, e variabilidades dos processos subseqüentes.

\subsubsection{Simulação individual de cada projeto da lista 1}

Conforme apresentado no capítulo 5, "Modelagem conceitual do problema e apresentação do método proposto", neste passo, não será avaliado como cada área ou departamento encontrou ou avaliou o efeito daquele projeto no sistema produtivo.

De posse de todas as informações apresentadas anteriormente, as seguintes premissas foram utilizadas:

- para facilitar a avaliação do comportamento dos processos, todas as curvas representativas do processo produtivo de cada etapa foram ajustadas e inseridas no simulador como curvas normal de probabilidade;

- utilizando-se a mesma situação inicial, tanto na simulação quanto na otimização, criou-se dois cenários base, um para cada modelo para servir como parâmetro de comparação quando aplicado os projetos durante a execução do método;

- a diminuição da variabilidade é traduzida no modelo de simulação como a redução do desvio padrão das curvas de probabilidade que representam o comportamento dos processos;

- a disponibilidade é avaliada na simulação como a própria redução da probabilidade de parada dos recursos do sistema. Não é de interesse avaliar se as restrições foram causadas por paradas programadas ou não;

- a capacidade é ajustada no modelo, aumentando ou diminuindo o nível de truncamento ou corte do sorteio aleatório da produção, mais o efeito de seu desvio padrão, ambos contemplados na curva de probabilidade;

- a produção pode ser analisada no simulador, alterando os valores da média da curva de probabilidade e/ou aumentando a capacidade do referido processo; 
- o investimento total previsto para cada empreendimento foi desdobrado em 3 períodos: no primeiro período: estudo e planejamento e nos outros dois: execução. Cada um representa proporcionalmente 20, 60 e $20 \%$ do total a ser investido em cada projeto.

Com estas premissas, a avaliação deste conjunto de projetos, após a simulação, deu-se da seguinte forma: alterou-se a variável principal, de acordo com o objetivo do empreendimento e mantiveram-se todas as outras informações restantes iguais ao cenário base e, deste modo, encontrou-se o efeito individual de cada projeto no sistema produtivo global.

Tanto estes resultados da simulação como as informações originais dos projetos são ilustrativos, mas tentam representar a visão local (restrita) de cada área proponente.

Assim sendo, há um pressuposto em cada projeto, que qualquer incremento gerado no início do processo representa um acréscimo proporcional no final do sistema produtivo.

O trabalho de elaboração das informações de um projeto de investimento de longo prazo é composto por um elenco de dados que necessitam ser tratados de maneira ordenada.

Portanto, além das informações de efeito destes projetos no processo produtivo global, as áreas informam o investimento previsto para a realização de cada um destes empreendimentos.

Estas informações são apresentadas, a seguir, na Tabela 8.3.

Tabela 8.3 - Investimento previsto para a implantação dos projetos originais

\begin{tabular}{|r|l|r|}
\hline \multicolumn{2}{|c|}{ Lista 1 - Projetos Originais } & \multicolumn{1}{|c|}{ MOEDA $^{\mathbf{1 9}}$} \\
\hline 1 & Aumento de 20\% produção na mina & 63.000 .000 \\
\hline 2 & Aumento de 10\% produção no beneficiamento 1 & 40.000 .000 \\
\hline 3 & Aumento de 2\% da disponibilidade no beneficiamento 1 & 10.000 .000 \\
\hline 4 & Redução de 20\% da variabilidade na produção do beneficiamento 1 & 8.500 .000 \\
\hline 5 & Aumento de 10\% no bombeamento de concentrado & 40.000 .000 \\
\hline 6 & Redução de 1\% na disponibilidade do mineroduto & 6.400 .000 \\
\hline 7 & Redução de 10\% da variabilidade do bombeamento & 4.200 .000 \\
\hline 8 & Aumento de 10\% no bombeamento de concentrado - Complexo Germano & 120.000 .000 \\
\hline 9 & Aumento de 10\% na capacidade da filtragem 1 e 2 & 40.000 .000 \\
\hline 10 & Aumento de 5\% na disponibilidade da filtragem 1 e 2 & 50.000 .000 \\
\hline
\end{tabular}

\footnotetext{
${ }^{19}$ Valor do capital a ser investido no projeto.
} 


\begin{tabular}{|l|l|r|}
\hline \multicolumn{2}{|c|}{ Lista 1 - Projetos Originais } & \multicolumn{1}{|c|}{ MOEDA $^{\mathbf{2 0}}$} \\
\hline 11 & Redução de 10\% da variabilidade da produção da filtragem 1 e 2 & 35.000 .000 \\
\hline 12 & Aumento de 10\% na capacidade das usinas 1 e 2 & 120.000 .000 \\
\hline 13 & Redução de 10\% da variabilidade da produção das usinas 1 e 2 & 50.000 .000 \\
\hline 14 & Aumento de 2\% da disponibilidade nas usinas 1 e 2 & 40.000 .000 \\
\hline
\end{tabular}

\subsection{PASSO 03 - ATENDE ÀS REGRAS DO NEGÓCIO?}

Neste passo, para cada empreendimento da carteira de projetos, cria-se, após a simulação, a lista 2 , com todos os efeitos globais de cada uma destas iniciativas.

Esta lista mostra a diferença entre a aplicação dos projetos no modelo de simulação e o cenário base inicial. Isto é, o efeito que cada empreendimento causa no sistema produtivo atual. Este efeito é o que posteriormente será utilizado para o cálculo de viabilidade econômico-financeira do projeto.

Tabela 8.4 - Efeitos individuais dos projetos no processo produtivo pós simulação

\begin{tabular}{|r|l|r|r|r|}
\hline \multicolumn{2}{|l|}{ Lista 2 - Efeitos individuais } & \multicolumn{2}{c|}{ Efeito no Processo Produtivo [tms] } \\
\cline { 3 - 5 } \multicolumn{2}{|l|}{} & \multicolumn{1}{c|}{ Pelotas } & \multicolumn{1}{c|}{$\begin{array}{c}\text { Pellet- } \\
\text { feed }\end{array}$} & \multicolumn{1}{c|}{$\begin{array}{c}\text { Pellet- } \\
\text { screening }\end{array}$} \\
\hline 1 & Aumento de 20\% produção na mina & \multicolumn{1}{c|}{-} & - \\
\hline 2 & Aumento de 10\% produção no beneficiamento 1 & 309.488 & $(17.095)$ & 7.737 \\
\hline 3 & Aumento de 2\% da disponibilidade no beneficiamento 1 & 253.020 & $(11.633)$ & 6.325 \\
\hline & $\begin{array}{l}\text { Redução de 20\% da variabilidade na produção do } \\
\text { beneficiamento 1 }\end{array}$ & 13.419 & 299 & 335 \\
\hline 5 & Aumento de 10\% no bombeamento de concentrado & $(61.796)$ & 29.914 & $(1.545)$ \\
\hline 6 & Redução de 1\% na disponibilidade do mineroduto & $(64.464)$ & 35.809 & $(1.612)$ \\
\hline 7 & Redução de 10\% da variabilidade do bombeamento & $(11.417)$ & 2.707 & $(285)$ \\
\hline & $\begin{array}{l}\text { Aumento de 10\% no bombeamento de concentrado - } \\
\text { Complexo Germano }\end{array}$ & 1.016 .464 & 47.669 & 25.412 \\
\hline 9 & Aumento de 10\% na capacidade da filtragem 1 e 2 & $(989.749)$ & 198.276 & $(24.744)$ \\
\hline 10 & Aumento de 5\% na disponibilidade da filtragem 1 e 2 & 669.369 & 111.297 & 16.734 \\
\hline & $\begin{array}{l}\text { Redução de 10\% da variabilidade da produção da } \\
\text { filtragem 1 e 2 }\end{array}$ & 18.945 & $(3.650)$ & \\
\hline 12 & Aumento de 10\% na capacidade das usinas 1 e 2 & 498.553 & $(136.272)$ & 12.464 \\
\hline & $\begin{array}{l}\text { Redução de 10\% da variabilidade da produção das } \\
\text { usinas 1 e 2 }\end{array}$ & 1.634 & $(1.836)$ & \\
\hline 14 & Aumento de 2\% da disponibilidade nas usinas 1 e 2 & 225.445 & $(98.270)$ & 5.636 \\
\hline \multicolumn{2}{|l|}{ TOTAL } & $\mathbf{1 . 8 7 8 . 9 1 1}$ & $\mathbf{1 5 7 . 2 1 5}$ & $\mathbf{4 6 . 9 7 2}$ \\
\hline
\end{tabular}

\footnotetext{
${ }^{20}$ Valor do capital a ser investido no projeto.
} 
Os projetos números: 5, 6, 7, e 9, mostrados na Tabela 8.4, apresentaram, após a simulação, uma redução no desempenho do processo, isto é, reduziram a produção de pelotas. Por conseguinte, como a regra do negócio é excluir projetos que reduzam a produção de pelotas, eles foram eliminados (classificados como inviáveis) do processo, antes mesmo de uma avaliação econômico-financeira.

É importante destacar que, neste caso, como o negócio da empresa é produção de pelotas, existe um pressuposto que qualquer projeto que reduza a produção deste tipo de produto seja classificado como inviável.

Este ponto merece atenção, pois, isto não quer dizer necessariamente, que esta é uma opção boa para se melhorar o desempenho empresarial, porque dependerá da situação prevista de mercado, na qual esta empresa está inserida. Nesta dissertação, este princípio serve como um exemplo para o emprego de regras do negócio, além de uma oportunidade de aprendizagem.

\subsection{PASSO 04 - AVALIAÇÃO ECONÔMICO-FINANCEIRA DOS PROJETOS}

A análise de projetos é desenvolvida através de critérios de avaliação que têm como objetivo mensurar a viabilidade econômico-financeira de investimentos de capital que possuam característica básica de retorno de longo prazo. Analisá-los significa avaliar a agregação de valor para a empresa.

Vale lembrar que, como as projeções de resultados de longo prazo possuem um grau de incerteza expressivo, primeiro, em função do tempo e, segundo, pelas variações dos dados projetados, como conseqüência do nível de conhecimento do investimento, torna-se significativamente importante a compensação da metodologia de orçamentação e de avaliação, em todas as suas nuances, para que se tenha um grau de confiabilidade que satisfaça, adequadamente, os objetivos do analista.

Neste passo todos os projetos da lista 2, exceto os que foram eliminados no passo anterior são avaliados pelos indicadores:

- eficiência: que será representado pela razão entre o VPL do investimento sobre o CAPEX ${ }^{21}$ ("Capital Expendured" - capital empregado);

\footnotetext{
${ }^{21}$ CAPEX - é uma sigla derivada da expressão em ingês de "capital expenditure", isto é, investimento de capital, que significa o capital utilizado para adquirir ou melhorar a vida útil dos recursos de uma empresa.
} 
- TIR: é uma sigla representativa da taxa interna de retorno de um fluxo de caixa; é a taxa de desconto que faz seu valor presente líquido ser igual a zero. Quando superior ao custo de capital investido, o projeto é viável. (PUCCINI, 2001)

- "Payback": é o período de tempo necessário para recuperação do investimento inicial, a partir das entradas de caixa. (GITMAN, 1997)

\subsection{PASSO 05 - O PROJETO É VIÁVEL?}

Neste passo, será verificado se os projetos ainda continuam viáveis, após a simulação, isto é, se ainda apresentam viabilidade econômico-financeira, ou atendem às regras do negócio estipuladas pela empresa.

$\mathrm{Na}$ Tabela 8.5, são apresentados todos os projetos originais da lista 1 e da lista 2, juntamente com os indicadores de viabilidade que foram utilizados no passo anterior.

Tabela 8.5 - Avaliação econômico-financeira dos projetos

\begin{tabular}{|c|c|c|c|c|c|}
\hline & Projetos & & $\begin{array}{c}\text { Eficiência } \\
\text { (VPL / } \\
\text { CAPEX) }\end{array}$ & TIR & Payback \\
\hline & \multirow{2}{*}{ Aumento de $20 \%$ produção na mina } & Lista 1 & $88,2 \%$ & 0,47 & 2,56 \\
\hline & & Lista 2 & $-90,4 \%$ & - & - \\
\hline \multirow{2}{*}{2} & \multirow{2}{*}{ Aumento de $10 \%$ produção no beneficiamento 1} & Lista 1 & $666,7 \%$ & 0,96 & 2,56 \\
\hline & & Lista 2 & $104,8 \%$ & 0,33 & 3,36 \\
\hline \multirow{2}{*}{3} & \multirow{2}{*}{ Aumento de $2 \%$ da disponibilidade no beneficiamento 1} & Lista 1 & $466,9 \%$ & 0,79 & 2,40 \\
\hline & & Lista 2 & $544,7 \%$ & 0,86 & 2,47 \\
\hline \multirow{2}{*}{4} & \multirow{2}{*}{$\begin{array}{l}\text { Redução de } 20 \% \text { da variabilidade na produção do } \\
\text { beneficiamento } 1\end{array}$} & Lista 1 & $564,7 \%$ & 0,88 & 2,49 \\
\hline & & Lista 2 & $-46,2 \%$ & $(0,08)$ & - \\
\hline \multirow{2}{*}{8} & \multirow{2}{*}{$\begin{array}{l}\text { Aumento de } 10 \% \text { no bombeamento de concentrado - } \\
\text { Complexo Germano }\end{array}$} & Lista 1 & $130,4 \%$ & 0,37 & 3,54 \\
\hline & & Lista 2 & $136,7 \%$ & 0,38 & 3,59 \\
\hline \multirow{2}{*}{10} & \multirow{2}{*}{ Aumento de $5 \%$ na disponibilidade da filtragem 1 e 2} & Lista 1 & $204,1 \%$ & 0,48 & 3,89 \\
\hline & & Lista 2 & $292,1 \%$ & 0,60 & 2,14 \\
\hline \multirow{2}{*}{ X } & \multirow{2}{*}{$\begin{array}{l}\text { Redução de } 10 \% \text { da variabilidade da produção da } \\
\text { filtragem } 1 \text { e } 2\end{array}$} & Lista 1 & $342,5 \%$ & 0,66 & 2,23 \\
\hline & & Lista 2 & $-75,4 \%$ & - & - \\
\hline \multirow{2}{*}{12} & \multirow{2}{*}{ Aumento de $10 \%$ na capacidade das usinas 1 e 2} & Lista 1 & $15,8 \%$ & 0,13 & 4,05 \\
\hline & & Lista 2 & $1,5 \%$ & 0,09 & 5,59 \\
\hline \multirow{2}{*}{13} & \multirow{2}{*}{$\begin{array}{l}\text { Redução de } 10 \% \text { da variabilidade da produção das } \\
\text { usinas } 1 \text { e } 2\end{array}$} & Lista 1 & $18,8 \%$ & 0,14 & 4,12 \\
\hline & & Lista 2 & $-90,0 \%$ & - & - \\
\hline \multirow{2}{*}{14} & \multirow{2}{*}{ Aumento de $2 \%$ da disponibilidade nas usinas 1 e 2} & Lista 1 & $11,1 \%$ & 0,12 & 5,91 \\
\hline & & Lista 2 & $18,7 \%$ & 0,14 & 4,12 \\
\hline
\end{tabular}




\subsection{PASSO 06 -TABULAÇÃO DE TODOS OS PROJETOS EM UMA ÚNICA LISTA}

O que se observa na Tabela 8.5 é que os projetos: $1,4,11$ e 13, que eram economicamente viáveis, quando se utilizavam as informações originais de aumento de produção, com a visão local e mantendo-se o pressuposto de que qualquer incremento de produção local representasse um aumento de produção de produtos finais, são agora, após a simulação e nova avaliação econômico-financeira, inviáveis.

Desta forma, conforme pode ser observado na lista 3 (Tabela 8.6), apenas 6 dos 14 projetos (43\%) iniciais seguem para o modelo de otimização.

Tabela 8.6 - Projetos viáveis que alimentarão o modelo de otimização

\begin{tabular}{|c|c|c|c|c|c|}
\hline \multirow{2}{*}{\multicolumn{2}{|c|}{ fores }} & \multicolumn{3}{|c|}{$\begin{array}{c}\text { Efeito no Processo Produtivo } \\
\text { [tms] }\end{array}$} & \multirow{3}{*}{$\begin{array}{r}\begin{array}{c}\text { Moeda } \\
\times 10^{6}\end{array} \\
40,0\end{array}$} \\
\hline & & & $t-$ & elle & \\
\hline 2 & Aumento de $10 \%$ produção no beneficia & 309.488 & $(17.095)$ & 7.737 & \\
\hline 3 & $\begin{array}{l}\text { Aumento de } 2 \% \text { da disponibilidade no } \\
\text { beneficiamento } 1\end{array}$ & 20 & 33) & .325 & 10,0 \\
\hline 8 & $\begin{array}{l}\text { Aumento de } 10 \% \text { no bombeamento de } \\
\text { concentrado - Complexo Germano }\end{array}$ & 1.0 & 669 & 412 & 120,0 \\
\hline 10 & $\begin{array}{l}\text { Aumento de } 5 \% \text { na disponibilidade da filtragem } 1 \\
\text { e } 2\end{array}$ & 669.369 & 111.297 & 16.734 & 50,0 \\
\hline 12 & $\begin{array}{l}\text { Aumento de } 10 \% \text { na capacidade das usinas } 1 \mathrm{e} \\
2\end{array}$ & 553 & $(136.272)$ & 12.464 & 120,0 \\
\hline 14 & $\begin{array}{l}\text { Aumento de } 2 \% \text { da disponibilidade nas usinas } 1 \\
\text { e } 2\end{array}$ & 225.445 & $(98.270)$ & 5.636 & 40,0 \\
\hline & Total & 2.972 .339 & $(104.304)$ & 74.308 & 380,0 \\
\hline
\end{tabular}

\subsection{PASSO 07 - EXECUÇÃO DO MODELO DE OTIMIZAÇÃO}

Neste passo, a lista da Tabela 8.6 (lista 3), será inserida no modelo de otimização, em busca da melhor opção de alocação para a realização deste portfólio de projetos.

\footnotetext{
${ }^{22}$ Valor do capital a ser investido no projeto.
} 


\subsection{PASSO 08 - AGRUPAMENTO DOS EFEITOS DE TODOS OS PROJETOS SUGERIDOS PELA OTIMIZAÇÃO EM UM ÚNICO PROJETO}

A saída da otimização foi uma lista dos projetos escolhidos para serem executados. A tabela a seguir, apresenta a lista 4 com a seqüência dos investimentos sugerida por este modelo.

Observa-se que o projeto 12 não consta nesta lista, pois foi considerado inviável e a otimização decidiu não executá-lo.

Tabela 8.7 - Seqüência sugerida pelo modelo de otimização

\begin{tabular}{|r|l|}
\hline \multicolumn{2}{|c|}{ Lista 4} \\
\hline 2 & Aumento de $10 \%$ produção no beneficiamento 1 \\
\hline 3 & Aumento de $2 \%$ da disponibilidade no beneficiamento 1 \\
\hline 8 & Aumento de $10 \%$ no bombeamento de concentrado - Complexo Germano \\
\hline 10 & Aumento de $5 \%$ na disponibilidade da filtragem 1 e 2 \\
\hline 14 & Aumento de $2 \%$ da disponibilidade nas usinas 1 e 2 \\
\hline
\end{tabular}

Como se pode observar, a seqüência sugerida na lista 4 é idêntica a 3 (exceto pela ausência do projeto 12).

Neste caso, como os projetos são tão atrativos, o otimizador optou por adiantar, o quanto antes, iniciando todos os projetos no primeiro período, em busca de melhorar o valor da empresa.

Este conjunto de projetos da lista 4 apresentados na Tabela 8.7 mostrou um ganho de valor para a empresa em torno de $13 \%$.

Isto quer dizer que, se o processo produtivo fosse capaz, de forma cumulativa, isto é, somente acrescentando os resultados finais de cada empreendimento, sem os efeitos entre os projetos de tal lista (conforme Tabela 8.8), $\mathrm{e}$, ainda, se os efeitos planejados durante os períodos de estudo, planejamento e execução se concretizassem, este portfólio acrescentaria $13 \%$ no valor da empresa para o período de análise. 
Tabela 8.8 - Efeito cumulativo dos projetos baseado nas informações da lista 3

\begin{tabular}{|c|c|c|c|c|c|}
\hline \multicolumn{2}{|r|}{ Lista 4} & $\begin{array}{l}\text { Moeda\$ } \\
23 \times 10^{6}\end{array}$ & Pelotas & $\begin{array}{l}\text { Pellet- } \\
\text { feed }\end{array}$ & $\begin{array}{c}\text { Pellet- } \\
\text { screening }\end{array}$ \\
\hline 2 & Aumento de $10 \%$ produção no beneficiamento 1 & 40 & 309.488 & $(17.095)$ & 7.737 \\
\hline 3 & $\begin{array}{l}\text { Aumento de } 2 \% \text { da disponibilidade no } \\
\text { beneficiamento } 1\end{array}$ & 10 & 253.020 & $(11.633)$ & 6.325 \\
\hline 8 & $\begin{array}{l}\text { Aumento de } 10 \% \text { no bombeamento de } \\
\text { concentrado - Complexo Germano }\end{array}$ & 120 & 1.016 .464 & 47.669 & 25.412 \\
\hline 10 & $\begin{array}{l}\text { Aumento de } 5 \% \text { na disponibilidade da filtragem } 1 \\
\text { e } 2\end{array}$ & 50 & 669.369 & 111.297 & 16.734 \\
\hline 14 & $\begin{array}{l}\text { Aumento de } 2 \% \text { da disponibilidade nas usinas } 1 \\
\text { e } 2\end{array}$ & 40 & 225.445 & $(98.270)$ & 5.636 \\
\hline & TOTAL & 260 & 2.473 .786 & 31.968 & 61.844 \\
\hline \multicolumn{5}{|c|}{ Valor da empresa em relação ao cenário base da otimização } & $+13 \%$ \\
\hline
\end{tabular}

\subsection{PASSO 09 - EXECUÇÃO DA SIMULAÇÃO}

Neste passo, foi simulado e quantificado o efeito global de todos os projetos da lista 4, das Tabelas 8.7 e 8.8 .

\subsection{PASSO 10 - AVALIAÇÃO DO RESULTADO DA SIMULAÇÃO}

O efeito do conjunto de projetos ordenadamente sugeridos pela otimização no sistema global, isto é, as saídas da simulação da lista 4, são mostrados na tabela a seguir.

Tabela 8.9 - Resultado da simulação da lista 4

\begin{tabular}{|c|c|c|c|}
\hline Lista 4 & Pelotas & $\begin{array}{l}\text { Pellet- } \\
\text { feed }\end{array}$ & $\begin{array}{c}\text { Pellet- } \\
\text { screening }\end{array}$ \\
\hline \multicolumn{4}{|r|}{ e } \\
\hline \multicolumn{4}{|l|}{3 Aumento de $2 \%$ da disponibilidade no beneficiamento 1} \\
\hline \multicolumn{4}{|c|}{8 Aumento de $10 \%$ no bombeamento de concentrado - Complexo Germano } \\
\hline \multicolumn{4}{|l|}{10 Aumento de $5 \%$ na disponibilidade da filtragem 1 e 2} \\
\hline 14 Aumento de $2 \%$ da disponibilidade nas usinas 1 e 2 & & & \\
\hline TOTAL & 2.267 .720 & 29.305 & 56.692 \\
\hline
\end{tabular}

\footnotetext{
${ }^{23}$ Valor do capital a ser investido no projeto.
} 


\subsection{PASSO 11 - ATENDE OS CRITÉRIOS DE PARADA?}

A solução sugerida pela otimizador, tornou-se inviável após o teste via simulação do conjunto de projetos (como se fossem um único projeto somando-se todos os efeitos sobre o sistema produtivo) sugeridos e alocados pela otimização, não atendendo aos critérios de parada. A diferença de produção de pelotas, entre o resultado global da lista sugerida na saída do otimizador no $1^{\circ}$ ciclo $(2.473 .786 \mathrm{tms})$, e o novo cenário simulado (2.267.720 tms), apresentou uma diferença superior ao limite aceitável de $5 \%$.

\subsection{PASSO 12 - AJUSTE DOS CRITÉRIOS OU DAS PREMISSAS DOS PROJETOS}

Após uma avaliação do resultado da simulação, analisando o gargalo, constatou-se que o projeto de aumento de $10 \%$ na produção do beneficiamento (projeto 2) não refletia no potfólio de projetos da lista 4 , o aumento de produção de pelotas esperado e, quantificado, na lista 3 , pois, chegou-se à capacidade limite de transporte (gargalo).

Como algumas regras não foram obedecidas, e, como alguns aprendizados adiquiridos durante a evolução do método devem ser considerados, alguns parâmetros e regras/restrições devem ser ajustadas no modelo de otimização, como por exemplo:

- retirar o projeto 2 para o próximo ciclo;

- a diferença entre a lista sugerida na saída do otimizador e o novo cenário simulado não deve ser superior ao limite aceitável de $5 \%$;

- a não avaliação neste primeiro ciclo de captação de dinheiro de terceiros para a realização deste conjunto de projetos, e, a necessidade de cumprir com uma política agressiva de pagamento de dividendos, leva à necessidade de se considerar um aumento da restrição de limite mínimo de caixa. 


\subsection{NOVO CICLO}

Após os ajustes dos parâmetros necessários, como por exemplo, o aumento do limite mínimo de disponibilidade de caixa para a empresa, de forma a atender os investimentos e a política de pagamento de dividendos, reduzindo a disponibilidade de recursos para investimentos, por período, em torno de $25 \%$, a lista 5 será inserida no modelo de otimização, em busca de uma nova solução que atenda todos estes fatores já citados, conforme Tabela 8.10.

Tabela 8.10 - Lista de projetos que alimentarão o modelo de otimização $-2^{\circ}$ ciclo

\begin{tabular}{|c|c|c|c|c|c|}
\hline \multirow{2}{*}{\multicolumn{2}{|c|}{ Lista 5}} & \multicolumn{3}{|c|}{ Efeito na Produção [tms] } & \multirow{2}{*}{$\begin{array}{l}\text { Moeda } \$^{24} \\
\times 10^{3}\end{array}$} \\
\hline & & Pelotas & $\begin{array}{l}\text { Pellet- } \\
\text { feed }\end{array}$ & $\begin{array}{c}\text { Pellet- } \\
\text { screening }\end{array}$ & \\
\hline 3 & $\begin{array}{l}\text { Aumento de } 2 \% \text { da disponibilidade no } \\
\text { beneficiamento } 1\end{array}$ & 253.020 & (11.633) & 6.325 & 10 \\
\hline 8 & $\begin{array}{l}\text { Aumento de } 10 \% \text { no bombeamento de } \\
\text { concentrado - Complexo Germano }\end{array}$ & 1.016 .464 & 47.669 & 25.412 & 120 \\
\hline 10 & $\begin{array}{l}\text { Aumento de } 5 \% \text { na disponibilidade da } \\
\text { filtragem } 1 \text { e } 2\end{array}$ & 669.369 & 111.297 & 16.734 & 50 \\
\hline 14 & $\begin{array}{l}\text { Aumento de } 2 \% \text { da disponibilidade nas } \\
\text { usinas } 1 \text { e } 2\end{array}$ & 225.445 & (98.270) & 5.636 & 40 \\
\hline & Total & 2.164 .298 & 49.063 & 54.107 & 220 \\
\hline
\end{tabular}

O resultado do modelo de otimização é apresentado na tabela a seguir.

Tabela 8.11 - Resultados do modelo de otimização $-2^{\circ}$ ciclo

\begin{tabular}{|c|c|c|c|c|c|c|c|}
\hline \multirow{2}{*}{\multicolumn{2}{|c|}{ Lista 5}} & \multicolumn{6}{|c|}{ Moeda $\$ \times 10^{3}$} \\
\hline & & \multirow{2}{*}{\begin{tabular}{|r|} 
Total \\
10
\end{tabular}} & \multirow{2}{*}{$\begin{array}{r}\text { Período } 1 \\
2\end{array}$} & \multirow{2}{*}{$\begin{array}{r}\text { Período } 2 \\
6\end{array}$} & \multirow{2}{*}{\begin{tabular}{|r|} 
Período 3 \\
2
\end{tabular}} & \multirow{2}{*}{$\begin{array}{l}\text { Período } 4 \\
\text { Operando }\end{array}$} & \multirow{2}{*}{\begin{tabular}{|l} 
Período 5 \\
Operando
\end{tabular}} \\
\hline 3 & $\begin{array}{l}\text { Aumento de } 2 \% \text { da } \\
\text { disponibilidade no } \\
\text { beneficiamento } 1\end{array}$ & & & & & & \\
\hline 8 & $\begin{array}{l}\text { Aumento de } 10 \% \text { no } \\
\text { bombeamento de } \\
\text { concentrado - } \\
\text { Complexo Germano }\end{array}$ & 120 & 24 & 72 & 24 & Operando & Operando \\
\hline 10 & $\begin{array}{l}\text { Aumento de } 5 \% \text { na } \\
\text { disponibilidade da } \\
\text { filtragem } 1 \text { e } 2\end{array}$ & 50 & 10 & 30 & 10 & Operando & Operando \\
\hline 14 & $\begin{array}{l}\text { Aumento de } 2 \% \text { da } \\
\text { disponibilidade nas } \\
\text { usinas } 1 \text { e } 2\end{array}$ & 40 & - & 8 & 24 & 8 & Operando \\
\hline \multirow{2}{*}{\multicolumn{7}{|c|}{ 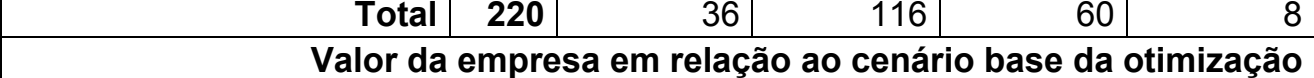 }} & \\
\hline & & & & & & & $+16 \%$ \\
\hline
\end{tabular}

\footnotetext{
${ }^{24}$ Valor do capital a ser investido no projeto.
} 
Como se pode observar, o modelo de otimização manteve todos os projetos da Tabela 8.10, mas desta vez, diferentemente do primeiro ciclo, em detrimento de uma política mais restritiva de disponibilidade de recursos por período, o otimizador optou por iniciar um projeto no segundo período, suavizando-o, pois, este detinha um elevado nível de investimento, dificultando o cumprimento das regras de negócio estabelecidas.

Além disso, vale ressalvar, que o valor da empresa em relação ao cenário base, neste segundo ciclo, foi superior ao primeiro. O que se pode concluir, é que, estava sendo utilizado recursos, realizando projetos, que ao ser inter-relacionados com os outros empreendimentos da carteira, ao invés de gerar valor, esta destruindo.

E para finalizar, quando a saída do otimizador ( $2^{\circ}$ ciclo) foi introduzida na simulação, o resultado obtido, conforme Tabela 8.12, está dentro do limite de $5 \%$ de variação na produção de pelotas tornando a solução viável.

Tabela 8.12 - Verificação de capacidade pelo simulador $-2^{\circ}$ ciclo

\begin{tabular}{|c|c|c|c|c|c|}
\hline \multirow{2}{*}{\multicolumn{2}{|c|}{ Lista 5}} & \multicolumn{3}{|c|}{$\begin{array}{l}\text { Efeito no Processo Produtivo } \\
{[\mathrm{tms}]-5^{\circ} \text { período }}\end{array}$} & \multirow{2}{*}{$\begin{array}{l}\text { Moeda } \$^{25} \\
\times 10^{3}\end{array}$} \\
\hline & & Pelotas & $\begin{array}{l}\text { Pellet- } \\
\text { feed }\end{array}$ & $\begin{array}{l}\text { Pellet- } \\
\text { screening }\end{array}$ & \\
\hline 3 & $\begin{array}{l}\text { Aumento de } 2 \% \text { da disponibilidade no } \\
\text { beneficiamento } 1\end{array}$ & & & & 10 \\
\hline 8 & $\begin{array}{l}\text { Aumento de } 10 \% \text { no bombeamento de } \\
\text { concentrado - Complexo Germano }\end{array}$ & & & & 120 \\
\hline 10 & $\begin{array}{l}\text { Aumento de } 5 \% \text { na disponibilidade da } \\
\text { filtragem } 1 \text { e } 2\end{array}$ & & & & 50 \\
\hline 14 & $\begin{array}{l}\text { Aumento de } 2 \% \text { da disponibilidade nas } \\
\text { usinas } 1 \text { e } 2\end{array}$ & & & & 40 \\
\hline & Total & 2.201 .669 & 28.451 & 55.041 & 220 \\
\hline
\end{tabular}

Para melhorar o entendimento das etapas deste processo, na tabela a seguir, são apresentados os detalhes dos principais passos desse método,mostrando o número de projetos por etapa, a descrição que caracteriza a fase, as tabelas do deste capítulo relacionadas, o efeito da aplicação dos projetos de acordo com o modelo (seja de otimização, seja de simulação.

\footnotetext{
${ }^{25}$ Valor do capital a ser investido no projeto.
} 
Tabela 8.13 - Resumo das tabelas que auxiliaram a descrição da aplicação do método

\begin{tabular}{|c|l|l|l|c|c|}
\hline $\begin{array}{c}\text { Número } \\
\text { de } \\
\text { Projetos }\end{array}$ & $\begin{array}{c}\text { Lista } \\
\text { referência }\end{array}$ & \multicolumn{1}{|c|}{ Descrição } & \multicolumn{1}{|c|}{ Tabela } & $\begin{array}{c}\text { Efeito } \\
\text { Pelotas } \\
\text { [tms] }\end{array}$ & $\begin{array}{c}\text { MOEDA } \\
\mathbf{x} \mathbf{1 0}^{\mathbf{2 7}}\end{array}$ \\
\hline 14 & Lista 01 & Antes Simulação Inicial & 8.2 e 8.3 & 2.445 .000 & 627.100 \\
\hline 14 & Lista 02 & Efeitos individuais & 8.4 & 1.878 .911 & 627.100 \\
\hline 10 & Lista 02 & $\begin{array}{l}\text { Cortes por redução na produção de } \\
\text { pelotas }\end{array}$ & & & \\
\hline 6 & Lista 02 & $\begin{array}{l}\text { Inviabilidade econômico-financeira } \\
\text { pós simulação }\end{array}$ & 8.5 & & \\
\hline 6 & Lista 03 & $\begin{array}{l}\text { Lista que alimenta o modelo de } \\
\text { otimização }\end{array}$ & 8.6 & 2.972 .339 & 380.000 \\
\hline 5 & Lista 04 & $\begin{array}{l}\text { Saída da otimização - 1o Ciclo } \\
\text { base lista 3 }\end{array}$ & 8.8 & 2.473 .786 & 260.000 \\
\hline 5 & Lista 04 & $\begin{array}{l}\text { Saída da otimização - 10 Ciclo } \\
\text { pós simulação }\end{array}$ & 8.9 & 2.267 .720 & 260.000 \\
\hline 4 & Lista 05 & $\begin{array}{l}\text { Lista que alimenta o modelo de } \\
\text { otimização - base lista 3 }\end{array}$ & 8.10 & 2.164 .298 & 220.000 \\
\hline 4 & Lista 05 & Saída da otimização - 2o Ciclo & 8.10 e 8.11 & 2.164 .298 & 220.000 \\
\hline 4 & Lista 05 & $\begin{array}{l}\text { Saída da otimizção - 2o Ciclo - Pós } \\
\text { simulação }\end{array}$ & 8.12 & 2.201 .670 & 220.000 \\
\hline
\end{tabular}

O gráfico a seguir apresenta a evolução na redução do investimento total em busca de resultados opercionais, como o aumento na produção de pelotas. Além disso, a diferença de esforço que seria necessário, em termos de número de projetos para atingir, praticamente, o mesmo ganho em termos de produção.

Gráfico 8.1 - Comportamento da expectativa de produção de pelotas e o nível de investimento durante a evolução do método

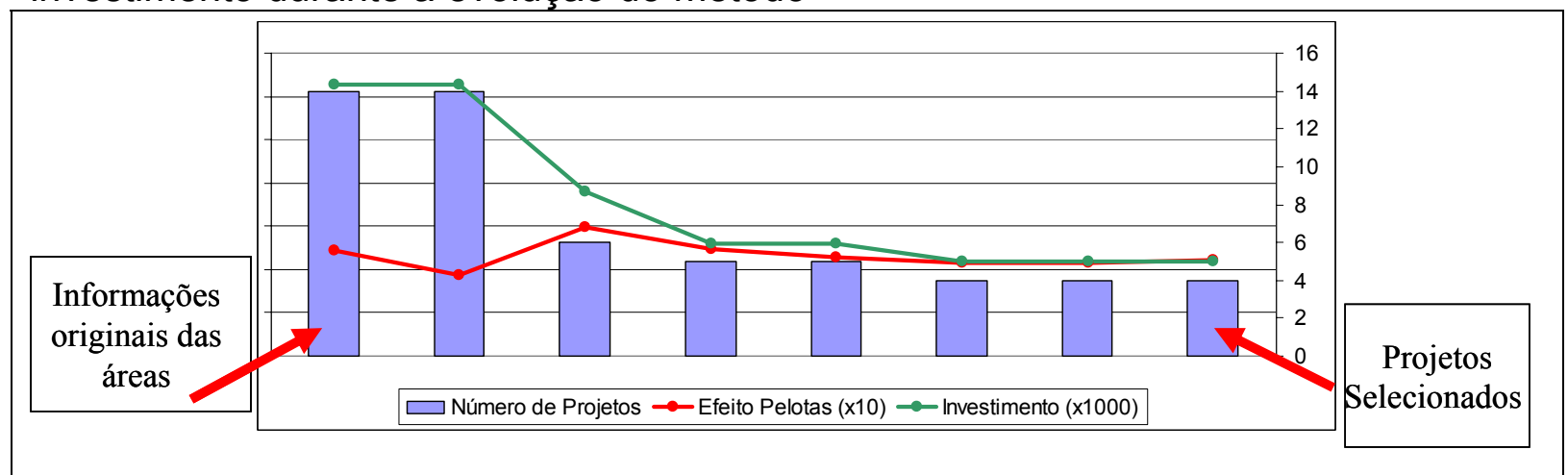

\footnotetext{
${ }^{26}$ Somatória dos efeitos individuais de produção de pelotas de cada projeto da referida lista

${ }^{27}$ Somatória do total de investimentos dos projetos da referida lista.
} 


\subsection{CONCLUSÕES DO CAPÍTULO}

Conforme supracitado, durante a fase conceitual do projeto (projetos originais), as informações só estão relacionadas a um tipo de produto, enquanto que, quando se utiliza o simulador, por ter uma visão sistêmica e mais realista do efeito do referido projeto no sistema global, é possível fazer uma comparação entre o cenário base e o cenário com o empreendimento, verificando as variações em todos os produtos.

Observa-se que, quando o projeto tem um olhar sistêmico sobre o processo como um todo, o seu resultado é muito mais significativo e robusto. Isto reforça a necessidade de uma análise bem fundamentada de resolução de problemas empresarias, através de uma política bem estruturada, baseada nos gargalos do processo produtivo global, e se possível, integrando alguns elos da cadeia de suprimentos.

Nos projetos que possuem apenas um olhar restrito de cada empreendimento, verifica-se uma grande discrepância dos efeitos no processo produtivo informado nos projetos originais, em comparação com as saídas do simulador.

Investimentos no início da cadeia produtiva, na Mina, por exemplo, sem uma ligação direta ou efeito mensurado durante o fluxo produtivo, até o final da cadeia, mostram-se inviáveis.

Em contrapartida, após atingir o limite da capacidade da linha produtiva, qualquer investimento na cadeia que não levar em consideração o aumento de capacidade da Mina, também se tornará inviável. Isto representa a real necessidade de uma análise do sistema produtivo, através de uma criteriosa avaliação de gargalos e/ou restrições de capacidade, anterior à criação de uma política de investimentos. Sendo assim, reforça-se a necessidade de equipes multidisciplinares para o planejamento de projetos e torna necessária uma avaliação por simulação, antes da tomada de decisão por otimização.

O que se pode observar, é que, aquele pressuposto de que qualquer incremento gerado no início do processo representa um acréscimo proporcional no final do sistema produtivo, foi invalidado após as diferenças encontradas nas saídas das simulações. 
Existe um fato muito importante a ser avaliado neste contexto: deve-se trabalhar ao máximo para que o detalhamento da otimização e, principalmente, da simulação retrate o sistema, para que os projetos possam ser avaliados, sem perda de qualidade para a tomada de decisão. Neste trabalho, devido as suas simplificações e a garantia da reserva das informações mais sensíveis da empresa em estudo, os resultados podem estar um pouco destorcidos, para aqueles que conhecem este processo produtivo em detalhes.

Com a utilização da simulação para a avaliação dos projetos no processo produtivo global, foi possível, neste exemplo, reduzir em $57 \%$ o número de projetos a serem avaliados pela otimização. O que poderia, sem este corte, além de gerar dificuldades de análise dos resultados, implicar em um maior tempo de execução do modelo decisório. 


\section{CONCLUSÕES E RECOMENDAÇÕES}

De acordo com o capítulo 1, "Introdução", este trabalho tem como foco o emprego de um método de tomada de decisão, no qual seja utilizada a simulaçãootimização durante o processo de planejamento negócio.

Como observado no capítulo 8, "Aplicação do método proposto", tal método foi aplicado durante o planejamento de negócio na cadeia produtiva de minérios de ferro da Samarco Mineração S/A, e, além de viável, este demonstrou um significante avanço na qualidade do processo decisório de escolha da melhor alternativa de investimentos para este plano.

Observou-se que o desdobramento em fases, garantido pelo método proposto, proporcionou uma convergência de fatores, desde o início da coleta das informações das áreas proponentes até o alinhamento às regras do negócio, simplificando e otimizando a tomada de decisão gerencial.

Os objetivos específicos foram alcançados, durante o desenvolvimento desta dissertação, proporcionando uma análise da evolução das técnicas de PO até o emprego conjunto de simulação-otimização, como mostrado no capítulo 4, "Simulação-otimização".

Ao avaliar e confrontar os conceitos de simulação, otimização e heurísticas no capítulo 3, "Revisão bibliográfica", observou-se que existe um caminho bem explorado de técnicas para resolução de problemas, no sentido de aprimorar, em cada uma destas áreas de conhecimento, separadamente, a busca da melhor solução, deixando de se aproveitar o potencial que se pode conseguir com a integração dessas técnicas.

Neste sentido, buscou-se, no capítulo 4, "Simulação-otimização", evidenciar que não era objetivo desta pesquisa analisar qual é a melhor ferramenta a ser empregada em cada problema que afeta os sistemas logísticos em geral.

Assim como muitos autores apresentados durante este trabalho afirmam que estas técnicas são complementares, a meta é estimular a discussão sobre o correto emprego destas ferramentas, utilizando-as em partes do processo decisório, em que suas características fundamentais podem ser potencializadas e bem exploradas, essenciais para garantir o sucesso da solução do problema ou da concretização da oportunidade. 
Os casos apresentados no capítulo 4, "Simulação-otimização", e o método proposto no capítulo 5, "Modelagem conceitual do problema e método proposto", reforçam que a aplicação destas técnicas, em conjunto, garante um melhor resultado do que se fossem utilizadas separadamente.

A construção dos dois modelos de simulação e de otimização, foi apresentada e discutida em detalhes, conforme objetivo desta dissertação, nos capítulos 6, "Descrição do modelo de otimização" e 7, "Descrição do modelo de simulação", o que possibilitou a aplicação do método proposto no capítulo 5, "Modelagem conceitual do problema e método proposto", tornando possível a avaliação dos benefícios que a integração destes dois modelos pode trazer.

\subsection{BENEFÍCIOS DO MÉTODO DE SIMULAÇÃO-OTIMIZAÇÃO}

1. Não se toma decisões sobre algum problema ou oportunidade, através de indagações como: "e se fosse feito isso...", e, sim, sobre, "qual é a melhor opção para...". Mas, para se chegar ao melhor resultado para o negócio, é necessária a correta avaliação do problema ou oportunidade e, neste cenário, os dois questionamentos são imprescindíveis. Então, nada mais enriquecedor, se as duas técnicas trabalhassem de forma colaborativa no processo decisório.

2. Garantia da aplicação dos métodos de PO nos problemas ou oportunidades na qual é possível potencializar seus resultados individuais, contribuindo para a melhor decisão global: a otimização para tomar a melhor decisão e a simulação para testar o comportamento do sistema.

3. Filtro de informações de acordo com o comportamento de sistema, melhorando a qualidade da informação de entrada e retirando possíveis ruídos ou erros que podem prejudicar o desempenho do próximo passo do método de tomada de decisão.

4. Formalização no mesmo método decisório das regras do negócio e do comportamento do sistema, contribuindo para um melhor desempenho do planejamento. 
5. Garantia de uma tomada de decisão sistêmica, levando em consideração as restrições do processo produtivo e as regras de decisão estratégicas.

6. Segurança de alinhamento entre os projetos do sistema produtivo global.

7. A simulação-otimização é uma abordagem poderosa, mas não substitui o analista. Ainda, consome um bom tempo de análise devido a variáveis qualitativas que podem ser incorporadas no processo e pode não garantir o ótimo.

\subsection{RECOMENDAÇÕES}

Conforme apresentado nesta dissertação, o processo de unificação das duas técnicas de PO para a resolução de problemas de sistemas logísticos podem ser aplicados em muitos sistemas produtivos e/ou decisórios que possuem características como:

- sistema produtivo complexo com alta variabilidade e/ou aleatoriedade;

- processo decisório possível de ser equacionado;

- processo decisório dentro de um sistema logístico complexo;

- uma realidade que integre um processo decisório a um planejamento de cenários, em que envolva uma alta variabilidade ou um processo logístico complexo.

Alguns sistemas que podem servir de exemplo no emprego deste método e de acordo com estas características mencionadas anteriormente são:

- Processos de integração de gestão de projetos e planejamento do negócio, isto se aplica a qualquer empresa de qualquer processo produtivo complexo.

- Processos que envolvem a variabilidade do processo produtivo e de seus deslocamentos e a tomada de decisão: para onde enviar os recursos de forma a minimizar custos? Isto se aplica nas indústrias como:

i. colheita de cana-de-açúcar;

ii. abastecimento de gás e/ou combustíveis;

iii. lavra de minérios;

iv. sistemas portuários. 


\subsection{CONCLUSÃO}

O método apresenta-se como uma ferramenta de grande utilidade para o processo de tomada de decisão na gestão de um sistema produtivo de minério de ferro, visto que integra as decisões empresariais às restrições operacionais, garantindo um melhor planejamento do negócio. Desta forma, ter acesso a essas ferramentas de auxílio ao estudo de soluções para otimizar os investimentos, tornase uma oportunidade vantajosa para a gestão estratégica desta organização. 


\section{REFERÊNCIAS}

ALVARENGA, G. B. Despacho ótimo de caminhões numa mineração de ferro utilizando algoritmo genético com processamento paralelo. 1997. 98 f. Mestrado em Engenharia Elétrica - Departamento de Engenharia Elétrica, Universidade Federal de Minas Gerais, Belo Horizonte, 1997.

ABREU, N. M. M., Um estudo algébrico e combinatório do problema quadrático de alocação segundo Koopmans e Beckmann. 1984. 153 f. Doutorado em Engenharia de Produção - Coordenação dos Programas de Pós-graduação de Engenharia, Universidade Federal do Rio de Janeiro, Rio de Janeiro, 1984.

ACKOFF, R. L.; SASIENI, M. W. Pesquisa operacional. Rio de Janeiro: Livros Técnicos e Científicos, 1977.

ANDRADE, E. L. Introdução à pesquisa operacional: métodos e modelos para a análise de decisão. 2.ed. Rio de Janeiro: Livros Técnicos e Científicos, 1998.

ARCAUTE, K. \& MODI, C. \& MORALES, D. \& OSPINA, M. C. Optimize foamvolute process through analysis of production constraints and performance variables using ARENA 5.0. El Paso, The University of Texas, 2001.

AZADIVAR, F.; LEE Y. H. Optimization of discrete variable stochastic systems by computer simulation. In: Mathematics and Computers in Simulation, v. 30, p. 331345, Sep.1988

AZADIVAR, F.; TALAVAGE, J. J. Optimization of stochastic simulation models. In: Mathematics and Computers in Simulation, v.22, p. 231-241, 1980.

AZADIVAR, F.; TOMPKINS, G. Simulation optimization with qualitative variables and structural model changes: a genetic algorithm approach. In: European Journal of Operational Research, v. 113, p. 169- 182, Feb. 1999.

AZADIVAR, F. Simulation optimization methodologies. In: Conference on Winter simulation: simulation, v.1, p.93-100, Phoenix, 1999.

BANKS, J.; GIBSON, R. Getting started in simulation modeling. In: Industrial Engineering Solutions, p. 34-39, Nov. 1996. 
BANKS, J. The future of simulation. In: The European Simulation Multiconference, Ghent, May 2000.

BARTON, R. F. A primer on simulation and gaming. New Jersey: Prentice-Hall: 1970. BELÉM, A. C. V.; DARÉ, C. T. Controle estatístico de processos. 2000. Apostila do curso oferecido pela Fundação de Desenvolvimento Gerencial, Belo Horizonte, 2000.

BILES, W.E.; SWAIN, J.J. Mathematical programming and the optimization of computer simulations. In: Mathematical Programming Study, v. 11, p. 189-207. 1979.

BILES, W.E. Design of computer simulation experiments: methodology and validation. In: Conference on Methodology and Validation, Orlando, v. 19, p. 7-12, Apr. 1987.

BORGES, F. J. L. Uma análise da cadeia logística de suprimento da indústria de petróleo utilizando a técnica de simulação: uma aplicação ao sistema bacia de Campos . 2000. 205 f. Mestrado em Engenharia de Produção, Universidade Federal de Santa Catarina, Florianópolis, 2000.

BOX, E. P. A new method for constrained optimization and a comparison with other methods. In: The Computer Journal, v. 8, p. 42-52, 1956.

BRASIL, H. G.; FREITAS, J. M.; MARTINS, V. I. O.; GONÇALVES, D. S.; RIBEIRO, E. Opções Reais: Conceitos e aplicações a empresas e negócios. $1^{a}$ ed., São Paulo: Saraiva, 2007.

BUSH, A.; BILES, W. E.; DePUY, G. W. Waterway, shipping, and ports: iterative optimization and simulation of barge traffic on an inland waterway. In: Winter Simulation Conference, New Orleans, p. 1751-1756, July 2003.

CARDOSO, J.; FARINES, J.; CURY, J. E. Controle de sistemas de manufatura. Apostilas do Curso de Pós-Graduação em Automação Industrial, em nível de especialização, Universidade Federal de Santa Catarina e Universidade de Caxias do Sul, set. 1994.

CASSANDRAS, C.G.; LAFORTUNE, S. Introduction to discrete event systems. $2^{\text {nd }}$ ed.; Boston: Kluwer Academic, 1999. 
CARVALHO, D. D. T. Metodologia de análise do desempenho da usina de concentração da Samarco Mineração S.A. baseada em simulação das operações. 2003. 103 f. Dissertação (Mestrado em Engenharia de Minas) Departamento de Engenharia de Minas, Universidade Federal de Ouro Preto, Ouro Preto, 2003.

CHAVES, A. P. Teoria e prática do tratamento de minérios. v. 1, 2. ed. São Paulo: Signus, 2002.

CHEN, H.; SCHMEISER, B. W. Stochastic root finding: problem definition, examples, and algorithms. In: Third Industrial Engineering Research Conference, p. 605610, Atlanta, May 1994.

CLAYTON, E. R.; WEBER, W.E.; TAYLOR B. W. A goal programming approach to the optimization of multiresponse simulation models. In: IIE Transactions, v.14, p. 282-287, Mar. 1982.

CVRD. Processo minério de ferro e pelotas. Disponível em: <http://www.cvrd.com.br/cvrd/cgi/cgilua.exe/sys/start.htm?sid=38>. Acesso em: 5 jul. 2005.

CRU. Monitor - Steel. London: CRU International, Monthy, Nov. 2006.

CREIT SUISSE. Iron Ore: Outlook. Americas: Credit Suisse, Monthy. Sep. 2006.

DAUGHERTY A. F.; TURNQUIST M. A. Simulation optimization using response surfaces based on spline approximations, In: Winter Simulation Conference, p. 183-193. Miami Beach, Jan. 1978.

DAVIS L. Handbook of genetic algorithms. Van Nostrand Reinhold, New York, 1991.

DIAS, E. G. C. S. Avaliação de impacto ambiental de projetos de mineração no Estado de São Paulo: a etapa de acompanhamento. 2001. 283 f. Tese (Doutorado em Engenharia de Minas) - Escola Politécnica, Universidade de São Paulo, São Paulo, 2001.

DÍAZ J. A.; e PÉREZ I. G.; Simulation and optimization of sugar cane transportation in harvest season. In: Winter Simulation Conference, v. 2, p. 1114-1117. Orlando, Dec. 2000. 
EHRLICH, P. J. Pesquisa operacional: curso introdutório. São Paulo: Atlas 1991.

FONSECA, C.M.; FLEMING, P.J. "Genetic algorithms for multi-objective optimization: Formulation, discussion, and generalization." In: International Conference on Genetic Algorithms, p. 416-423. 1993.

FORRESTER, J. W. Industrial dynamics. Portland: Productivity Press, 1961.

FREITAS, P. J. Introdução à modelagem e simulação de sistemas: com aplicações em ARENA. Florianópolis: Visual Books, 2001.

GAVIRA, M. O. Simulação computacional como uma ferramenta de aquisição de conhecimento. 2003. 150 f. Mestrado em Engenharia de Produção - Escola de Engenharia de São Carlos, Universidade de São Paulo, São Carlos, 2003.

GITMAN, Lawrence J. Princípios de Administração Financeira. São Paulo: Harbra. $7^{a}$ edição. 1997. pg 340.

GLOVER, F.; KELLY, J. P.; LAGUNA, M. New advances for wedding optimization and simulation. In: Winter Simulation Conference, p. 255-260. Phoenix, Dec. 1999.

GLYNN P. W. Optimization of stochastic systems. In: Winter Simulation Conference, p. 356-365. Washington, Dec. 1986.

Likelihood ratio gradient estimation: an overview, In: Winter Simulation Conference, p. 366-375. Atlanta, Dec. 1987.

GOLDBARG, M. C. Otimização combinatória e PL: modelos e algoritmos. São Paulo: Campus, 2000.

GOLDBERG, D. E. Genetic algorithms in search, optimization, and machine learning. Boston: Addison-Wesley Longman Publishing, 1989.

GRANGER, J.; KRISHNAMURTHY, A.; ROBINSON, S. M. Approximation and optimization for stochastic networks. In: Dynamic Stochastic Optimization, p. 6779. Berlin, Mar. 2002.

HILLIER, F.S.; LIEBERMAN, G. J. Introdução à pesquisa operacional. Ed. USP, São Paulo, 1988.

HO, Y. C.; CAO, X. R. Perturbation analysis of discrete event dynamic systems. New York: Kluwer Academic, Jun. 1991. 
HO, Y. C.; CAO, X. R.; CASSANDRAS, C. Infinitesimal and finite perturbation analysis of queuing networks, In: Automatica, v. 19, p. 439-445. April 1983.

HO, Y. C. Perturbation analysis methods for discrete event dynamical systems and simulations, In: Winter Simulation Conference, p. 170-173. Dallas, Nov. 1984.

HOLLOCKS, B. A well-kept secret? Simulation in manufacturing reviewed. In: Operational Research Insight, v.5, p. 12-17. Oct. 1992.

IRON ORE OUTLOOK - IOO. Sydney: AME Mineral Economics, September / 2005. Mensal. ISSN 1321-6775.

JACOBSON, S. H.; SCHRUBEN, L. W. Techniques for simulation response optimization. In: Operations Research Letters, v. 8, p. 1-9. Feb. 1989.

JACOBSON, S. H.; BUSS, A. H.; SCHRUBEN, L. W. Driving frequency selection for frequency domain simulation experiments. In: Operations Research, v. 39, p. 917924. Maryland, Nov. 1991.

JURAN, J. M. The quality control process. In: JURAN, J. M. Juran's quality control handbook. 5. ed. New York: McGraw-Hill, 1998. p. 4.1 - 4.29.

KIEFER, J.; WOLFOWITZ, J. Stochastic estimation of the maximum of a regression function, In: Annals of Mathematical Statistics, v. 23, p. 462-446. Sep.1952.

KIRPATRICK, S.; GELATT, C. D.; VECCHI, M. P. Optimization by simulated annealing. Science, v. 220, p. 671-680. May 1983.

KÖCHEL, P.; KUNZE, S.; NIELANDER, U. Optimal control of a distributed service system with moving resources: application to the fleet sizing and allocation problem. In: Int. J. Production Economics, v. 81-82, p. 443-459, Jan. 2003.

LAKATOS, E. M.; MARCONI, M. de A., Metodologia do trabalho científico. São Paulo: Atlas, 1991.

LAW, A. M.; KELTON, W. D. Simulation Modeling and Analysis. $3^{\text {rd }}$ ed. New York: McGraw-Hill, 2000.

MARUJO, L. G. O problema quadrático de alocação na logística interna de um centro de distribuição Mestrado em Tecnologia - Centro Federal de Educação Tecnológica Celso Suckow da Fonseca, Rio de Janeiro, 2003. 
MAXIMIANO, A. C. A. Administração de Projetos: como transformar idéias em resultados. 2a . Ed. São Paulo: Atlas, 2002.

LUZ, A. B. et al. Tratamento de minérios. 4. ed. Rio de Janeiro: Centro de Tecnologia Mineral - Ministério da Ciência e Tecnologia, 2004.

MARTINS, M. A. S.; PEREIRA, F. F.; SILVA, C. J. Balanço de massas automático na Mina de Carajás da Cia Vale do Rio Doce. In: SIMPÓSIO BRASILEIRO DE MINÉRIO DE FERRO, 33 e 34, 2003, Ouro Preto. Anais... Ouro Preto: ABM, 2003.

MELIÁN, B.; MORENO PÉREZ, J.A.; MORENO VEGA, J.M. Metaheuristics: A Global View. Inteligência Artificial. In: Revista Iberoamericana de Inteligência Artificial, v.2, n.19. p. 7-28. 2003.

METROPOLIS, N. et al. Equation of state calculation by fast computing machines. In: Journal of Chemical Physics, v. 21, p. 1087-1092. 1953

MOLLAGHASEMI, M.; EVANS, G.W.; BILES, W. E. An approach for optimizing multiple response simulation models, In: Annual Conference in Computers and Industrial Engineering, p. 201-203. 1991.

MORITO, S. et al. Simulation based constraint generation with applications to optimization of logistic system design. In: Winter Simulation Conference, v. 1, p. 531-536. Phoenix, Dec. 1999.

NELDER, J. A.; MEAD, R.. A simplex method for function minimization. In: Computer Journal, v. 7, p. 308-313. 1965.

NETO, L. Ribeiro C. Modelagem e simulação da cadeia produtiva do minério de ferro. São Paulo, Dez 2006

PEGDEN, C. D.; AHANNON, R. E.; SADOWSKI, R. P. Introduction to simulation using SIMAN. New York: McGraw-Hill, $2^{\text {nd }}$ ed. 1995.

PIDD, M. Computer simulation in management science. $4^{\text {th }}$ ed. Great Britain: John Wiley and Sons, 1998.

PINTO, L. R. Uso de técnicas de pesquisa operacional na otimização das operações de lavra. In: Anais do Congresso Brasileiro de Mineração, p. 53-61. Salvador, ago. 1995. 
PINSONNEAULT, A. and KRAEMER, K. L., Survey research methodology in management information systems: an assessment. Journal of Management Information Systems, v.10, n.2, Autumn, p.75-105, 1993.

PFIFFER, E. A. Adequação estratégica dos processos de fusões e aquisições no setor de minério de ferro - estudo de caso da Companhia Vale do Rio Doce. 2004. 228 f. Dissertação (Mestrado em Administração de Empresas) - Programa de Pós-Graduação em Administração de Empresas, Pontifícia Universidade Católica do Rio de Janeiro, Rio de Janeiro, 2004

PMBoK. Project Management of Body Knowledge. Belo Horizonte: PMI (Projest Management Institute) - MG, 2002.

PRADO, D. S. Teoria das filas e da simulação. Belo Horizonte: Desenvolvimento Gerencial, 1999.

PUCCINI, Abelardo de Lima. Matemática Financeira. São Paulo: Saraiva. $6^{\text {a }}$ edição. 2001. pg.125.

REEVES, C. R. Modern heuristic techniques for combinatorial problems. Oxford: Blackwell Scientific Publications, 1993.

REES, L. P.; CALYTON, E. R.; TAYLOR, B. W. Solving multiple response simulation models using response surface methodology within a lexicographic goal programming framework. In: IIE Transactions, v. 17, p. 47-57. 1985.

ROBBINS, H.; MONRO, S. A stochastic approximation method. In: Annals of Mathematical Statistics. v. 22, p. 400-407. Sep. 1951.

RODRIGUES, L. H. Developing an approach to help companies synchronise manufacturing. Tese de doutorado - Department of Management Sciences, University of Lancaster. 1994.

Simulação. Notas de Aula. PPGEP - UFRGS. Porto Alegre, 1995.

RUBINSTEIN, R. Y. Sensitivity analysis and performance extrapolation for computer simulation methods, In: Operations Research, v. 37: 1989.

SALIBY, E. Repensando a simulação: a amostragem descritiva. São Paulo: Atlas, 1989. 
SAMARCO. Operação. Disponível em: <http://www.samarco.com.br>. Acesso em: 2 jul. 2005.

SCHRIBER, T. J. An introduction to simulation using GPSS/H. New York: John Wiley \& Sons, 1974.

SCHRUBEN, L. W.; COGLIANO, V. J. Simulation sensitivity analysis: a frequency domain approach. In: Winter Simulation Conference, v. 2, p. 455-459. Atlanta: 1991.

SHANNON, R. E. Systems simulation: the art and science. New Jersey: PrenticeHall Inc., 1995.

SHAPIRO, A. Simulation based optimization. In: Winter Simulation Conference, p. 332-336. Coronado, Dec. 1996.

SILVA, E. L. e MENEZES, E. M., Metodologia de Pesquisa e Elaboração de Dissertação. Florianópolis : UFSC,PPGEP,LED, 113p, 2000.

SILVA NETO, A. B. Introdução aos algoritmos genéticos. In: I Oficina de Inteligência Artificial, Pelotas, 1997.

SMITH, D. E. Automatic optimum-seeking program for digital simulation. Simulation, v. 27, p. 27-32. July 1976.

SOARES, L. F. G. Modelagem e simulação discreta de sistemas. São Paulo: IMEUSP, 1990.

SURI, R. Infinitesimal perturbation analysis of discrete even dynamic systems: a general theory. In: IEEE Conference. San Antonio, Dec. 1983.

SZYMANKIEWCI, J.; MCDONALD, J.; TURNER, K. Solving business problems by simulation. London: McGraw-Hill Book Company, 1988.

THE ANNUAL OUTLOOK FOR IRON ORE (TAOFIO). London: CRU International Limited, 2004.

TELEB, R.; AZADIVAR, F. A methodology for solving multi-objective simulationoptimization problems. In: European Journal of Operational Research, v. 72, p. 135-145. Amsterdam, Jan. 1994. 
VAMANAN, M. et al. Integration of COTS "software" products ARENA and CPLEX for an inventory/logistics problem. In: Computers \& Operations Research, p. 533-547. Mar. 2000

VASHI, V. H.; BIENSTOCK, C. C.; MENTZER, J. T. The use of response surface methodology to optimize logistics simulation models. In: Journal of Business Logistics, v. 14. p. 197-225. 1995

WILSON, J. R. Future direction in response surface methodology for simulation. In: Winter Simulation Conference, p. 378-381. Atlanta, Dec. 1987. 


\section{APÊNDICE A - MODELO DE SIMULAÇÃO EM ARENA}

O modelo de simulação está dividido em 14 etapas, conforme considerado no modelo apresentado na Figura 7.4. Estas etapas são apresentadas, a seguir, e servirão de base para a construção do modelo em ARENA:

A - Mina da Samarco;

B - Minério de Fazendão;

C - Concentração 1;

D - Concentrado CVRD;

E - Beneficiamento 1;

F - Beneficiamento 2;

$G$ - Mineroduto 1;

$\mathrm{H}$ - Mineroduto 2;

I - Filtragem 1;

$\mathrm{J}$ - Filtragem 2;

$\mathrm{K}$ - Filtragem 3;

L - Usina de Pelotização 1;

M - Usina de Pelotização 2;

N - Usina de Pelotização 3.

\section{A - Mina da Samarco}

Para efeito de modelagem, as entidades da simulação seguem a seguinte regra:

Create $^{28}$ : "producao mina hora"

Entrada constante de 01 entidade por hora.

Para criar as produções, o simulador aplica à produção de minério e estéril os seguintes atributos:

$\checkmark$ prod_mina é a produção de minério (ROM) da minas da Samarco;

$\checkmark$ esteril é a geração de estéril decorrente da atividade de lavra.

\footnotetext{
${ }^{28}$ Create - é um módulo do aplicativo da simulação (ARENA) que tem a função de gerar as entidades.
} 
A partir de então, iniciam-se as seguintes regras e atribuições:

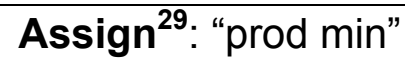

Atributo: prod_mina $\rightarrow^{30}$ norm(med_prod_mina, desv_prod_mina)

Atributo: esteril $\rightarrow$ prod_mina $x$ esteril_min

Onde:

$\checkmark$ norm é uma função do aplicativo que trata a expressão como uma função normal de probabilidade.

$\checkmark$ med_prod_mina é um dado de entrada e representa média da produção da mina.

$\checkmark$ desv_prod_mina é um dado de entrada e representa o desvio padrão da produção da mina.

$\checkmark$ esteril_min é um dado de entrada e representa a quantidade média de estéril gerada em função da produção da mina.

Após a escolha/sorteio da produção de ROM da Samarco e geração de estéril serão avaliadas algumas restrições, como:

1. Capacidade da pilha de ROM

2. Disponibilidade dos recursos da mina

3. Capacidade de transporte da mina (truncamento).

1.Decisão da capacidade da pilha de homogeneização

Decide $^{31}$ : "A pilha de ROM esta cheia?"

Decisão: total_pilha <= capacidade_pilha

Verdade: segue o fluxo de produção para Decide: "A disponibilidade da mina samarco atende?"

Falsa: segue para Assign: "Perda producao Pilha Cheia"

Assign: "Perda producao Pilha Cheia"

Variável: perda_mina_pilha_cheia $\rightarrow$ perda_mina_pilha_cheia + prod_mina

Variável: total_esteril $\rightarrow$ total_esteril + estéril

\footnotetext{
${ }^{29}$ Assign - é um módulo do aplicativo da simulação (ARENA) que tem a função de atribuir características às variáveis e aos atributos do modelo.

${ }^{30} \rightarrow$ este símbolo quer dizer: recebe como novo valor a expressão (ou variável) a seguir

${ }^{31}$ Decide - é um módulo do aplicativo da simulação (ARENA) que tem a função de as decisões ou alternativas de tomada de decisão.
} 
Onde,

$\checkmark$ total_pilha é uma variável que informa a quantidade atual de minério na pilha;

$\checkmark$ capacidade_pilha é um dado de entrada que informa a capacidade de armazenamento da pilha de ROM;

$\checkmark$ perda_mina_pilha_cheia é uma variável que informa a quantidade de produção perdida, devido à restrição por pilha cheia;

$\checkmark$ prod_mina é o atributo de produção de minério (ROM) da minas da Samarco.

$\checkmark$ total_esteril é uma variável que soma as quantidades de estéril gerada por período;

$\checkmark$ estéril é o atributo de geração de estéril decorrente da atividade de lavra.

2. Disponibilidade dos recursos da mina

Decide: "A disponibilidade da mina samarco atende?"

Percentagem verdadeira: disp_min_SAM

Verdade: segue para Decide: "Capacidade de transporte da mina_fator de truncamento".

Falsa: segue para Assign: "Contador prod perdida por disponibilidade mina Samarco".

Assign: "Contador prod perdida por disponibilidade mina Samarco"

Variável: prod_perdida $\rightarrow$ prod_perdida + prod_mina

Onde,

$\checkmark$ disp_min_SAM é um dado de entrada que informa a disponibilidade geral dos recursos da mina da Samarco até a pilha;

$\checkmark$ prod_perdida é uma variável que mede a quantidade de produção perdida por falta de disponibilidade dos recursos da mina;

$\checkmark$ prod_mina é o atributo de produção de minério (ROM) da minas da Samarco.

3. Capacidade de transporte da mina (truncamento).

Avalia se a produção da mina sorteada é superior à capacidade de transporte da mina. Se for verdade, ocorre o truncamento na capacidade total de transporte, senão, a produção segue normalmente. 
Decide: "Capacidade de transporte da mina_fator de truncamento"

Decisão: prod_mina > cap_mina

Verdade: segue para Assign: "Produção da Mina Samarco ajustado"

Falsa: segue para Assign: "Produção da Mina Samarco".

Assign: "Produção da Mina Samarco ajustado"

Variável: capacidade_perdida $\rightarrow$ capacidade_perdida + (prod_mina - cap_mina)

Atributo: prod_mina $\rightarrow$ cap_mina

Variável: prod_total $\rightarrow$ prod_total + prod_mina

Variável: total_esteril $\rightarrow$ total_esteril + esteril

Assign: "Produção da Mina Samarco"

Variável: prod_total $\rightarrow$ prod_total + prod_mina

Variável: total_esteril $\rightarrow$ total_esteril + esteril

Onde,

$\checkmark$ prod_mina é o atributo de produção de minério (ROM) da mina da Samarco.

$\checkmark$ cap_mina é um dado de entrada que representa a capacidade de transporte da mina da Samarco..

$\checkmark$ capacidade perdida é uma variável que informa a quantidade de produção perdida devido à restrição por capacidade;

$\checkmark$ prod_total é uma variável que informa a quantidade total de produção da mina da Samarco.

$\checkmark$ total_esteril é uma variável que soma as quantidades de estéril gerada por período;

$\checkmark$ estéril é o atributo de geração de estéril decorrente da atividade de lavra.

Após estas decisões, se resta somar a produção na pilha conforme:

Assign: "total pilha"

Variável: total_pilha $\rightarrow$ total_pilha + prod_mina

Onde, 
$\checkmark$ total_pilha é uma variável que informa a quantidade atual de minério na pilha (status atual);

$\checkmark$ prod_mina é o atributo de produção de minério (ROM) da mina da Samarco.

Todas estas decisões da produção da mina da Samarco podem ser melhor acompanhadas pela Figura A.1 a seguir.

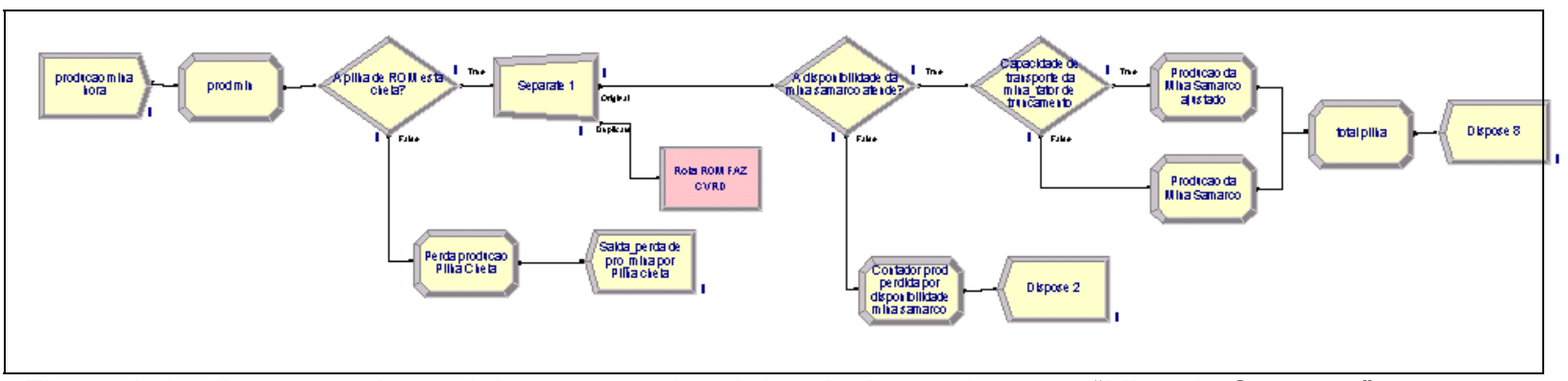

Figura A.1 - llustração do modelo computacional das decisões da etapa "Mina da Samarco"

\section{B - Minério de Fazendão}

Assign: "prod mina cvrd"

Atributo: prod_mina_cvrd $\rightarrow$ norm(med_prod_faz, desv_prod_faz)

Onde:

$\checkmark$ norm é uma função do aplicativo que trata a expressão como uma função normal de probabilidade;

$\checkmark$ prod_mina_cvrd é uma variável que representa a produção, ou melhor, o recebimento de ROM da CVRD;

$\checkmark$ med_prod_faz é um dado de entrada e representa a média da produção da mina de Fazendão.

$\checkmark$ desv_prod_cvrd é um dado de entrada e representa o desvio padrão da produção da mina de Fazendão.

Após a escolha/sorteio da produção de ROM de Fazendão, serão avaliadas algumas restrições, como:

1. Capacidade da pilha de ROM, que já foi avaliada anteriormente e é prérequisito para o início destas novas etapas relacionadas ao minério de Fazendão (CVRD).

2. Disponibilidade dos recursos da mina de Fazendão;

3. Capacidade de transporte da mina de Fazendão (truncamento). 
2. Disponibilidade dos recursos da mina de Fazendão

Decide: "A disponibilidade da mina cvrd atende?"

Percentagem verdadeira: disp_mina_cvrd

Verdade: segue para Decide: "Capacidade de transporte da mina cvrd_fator de truncamento".

Falsa: termina, entidade sai do sistema.

Onde,

$\checkmark$ disp_min_cvrd é um dado de entrada que informa a disponibilidade geral dos recursos da mina da CVRD (Fazendão) até a pilha;

3. Capacidade de transporte da mina de Fazendão (truncamento).

Avalia se a produção da mina de Fazendão sorteada é superior à capacidade de transporte. Se for verdade, ocorre o truncamento na capacidade total de transporte, senão, a produção segue normalmente.

Decide: "Capacidade de transporte da mina cvrd_fator de truncamento"

Atributo: prod_mina_cvrd > cap_faz

Verdade: segue para Assign: "Producao da Mina Fazendao ajustado"

Falsa: segue para Assign: "Producao da Mina Fazendão".

Assign: "Producao da Mina Fazendao ajustado"

Variável: capacidade_perdida_cvrd $\rightarrow$ capacidade_perdida_cvrd + (prod_mina_cvrd - (cap_minaxlimite_faz))

Atributo: prod_mina_cvrd $\rightarrow$ cap_mina $x$ limite_faz

Variável: prod_total_cvrd $\rightarrow$ prod_total_cvrd + prod_mina_cvrd

Assign: "Produção da Mina Fazendao"

Variável: prod_total_cvrd $\rightarrow$ prod_total_cvrd + prod_mina_cvrd

Onde,

$\checkmark$ prod_mina_cvrd é o atributo de produção de minério (ROM) da mina da CVRD (Fazendão); 
$\checkmark$ cap_mina é um dado de entrada que representa a capacidade de transporte da mina da Samarco;

$\checkmark$ capacidade_perdida_cvrd é uma variável que informa a quantidade de produção perdida devido à restrição por capacidade;

$\checkmark$ prod_total_cvrd é uma variável que informa a quantidade total de produção da mina da CVRD.

$\checkmark$ limite_faz é um dado de entrada que limita por contrato uma participação do ROM da CVRD no mix total de ROM da Samarco que alimentará o processo de beneficiamento.

Novamente, após estas decisões, se resta somar a produção de ROM Samarco e da CVRD na pilha minério, conforme a seguir:

Assign: "total pilha2"

Variável: total_pilha $\rightarrow$ total_pilha + prod_mina_cvrd

Onde,

$\checkmark$ total_pilha é uma variável que informa a quantidade atual de minério na pilha (status atual);

$\checkmark$ prod_mina é o atributo de produção de minério (ROM) da mina da Samarco.

Todas estas decisões da produção de Fazendão podem ser melhor acompanhadas pela Figura A.2 a seguir.

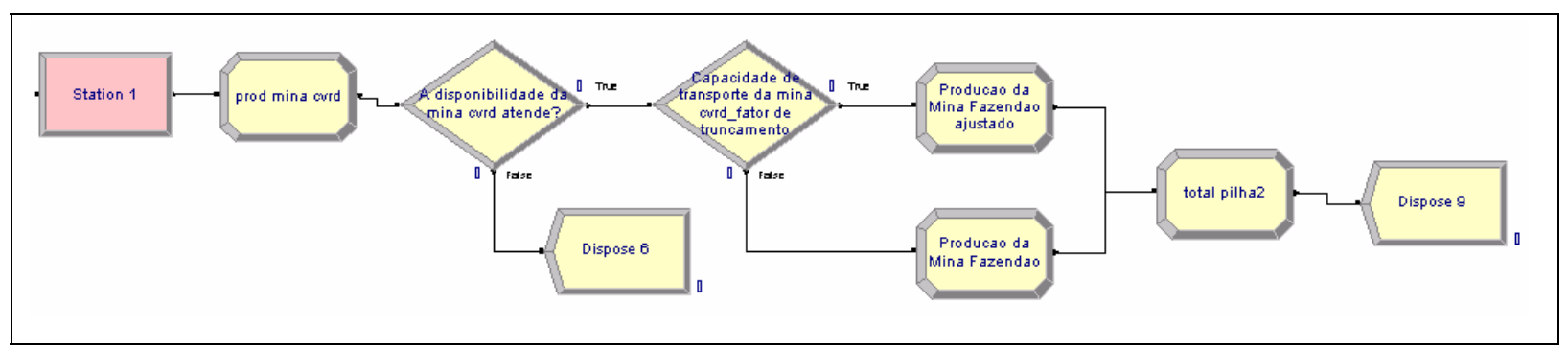

Figura A.2 - llustração do modelo computacional das decisões da etapa "Minério de Fazendão"

\section{C - Concentração 1}

Create: "producao beneficiamento1 hora"

Entrada constante de 01 entidade por hora. 
Para criar as produções, o simulador aplica à produção de concentrado o seguinte atributo:

$\checkmark$ prod_ben1 é a produção de concentrado do beneficiamento 1 .

A partir de então, iniciam-se as seguintes regras e atribuições:

Assign: "Producao concentracao 1"

Atributo: prod_ben1 $\rightarrow$ norm(med_prod_ben1,desv_prod_ben1)

Onde:

$\checkmark$ norm é uma função do aplicativo que trata a expressão como uma função normal de probabilidade.

$\checkmark$ med_prod_ben1 é um dado de entrada e representa a média da produção de concentrado na concentração 1.

$\checkmark$ desv_prod_ben1 é um dado de entrada e representa o desvio padrão da produção de concentrado na concentração 1 .

Após a escolha/sorteio da produção concentrado do beneficiamento 1, são avaliadas algumas restrições, como:

1. Verifica se o tanque de concentrado do beneficiamento 1 está cheio;

2. Verifica a disponibilidade dos recursos do beneficiamento 1 ;

3. Verifica a capacidade do beneficiamento 1 ;

4. Verifica se material na pilha de ROM.

1. Verifica se o tanque de concentrado do beneficiamento 1 está cheio

Decide: "verifica se o tanque1 está cheio"

Decisão: tanque1 <= cap_tanque1

Verdade: segue o fluxo de produção para Decide: "disponibilidade_ben1"

Falsa: segue para Assign: "perda de producao por tanque cheio"

Assign: "perda de producao por tanque cheio"

Variável: perda_prod_tk_cheio $\rightarrow$ perda_prod_tk_cheio + prod_ben1

Onde,

$\checkmark$ tanque1 é uma variável que indica o volume de concentrado do beneficiamento 1 no tanque de homogeneização 1 ; 
$\checkmark$ cap_tanque1 é um dado de entrada que determina a capacidade do tanque de homogeneização 1 do beneficiamento 1 ;

$\checkmark$ perda_prod_tk_cheio é uma variável que contabiliza a perda de produção devido à restrição de produção por tanque 1 estar cheio;

$\checkmark$ prod_ben1 é um atributo de produção de concentrado na concentração 1.

2. Verifica a disponibilidade dos recursos do beneficiamento 1

Decide: "disponibilidade_ben1"

Percentagem verdadeira: disp_ben1

Verdade: segue para Decide: "ver capacidade ben1".

Falsa: segue para Assign: "contabilizar prod perdida ben1".

Assign: "contabilizar prod perdida ben1"

Variável: prod_perdida_ben1 $\rightarrow$ prod_perdida_ben1 + prod_ben1

onde,

$\checkmark$ disp_ben1 é um dado de entrada que informa a disponibilidade geral dos recursos na concentração 1 ;

$\checkmark$ prod_perdida_ben1 é uma variável que mede a quantidade de produção perdida, por falta de disponibilidade dos recursos na concentração 1;

$\checkmark$ prod_ben1 é o atributo de produção de concentrado na concentração 1;

3. Verifica a capacidade do beneficiamento 1 (truncamento).

Avalia se a produção de concentrado na concentração 1 sorteada é superior à capacidade de processamento da concentração 1. Se for verdade, ocorre o truncamento na capacidade total, senão a produção segue normalmente.

Decide: "ver capacidade ben1"

Decisão: prod_ben1 > cap_ben1

Verdade: segue para Assign: "prod ben1 ajustado"

Falsa: segue para Decide: "ver se tem material na pilha".

Assign: "prod ben1 ajustado"

Variável: cap_perdida_ben1 $\rightarrow$ cap_perdida_ben1 + (prod_ben1 - cap_ben1)

Atributo: prod_ben1 $\rightarrow$ cap_ben1 
Onde,

$\checkmark$ prod_ben1 é o atributo de produção de concentrado na concentração 1.

$\checkmark$ cap_ben1 é um dado de entrada que determina a capacidade de processamento da concentração 1;

$\checkmark$ cap_perdida_ben1 é uma variável que informa a quantidade de produção perdida devido à restrição por capacidade (cap_ben1);

\section{Verifica-se material na pilha de ROM}

Avalia se existe material suficiente na pilha de ROM para a produção de concentrado do beneficiamento 1. Se houver, retira-se o material sorteado da pilha, senão, retira-se somente o que tem na pilha e o restante é contabilizado como perda.

Decide: "ver se tem material na pilha"

Decisão: total_pilha >= prod_ben1

Verdade: segue para Assign: "tira da pilha"

Falsa: segue para Assign: "zera pilha"

Assign: "tira da pilha"

Variável: total_pilha $\rightarrow$ total_pilha - prod_ben1

Atributo: prod_ben $1 \rightarrow$ prod_ben $1 \mathrm{x}$ rec_massa_ben1

Atributo: prod_rejeito $\rightarrow$ prod_rejeito + prod_ben1 x (1 - rec_massa_ben1)

Variável: total_rejeito $\rightarrow$ total_rejeito + prod_rejeito

Variável: total_prod_ben1 $\rightarrow$ total_prod_ben1 + prod_ben1

Assign: "zera pilha"

Atributo: prod_ben1 $\rightarrow$ total_pilha

Variável: total_pilha $\rightarrow 0$

Atributo: prod_ben1 $\rightarrow$ prod_ben1 $\mathrm{x}$ rec_massa_ben1

Atributo: prod_rejeito $\rightarrow$ prod_rejeito+ prod_ben1 x (1 - rec_massa_ben1)

Variável: total_rejeito $\rightarrow$ total_rejeito+prod_rejeito

Variável: total_prod_ben1 $\rightarrow$ total_prod_ben1 + prod_ben1

Onde, 
$\checkmark$ total_pilha é uma variável que informa a quantidade atual de minério na pilha (status atual);

$\checkmark$ prod_ben1 é o atributo de produção de concentrado na concentração 1;

$\checkmark$ rec_massa_ben1 é um dado de entrada que determina a partição ou rendimento do processo de concentração, isto representa a percentagem da recuperação metálica alimentada na concentração 1;

$\checkmark$ prod_rejeito é uma variável que quantifica a geração de rejeito na concentração 1;

$\checkmark$ total_rejeito é uma variável que contabiliza o total acumulado de rejeito gerado na concentração 1 .

$\checkmark$ total_prod_ben1 é uma variável que contabiliza o total acumulado de concentrado produzido na concentração 1 .

Todas estas decisões da Concentração 1 podem ser melhor acompanhadas pela Figura $A .3$ a seguir.

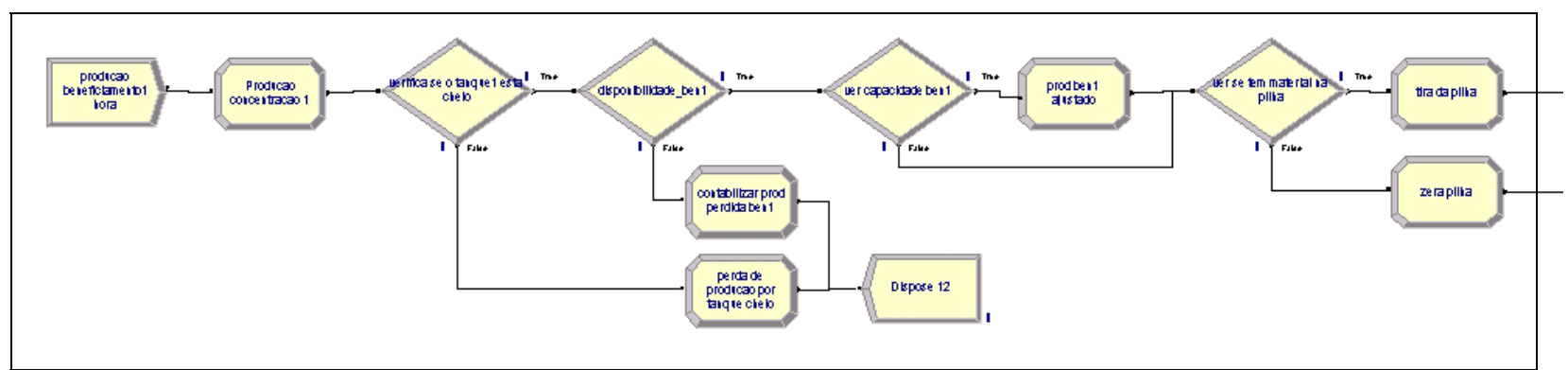

Figura A.3 - Ilustração do modelo computacional das decisões da etapa "Concentração 1"

\section{D - Concentrado CVRD}

Create: "producao concentrado cvrd hora"

Entrada constante de 01 entidade por hora.

Para criar as produções, o simulador aplica à produção de concentrado CVRD (ou, concentrado bombeado) o seguinte atributo:

$\checkmark$ bomb_conc_cvrd é o atributo que corresponde ao concentrado CVRD bombeado até a concentração do beneficiamento 1 .

A partir de então, iniciam-se as seguintes regras e atribuições: 
Assign: "Bombeado conc_cvrd"

Atributo: bomb_conc_cvrd $\rightarrow$ norm(med_bomb_conc_cvrd,desv_bomb_conc_cvrd)

Onde:

$\checkmark$ norm é uma função do aplicativo que trata a expressão como uma função normal de probabilidade.

$\checkmark$ med_bomb_conc_cvrd é um dado de entrada e representa a média do concentrado CVRD bombeado até a concentração do beneficiamento 1;

$\checkmark$ desv_bomb_conc_cvrd é um dado de entrada e representa o desvio padrão do concentrado CVRD bombeado até a concentração do beneficiamento 1;

$\checkmark$ bomb_conc_cvrd é um atributo que quantifica o concentrado CVRD bombeado.

Após a escolha/sorteio da quantidade de concentrado CVRD a ser bombeada ao beneficiamento 1 são avaliadas algumas restrições, como:

1 verifica se o tanque de concentrado do beneficiamento 1 está cheio;

2 verifica a disponibilidade dos recursos do mineroduto da CVRD;

3 verifica a capacidade do mineroduto da CVRD;

1. Verifica se o tanque de concentrado do beneficiamento 1 está cheio

Decide: "verifica se o tanque1 esta cheio"

Decisão: tanque $1<=$ cap_tanque 1

Verdade: segue o fluxo de produção para Decide: "disponibilidade_conc_cvrd"

Falsa: segue para Assign: "perda de producao por tanque cheio1"

Assign: "perda de producao por tanque cheio1"

Variável: perda_prod_tk_cheio $\rightarrow$ perda_prod_tk_cheio + bomb_conc_cvrd

Onde,

$\checkmark$ tanque1 é uma variável que indica o volume de concentrado do beneficiamento 1 no tanque de homogeneização 1;

$\checkmark$ cap_tanque1 é um dado de entrada que determina a capacidade do tanque de homogeneização 1 do beneficiamento 1 ; 
$\checkmark$ perda_prod_tk_cheio é uma variável que contabiliza a perda de produção, devido à restrição de produção por tanque 1 estar cheio;

$\checkmark$ bomb_conc_cvrd é um atributo que quantifica o concentrado CVRD bombeado.

2. Verifica a disponibilidade dos recursos do mineroduto da CVRD

Decide: "disponibilidade_ben1"

Percentagem verdadeira: disp_conc_cvrd

Verdade: segue para Decide: "ver capacidade Bomb_Conc_Cvrd".

Falsa: segue para Assign: "contabilizar conc cvrd perdida".

Assign: "contabilizar conc cvrd perdida"

Variável: prod_perdida_conc_cvrd $\rightarrow$ prod_perdida_conc_cvrd + bomb_conc_cvrd

Onde,

$\checkmark$ disp_conc_cvrd é um dado de entrada que informa a disponibilidade geral dos recursos do mineroduto da CVRD;

$\checkmark$ prod_perdida_conc_cvrd é uma variável que mede a quantidade de produção perdida por falta de disponibilidade dos recursos do mineroduto da CVRD;

$\checkmark$ bomb_conc_cvrd é um atributo que quantifica o concentrado CVRD bombeado.

3. Verifica a capacidade do mineroduto da CVRD (truncamento).

Avalia se o concentrado CRVD bombeado sorteado é superior à capacidade de transporte do mineroduto da CVRD. Se for verdade, ocorre o truncamento na capacidade total, senão, o bombeado sorteado segue normalmente.

Decide: "ver capacidade Bomb_Conc_Cvrd"

Decisão: bomb_conc_cvrd > cap_bomb_conc_cvrd

Verdade: segue para Assign: "Bomb conc cvrd ajustado"

Falsa: segue para Assign: "prod total_bomb_conc_cvrd". 


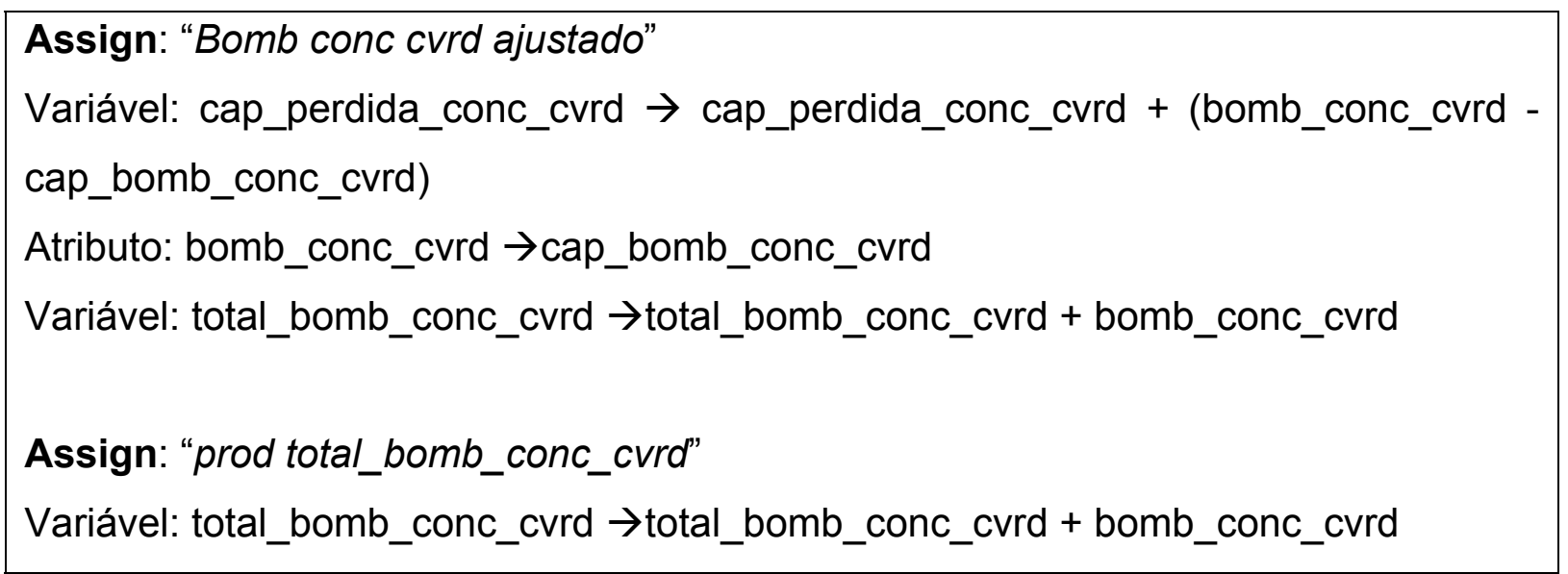

Onde,

$\checkmark$ bomb_conc_cvrd é um atributo que quantifica o concentrado CVRD bombeado.

$\checkmark$ cap_bomb_conc_cvrd é um dado de entrada que determina a capacidade de bombeamento de concentrado do mineroduto CVRD;

$\checkmark$ cap_perdida_conc_cvrd é uma variável que mede a quantidade de produção perdida por falta de capacidade do mineroduto da CVRD;

$\checkmark$ total_bomb_conc_cvrd é uma variável que contabiliza o total acumulado de concentrado CVRD bombeado.

Todas estas decisões do Concentrado CVRD podem ser melhor acompanhadas pela Figura A.4 a seguir.

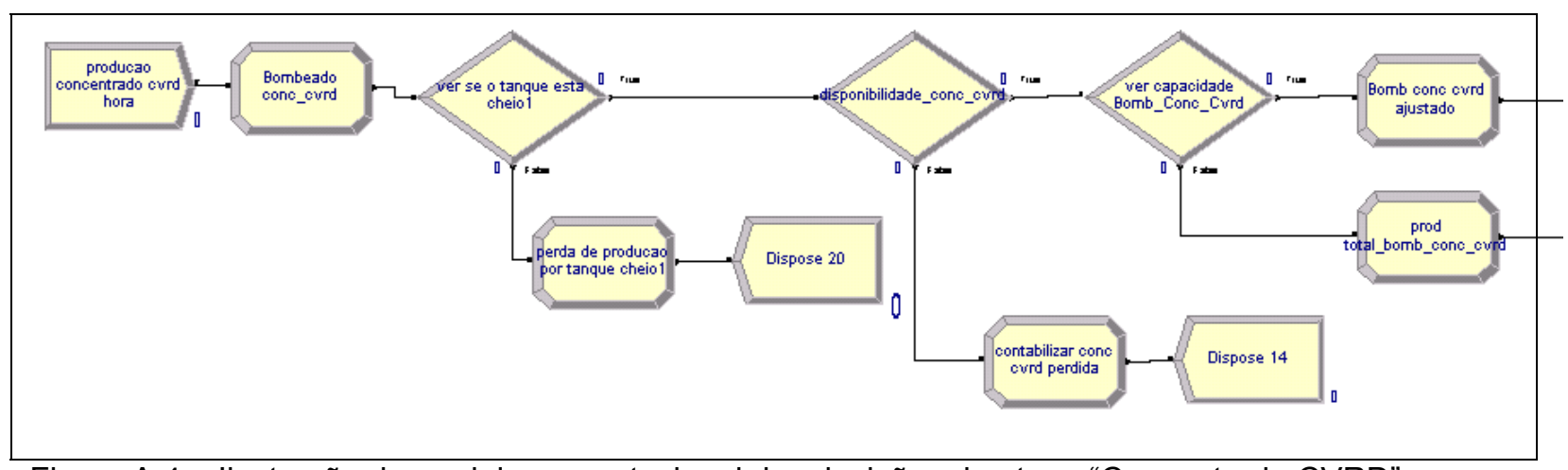

Figura A.4 - Ilustração do modelo computacional das decisões da etapa "Concentrado CVRD" 


\section{E - Beneficiamento 1}

Esta etapa do modelo representa apenas a junção do concentrado produzido na concentração 1 e o concentrado CVRD bombeado, dando origem ao concentrado total do processo de beneficiamento 1 , que será, a seguir, transportado pelo mineroduto 1.

\section{Assign: "Produção Total Beneficiamento 1"}

Variável: prod_total_ben $\rightarrow$ total_prod_ben $1+$ total_bomb_conc_cvrd

Variável: tanque $1 \rightarrow$ tanque1+ prod_ben1 + bomb_conc_cvrd

Onde,

$\checkmark$ prod_total_ben é uma variável que contabiliza o total acumulado de concentrado produzido no beneficiamento 1 ;

$\checkmark$ total_prod_ben1 é uma variável que contabiliza o total acumulado de concentrado produzido na concentração 1 ;

$\checkmark$ total_bomb_conc_cvrd é uma variável que contabiliza o total acumulado de concentrado CVRD bombeado.

$\checkmark$ tanque1 é uma variável que indica o volume de concentrado do beneficiamento 1 no tanque de homogeneização 1;

$\checkmark$ bomb_conc_cvrd é um atributo que quantifica o concentrado CVRD bombeado.

$\checkmark$ prod_ben1 é o atributo de produção de concentrado do beneficiamento 1;

\section{F - Beneficiamento 2}

Create: "producao beneficiamento2 hora"

Entrada constante de 01 entidade por hora.

Para criar as produções, o simulador aplica à produção de concentrado o seguinte atributo:

$\checkmark$ prod_ben2 que representa a produção de concentrado do beneficiamento 2 .

A partir de então, iniciam-se as seguintes regras e atribuições: 
Assign: "prod ben2"

Atributo: prod_ben2 $\rightarrow$ norm(med_prod_ben2,desv_prod_ben2)

Onde:

$\checkmark$ norm é uma função do aplicativo que trata a expressão como uma função normal de probabilidade;

$\checkmark$ med_prod_ben2 é um dado de entrada e representa a média da produção de concentrado na concentração 2 ;

$\checkmark$ desv_prod_ben2 é um dado de entrada e representa o desvio padrão da produção de concentrado na concentração 2 .

Após a escolha/sorteio da produção concentrado do beneficiamento 2, são avaliadas algumas restrições, como:

1 Verifica se o tanque de concentrado do beneficiamento 2 está cheio;

2 Verifica a disponibilidade dos recursos do beneficiamento 2;

3 Verifica a capacidade do beneficiamento 2;

4 Verifica se tem material na pilha de ROM.

1. Verifica se o tanque de concentrado do beneficiamento 2 está cheio

Decide: "verifica se o tanque2 esta cheio"

Decisão: tanque2 <= cap_tanque2

Verdade: segue o fluxo de produção para Decide: "disponibilidade_ben2"

Falsa: segue para Assign: "perda de producao por tanque2 cheio"

Assign: "perda de producao por tanque2 cheio"

Variável: perda_prod_tk2_cheio $\rightarrow$ perda_prod_tk2_cheio + prod_ben2

Onde,

$\checkmark$ tanque2 é uma variável que indica o volume de concentrado do beneficiamento 2 no tanque de homogeneização 2 ;

$\checkmark$ cap_tanque2 é um dado de entrada que determina a capacidade do tanque de homogeneização 2 do beneficiamento 2;

$\checkmark$ perda_prod_tk2_cheio é uma variável que contabiliza a perda de produção devido à restrição de produção por tanque 2 estar cheio; 
$\checkmark$ prod_ben2 é um atributo de produção de concentrado do beneficiamento 2 .

2. Verifica a disponibilidade dos recursos do beneficiamento 2

Decide: "disponibilidade_ben2"

Percentagem verdadeira: disp_ben2

Verdade: segue para Decide: "ver capacidade ben2".

Falsa: segue para Assign: "contabilizar prod perdida ben2".

Assign: "contabilizar prod perdida ben2"

Variável: prod_perdida_ben2 $\rightarrow$ prod_perdida_ben2 + prod_ben2

Onde,

$\checkmark$ disp_ben2 é um dado de entrada que informa a disponibilidade geral dos recursos do beneficiamento 2 ;

$\checkmark$ prod_perdida_ben2 é uma variável que mede a quantidade de produção perdida por falta de disponibilidade dos recursos do beneficiamento 2;

$\checkmark$ prod_ben2 é o atributo de produção de concentrado do beneficiamento 2;

3. Verifica a capacidade do beneficiamento 2 (truncamento).

Avalia se a produção de concentrado na concentração 1 sorteada é superior à capacidade de processamento da concentração 2. Se for verdade, ocorre o truncamento na capacidade total, senão a produção segue normalmente.

Decide: "ver capacidade ben2"

Atributo: prod_ben2 > cap_ben2

Verdade: segue para Assign: "prod ben2 ajustado"

Falsa: segue para Decide: "ver se tem material na pilha para ben2"

Assign: "prod ben2 ajustado"

Variável: cap_perdida_ben2 $\rightarrow$ cap_perdida_ben2 + (prod_ben2 - cap_ben2)

Atributo: prod_ben2 $\rightarrow$ cap_ben2 
Onde,

$\checkmark$ prod_ben2 é o atributo de produção de concentrado na concentração 2.

$\checkmark$ cap_ben2 é um dado de entrada que determina a capacidade de processamento do beneficiamento 2;

$\checkmark$ cap_perdida_ben2 é uma variável que informa a quantidade de produção perdida devido à restrição por capacidade (cap_ben2);

4. Verifica se tem material na pilha de ROM

Avalia se existe material suficiente na pilha de ROM para a produção de concentrado do beneficiamento 2. Se houver, retira-se o material sorteado da pilha, senão, retira-se somente o que tem na pilha e o restante é contabilizado como perda.

Decide: "ver se tem material na pilha para ben2"

Decisão: total_pilha >= prod_ben2

Verdade: segue para Assign: "tira da pilha p ben2"

Falsa: segue para Assign: "zera pilha por ben2"

Assign: "tira da pilha p ben2"

Variável: total_pilha $\rightarrow$ total_pilha - prod_ben2

Atributo: prod_ben2 $\rightarrow$ prod_ben2 $\times$ rec_massa_ben2

Atributo: prod_rejeito $\rightarrow$ prod_rejeito + prod_ben2 $\times(1-$ rec_massa_ben2)

Variável: total_rejeito $\rightarrow$ total_rejeito + prod_rejeito

Variável: total_prod_ben2 $\rightarrow$ total_prod_ben2 + prod_ben2

Assign: "zera pilha por ben2"

Atributo: prod_ben2 $\rightarrow$ total_pilha

Variável: total_pilha $\rightarrow 0$

Atributo: prod_ben2 $\rightarrow$ prod_ben2 $\mathrm{x}$ rec_massa_ben2

Atributo: prod_rejeito $\rightarrow$ prod_rejeito + prod_ben2 $\times(1$ - rec_massa_ben2)

Variável: total_rejeito $\rightarrow$ total_rejeito + prod_rejeito

Variável: total_prod_ben2 $\rightarrow$ total_prod_ben2 + prod_ben2

Onde, 
$\checkmark$ total_pilha é uma variável que informa a quantidade atual de minério na pilha;

$\checkmark$ prod_ben2 é o atributo de produção de concentrado do beneficiamento 2;

$\checkmark$ rec_massa_ben2 é um dado de entrada que determina a partição ou rendimento do processo de concentração. Isto representa a percentagem da recuperação metálica alimentada do beneficiamento 2;

$\checkmark$ prod_rejeito é uma variável que quantifica a geração de rejeito do beneficiamento 2;

$\checkmark$ total_rejeito é uma variável que contabiliza o total acumulado de rejeito gerado do beneficiamento 2 .

$\checkmark$ total_prod_ben2 é uma variável que contabiliza o total acumulado de concentrado produzido no beneficiamento 2 .

Todas estas decisões do Beneficiamento 2 podem ser melhor acompanhadas pela Figura A.5 a seguir.

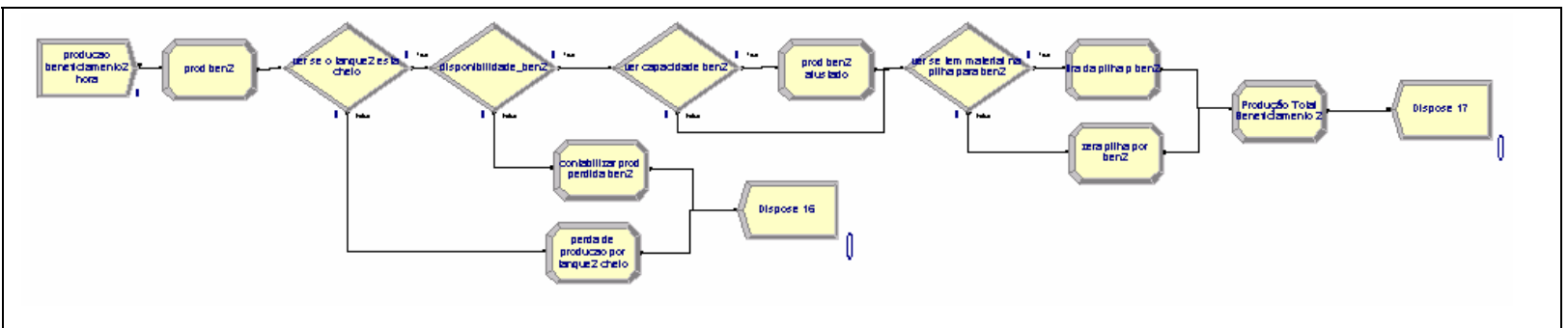

Figura A.5 - llustração do modelo computacional das decisões da etapa "Beneficiamento 2"

\section{G - Mineroduto 1}

Create: "bombeado mineroduto 1"

Entrada constante de 01 entidade por hora.

Para criar o bombeamento, o simulador aplica o seguinte atributo:

$\checkmark$ bomb1 que representa o bombeamento de concentrado do mineroduto 1 .

A partir de então, iniciam-se as seguintes regras e atribuições:

Assign: "bomb hora"

Atributo: bomb1 $\rightarrow$ norm(med_bomb1,desv_bomb1)

Onde: 
$\checkmark$ norm é uma função do aplicativo que trata a expressão como uma função normal de probabilidade.

$\checkmark$ med_bomb1 é um dado de entrada e representa a média de bombeamento de concentrado do mineroduto 1 .

$\checkmark$ desv_bomb1 é um dado de entrada e representa o desvio padrão de bombeamento de concentrado do mineroduto 1 .

Após a escolha/sorteio do bombeamento de concentrado para o mineroduto 1, são avaliadas algumas restrições, como:

1. Verifica a capacidade do mineroduto 1

2. Verifica a disponibilidade do mineroduto 1

3. Verifica se tem concentrado no tanque1.

1. Verifica a capacidade do mineroduto 1

Decide: "ver capacidade min1"

Decisão: bomb1 > cap_min1

Verdade: segue o fluxo de produção para Assign: "prod min1 ajustado"

Falsa: segue para Decide: "disponibilidade_mineroduto1"

Assign: "prod min1 ajustado"

Variável: cap_perdida_min1 $\rightarrow$ cap_perdida_min1 $+($ bomb1 - cap_min1)

Atributo: bomb1 $\rightarrow$ cap_min1

Onde,

$\checkmark$ bomb1 é uma variável que indica o volume de concentrado a ser bombeado pelo mineroduto 1 ;

$\checkmark$ cap_min1 é um dado de entrada que determina a capacidade de bombeamento do mineroduto 1 ;

$\checkmark$ cap_perdida_min1 é uma variável que contabiliza a perda bombeamento de concentrado, devido à restrição de capacidade;

2. Verifica a disponibilidade do mineroduto 1 
Decide: "disponibilidade_mineroduto1"

Percentagem verdadeira: disp_min1

Verdade: segue para Decide: "ver se tem material no tanque1".

Falsa: segue para Assign: "contabilizar prod perdida min1".

Assign: "contabilizar prod perdida min1"

Variável: prod_perdida_min1 $\rightarrow$ prod_perdida_min1 + bomb1

Onde,

$\checkmark$ disp_min1 é um dado de entrada que informa a disponibilidade do mineroduto 1 ;

$\checkmark$ prod_perdida_min1 é uma variável que mede a quantidade de produção perdida por falta de disponibilidade do mineroduto 1 ;

$\checkmark$ bomb1 é uma variável que indica o volume de concentrado a ser bombeado pelo mineroduto 1 ;

3. Verifica se tem concentrado no tanque1

Avalia se existe material suficiente no tanque 1 para o bombeamento de concentrado pelo mineroduto 1 . Se houver, retira-se o material sorteado do tanque, senão, retira-se somente o que tiver e o restante é contabilizado como perda.

Decide: "ver se tem material no tanque1"

Decisão: tanque1 >= bomb1

Verdade: segue para Assign: "tira do tanque1"

Falsa: segue para Assign: "zera tanque1"

Assign: "tira do tanque1"

Variável: tanque $1 \rightarrow$ tanque 1 - bomb1

Variável: total_bomb1 $\rightarrow$ total_bomb1 + bomb1

Assign: "zera tanque1"

Atributo: bomb1 $\rightarrow$ tanque1

Variável: tanque $1 \rightarrow 0$

Atributo: total_bomb1 $\rightarrow$ total_bomb1 + bomb1

Onde, 
$\checkmark$ tanque1 é uma variável que indica o volume de concentrado do beneficiamento 1 no tanque de homogeneização 1;

$\checkmark$ bomb1 é uma variável que indica o volume de concentrado a ser bombeado pelo mineroduto 1 ;

$\checkmark$ total_bomb1 é uma variável que contabiliza o total acumulado de concentrado bombeado pelo mineroduto 1 .

Todas estas decisões do Mineroduto 1 podem ser melhor acompanhadas pela Figura A.6 a seguir.

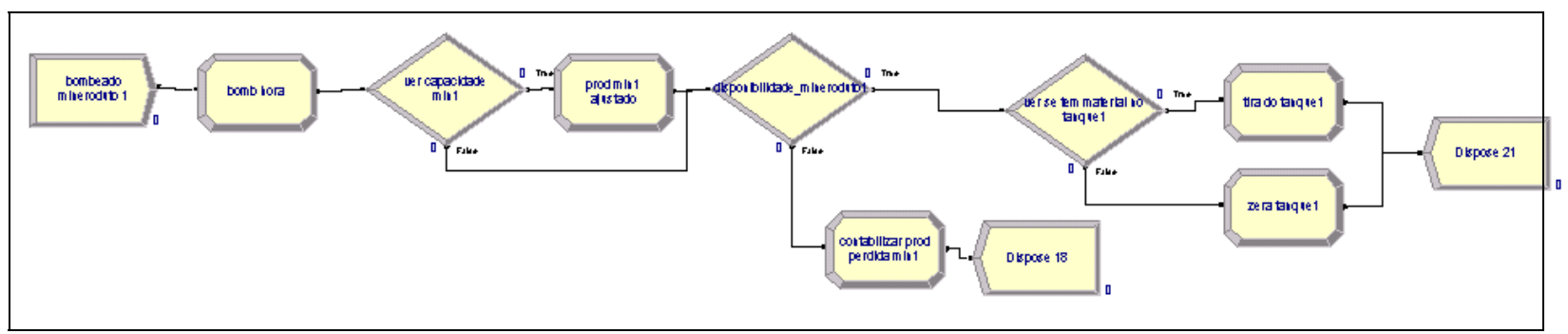

Figura A.6 - Ilustração do modelo computacional das decisões da etapa "Mineroduto 1"

\section{G - Mineroduto 2}

Create: "bombeado mineroduto 2"

Entrada constante de 01 entidade por hora.

Para criar o bombeamento, o simulador aplica o seguinte atributo:

$\checkmark$ bomb2 é o bombeamento do mineroduto 2 .

A partir de então, iniciam-se as seguintes regras e atribuições:

Assign: " bomb hora min2"

Atributo: bomb2 $\rightarrow$ norm(med_bomb2,desv_bomb2)

Onde:

$\checkmark$ norm é uma função do aplicativo que trata a expressão como uma função normal de probabilidade.

$\checkmark$ med_bomb2 é um dado de entrada e representa a média de bombeamento de concentrado do mineroduto 2.

$\checkmark$ desv_bomb2 é um dado de entrada e representa o desvio padrão de bombeamento de concentrado do mineroduto 2 . 
Após a escolha/sorteio do bombeamento de concentrado para o mineroduto 2, são avaliadas algumas restrições, como:

1. Verifica a capacidade do mineroduto 2

2. Verifica a disponibilidade do mineroduto 2

3. Verifica se tem concentrado no tanque2.

1. Verifica a capacidade do mineroduto 2

Decide: "ver capacidade min2"

Decisão: bomb2 > cap_min2

Verdade: segue o fluxo de produção para Assign: "prod min2 ajustado"

Falsa: segue para Decide: “disponibilidade_mineroduto2”

Assign: "prod min2 ajustado"

Variável: cap_perdida_min2 $\rightarrow$ cap_perdida_min2 + (bomb2 - cap_min2)

Atributo: bomb2 $\rightarrow$ cap_min2

Onde,

$\checkmark$ bomb2 é uma variável que indica o volume de concentrado a ser bombeado pelo mineroduto 2;

$\checkmark$ cap_min2 é um dado de entrada que determina a capacidade de bombeamento do mineroduto 2;

$\checkmark$ cap_perdida_min2 é uma variável que contabiliza a perda bombeamento de concentrado devido à restrição de capacidade;

2. Verifica a disponibilidade do mineroduto 2

Decide: "disponibilidade_mineroduto2"

Percentagem verdadeira: disp_min2

Verdade: segue para Decide: "ver se tem material no tanque2".

Falsa: segue para Assign: "contabilizar prod perdida min2".

Assign: "contabilizar prod perdida min2"

Variável: prod_perdida_min2 $\rightarrow$ prod_perdida_min2+bomb2 
Onde,

$\checkmark$ disp_min2 é um dado de entrada que informa a disponibilidade do mineroduto 2;

$\checkmark$ prod_perdida_min2 é uma variável que mede a quantidade de produção perdida por falta de disponibilidade do mineroduto 2;

$\checkmark$ bomb2 é uma variável que indica o volume de concentrado a ser bombeado pelo mineroduto 2;

3. Verifica se tem concentrado no tanque2

Avalia se existe material suficiente no tanque 2 para o bombeamento de concentrado pelo mineroduto 2 . Se houver, retira-se o material sorteado do tanque, senão, retira-se somente o que tiver e o restante é contabilizado como perda.

Decide: "ver se tem material no tanque2"

Decisão: tanque2 >= bomb2

Verdade: segue para Assign: "tira do tanque2"

Falsa: segue para Assign: "zera tanque2"

Assign: "tira do tanque2"

Variável: tanque2 $\rightarrow$ tanque2 - bomb2

Variável: total_bomb2 $\rightarrow$ total_bomb2 + bomb2

Assign: "zera tanque2"

Atributo: bomb2 $\rightarrow$ tanque2

Variável: tanque2 $\rightarrow 0$

Atributo: total_bomb2 $\rightarrow$ total_bomb2 + bomb2

Onde,

$\checkmark$ tanque2 é uma variável que indica o volume de concentrado do beneficiamento 2 no tanque de homogeneização 2;

$\checkmark$ bomb2 é uma variável que indica o volume de concentrado a ser bombeado pelo mineroduto 2 ;

$\checkmark$ total_bomb2 é uma variável que contabiliza o total acumulado de concentrado bombeado pelo mineroduto 2 . 
Todas estas decisões do Mineroduto 2 podem ser melhor acompanhadas pela Figura $A .7$ a seguir.

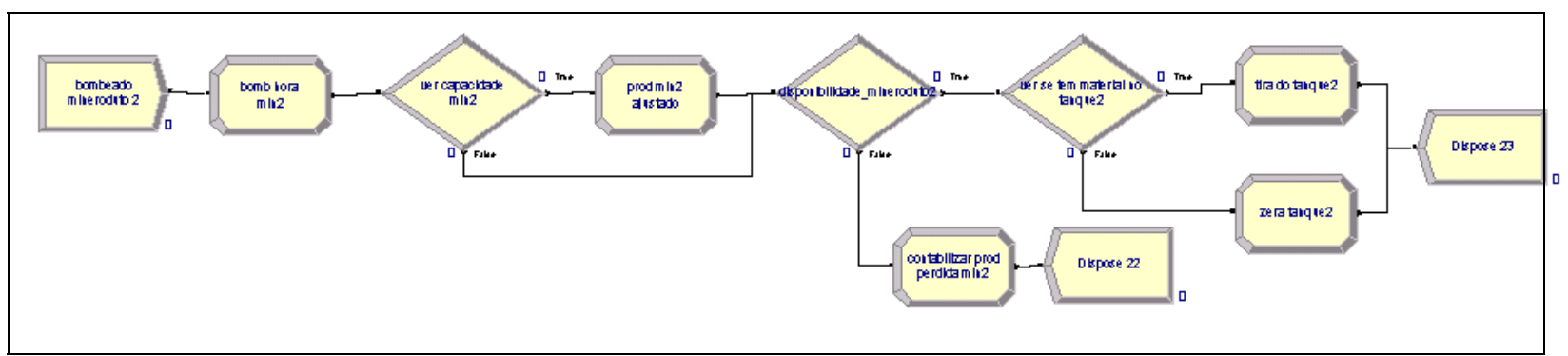

Figura A.7 - llustração do modelo computacional das decisões da etapa "Mineroduto 2"

\section{I - Filtragem 1}

Create: "producao filtragem1 hora"

Entrada constante de 01 entidade por hora.

Para criar a produção da filtragem, o simulador aplica o seguinte atributo:

$\checkmark$ prod_filtrag1 que representa a produção da filtragem 1

A partir de então, iniciam-se as seguintes regras e atribuições, tais como:

Assign: "prod filtrag1"

Atributo: prod_filtrag1 $\rightarrow$ norm(med_prod_filtrag1,desv_prod_filtrag1)

Onde:

$\checkmark$ norm é uma função do aplicativo que trata a expressão como uma função normal de probabilidade.

$\checkmark$ med_prod_filtrag1 é um dado de entrada e representa a média de produção da filtragem 1.

$\checkmark$ desv_prod_filtrag1 é um dado de entrada e representa o desvio padrão de produção da filtragem 1.

Após a escolha/sorteio da produção da filtragem, são avaliadas algumas restrições, como:

1. Verifica a capacidade da filtragem 1

2. Verifica a disponibilidade de matéria-prima para a filtragem 1 
3. Verifica se o silo de pellet-feed da filtragem 1 está cheio

4. Verifica a disponibilidade da filtragem 1.

1. Verifica a capacidade da filtragem 1

Decide: "ver capacidade filtrag1"

Decisão: prod_filtrag1 > cap_filtrag1

Verdade: segue o fluxo de produção para Assign: "prod filtrag1 ajustado"

Falsa: segue para Decide: "ver se tem material no tanque ubu por filtrag1"

Assign: "prod filtrag1 ajustado"

Variável: cap_perdida_filtrag1 $\rightarrow$ cap_perdida_filtrag1 + (prod_filtrag1 - cap_filtrag1)

Atributo: prod_filtrag1 $\rightarrow$ cap_filtrag1

Onde,

$\checkmark$ prod_filtrag1 é um atributo de produção da filtragem 1;

$\checkmark$ cap_filtrag1 é um dado de entrada que determina a capacidade de produção da filtragem 1;

$\checkmark$ cap_perdida_filtrag1 é uma variável que contabiliza a perda de produção da filtragem 1, devido à restrição de capacidade.

2. Verifica a disponibilidade de matéria-prima para a filtragem 1

Neste item, tem-se uma série de decisões a serem tomadas de forma a garantir o abastecimento da filtragem.

Além do próprio material bombeado pelo mineroduto, existem mais duas opções de abastecimento da filtragem.

A segunda seria retornar com material da Bacia de Polpa (onde, anteriormente alguma parte da produção pode ter sido desviada por problemas operacionais).

E a última, e uma pouco mais trabalhosa, seria o envio de pellet-feed do pátio de estocagem para a filtragem.

Decide: "ver se tem material no tanque ubu por filtrag1"

Decisão: tanque_ubu >= prod_filtrag1

Verdade: segue para Assign: "tira do tanque ubu por filtrag1". 
Falsa: segue para Assign: "zera tanque ubu por filtrag1".

Assign: "tira do tanque ubu por filtrag1"

Variável: tanque_ubu $\rightarrow$ tanque_ubu - prod_filtrag1

Variável: total_prod_filtrag1 $\rightarrow$ total_prod_filtrag1 + prod_filtrag1

Assign: "zera tanque ubu por filtrag1"

Variável: prod_filtrag1 $\rightarrow$ tanque_ubu

Variável: tanque_ubu $\rightarrow 0$

Variável: total_prod_filtrag1 $\rightarrow$ total_prod_filtrag1+prod_filtrag1

Decide: "ver se tem material na Bacia para filtrag1" Decisão: bacia_polpa >= prod_filtrag1

Verdade: segue para Assign: "tira bacia de polpa por filtrag1".

Falsa: segue para Assign: "zera Bacia Polpa por filtrag1".

Assign: "tira bacia de polpa por filtrag1"

Variável: bacia_polpa $\rightarrow$ bacia_polpa - prod_filtrag1

Variável: total_prod_filtrag1 $\rightarrow$ total_prod_filtrag1 + prod_filtrag1

Assign: "zera Bacia Polpa por filtrag1"

Variável: prod_filtrag1 $\rightarrow$ bacia_polpa

Variável: bacia_polpa $\rightarrow 0$

Variável: total_prod_filtrag1 $\rightarrow$ total_prod_filtrag1 + prod_filtrag1

Decide: "ver se tem material no Patio para filtrag1" Decisão: patio_pf $>=$ prod_filtrag1

Verdade: segue para Assign: "tira do patio pf por filtrag1".

Falsa: segue para Assign: "zera Patio PF por filtrag1".

Assign: "tira do patio pf por filtrag1"

Variável: patio_pf $\rightarrow$ patio_pf - prod_filtrag1

Variável: total_prod_filtrag1 $\rightarrow$ total_prod_filtrag1 + prod_filtrag1 
Assign: "zera Patio PF por filtrag1"

Variável: prod_filtrag1 $\rightarrow$ patio_pf

Variável: patio_pf $\rightarrow 0$

Variável: total_prod_filtrag1 $\rightarrow$ total_prod_filtrag1 + prod_filtrag1

Onde,

$\checkmark$ prod_filtrag1 é um atributo de produção da filtragem 1;

$\checkmark$ tanque_ubu é uma variável que indica o volume de concentrado em Ubu para as três unidades produtivas de filtragem;

$\checkmark$ total_prod_filtrag1 é uma variável que contabiliza o total acumulado de produção de pellet-feed da filtragem 1 ;

$\checkmark$ bacia_polpa é uma variável que indica o volume de concentrado na Bacia de Polpa em Ubu, que pode abastecer as unidades produtivas, caso seja necessário;

$\checkmark$ patio_pf é uma variável que indica o total de pellet-feed estocado no pátio, que pode tanto ser vendido como retornar à filtragem para produção de pelotas.

3. Verifica se o silo de pellet-feed da filtragem 1 está cheio

Decide: "ver se o tanque_pf1 esta cheio"

Decisão: cap_tanque_pf1 > tanque_pf1 + prod_filtrag1

Verdade: segue o fluxo de produção para Decide: "disponibilidade_filtrag1"

Falsa: segue para Assign: "envio de pellet-feed para o patio por filtrag1"

Assign: "envio de pellet-feed para o patio por filtrag1"

Variável: patio_pf $\rightarrow$ patio_pf + prod_filtrag1

Onde,

$\checkmark$ prod_filtrag1 é um atributo de produção da filtragem 1;

$\checkmark$ tanque_pf1 é uma variável que indica o volume de pellet-feed no silo de produto acabado, logo após a filtragem 1 , antes de abastecer a usina de pelotização 1; 
$\checkmark$ cap_tanque_pf1 é um dado de entrada que determina a capacidade do silo de produto acabado, logo após a filtragem 1, antes de abastecer a usina de pelotização 1.

$\checkmark$ patio_pf é uma variável que indica o total de pellet-feed estocado no pátio, que pode tanto ser vendido como retornar à filtragem para produção de pelotas.

4. Verifica a disponibilidade da filtragem 1

Decide: "disponibilidade_filtrag1"

Percentagem verdadeira $=$ disp_filtrag 1

Verdade: segue para Assign: "Produção Total Filtragem 1".

Falsa: segue para Assign: "contabilizar prod perdida filtrag1".

Assign: "Produção Total Filtragem 1"

Variável: tanque_pf1 $\rightarrow$ tanque_pf1+ prod_filtrag1

Assign: "contabilizar prod perdida filtrag1"

Variável: prod_perdida_filtrag1 $\rightarrow$ prod_perdida_filtrag1+prod_filtrag1

Onde,

$\checkmark$ disp_filtrag1 é um dado de entrada que informa a disponibilidade da filtragem 1 ;

$\checkmark$ prod_perdida_filtrag1 é uma variável que mede a quantidade de produção perdida, por falta de disponibilidade da filtragem 1;

$\checkmark$ prod_filtrag1 é um atributo de produção da filtragem 1;

$\checkmark$ tanque_pf1 é uma variável que indica o volume de pellet-feed no silo de produto acabado, logo após a filtragem 1 , antes de abastecer a usina de pelotização 1.

Todas estas decisões da Filtragem 1 podem ser melhor acompanhadas pela Figura A.8 a seguir. 


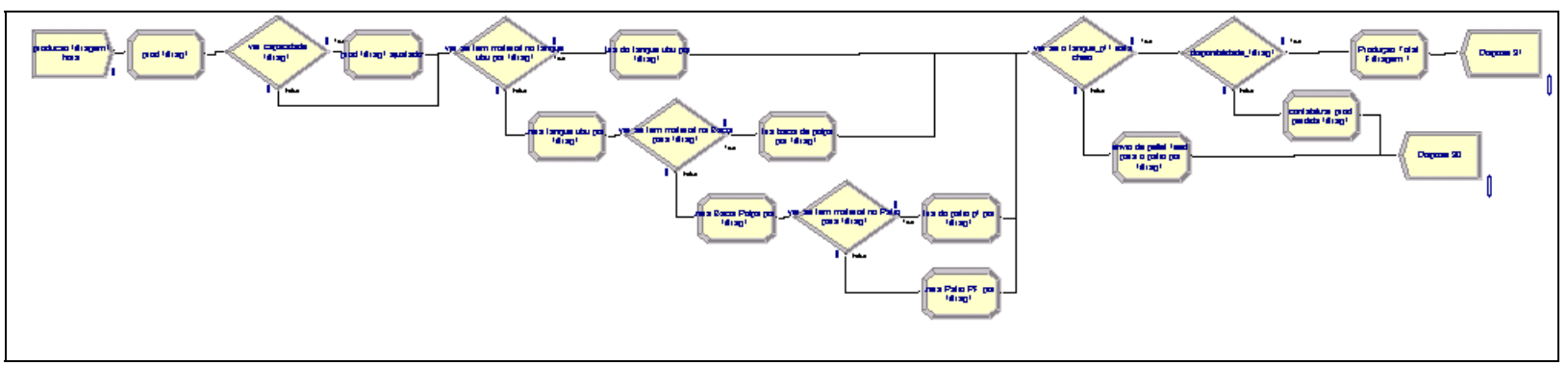

Figura A.8 - llustração do modelo computacional das decisões da etapa "Filtragem 1"

Não será necessário apresentar a modelagem conceitual da Filtragem 2 e 3, porque é exatamente igual à Filtragem 1. A diferença está nos valores de produtividade, capacidade e disponibilidade que são intrínsecos a cada unidade produtiva.

\section{L - Usina de Pelotização 1}

Create: "producao pelotizacao1 hora"

Entrada constante de 01 entidade por hora.

Para criar a produção da pelotização 1, o simulador aplica o seguinte atributo:

$\checkmark$ prod_pelotiz1 que representa a produção de pelotas da pelotização 1 .

A partir de então, iniciam-se as seguintes regras e atribuições, tais como:

Assign: "prod pelotiz1"

Atributo: prod_pelotiz1 $\rightarrow$ norm(med_prod_pelotiz1,desv_prod_pelotiz1)

Onde:

$\checkmark$ norm é uma função do aplicativo que trata a expressão como uma função normal de probabilidade.

$\checkmark$ med_prod_pelotiz1 é um dado de entrada e representa a média de produção da pelotização 1 .

$\checkmark$ desv_prod_pelotiz1 é um dado de entrada e representa o desvio padrão de produção da pelotização 1.

Após a escolha/sorteio da produção da pelotização 1, são avaliadas algumas restrições, como:

1. Verifica se tem capacidade de armazenagem no pátio de pelotas

2. Verifica a disponibilidade da pelotização 1 
3. Verifica a capacidade da pelotização 1

4. Verifica a disponibilidade de matéria-prima para a pelotização 1.

1. Verifica se tem capacidade de armazenagem no pátio de pelotas

Decide: "ver capacidade do patio de pelotas para pelotiz1"

Decisão: cap_patio_pelota > patio_pelota + prod_pelotiz1

Verdade: segue o fluxo de produção para Hold: "aguardo lugar patio para pelotiz1"

Falsa: segue para Decide: "disponibilidade_pelotiz1"

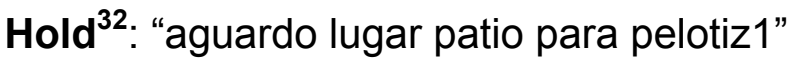

Condição: cap_patio_pelota > (patio_pelota + prod_pelotiz1)

Onde,

$\checkmark$ prod_pelotiz1 é um atributo de produção da pelotização 1;

$\checkmark$ cap_patio_pelota é um dado de entrada que determina a capacidade de armazenamento para pelotas;

$\checkmark$ pátio_pelota é uma variável que informa a quantidade atual de pelotas no pátio;

2. Verifica a disponibilidade da pelotização 1

Decide: "disponibilidade_pelotiz1"

Percentagem verdadeira: disp_pelotiz1

Verdade: segue para Decide: "ver capacidade pelotiz1".

Falsa: segue para Assign: "contabilizar prod perdida por falta de dispon pelotiz1".

Assign: "contabilizar prod perdida por falta de dispon pelotiz1"

Variável: prod_perdida_pelotiz1 $\rightarrow$ prod_perdida_pelotiz1 + prod_pelotiz1

Onde,

\footnotetext{
${ }^{32}$ Hold é um módulo do aplicativo da simulação (ARENA) que tem a função "segurar" as entidades até que seja satisfeita a condição informada.
} 
$\checkmark$ disp_pelotiz1 é um dado de entrada que informa a disponibilidade da pelotização 1;

$\checkmark$ prod_perdida_pelotiz1 é uma variável que mede a quantidade de produção perdida por falta de disponibilidade da pelotização 1 ;

$\checkmark$ prod_pelotiz1 é um atributo de produção da pelotização 1;

3. Verifica a capacidade da pelotização 1

\section{Decide: "ver capacidade pelotiz1"}

Decisão: prod_pelotiz1> cap_pelotiz1

Verdade: segue o fluxo de produção para Assign: "prod pelotiz1 ajustado"

Falsa: segue para Decide: "ver se tem material no tanque pf1 por pelotiz1"

Assign: "prod pelotiz1 ajustado"

Variável: cap_perdida_pelotiz1 $\rightarrow$ cap_perdida_pelotiz1 + (prod_pelotiz1 cap_pelotiz1)

Atributo: prod_pelotiz1 $\rightarrow$ cap_pelotiz1

Onde,

$\checkmark$ prod_pelotiz1 é um atributo de produção da pelotização 1;

$\checkmark$ cap_pelotiz1é um dado de entrada que determina a capacidade de produção da pelotização 1;

$\checkmark$ cap_perdida_pelotiz1é uma variável que contabiliza a perda de produção da pelotização 1 devido à restrição de capacidade;

4. Verifica a disponibilidade de matéria-prima para a pelotização 1

Decide: "ver se tem material no tanque pf1 por pelotiz1"

Decisão: tanque_pf1 >= prod_pelotiz1

Verdade: segue para Assign: "tira do tanque pf1 por pelotiz1".

Falsa: segue para Assign: "zera tanque_pf1 por pelotiz1".

Assign: "tira do tanque pf1 por pelotiz1"

Variável: tanque_pf1 $\rightarrow$ tanque_pf1 - (prod_pelotiz1 x fator_conv_pel_pf)

Variável: total_prod_pelotiz1 $\rightarrow$ total_prod_pelotiz1 + prod_pelotiz1 
Variável: prod_psc1 $\rightarrow$ prod_psc1 + (prod_pelotiz1 x perc_psc)

Variável: patio_pelota $\rightarrow$ patio_pelota + prod_pelotiz1

Assign: "zera tanque_pf1 por pelotiz1"

Variável: prod_pelotiz1 $\rightarrow$ tanque_pf1 / fator_conv_pel_pf

Variável: tanque_pf1 $\rightarrow 0$

Variável: total_prod_pelotiz1 $\rightarrow$ total_prod_pelotiz1 + prod_pelotiz1

Variável: prod_perdida_falta_pf1 $\rightarrow$ prod_perdida_falta_pf1 + prod_pelotiz1

Variável: prod_psc1 $\rightarrow$ prod_psc1 + (prod_pelotiz1 x perc_psc)

Variável: patio_pelota $\rightarrow$ patio_pelota + prod_pelotiz1

Onde,

$\checkmark$ tanque_pf1 é uma variável que indica o volume de pellet-feed no silo de produto acabado logo após a filtragem 1 antes de abastecer a usina de pelotização 1.

$\checkmark$ prod_pelotiz1 é um atributo de produção da pelotização 1;

$\checkmark$ fator_conv_pel_pf é um dado de entrada que informa a taxa de conversão de massa de pellet-feed em pelota;

$\checkmark$ total_prod_pelotiz1 é uma variável que contabiliza o total acumulado de produção de pelotas da pelotização 1;

$\checkmark$ cap_patio_pelota é um dado de entrada que determina a capacidade de armazenamento para pelotas;

$\checkmark$ pátio_pelota é uma variável que informa a quantidade atual de pelotas no pátio;

$\checkmark$ prod_psc1 é variável que informa a geração de pellet-screening da pelotização 1;

$\checkmark$ perc_psc é um dado de entrada que informa o percentual de geração de pellet-screening na produção de pelotas;

Todas estas decisões da Pelotização 1 podem ser melhor acompanhadas pela Figura A.9 a seguir. 


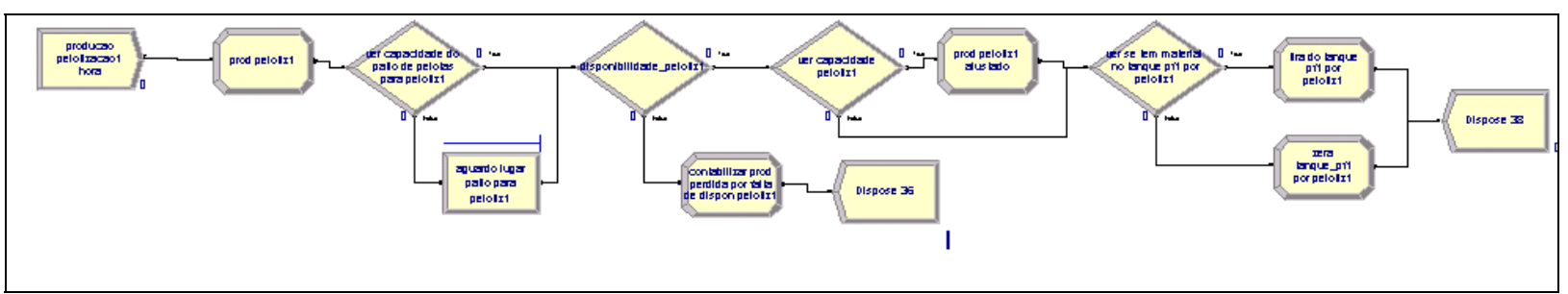

Figura A.9 - llustração do modelo computacional das decisões da etapa "Pelotização 1"

Não será necessário apresentar a modelagem conceitual da Pelotização 2 e 3 porque é exatamente igual à Pelotização 1. A diferença está nos valores de produtividade, capacidade e disponibilidade que são intrínsecos a cada unidade produtiva. 


\section{APÊNDICE B - MODELO DE OTIMIZAÇÃO}

Neste capítulo, será apresentada a descrição do modelo matemático de otimização utilizado para a quantificação dos cenários em estudo. Como já informado anteriormente este modelo foi construído, utilizando modelagem matemática via programação linear inteira mista (MILP). A implementação foi realizada através do "solver" Lingo 10.0, utilizando como interface de dados o Microsoft Office Excel 2003.

NOTAÇÃO

t período

n número de períodos de análise

i tipo de produto

r macrorregião de vendas

p projeto

VARIÁVEL DE DECISÃO

execute Variável de decisão:

1: Realizar o projeto $\mathrm{p}$ no período $\mathrm{t}$

0: Não realizar o projeto $p$ no período t, por projeto (1..np) e por período (1..nt) 
A função objetivo deste modelo é maximizar uma combinação linear entre o valor presente líquido (VPL) e seus pagamentos de dividendos no horizonte de tempo determinado. Eventuais faltas de atendimento de mínimos de venda ou de SOFE $^{33}$ serão penalizadas.

$\operatorname{Max} a \cdot \sum_{\mathrm{t}=1}^{\mathrm{nt}} \frac{\operatorname{freecf}(\mathrm{t})}{(1+\operatorname{wacc}(\mathrm{t}))^{\mathrm{t}}}+\mathrm{b} \cdot \sum_{\mathrm{t}=1}^{\mathrm{nt}} \frac{\operatorname{dividends}(\mathrm{t})}{(1+\operatorname{wacc}(\mathrm{t}))^{\mathrm{t}}}$
-BigNumbert1. $\sum_{\mathrm{i}=1}^{\mathrm{ni}} \sum_{\mathrm{t}=1}^{\mathrm{nt}} \sum_{\mathrm{r}=1}^{\mathrm{nr}}$ Slacksale(i,t,r)-BigNumber2. $\sum_{\mathrm{t}=1}^{\mathrm{nt}}$ Slacksofe (t)

Onde:

\begin{tabular}{|l|l|l|l|l|}
\hline Variável & Descrição & Unidade & Dimensões & Tipo \\
\hline freecf & Fluxo de caixa livre para a firma & US\$ & Por período (1..nt) & Output \\
\hline dividends & Dividendos & U4 $\$$ & Por período (1..nt) & Output \\
\hline wacc $^{35}$ & Taxa de antecipação de custo de capital & Não há & Por período (1..nt) & Input \\
\hline a & Constante de proporcionalidade & Não há & Único & Input \\
\hline b & Constante de proporcionalidade & Não há & Único & Input \\
\hline
\end{tabular}

\section{RESTRIÇÕES}

As restrições deste modelo matemático de otimização foram agrupadas em diversas classes de restrição, respeitando-se suas inter-relações e similaridades.

\footnotetext{
${ }^{33}$ SOFE - adiantamento de contratos de crédito

${ }^{34}$ Dividendo é a parte do lucro que uma empresa distribui aos acionistas. A quantidade de dividendos que um acionista recebe é proporcional à quantidade e ao tipo de ações que ele possui.

${ }^{35}$ WACC (Weighted Avarage Cost of Capital). É a média ponderada entre o custo de capital próprio e o custo do capital de terceiros.
} 


\section{1 - Restrição de mix de produção}

Restrições quanto à produção de pelotas de alto forno $\left(\mathrm{PBF}^{36}\right)$ e de redução direta $\left(\mathrm{PDR}^{37}\right)$. A produção de $\mathrm{PBF}$ deve ser superior a um percentual mínimo da soma das produções de pelotas PBF e PDR.

$\operatorname{prodqty}(p b f, t) \geq \% \operatorname{prod} *(\operatorname{prodqty}(p b f, t)+\operatorname{prodqty}(p d r, t)) \quad \forall t=1 . . n t$

Onde:

\begin{tabular}{|l|l|l|l|l|}
\hline Variável & Descrição & Unidade & Dimensões & Tipo \\
\hline prodqty & Quantidade produzida & $\operatorname{tms}^{38}$ & $\begin{array}{l}\text { Por produto (1..ni) } \\
\text { Por período (1..nt) }\end{array}$ & Output \\
\hline \%prod & $\begin{array}{l}\text { Proporção mínima entre PBF e a } \\
\text { soma de PBF e PDR }\end{array}$ & Não há & Único & Input \\
\hline
\end{tabular}

\section{2 - Restrições de mercado}

Restrição quanto à venda de pelotas por mercado não pode exceder limites estabelecidos de atratividade ou limites estratégicos.

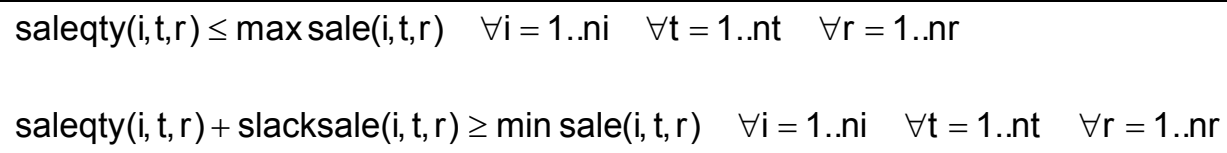

\footnotetext{
${ }^{36}$ PBF - do inglês "Pellets of Blast Furnace" - Pelotas de Alto Forno

${ }^{37}$ PDR - do inglês "Pellets of Direct Reduction" - Pelotas de Redução Direta

${ }^{38} \mathrm{tms}$ - toneladas métricas secas
} 
Onde:

\begin{tabular}{|l|l|l|l|l|}
\hline Variável & Descrição & Unidade & Dimensões & Tipo \\
\hline saleqty & Quantidade vendida & tms & $\begin{array}{l}\text { Por produto (1..ni) } \\
\text { Por período (1..nt) } \\
\text { Por região (1..nr) }\end{array}$ & Output \\
\hline slacksale & Variável auxiliar & tms & $\begin{array}{l}\text { Por produto (1..ni) } \\
\text { Por período (1..nt) } \\
\text { Por região (1..nr) }\end{array}$ & Output \\
\hline minsale & Previsão mínima de vendas & tms & $\begin{array}{l}\text { Por produto (1..ni) } \\
\text { Por período (1..nt) } \\
\text { Por região (1..nr) }\end{array}$ & Input \\
\hline maxsale & Previsão máxima de vendas & tms & $\begin{array}{l}\text { Por produto (1..ni) } \\
\text { Por período (1..nt) } \\
\text { Por região (1..nr) }\end{array}$ & Input \\
\hline
\end{tabular}

\section{3 - Restrição de produção, vendas e estocagem}

As quantidades vendidas de pelotas são iguais às quantidades produzidas, eventualmente decrescidas de um percentual de perdas e de segurança, além do balanço de estoques gerados entre períodos.

$$
\sum_{r=1}^{\mathrm{nr}} \text { saleqty }(\mathrm{i}, \mathrm{t}, \mathrm{r})=\operatorname{prodqty}(\mathrm{i}, \mathrm{t})+\mathrm{inv}(\mathrm{i}, \mathrm{t}-1)-\operatorname{inv}(\mathrm{i}, \mathrm{t}) \quad \forall \mathrm{i}=1 . . \mathrm{ni} \quad \forall \mathrm{t}=1 \text {..nt }
$$

Onde:

\begin{tabular}{|l|l|l|l|l|}
\hline Variável & Descrição & Unidade & Dimensões & Tipo \\
\hline saleqty & Quantidade vendida & tms & $\begin{array}{l}\text { Por produto (1..ni) } \\
\text { Por período (1..nt) } \\
\text { Por região (1..nr) }\end{array}$ & Output \\
\hline prodqty & Quantidade produzida & tms & $\begin{array}{l}\text { Por produto (1..ni) } \\
\text { Por período (1..nt) }\end{array}$ & Output \\
\hline inv & Quantidade em estoque & tms & $\begin{array}{l}\text { Por produto (1..ni) } \\
\text { Por período (1..nt) }\end{array}$ & Output \\
\hline inv $(\mathrm{i}, 0)$ & Quantidade em estoque no período 0 & tms & Por produto (1..ni) & Input \\
\hline
\end{tabular}




\section{4 - Restrição de inventário (produto acabado)}

As quantidades estocadas não podem exceder um limite máximo por período.

$$
\sum_{i=1}^{n i} \operatorname{inv}(i, t) \leq \operatorname{maxinv}+\sum_{p=1}^{n p} \operatorname{prjdeltainv}(p, t)^{*} \operatorname{execute}(p, t) \quad \forall t=1 . . n t
$$

Onde:

\begin{tabular}{|l|l|l|l|l|}
\hline Variável & Descrição & Unidade & Dimensões & Tipo \\
\hline inv & Quantidade em estoque & tms & $\begin{array}{l}\text { Por produto (1..ni) } \\
\text { Por período (1..nt) }\end{array}$ & Output \\
\hline maxinv & Quantidade nominal de estoque & tms & Único & Input \\
\hline prjdeltainv & $\begin{array}{l}\text { Impacto do projeto na capacidade de } \\
\text { estocagem }\end{array}$ & tms & $\begin{array}{l}\text { Por projeto (1..np) } \\
\text { Por período (1..nt) }\end{array}$ & Input \\
\hline execute & $\begin{array}{l}\text { Variável de decisão } \\
\text { 1: Realizar o projeto p no período t } \\
\text { 0: Não realizar o projeto p no período t }\end{array}$ & Não há & $\begin{array}{l}\text { Por projeto (1..np) } \\
\text { Por período (1..nt) }\end{array}$ & Output \\
\hline
\end{tabular}

\section{5 - Restrições de disponibilidade de concentrado de minérios de ferro ${ }^{39}$}

Como o processo produtivo não possui estoques intermediários em sua linha de produção, a matéria-prima deverá respeitar a produtividade de pelotas, realizando um sistema puxado de produção. As quantidades estocadas não podem exceder o limite máximo de estocagem por período. A quantidade de concentrado para BF deve gerar pellet-feed PFN ou pelotas BF. A quantidade de concentrado para DR deve gerar pelotas DR ou pellet-feed PFL. A produção de pelotas ou pelletfeed é opcional. A produção de pellet-screening (sinter feed) é dada por um percentual de geração sobre a quantidade produzida de pelotas BF e DR.

\footnotetext{
${ }^{39}$ Concentrado de minérios de ferro - é o produto do beneficiamento dos minérios de ferro lavrados pela Samarco Mineração S/A que, após retirada a água e umidade, será utilizado para produção de pelotas. Como o minério é de baixo teor de ferro metálico ( $\mathrm{Fe}$ ) e devido ao tipo de transporte feito por duto (mineroduto), faz-se necessário, primeiro, concentrar o material, elevando-se o teor de $\mathrm{Fe}$, e, depois, regular seu percentual de sólidos para melhorar o desempenho do transporte.
} 


$$
\begin{aligned}
& \operatorname{conc}(\mathrm{i}, \mathrm{t})=\operatorname{prodqty}(\mathrm{i}, \mathrm{t})^{*} \text { factorMC }(\mathrm{i}, \mathrm{t})+\operatorname{prodPF}(\mathrm{i}, \mathrm{t}) \quad \forall \mathrm{i}=1 . . \mathrm{ni}(\neq \mathrm{PF}, \mathrm{SF}) \quad \forall \mathrm{t}=1 . . \mathrm{nt} \\
& \sum_{\mathrm{i}=1}^{\mathrm{ni}} \operatorname{conc}(\mathrm{i}, \mathrm{t}) \leq \max \operatorname{conc}(0)+\sum_{\mathrm{p}=1}^{\mathrm{np}} \operatorname{prjdeltaconc}(\mathrm{p}, \mathrm{t})^{*} \operatorname{execute}(\mathrm{p}, \mathrm{t}) \quad \forall \mathrm{i}=1 . . \mathrm{ni}(\neq \mathrm{PF}, \mathrm{SF}) \quad \forall \mathrm{t}=1 . . n \mathrm{nt} \\
& \operatorname{prodqty}(\mathrm{pf}, \mathrm{t})=\sum_{\mathrm{i}=1}^{\mathrm{ni}} \operatorname{prodPF}(\mathrm{i}, \mathrm{t}) \quad \forall \mathrm{t}=1 . . \mathrm{nt} \\
& \operatorname{prodqty}(\mathrm{sf}, \mathrm{t})=\left(\text { factorSF }+\sum_{\mathrm{p}=1}^{\mathrm{np}} \operatorname{prjdeltafactorSF}(\mathrm{p}, \mathrm{t})^{*} \operatorname{execute}(\mathrm{p}, \mathrm{t})\right) * \sum_{\substack{\mathrm{i}=1 \\
\mathrm{i} \neq \mathrm{sf}}}^{\mathrm{ni}} \operatorname{prodqty}(\mathrm{i}, \mathrm{t}) \quad \forall \mathrm{t}=1 . . n t
\end{aligned}
$$

Onde:

\begin{tabular}{|l|l|l|l|l|}
\hline Variável & Descrição & Unidade & Dimensões & Tipo \\
\hline conc & Quantidade de concentrado & tms & $\begin{array}{l}\text { Por produto (1..ni) } \\
\text { Por período (1..nt) }\end{array}$ & Output \\
\hline prodqty & Quantidade produzida & tms & $\begin{array}{l}\text { Por produto (1..ni) } \\
\text { Por período (1..nt) }\end{array}$ & Output \\
\hline maxconc(0) & Quantidade nominal de concentrado & tms & Único & Input \\
\hline factorMC & Fator de conversão de massa & Não há & $\begin{array}{l}\text { Por produto (1..ni) } \\
\text { Por período (1..nt) }\end{array}$ & Input \\
\hline prodPF & $\begin{array}{l}\text { Quantidade de Pellet-feed }{ }^{40}(\mathrm{PF}) \\
\text { produzida }\end{array}$ & tms & $\begin{array}{l}\text { Por produto (1..ni) } \\
\text { Por período (1..nt) }\end{array}$ & Output \\
\hline factorSF & $\begin{array}{l}\text { Fator de produção de Sinter-Feed } \\
\text { (SF) }\end{array}$ & Não há & Único & Input \\
\hline prjdeltafconc & $\begin{array}{l}\text { Impacto do projeto no recebimento de } \\
\text { concentrado }\end{array}$ & Não há & $\begin{array}{l}\text { Por projeto (1..np) } \\
\text { Por período (1..nt) }\end{array}$ & Input \\
\hline prjdeltafactorSF & $\begin{array}{l}\text { Impacto do projeto na produção de } \\
\text { Sinter-Feed }\end{array}$ & Não há & $\begin{array}{l}\text { Por projeto (1..np) } \\
\text { Por período (1.nt) }\end{array}$ & Input \\
\hline execute & $\begin{array}{l}\text { Variável de decisão } \\
1: \text { Realizar o projeto p no período t } \\
\text { 0: Não realizar projeto p no período t }\end{array}$ & Não há & $\begin{array}{l}\text { Por projeto (1..np) } \\
\text { Por período (1..nt) }\end{array}$ & Output \\
\hline
\end{tabular}

\section{6 - Restrições de capacidade produtiva}

A capacidade produtiva da empresa é dada pelo seu valor nominal acrescido do impacto dos projetos ao longo do horizonte. Este valor é calculado em função do forno de endurecimento de pelotas. É uma medida de referência para comparação

40 Pellet-feed - é a matéria-prima para produção de pelotas. É o concentrado de minérios de ferro sem água e a certa umidade. Também pode ser vendido como produto acabado.

41 Sinter-feed ou Pellet-screening - é o produto final de pelota após a queima que está fora das especificações técnicas, isto é, produto fora de especificação que também é vendido. 
entre usinas de pelotização; e é mensurada em função da produção, por hora, por área da grelha do forno.

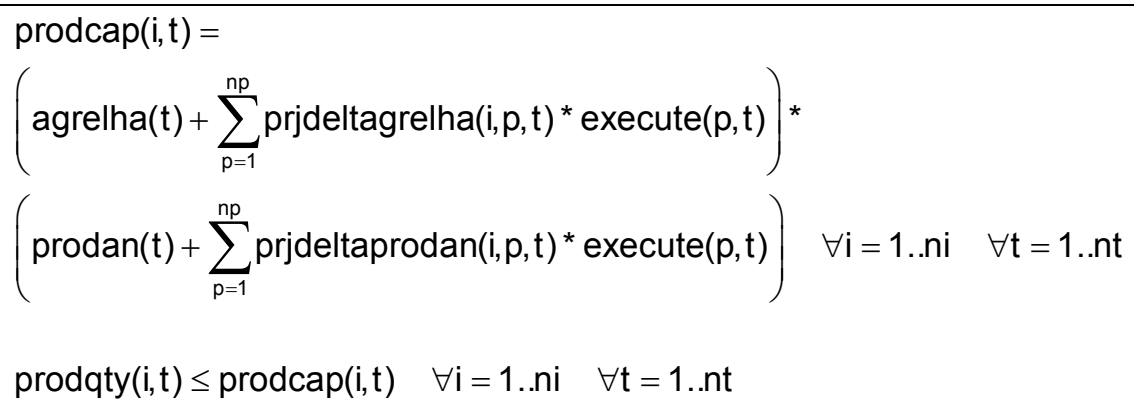

Onde:

\begin{tabular}{|c|c|c|c|c|}
\hline Variável & Descrição & Unidade & Dimensões & Tipo \\
\hline prodcap & Capacidade produtiva total & tms & $\begin{array}{l}\text { Por produto } \\
(1 . . n i) \\
\text { Por período } \\
\text { (1..nt) }\end{array}$ & Output \\
\hline agrelha & Área total da grelha ${ }^{42}$ & $\mathrm{~m}^{2}$ & $\begin{array}{l}\text { Por período } \\
\text { (1..nt) }\end{array}$ & Input \\
\hline prjdeltagrelha & $\begin{array}{l}\text { Impacto do projeto na área total da } \\
\text { grelha }\end{array}$ & $\mathrm{m}^{2}$ & $\begin{array}{l}\text { Por produto } \\
\text { (1..ni) } \\
\text { Por projeto } \\
\text { (1..np) } \\
\text { Por período } \\
\text { (1..nt) }\end{array}$ & Input \\
\hline prodan & Produtividade no período & $\mathrm{tms} / \mathrm{m}^{2}$ & $\begin{array}{l}\text { Por período } \\
\text { (1..nt) }\end{array}$ & Input \\
\hline $\begin{array}{l}\text { prjdeltaproda } \\
\mathrm{n}\end{array}$ & $\begin{array}{l}\text { Impacto do projeto na produtividade } \\
\text { no período }\end{array}$ & $\mathrm{tms} / \mathrm{m}^{2}$ & $\begin{array}{l}\text { Por produto } \\
\text { (1..ni) } \\
\text { Por projeto } \\
\text { (1..np) } \\
\text { Por período } \\
\text { (1..nt) }\end{array}$ & Input \\
\hline execute & $\begin{array}{l}\text { Variável de decisão } \\
\text { 1: Realizar o projeto p no período t } \\
0: \text { Não realizar o projeto p no } \\
\text { período t }\end{array}$ & Não há & $\begin{array}{l}\text { Por projeto } \\
\text { (1..np) } \\
\text { Por período } \\
\text { (1..nt) }\end{array}$ & Output \\
\hline prodqty & Quantidade produzida & tms & $\begin{array}{l}\text { Por produto } \\
\text { (1..ni) } \\
\text { Por período } \\
\text { (1..nt) }\end{array}$ & Output \\
\hline
\end{tabular}

\footnotetext{
${ }^{42}$ Área da Grelha é a área do forno de endurecimento (queima) de pelotas. Esta é uma referência mundial para comparação entre as usinas de pelotização.
} 


\section{7 - Restrições de integridade de projetos}

Um projeto deve ter início somente na janela de tempo permitida. Uma vez iniciado, seus efeitos permanecem ao longo do horizonte de estudo. Se um projeto for executado, todos os seus desembolsos deverão ser executados. O desembolso (d) de um projeto ( $p$ ) deve acontecer no período ( $t$ ). Os demais desembolsos devem seguir o mesmo padrão de atraso do primeiro desembolso.

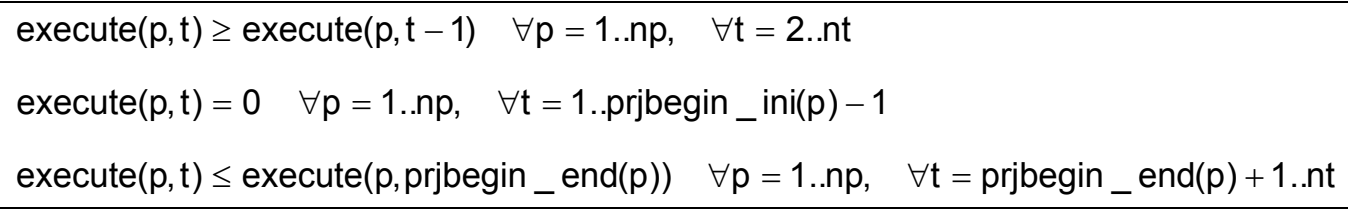

Onde:

\begin{tabular}{|l|l|l|l|l|}
\hline Variável & Descrição & Unidade & Dimensões & Tipo \\
\hline execute & $\begin{array}{l}\text { Variável de decisão } \\
\text { 1: Realizar o projeto p no período t } \\
\text { 0: Não realizar o projeto p no período t }\end{array}$ & Não há & $\begin{array}{l}\text { Por projeto (1..np) } \\
\text { Por período (1..nt) }\end{array}$ & Output \\
\hline prjbegin_ini & Início da janela de start do projeto & Não há & Por projeto (1..np) & Input \\
\hline prjbegin_end & Fim da janela de start do projeto & Não há & Por projeto (1..np) & Input \\
\hline
\end{tabular}

\section{8 - Restrições de "excludência" entre projetos}

A realização de um projeto deve impedir a execução de outro.

$$
\sum_{\mathrm{d}=1}^{\mathrm{nt}} \text { execute }(\mathrm{p} 1)+\operatorname{execute}(\mathrm{p} 2) \leq 1 \quad \forall \mathrm{p} 1=1 . \mathrm{np} \quad \forall \mathrm{p} 2=\mathrm{p} 1+1 . \mathrm{np} \quad \forall \mathrm{p} 1 \text { e } \mathrm{p} 2 \text { excludentes }
$$


Onde

\begin{tabular}{|l|l|l|l|l|}
\hline Variável & Descrição & Unidade & Dimensões & Tipo \\
\hline execute & $\begin{array}{l}\text { Variável de decisão } \\
\text { 1: Realizar o projeto p no período t } \\
\text { 0: Não realizar o projeto p no período t }\end{array}$ & Não há & $\begin{array}{l}\text { Por projeto (1..np) } \\
\text { Por período (1..nt) }\end{array}$ & Output \\
& & & \\
\hline
\end{tabular}

\section{9 - Restrições financeiras}

O fluxo de caixa após os financiamentos é a soma do fluxo de caixa antes dos financiamentos, com os efeitos de execução de projetos, financiamentos (valor principal, amortização e juros da dívida) e ganhos fiscais ${ }^{43}$.

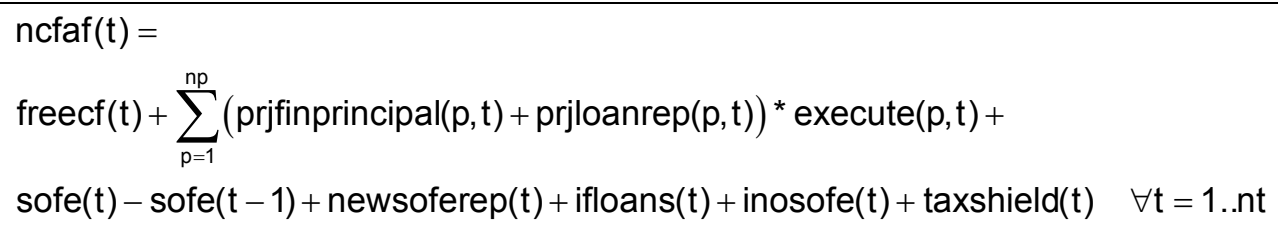

Onde:

\begin{tabular}{|l|l|l|l|l|}
\hline Variável & Descrição & Unidade & Dimensões & Tipo \\
\hline ncfaf & $\begin{array}{l}\text { Fluxo de caixa livre depois dos } \\
\text { financiamentos }\end{array}$ & US\$ & Por período (1..nt) & Output \\
\hline freecf & Fluxo de caixa livre para a firma & US\$ & Por período (1..nt) & Output \\
\hline execute & $\begin{array}{l}\text { Variável de decisão } \\
\text { 1: Realizar o projeto p no período t } \\
\text { 0: Não realizar o projeto p no período t }\end{array}$ & Não há & $\begin{array}{l}\text { Por projeto (1..np) } \\
\text { Por período (1..nt) }\end{array}$ & Output \\
\hline $\begin{array}{l}\text { prjfinprincipa } \\
\text { Project finance principal }\end{array}$ & US\$ & $\begin{array}{l}\text { Por projeto (1..np) } \\
\text { Por período (1.nt) }\end{array}$ & Input \\
\hline prjloanrep & Project loan repayment & US\$ & $\begin{array}{l}\text { Por projeto (1.np) } \\
\text { Por período (1.nt) }\end{array}$ & Input \\
\hline sofe & SOFE & US\$ & Por período (1..nt) & Output \\
\hline Sofe(0) & SOFE do período 0 & US\$ & Único & Input \\
\hline newsoferep & Repagamento de SOFE & US\$ & Por período (1..nt) & Output \\
\hline ifloans & Interest and fees on loans & US\$ & Por período (1..nt) & Input \\
\hline ionsofe & Interest on SOFE & US\$ & Por período (1..nt) & Output \\
\hline taxshield & Tax shield & US\$ & Por período (1..nt) & Output \\
\hline
\end{tabular}

${ }^{43}$ Ganhos fiscais ou "Tax Shield" 
O faturamento bruto é dado pelo total de entradas pela venda de produtos mais serviços logísticos.

Vale lembrar que minérios são vendidos através de seu conteúdo metálico, por isso existe a necessidade de se declarar o teor de Fe dos produtos acabados.

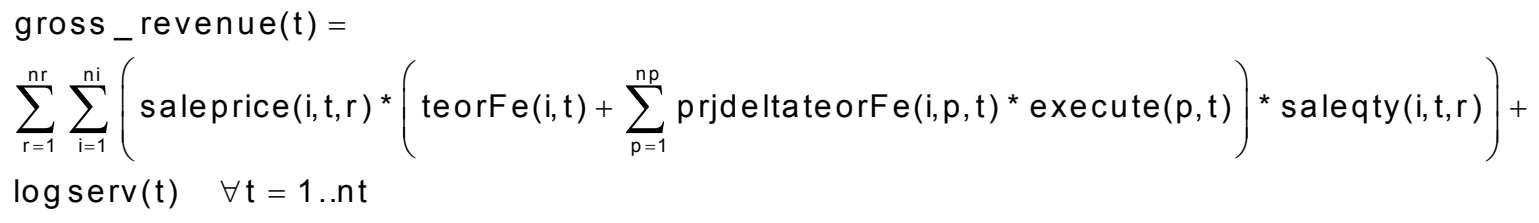

Onde:

\begin{tabular}{|c|c|c|c|c|}
\hline Variável & Descrição & Unidade & Dimensões & Tipo \\
\hline gross_revenue & Receita bruta & US\$ & Por período (1..nt) & Output \\
\hline saleprice & Preço de venda & $\begin{array}{l}\text { US\$/(t } \\
\left.\mathrm{Fe}^{44}\right)\end{array}$ & $\begin{array}{l}\text { Por produto (1..ni) } \\
\text { Por período (1..nt) } \\
\text { Por região (1..nr) }\end{array}$ & Input \\
\hline teorFe & Teor de ferro & $\begin{array}{l}(\mathrm{t} \\
\mathrm{Fe}) / \mathrm{tms}\end{array}$ & $\begin{array}{l}\text { Por produto (1..ni) } \\
\text { Por período (1..nt) }\end{array}$ & Input \\
\hline prjdeltateorFe & Impacto do projeto no teor de ferro & $\begin{array}{l}(\mathrm{t} \\
\mathrm{Fe}) / \mathrm{tms}\end{array}$ & $\begin{array}{l}\text { Por produto (1..ni) } \\
\text { Por projeto }(1 . . \mathrm{np}) \\
\text { Por período (1..nt) }\end{array}$ & Input \\
\hline execute & $\begin{array}{l}\text { Variável de decisão } \\
\text { 1: Realizar o projeto } \mathrm{p} \text { no período } \mathrm{t} \\
0 \text { : Não realizar o projeto } \mathrm{p} \text { no período } \mathrm{t}\end{array}$ & Não há & $\begin{array}{l}\text { Por projeto (1..np) } \\
\text { Por período (1..nt) }\end{array}$ & Output \\
\hline saleqty & Quantidade vendida & tms & $\begin{array}{l}\text { Por produto }(1 . . n i) \\
\text { Por período }(1 . . n t) \\
\text { Por região }(1 . . n r)\end{array}$ & Output \\
\hline logserv & $\begin{array}{l}\text { Serviços logísticos } \\
\text { (Área para locação, Operações portuárias, } \\
\text { Tup }{ }^{45} \text {, Rebocadores) }\end{array}$ & US\$ & Por período (1..nt) & Input \\
\hline
\end{tabular}

O repagamento de SOFE é a soma das novas necessidades de SOFE do período anterior.

soferep $(\mathrm{t})=$ newsoferep $(\mathrm{t}-1) \quad \forall \mathrm{t}=1 . . \mathrm{nt}$

Onde:

\begin{tabular}{|l|l|l|l|l|}
\hline Variável & Descrição & Unidade & Dimensões & Tipo \\
\hline soferep & SOFE repayment & US\$ & Por período (1..nt) & Output \\
\hline newsoferep & New SOFE repayment & US\$ & Por período (1..nt) & Output \\
\hline newsoferep(0) & $\begin{array}{l}\text { New SOFE repayment do } \\
\text { período 0 }\end{array}$ & Não há & Único & Input \\
\hline
\end{tabular}

${ }^{44}$ ( $\mathrm{Fe}$ ) - tonelada do conteúdo metálica ferro ( $\left.\mathrm{Fe}\right)$.

45 TUP - Terminal de Uso Privativo 
Os juros sobre SOFE são dados pela soma do SOFE com um percentual de juros sobre o repagamento de SOFE.

ionsofe $(t)=(\operatorname{sofe}(t)+$ newsoferep $(t)) * \%$ onsofe $\quad \forall t=1 . . n t$

Onde:

\begin{tabular}{|l|l|l|l|l|}
\hline Variável & Descrição & Unidade & Dimensões & Tipo \\
\hline ionsofe & Interest on SOFE & US\$ & Por período (1..nt) & Output \\
\hline sofe & SOFE & US\$ & Por período (1..nt) & Output \\
\hline newsoferep & Repagamento do Novo SOFE & US\$ & Por período (1..nt) & Output \\
\hline$\%$ onsofe & \% of interest rate on sofe & Não há & Único & Input \\
\hline
\end{tabular}

O tax shield é dado pela incidência de imposto de renda (IR) sobre os juros, sobre SOFE e sobre empréstimos.

taxshield $(\mathrm{t})=($ ionsofe $(\mathrm{t})+$ ifloans $(\mathrm{t})) * \% \mathrm{I} \quad \forall \mathrm{t}=1 . . \mathrm{nt}$

Onde:

\begin{tabular}{|l|l|l|l|l|}
\hline Variável & Descrição & Unidade & Dimensões & Tipo \\
\hline taxshield & Tax shield & US\$ & Por período (1..nt) & Output \\
\hline ionsofe & Interest on SOFE & US\$ & Por período (1.nt) & Output \\
\hline ifloans & Interest and fees on loans & US\$ & Por período (1..nt) & Input \\
\hline$\%$ IR & Percentual do IR & Não há & Único & Input \\
\hline
\end{tabular}

O caixa para a empresa é dado pelas necessidades de despesas de capital e fluxo de caixa operacional.

freecf $(\mathrm{t})=\operatorname{capex}(\mathrm{t})+\operatorname{opercf}(\mathrm{t}) \quad \forall \mathrm{t}=1$. .nt

Onde:

\begin{tabular}{|l|l|l|l|l|}
\hline Variável & Descrição & Unidade & Dimensões & Tipo \\
\hline freecf & Fluxo de caixa livre para a firma & US\$ & Por período (1..nt) & Output \\
\hline capex & Despesas de Capital & US\$ & Por período (1.nt) & Output \\
\hline opercf & Fluxo de Caixa Operacional & US\$ & Por período (1..nt) & Output \\
\hline
\end{tabular}

O caixa mínimo limita a necessidade de caixa para a empresa.

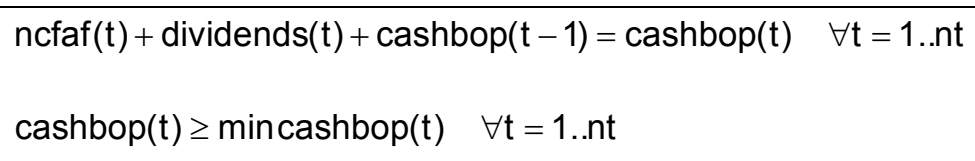


Onde:

\begin{tabular}{|l|l|l|l|l|}
\hline Variável & Descrição & Unidade & Dimensões & Tipo \\
\hline ncfaf & $\begin{array}{l}\text { Fluxo de caixa livre depois do } \\
\text { financiamento }\end{array}$ & US\$ & Por período (1..nt) & Output \\
\hline dividends & Dividendos & US\$ & Por período (1.nt) & Output \\
\hline cashbop & Caixa no início do período & US\$ & Por período (1..nt) & Output \\
\hline cashbop(0) & Caixa no início do período 0 & US\$ & Único & Input \\
\hline mincashbop & Caixa mínimo no início de cada período & US\$ & Por período (1..nt) & Input \\
\hline
\end{tabular}

As despesas de capital são dadas pela soma dos investimentos sobre os projetos, do capital de sustentação e do custo de fechamento.

$$
\begin{aligned}
& \operatorname{capex}(\mathrm{t})=\sum_{\mathrm{p}=1}^{\mathrm{np}} \operatorname{prjinvestment}(\mathrm{p}, \mathrm{t})^{*} \operatorname{execute}(\mathrm{p}, \mathrm{t})+\operatorname{suscap}(\mathrm{t}) \quad \forall \mathrm{t}=1 . . \mathrm{nt}-1 \\
& \operatorname{capex}(\mathrm{nt})=\sum_{\mathrm{p}=1}^{\mathrm{np}} \operatorname{prjinvestment}(\mathrm{p}, \mathrm{nt})^{*} \operatorname{execute}(\mathrm{p}, \mathrm{nt})+\operatorname{suscap}(\mathrm{nt})+\mathrm{ccos} \mathrm{t}
\end{aligned}
$$

Onde:

\begin{tabular}{|l|l|l|l|l|}
\hline Variável & Descrição & Unidade & Dimensões & Tipo \\
\hline capex & Despesas de capital & US\$ & Por período (1..nt) & Output \\
\hline prjinvestment & Investimento necessário para o projeto & US\$ & $\begin{array}{l}\text { Por projeto (1..np) } \\
\text { Por período (1..nt) }\end{array}$ & Input \\
\hline execute & $\begin{array}{l}\text { Variável de decisão } \\
\text { 1: Realizar o projeto p no período t } \\
\text { 0: Não realizar o projeto p no período t }\end{array}$ & Não há & $\begin{array}{l}\text { Por projeto (1..np) } \\
\text { Por período (1..nt) }\end{array}$ & Output \\
\hline suscap & Capital de sustentação & US\$ & Por período (1..nt) & Output \\
\hline ccost & Closure cost & US $\$$ & Único & Output \\
\hline
\end{tabular}

O caixa operacional é dado pela soma da receita líquida com os custos de produção, outros custos associados (embarque, administrativos e comerciais), outras despesas, taxas e capital operacional.

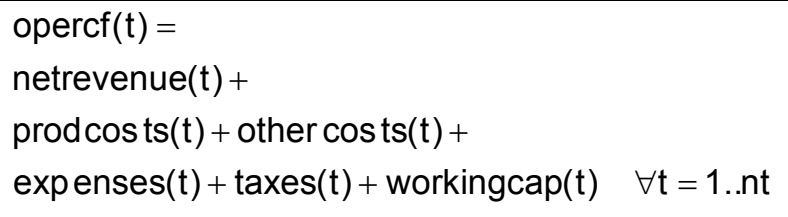

\footnotetext{
${ }^{46}$ Closure cost - é o custo estimado para cobrir as atividades de fechamento do negócio, incluindo remoção ou tratamento final do inventário de rejeitos, descontaminação, amostragem e análises, além do certificado de fechamento. De forma geral, deve buscar recompor toda a área degradada e torná-la o mais próximo possível do ambiente em que se encontrava antes da instalação de tal empreendimento.
} 
Onde:

\begin{tabular}{|l|l|l|l|l|}
\hline Variável & Descrição & Unidade & Dimensões & Tipo \\
\hline opercf & Fluxo de caixa operacional & US\$ & Por período (1..nt) & Output \\
\hline netrevenue & Receita líquida & US\$ & Por período (1..nt) & Output \\
\hline prodcosts & Custo de Produção & US\$ & Por período (1..nt) & Output \\
\hline othercosts & $\begin{array}{l}\text { Outros custos (embarque, } \\
\text { administrativos e comerciais) }\end{array}$ & US\$ & Por período (1..nt) & Input \\
\hline expenses & Despesas & US\$ & Por período (1..nt) & Ouput \\
\hline taxes & Taxas & US\$ & Por período (1..nt) & Output \\
\hline workingcap & Working capital & US\$ & Por período (1..nt) & Output \\
\hline
\end{tabular}

A receita líquida é dada pela diferença entre a receita bruta e as taxações sobre as vendas.

netrevenue $(\mathrm{t})=$ grossrevenue $(\mathrm{t})-$ taxesonsales $(\mathrm{t}) \quad \forall \mathrm{t}=1$..nt

Onde:

\begin{tabular}{|l|l|l|l|l|}
\hline Variável & Descrição & Unidade & Dimensões & Tipo \\
\hline netrevenue & Receita líquida & US\$ & Por período (1..nt) & Output \\
\hline grossrevenue & Receita bruta & US\$ & Por período (1..nt) & Output \\
\hline taxesonsales & Taxas sobre as vendas & US\$ & Por período (1..nt) & Output \\
\hline
\end{tabular}

Os custos de produção são dados pelo somatório das quantidades produzidas multiplicadas pelos valores unitários de produção (eventualmente afetados pelos projetos executados), mais os custos fixos totais.

$$
\begin{aligned}
& \operatorname{prodcos} t s(t)= \\
& \sum_{i=1}^{n i}\left(\operatorname{prodqty}(i, t) *\left(\text { unvalue }(i, t)+\sum_{p=1}^{n p} \operatorname{prjdeltavarcos} t(i, p, t) * \operatorname{execute}(p, t)\right)\right)+ \\
& \left(\text { totalfixedcosts }(t)+\sum_{p=1}^{n p} \text { prjdeltafixedcost }(p, t)^{*} \text { execute }(p, t)\right) \quad \forall t=1 . . n t
\end{aligned}
$$

Onde:

\begin{tabular}{|l|l|l|l|l|}
\hline Variável & Descrição & Unidade & Dimensões & Tipo \\
\hline prodcosts & Custos de produção & US\$ & Por período (1..nt) & Output \\
\hline prodqty & Quantidade produzida & tms & $\begin{array}{l}\text { Por produto (1..ni) } \\
\text { Por período (1..nt) }\end{array}$ & Output \\
\hline unvalue & Custo unitário de produção & US\$ / tms & $\begin{array}{l}\text { Por produto (1..ni) } \\
\text { Por período (1..nn) }\end{array}$ & Input \\
\hline prjdeltavarcost & $\begin{array}{l}\text { Impacto do projeto sobre o custo } \\
\text { unitário variável de produção }\end{array}$ & US\$ / tms & $\begin{array}{l}\text { Por produto (1..ni) } \\
\text { Por projeto (1..np) } \\
\text { Por período (1..nt) }\end{array}$ & Input \\
\hline totalfixedcosts & Total de custos fixos & Por período (1..nt) & Input \\
\hline prjdeltafixedcost & $\begin{array}{l}\text { Impacto do projeto sobre o custo } \\
\text { unitário fixo de produção }\end{array}$ & US\$ & $\begin{array}{l}\text { Por projeto (1..np) } \\
\text { Por período (1..nt) }\end{array}$ & Input \\
\hline execute & $\begin{array}{l}\text { Variável de decisão } \\
1: \text { Realizar o projeto p no período t } \\
\text { 0: Não realizar o projeto p no período t }\end{array}$ & Não há & $\begin{array}{l}\text { Por projeto (1..np) } \\
\text { Por período (1..nt) }\end{array}$ & Output \\
\hline
\end{tabular}


As despesas são dadas pelos valores da Usina Hidrelétrica de Guilman Amorim $^{47}, \mathrm{CFEM}^{48}$, investimentos sociais, participação dos empregados nos lucros, royalties e outras despesas.

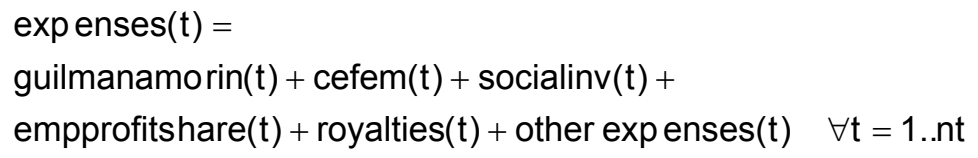

Onde:

\begin{tabular}{|l|l|l|l|l|}
\hline Variável & Descrição & Unidade & Dimensões & Tipo \\
\hline expenses & Despesas & US\$ & Por período (1..nt) & Ouput \\
\hline guilmanamorim & Despesas com Guilman Amorim & US\$ & Por período (1..nt) & Input \\
\hline cefem & Despesas com CFEM & US\$ & Por período (1..nt) & Output \\
\hline socialinv & $\begin{array}{l}\text { Despesas com investimentos } \\
\text { sociais }\end{array}$ & US\$ & Por período (1..nt) & Input \\
\hline empprofitshare & Participação nos lucros & US\$ & Por período (1..nt) & Output \\
\hline royalties & Royalties sobre os dividendos & US\$ & Por período (1..nt) & Output \\
\hline otherexpenses & Outras despesas & US\$ & Por período (1..nt) & Output \\
\hline
\end{tabular}

As demais despesas são dadas por um percentual de recuperação de PIS/COFINS sobre os custos de produção.

other expenses $(t)=\operatorname{prod} \cos t s(t) * \% \operatorname{recPC} \quad \forall t=1 . . n t$

Onde:

\begin{tabular}{|c|c|c|c|c|}
\hline Variável & Descrição & Unidade & Dimensões & Tipo \\
\hline otherexpenses & Other expenses & US\$ & Por período (1..nt) & Output \\
\hline prodcosts & Custos totais de produção & US\$ & Por período (1..nt) & Output \\
\hline \%recPC & \% de recuperação de PIS/COFINS ${ }^{49}$ & Não há & Único & Input \\
\hline
\end{tabular}

As taxas são calculadas considerando a recuperação de ICMS em despesas de capital e despesas operacionais, imposto de renda, não recuperação de ICMS em despesas de capital e PIS/COFINS sobre o imposto de renda.

\footnotetext{
${ }^{47}$ Guilman Amorim é uma unidade de geração de energia elétrica que a Samarco Mineração S/A detém 49\% das ações.

${ }^{48}$ CFEM - Compensação Financeira sobre Exploração de Recursos Minerais.

${ }^{49}$ PIS - Plano de Integração Social - é uma contribuição social de natureza tributária devida pelas pessoas jurídicas, com o objetivo de financiar o pagamento do seguro desemprego e do abono para os trabalhadores que ganham até dois salários mínimos.
} 
$\operatorname{taxes}(\mathrm{t})=$

icmscapexrec $(\mathrm{t})+\mathrm{icmsopexrec}(\mathrm{t})+\mathrm{ir}(\mathrm{t})+\mathrm{icmscapexnonrec}(\mathrm{t})+\mathrm{PCoverIR}(\mathrm{t}) \quad \forall \mathrm{t}=1$..nt

Onde:

\begin{tabular}{|l|l|l|l|l|}
\hline Variável & Descrição & Unidade & Dimensões & Tipo \\
\hline taxes & Taxas & US\$ & Por período (1..nt) & Output \\
\hline icmscapexrec & $\begin{array}{l}\text { Recuperação de ICMS } \\
\text { CAPEX }\end{array}$ & US $\$$ & Por período (1..nt) & Output \\
\hline icmsopexrec & Recuperação do ICMS no OPEX $^{52}$ & US\$ & Por período (1..nt) & Output \\
\hline ir & Imposto de Renda & US\$ & Por período (1..nt) & Output \\
\hline icmscapexnonrec & $\begin{array}{l}\text { Não recuperação deICMS no } \\
\text { CAPEX }\end{array}$ & US\$ & Por período (1..nt) & Output \\
\hline PCoverIR & $\begin{array}{l}\text { Recuperação de PIS/COFINS } \\
\text { acima do IR }\end{array}$ & US\$ & Por período (1..nt) & Output \\
\hline
\end{tabular}

O capital operacional é calculado pelo balanço entre inventário, contas a receber e pagamento de fornecedores.

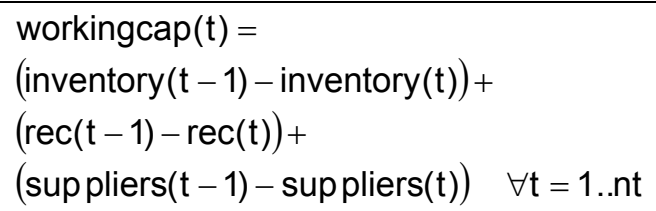

Onde:

\begin{tabular}{|l|l|l|l|l|}
\hline Variável & Descrição & Unidade & Dimensões & Tipo \\
\hline workingcap & Working capital & US\$ & Por período (1..nt) & Output \\
\hline inventory & Despesas com inventário & US\$ & Por período (1..nt) & Output \\
\hline inventory(0) & Despesas com inventário no período 0 & US\$ & Único & Input \\
\hline Rec & Contas a receber & US\$ & Por período (1..nt) & Output \\
\hline rec(0) & Contas a receber no período 0 & US\$ & Único & Input \\
\hline suppliers & Pagamento de fornecedores & US\$ & Por período (1..nt) & Output \\
\hline suppliers(0) & $\begin{array}{l}\text { Pagamento de fornecedores no período } \\
0\end{array}$ & US\$ & Único & Input \\
\hline
\end{tabular}

A provisão e o custo de fechamento são dados pelo produto do valor unitário de fechamento e da capacidade de produção em cada período.

\footnotetext{
${ }^{50}$ ICMS - Imposto sobre circulação de Mercadorias e Prestação de Serviços - é um imposto estadual.

${ }^{51}$ CAPEX - Capital Expenditure - é o capital utilizado para adquirir os ativos de uma empresa.

52 OPEX - Operational Expenditure - é o capital utilizado para melhorar os ativos de uma empresa

${ }^{53}$ COFINS - Contribuição para o Financiamento da Seguridade Social - é uma contribuição federal, de natureza tributária, incidente sobre a receita bruta das empresas em geral, destinada a financiar a seguridade social.
} 


$$
\begin{aligned}
& \operatorname{ccos} \operatorname{tprov}(\mathrm{t})=\text { unclosevalue } * \sum_{\mathrm{i}=1}^{\mathrm{ni}} \operatorname{prodcap}(\mathrm{i}, \mathrm{t}) \quad \forall \mathrm{t}=1 . . \mathrm{nt} \\
& \mathrm{ccos} \mathrm{t}=\text { unclosevalue } \sum_{\mathrm{i}=1}^{\mathrm{ni}} \operatorname{prodcap}(\mathrm{i}, \mathrm{nt})
\end{aligned}
$$

Onde:

\begin{tabular}{|l|l|l|l|l|}
\hline Variável & Descrição & Unidade & Dimensões & Tipo \\
\hline ccostprov & Provisão de custo de fechamento & US\$ & Por período (1..nt) & Output \\
\hline Ccost & Custo de fechamento & US\$ & Único & Output \\
\hline unclosevalue & Custo de fechamento unitário & US\$ /tms & Único & Input \\
\hline Prodcap & Capacidade produtiva & tms & $\begin{array}{l}\text { Por produto (1..ni) } \\
\text { Por período (1..nt) }\end{array}$ & Output \\
\hline
\end{tabular}

As taxas sobre vendas são dadas pela incidência de CPMF, PIS/COFINS sobre serviços e ISS.

taxesonsales $(\mathrm{t})=\mathrm{CPMF}(\mathrm{t})+\mathrm{PCoverServ}(\mathrm{t})+\mathrm{ISS}(\mathrm{t}) \quad \forall \mathrm{t}=1 . \mathrm{nt}$

\begin{tabular}{|c|c|c|c|c|}
\hline Variável & Descrição & Unidade & Dimensões & Tipo \\
\hline taxesonsales & Taxas sobre vendas & US\$ & Por período (1..nt) & Output \\
\hline CPMF & Despesas com CPMF $^{54}$ & US\$ & Por período (1..nt) & Output \\
\hline PCoverServ & PIS/COFINS sobre serviços & US\$ & Por período (1..nt) & Input \\
\hline ISS & Despesas com ISS 55 & US\$ & Por período (1..nt) & Input \\
\hline
\end{tabular}

Onde:

A incidência de CPMF é dada por um percentual sobre a receita bruta.

$$
\operatorname{CPMF}(\mathrm{t})=\text { grossrevenue }(\mathrm{t}) * \% \mathrm{CPMF} \quad \forall \mathrm{t}=1 . . \mathrm{nt}
$$

Onde:

\begin{tabular}{|l|l|l|l|l|}
\hline Variável & Descrição & Unidade & Dimensões & Tipo \\
\hline CPMF & Valor do CPMF & US\$ & Por período (1..nt) & Output \\
\hline grossrevenue & Receita bruta & US\$ & Por período (1..nt) & Output \\
\hline$\%$ CPMF & $\%$ of CMPF & Não há & Único & Input \\
\hline
\end{tabular}

A recuperação de ICMS sobre as despesas de capital é dada pelo produto de um índice de recuperação sobre o total de ICMS associado aos projetos realizados.

\footnotetext{
${ }^{54}$ CPMF - Contribuição Provisória sobre Movimentação ou Transação de Valores e de Créditos e Direitos de Natureza Financeira.

${ }^{55}$ ISS - Imposto sobre Serviços de qualquer natureza - imposto municipal.
} 


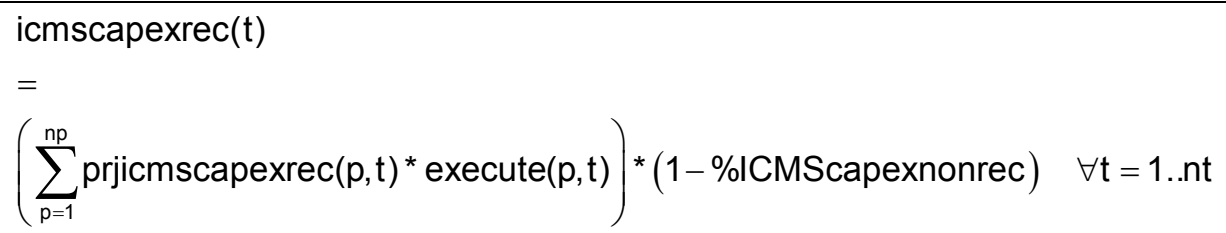

Onde:

\begin{tabular}{|l|l|l|l|l|}
\hline Variável & Descrição & Unidade & Dimensões & Tipo \\
\hline icmscapexrec & Recuperação de ICMS no CAPEX & US\$ & Por período (1..nt) & Output \\
\hline Execute & $\begin{array}{l}\text { Variável de decisão } \\
\text { 1: Realizar o projeto p no período t } \\
\text { 0: Não realizar o projeto p no período t }\end{array}$ & Não há & $\begin{array}{l}\text { Por projeto (1..np) } \\
\text { Por período (1..nt) }\end{array}$ & Output \\
\hline prjicmscapexrec & $\begin{array}{l}\text { Impacto do projeto no ICMS sobre } \\
\text { CAPEX }\end{array}$ & US\$ & $\begin{array}{l}\text { Por projeto (1..np) } \\
\text { Por período (1..nt) }\end{array}$ & Input \\
\hline \%ICMScapexnonrece & $\begin{array}{l}\text { \% de Não recuperação de ICMS do } \\
\text { CAPEX }\end{array}$ & Não há & Único & Input \\
\hline
\end{tabular}

A recuperação de ICMS sobre as despesas operacionais é dada pelo produto de um índice de geração de crédito sobre os custos de produção.

icmsopexrec $(\mathrm{t})=$ prod cos ts $(\mathrm{t}) * \%$ ICMScreditgen $\quad \forall \mathrm{t}=1 . . \mathrm{nt}$

Onde:

\begin{tabular}{|c|c|c|c|c|}
\hline Variável & Descrição & Unidade & Dimensões & Tipo \\
\hline icmsopexrec & $\begin{array}{l}\text { Recuperação de ICMS no } \\
\text { OPEX }\end{array}$ & US\$ & Por período (1..nt) & Output \\
\hline prodcosts & Custos de produção & US\$ & Por período (1..nt) & Output \\
\hline \%ICMScreditgen & $\begin{array}{l}\text { \% de geração de crédito de } \\
\text { ICMS } \\
\text { (mais \% de não recuperação de } \\
\text { ICMS do OPEX) }\end{array}$ & Não há & Único & Input \\
\hline
\end{tabular}

O imposto de renda é calculado pela incidência da alíquota de imposto sobre a diferença entre a receita bruta e as taxas sobre vendas, os custos de produção, as despesas, outros custos, a provisão de custo de fechamento e a depreciação.

Desse montante é subtraído o valor de recuperação de PIS/COFINS, associado às despesas operacionais dos projetos e aos custos operacionais. 


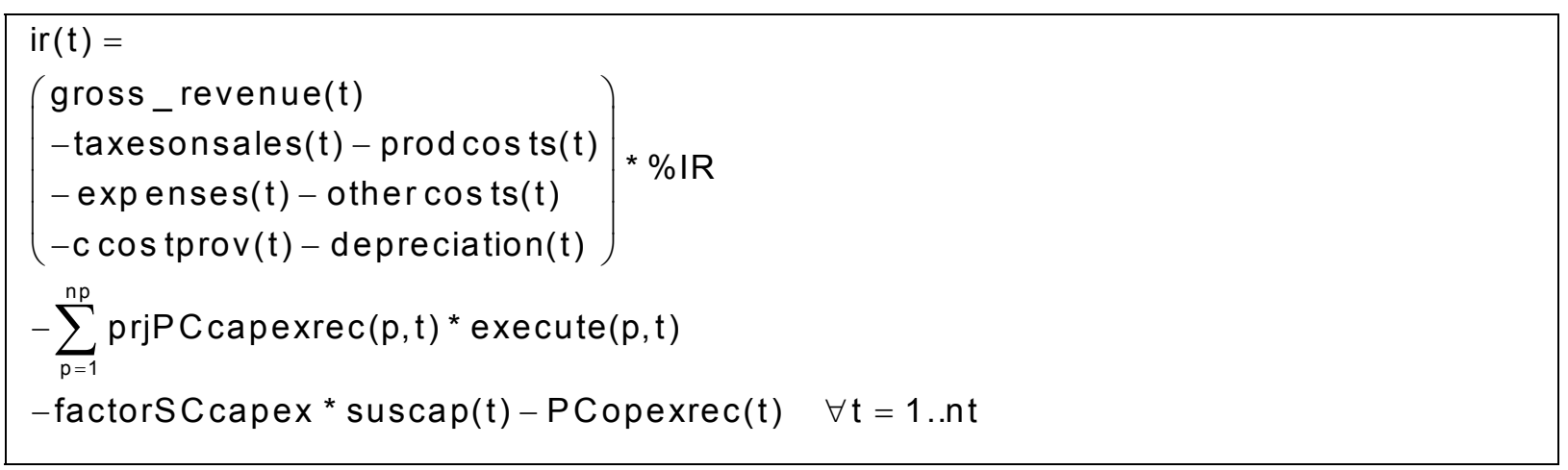

Onde:

\begin{tabular}{|l|l|l|l|l|}
\hline Variável & Descrição & Unidade & Dimensões & Tipo \\
\hline Ir & Imposto de Renda & US\$ & Por período (1..nt) & Output \\
\hline gross revenue & Receita bruta & US\$ & Por período (1..nt) & Output \\
\hline taxesonsales & Taxas sobre as vendas & US\$ & Por período (1..nt) & Output \\
\hline Variável & Descrição & Unidade & Dimensões & Tipo \\
\hline prodcosts & Custo de Produção & US\$ & Por período (1..nt) & Output \\
\hline expenses & Despesas & US\$ & Por período (1..nt) & Ouput \\
\hline othercosts & $\begin{array}{l}\text { Outros custos (Embarque, } \\
\text { Administrativo, Comercial) }\end{array}$ & US\$ & Por período (1..nt) & Input \\
\hline ccostprov & Provisão de Custo de Fechamento & US\$ & Por período (1..nt) & Output \\
\hline depreciation & Depreciação & US $\$$ & Por período (1..nt) & Output \\
\hline \%IR & Alíquota de Imposto de Renda & Não há & Único & Input \\
\hline prjPCcapexrec & $\begin{array}{l}\text { Impacto do projeto na recuperação de } \\
\text { PIS/COFINS CAPEX }\end{array}$ & US\$ & $\begin{array}{l}\text { Por projeto (1.np) } \\
\text { Por período (1..nt) }\end{array}$ & Input \\
\hline execute & $\begin{array}{l}\text { Variável de decisão } \\
\text { 1: Realizar o projeto p no período t } \\
\text { 0: Não realizar o projeto p no período t }\end{array}$ & Não há & $\begin{array}{l}\text { Por projeto (1.np) } \\
\text { Por período (1..nt) }\end{array}$ & Output \\
\hline factorSCcapex & $\begin{array}{l}\text { Fator de recuperaçãa de Capex no } \\
\text { capital de sustentação }\end{array}$ & Não há & Único & Input \\
\hline PCopexrec & $\begin{array}{l}\text { Recuperação de PIS/COFINS do } \\
\text { OPEX }\end{array}$ & US\$ & Por período (1..nt) & Output \\
\hline
\end{tabular}

O valor de recuperação de PIS/COFINS sobre despesas operacionais é calculado como um percentual sobre os custos produtivos.

PCopexrec $(t)=\operatorname{prod} \cos t s(t) * \%$ PCopexrec $\quad \forall t=1$..nt

Onde:

\begin{tabular}{|l|l|l|l|l|}
\hline Variável & Descrição & Unidade & Dimensões & Tipo \\
\hline PCopexrec & $\begin{array}{l}\text { Recuperação de PIS/COFINS do } \\
\text { OPEX }\end{array}$ & US\$ & Por período (1..nt) & Output \\
\hline prodcosts & Custo de produção & US\$ & Por período (1..nt) & Output \\
\hline \%PCopexrec & $\begin{array}{l}\text { \% de recuperação de PIS/COFINS do } \\
\text { OPEX }\end{array}$ & US\$ & Único & Input \\
\hline
\end{tabular}

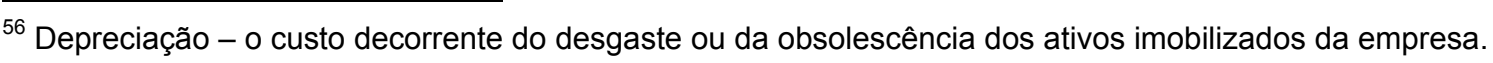


A não recuperação de ICMS sobre as despesas de capital é dada pelo produto de um índice de recuperação sobre o total de ICMS associado aos projetos realizados.

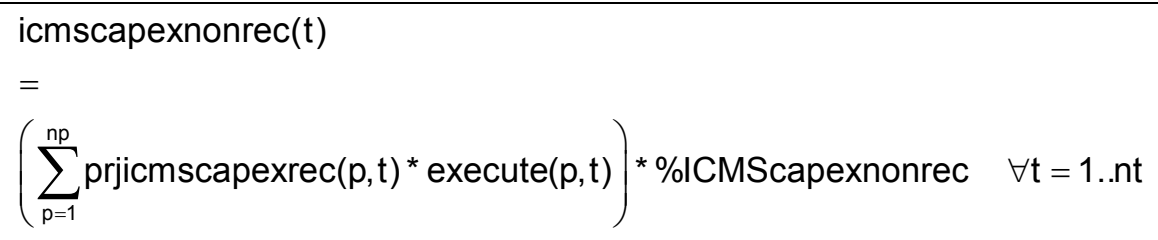

Onde:

\begin{tabular}{|l|l|l|l|l|}
\hline Variável & Descrição & Unidade & Dimensões & Tipo \\
\hline icmscapexnonrec & Recuperação de ICMS do CAPEX & US\$ & Por período (1..nt) & Output \\
\hline Execute & $\begin{array}{l}\text { Variável de decisão } \\
\text { 1: Realizar o projeto p no período t } \\
\text { 0: Não realizar o projeto p no período t }\end{array}$ & Não há & $\begin{array}{l}\text { Por projeto (1..np) } \\
\text { Por período (1..nt) }\end{array}$ & Output \\
\hline Variável & Descrição & Unidade & Dimensões & Tipo \\
\hline prjicmscapex & ICMS do CAPEX do projeto & US\$ & $\begin{array}{l}\text { Por projeto (1..np) } \\
\text { Por período (1..nt) }\end{array}$ & Input \\
\hline$\%$ ICMScapexnonrec & $\begin{array}{l}\text { \% de não recuperação de ICMS do } \\
\text { CAPEX }\end{array}$ & Não há & Único & Input \\
\hline
\end{tabular}

O cálculo de recuperação de PIS/COFINS sobre o IR é dado da seguinte forma:

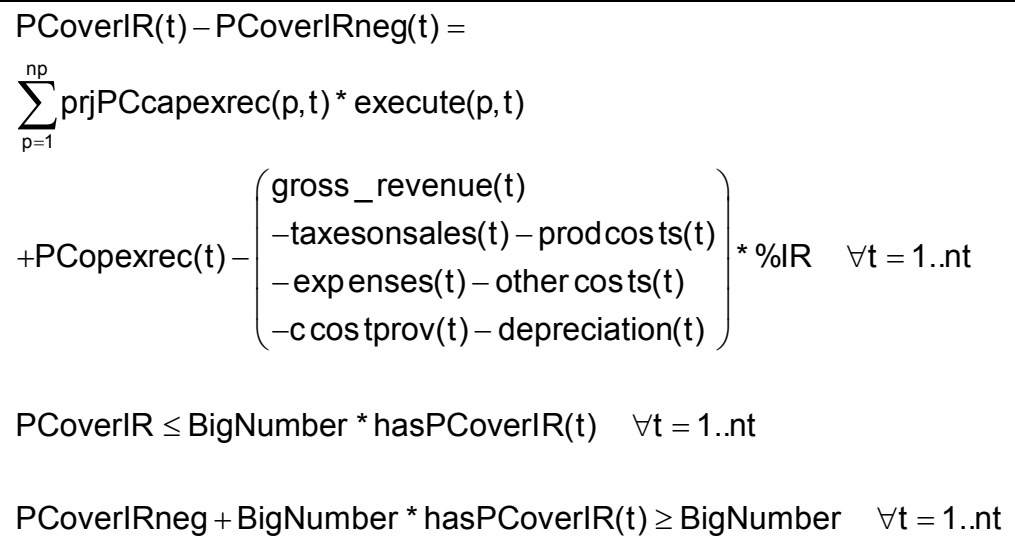

Onde:

\begin{tabular}{|l|l|l|l|l|}
\hline Variável & Descrição & Unidade & Dimensões & Tipo \\
\hline PCoverIR & PIS/COFINS exceeded over IR recovery & US\$ & Por período (1..nt) & Output \\
\hline PCoverIRneg & Dummy variable & US\$ & Por período (1..nt) & Output \\
\hline hasPCoverIR & Binary dummy variable & US\$ & Por período (1.nt) & Output \\
\hline hasnotPCoverIR & Binary dummy variable & US\$ & Por período (1..nt) & Output \\
\hline BigNumber & Parâmetro de modelagem & Não há & Único & Par \\
\hline
\end{tabular}


Os custos de inventário são obtidos pela ponderação do custo total de caixa operacional pelo número de dias disponíveis no período.

inventory $(\mathrm{t})=$ optcash $\cos \mathrm{t}(\mathrm{t}){ }^{*}$ yeardays $(\mathrm{t}) /$ perdays $(\mathrm{t}) \quad \forall \mathrm{t}=1$..nt

Onde:

\begin{tabular}{|l|l|l|l|l|}
\hline Variável & Descrição & Unidade & Dimensões & Tipo \\
\hline inventory & Inventário & US\$ & Por período (1..nt) & Output \\
\hline optcashcost & Custo total de caixa operacional & US\$ & Por período (1..nt) & Output \\
\hline yeardays & Números de dias por ano & Dias & Por período (1..nt) & Input \\
\hline Perdays & Número de dias por período & Dias & Por período (1..nt) & Input \\
\hline
\end{tabular}

O valor de contas a receber é dado por um fator de incidência sobre a receita bruta.

$\operatorname{rec}(\mathrm{t})=$ grossrevenue $(\mathrm{t}){ }^{*} \mathrm{MTTrec} /$ perdays $(\mathrm{t}) \quad \forall \mathrm{t}=1 . \mathrm{nt}$

Onde:

\begin{tabular}{|l|l|l|l|l|}
\hline Variável & Descrição & Unidade & Dimensões & Tipo \\
\hline Rec & Contas a receber & US\$ & Por período (1..nt) & Output \\
\hline grossrevenue & Receita bruta & US\$ & Por período (1..nt) & Output \\
\hline MTTrec & Ciclo de recebimento & Dias & Único & Input \\
\hline Perdays & Número de dias por período & Dias & Por período (1..nt) & Input \\
\hline
\end{tabular}

O valor de pagamento de fornecedores é dado pela soma das ponderações dos valores de investimento e custo total de caixa operacional.

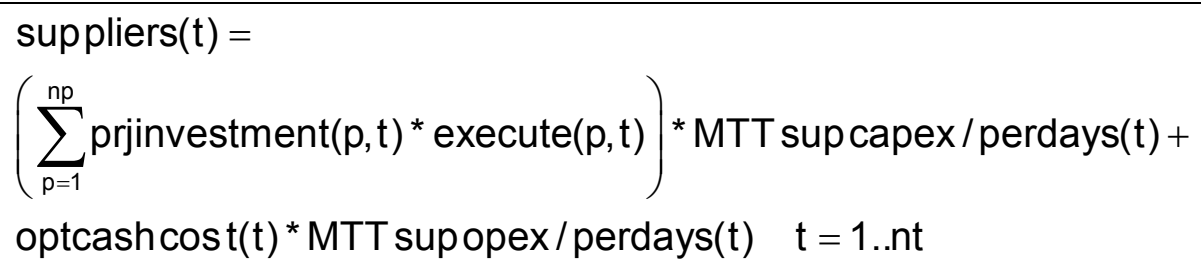


Onde:

\begin{tabular}{|c|c|c|c|c|}
\hline Variável & Descrição & Unidade & Dimensões & Tipo \\
\hline suppliers & Pagamento de fornecedores & & $\begin{array}{l}\text { Por período } \\
\text { (1..nt) }\end{array}$ & Output \\
\hline prjinvestment & $\begin{array}{l}\text { Investimento necessário para o } \\
\text { projeto }\end{array}$ & US\$ & $\begin{array}{l}\text { Por projeto } \\
(1 . . n p) \\
\text { Por período } \\
\text { (1..nt) }\end{array}$ & Input \\
\hline Execute & $\begin{array}{l}\text { Variável de decisão } \\
\text { 1: Realizar o projeto p no período t } \\
0: \text { Não realizar o projeto p no } \\
\text { período t }\end{array}$ & Não há & $\begin{array}{l}\text { Por projeto } \\
\text { (1..np) } \\
\text { Por período } \\
\text { (1..nt) }\end{array}$ & Output \\
\hline $\begin{array}{l}\text { MTTsupcape } \\
x\end{array}$ & $\begin{array}{l}\text { Ciclo de pagamento do CAPEX } \\
\text { para os fornecedores }\end{array}$ & Dias & Único & Input \\
\hline optcashcost & Custo total de caixa operacional & US\$ & $\begin{array}{l}\text { Por período } \\
\text { (1..nt) }\end{array}$ & Output \\
\hline MTTsupopex & $\begin{array}{l}\text { Ciclo de pagamento do OPEX para } \\
\text { os fornecedores }\end{array}$ & Dias & Único & Input \\
\hline Perdays & Número de dias por período & Dias & $\begin{array}{l}\text { Por período } \\
\text { (1..nt) }\end{array}$ & Input \\
\hline
\end{tabular}

A depreciação é dada pela soma das depreciações existentes mais as novas depreciações decorrentes dos projetos.

depreciation $(t)=$ existingdep $(t)+$ newdep $(t) \quad t=1$..nt

Onde:

\begin{tabular}{|l|l|l|l|l|}
\hline Variável & Descrição & Unidade & Dimensões & Tipo \\
\hline depreciation & Depreciação & US\$ & Por período (1..nt) & Output \\
\hline existingdep & Depreciação existente & US\$ & Por período (1..nt) & Input \\
\hline Newdep & Nova depreciação & US\$ & Por período (1..nt) & Output \\
\hline
\end{tabular}

O valor de novas depreciações é dado pela incidência de valores a depreciar associados aos projetos executados.

$\operatorname{newdep}(t)=\sum_{p=1}^{n p} \operatorname{prjdep}(p, t)^{*} \operatorname{execute}(p, t) \quad t=1 . . n t$

Onde:

\begin{tabular}{|l|l|l|l|l|}
\hline Variável & Descrição & Unidade & Dimensões & Tipo \\
\hline Newdep & Nova depreciação & US\$ & Por período (1..nt) & Output \\
\hline Prjdep & $\begin{array}{l}\text { Depreciação do Projeto } \\
\text { Somatório do (total de depreciação por classe/ } \\
\text { tempo de depreciação da classe) }\end{array}$ & US\$ & $\begin{array}{l}\text { Por projeto (1..np) } \\
\text { Por período (1..nnt) }\end{array}$ & Input \\
\hline Execute & $\begin{array}{l}\text { Variável de decisão } \\
\text { 1: Realizar o projeto p no período t } \\
\text { 0: Não realizar o projeto p no período t }\end{array}$ & Não há & $\begin{array}{l}\text { Por projeto (1..np) } \\
\text { Por período (1..nt) }\end{array}$ & Output \\
\hline
\end{tabular}


O lucro líquido acumulado com dividendos é dado pela soma do lucro líquido acumulado com os dividendos até o período de cálculo.

cumnpnd $(t)=$ cumnetprof $i t(t)+\sum_{i t=1}^{t}$ dividends (it) $t=1 . . n t$

Onde:

\begin{tabular}{|l|l|l|l|l|}
\hline Variável & Descrição & $\begin{array}{l}\text { Unidad } \\
\mathbf{e}\end{array}$ & Dimensões & Tipo \\
\hline cumnpnd & $\begin{array}{l}\text { Lucro líquido acumulado sobre os } \\
\text { dividendos }\end{array}$ & US\$ & Por período (1..nt) & Output \\
\hline cumnetprofit & Lucro líquido acumulado & US\$ & Por período (1..nt) & Output \\
\hline dividends & Dividendos & US\$ & Por período (1..nt) & Output \\
\hline
\end{tabular}

O lucro líquido acumulado é dado pela soma dos lucros líquidos dos períodos anteriores até o período de cálculo.

cumnetprofit(t) $=\sum_{i t=1}^{t}$ netprofit(it) $\quad t=1$..nt

Onde:

\begin{tabular}{|l|l|l|l|l|}
\hline Variável & Descrição & Unidade & Dimensões & Tipo \\
\hline cumnetprofit & Lucro líquido acumulado & US\$ & Por período (1..nt) & Output \\
\hline Netprofit & Lucro líquido & US\$ & Por período (1..nt) & Output \\
\hline
\end{tabular}

O lucro líquido de um período é dado pela diferença entre a receita bruta e o custo de produtos vendidos, outros custos, juros sobre empréstimos, juros sobre SOFE e outras despesas. A esse valor ainda são acrescidas outras entradas de capital e o imposto de renda.

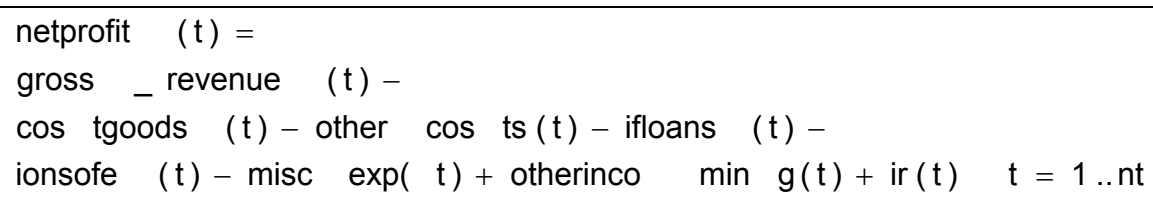


Onde:

\begin{tabular}{|l|l|l|l|l|}
\hline Variável & Descrição & Unidade & Dimensões & Tipo \\
\hline Netprofit & Lucro líquido & US\$ & Por período (1..nt) & Output \\
\hline gross_revenue & Receita bruta & US\$ & Por período (1..nt) & Output \\
\hline costgoods & Custo sobre produtos vendidos & US\$ & Por período (1..nt) & Output \\
\hline othercosts & $\begin{array}{l}\text { Outros Custos } \\
\text { (Embarque, Administrativos, } \\
\text { Comercial) }\end{array}$ & US\$ & Por período (1..nt) & Input \\
\hline Ifloans & Interest and fees on loans & US\$ & Por período (1..nt) & Input \\
\hline lonsofe & Interest on SOFE & US\$ & Por período (1..nt) & Output \\
\hline Miscexp & Despesas Gerais & US\$ & Por período (1..nt) & Output \\
\hline otherincoming & Other incoming & US\$ & Por período (1..nt) & Output \\
\hline Ir & IR & US\$ & Por período (1..nt) & Output \\
\hline
\end{tabular}

O custo de produtos vendidos é dado pelos custos de produção acrescido de depreciação, despesas com a Usina Hidrelétrica de Guilman Amorim e CFEM.

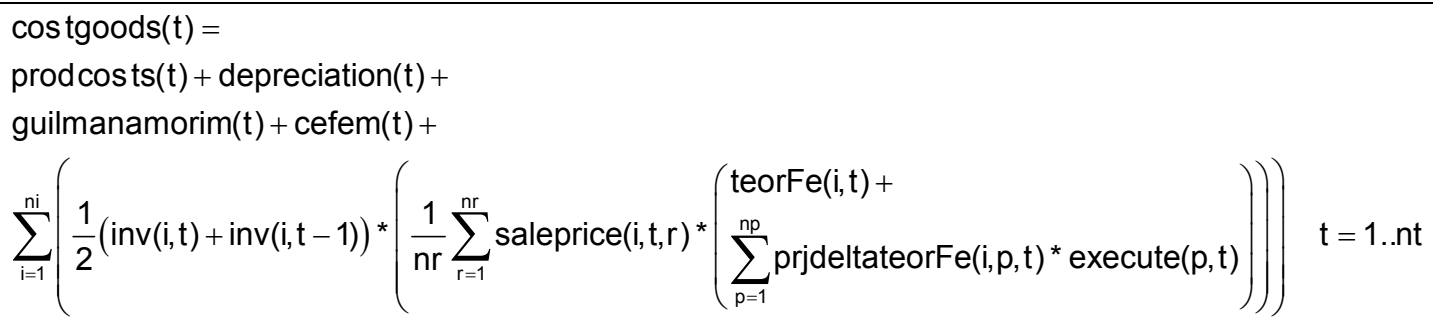

Onde:

\begin{tabular}{|c|c|c|c|c|}
\hline Variável & Descrição & Unidade & Dimensões & Tipo \\
\hline costgoods & Custo sobre produtos vendidos & US\$ & Por período (1..nt) & Output \\
\hline prodcosts & Custos de produção & US\$ & Por período (1..nt) & Output \\
\hline depreciation & Depreciação & US\$ & Por período (1..nt) & Output \\
\hline guilmanamorim & Despesas com Guilman Amorim & US\$ & Por período (1..nt) & Input \\
\hline Cefem & Despesas com CFEM & US\$ & Por período (1..nt) & Output \\
\hline $\ln v$ & Quantidade em estoque & tms & $\begin{array}{l}\text { Por produto (1..ni) } \\
\text { Por período (1..nt) }\end{array}$ & Output \\
\hline $\operatorname{inv}(\mathrm{i}, 0)$ & Quantidade em estoque no período 0 & tms & Por produto (1..ni) & Input \\
\hline saleprice & Preço de venda & US\$/ t Fe & $\begin{array}{l}\text { Por produto (1..ni) } \\
\text { Por período (1..nt) } \\
\text { Por região (1..nr) }\end{array}$ & Input \\
\hline Variável & Descrição & Unidade & Dimensões & Tipo \\
\hline teorFe & Teor de ferro & $\mathrm{t} F e / \mathrm{tms}$ & $\begin{array}{l}\text { Por produto (1..ni) } \\
\text { Por período (1..nt) }\end{array}$ & Input \\
\hline prjdeltateorFe & Impacto do projeto no teor de ferro & $\mathrm{tFe} / \mathrm{tms}$ & $\begin{array}{l}\text { Por produto (1..ni) } \\
\text { Por período (1..nt) }\end{array}$ & Input \\
\hline Execute & $\begin{array}{l}\text { Variável de decisão } \\
\text { 1: Realizar o projeto } \mathrm{p} \text { no período } \mathrm{t} \\
0 \text { : Não realizar o projeto } \mathrm{p} \text { no período } \mathrm{t}\end{array}$ & Não há & $\begin{array}{l}\text { Por projeto }(1 . . \mathrm{np}) \\
\text { Por período (1..nt) }\end{array}$ & Output \\
\hline
\end{tabular}


As despesas gerais são dadas pela provisão de custo de fechamento, acrescida da participação dos empregados nos lucros da empresa, dos royalties e das outras despesas.

misc $\exp (t)=c \cos$ tprov $(t)+$ empprofitshare $(t)+$ royalties $(t)+$ other exp enses $(t) \quad t=1 . . n t$

Onde:

\begin{tabular}{|l|l|l|l|l|}
\hline Variável & Descrição & Unidade & Dimensões & Tipo \\
\hline Miscexp & Despesas Gerais & US\$ & Por período (1..nt) & Output \\
\hline ccostprov & Provisão de Custo de Fechamento & US\$ & Por período (1..nt) & Output \\
\hline empprofitshare & Participação nos lucros & US\$ & Por período (1..nt) & Output \\
\hline Royalties & Royalties $^{\prime \prime}$ sobre dividendos & US\$ & Por período (1..nt) & Output \\
\hline otherexpenses & Outras despesas & US\$ & Por período (1..nt) & Output \\
\hline
\end{tabular}

As outras entradas de capital são dadas pela soma dos ganhos financeiros e da receita da Usina Hidrelétrica de Guilman Amorim.

otherinco $\min g(t)=$ financialearnings $(t)+$ equityGA(t) $\quad t=1 . . n t$

Onde:

\begin{tabular}{|l|l|l|l|l|}
\hline Variável & Descrição & Unidade & Dimensões & Tipo \\
\hline otherincoming & Other incoming & US\$ & Por período (1..nt) & Output \\
\hline financialearnings & Ganhos financeiros & US\$ & Por período (1..nt) & Output \\
\hline equityGA & Receita de Guilman Amorim & US\$ & Por período (1..nt) & Input \\
\hline
\end{tabular}

Os ganhos financeiros são calculados como um percentual sobre o balanço de caixa no início do período.

fiinancialearnings $(t)=(\operatorname{cashbop}(t)-\operatorname{cashbop}(t-1)) * \% S T$ int $\quad t=1$..nt

Onde:

\begin{tabular}{|l|l|l|l|l|}
\hline Variável & Descrição & Unidade & Dimensões & Tipo \\
\hline financialearnings & Ganhos financeiros & US\$ & Por período (1..nt) & Output \\
\hline Cashbop & Caixa no início do período & US\$ & Por período (1..nt) & Output \\
\hline Variável & Descrição & Unidade & Dimensões & Tipo \\
\hline Cashbop(0) & Caixa no início do período 0 & US\$ & Único & Input \\
\hline$\% S T i n t$ & Taxa de juros de curto prazo & Não há & Único & Input \\
\hline
\end{tabular}

O custo operacional total de caixa é dado pelos custos de produção acrescidos de outros custos. A este montante são acrescidos os impactos sobre o custo total associados à execução de projetos.

\footnotetext{
${ }^{57}$ Royalties - importância cobrada pelo proprietário de uma patente de produto, processo de produção, marca, entre outros, ou pelo autor de uma obra, para permitir seu uso ou comercialização.
} 
$\operatorname{optcash} \cos t(t)=\operatorname{prod} \cos t s(t)+$ othercosts $(t)+\sum_{p=1}^{n p} \operatorname{prjdeltaopt} \cos t(p, t)^{*}$ execute $(p, t) \quad \forall t=1$..nt

Onde:

\begin{tabular}{|l|l|l|l|l|}
\hline Variável & Descrição & Unidade & Dimensões & Tipo \\
\hline optcashcost & Custo Total de Caixa Operacional & US\$ & Por período (1..nt) & Output \\
\hline prodcosts & Custos de produção & US\$ & Por período (1..nt) & Output \\
\hline othercosts & $\begin{array}{l}\text { Outros custos } \\
\text { (Embarque, Administrativos, } \\
\text { Comercial) }\end{array}$ & US\$ & Por período (1..nt) & Input \\
\hline prjdeltaoptcost & $\begin{array}{l}\text { Impacto dos projetos no Custo Total } \\
\text { de Caixa Operacional }\end{array}$ & US\$ & $\begin{array}{l}\text { Por projeto (1..np) } \\
\text { Por período (1..nt) }\end{array}$ & Input \\
\hline Execute & $\begin{array}{l}\text { Variável de decisão } \\
\text { 1: Realizar o projeto p no período t } \\
\text { 0: Não realizar o projeto p no período } \\
\mathrm{t}\end{array}$ & Não há & $\begin{array}{l}\text { Por projeto (1..np) } \\
\text { Por período (1..nt) }\end{array}$ & Output \\
\hline
\end{tabular}

